\title{
Fate and transport of Methamphetamine and related compounds in remediated clandestine laboratories
}

Holly A. McCall

West Virginia University

Follow this and additional works at: https://researchrepository.wvu.edu/etd

\section{Recommended Citation}

McCall, Holly A., "Fate and transport of Methamphetamine and related compounds in remediated clandestine laboratories" (2013). Graduate Theses, Dissertations, and Problem Reports. 3656.

https://researchrepository.wvu.edu/etd/3656

This Dissertation is protected by copyright and/or related rights. It has been brought to you by the The Research Repository @ WVU with permission from the rights-holder(s). You are free to use this Dissertation in any way that is permitted by the copyright and related rights legislation that applies to your use. For other uses you must obtain permission from the rights-holder(s) directly, unless additional rights are indicated by a Creative Commons license in the record and/ or on the work itself. This Dissertation has been accepted for inclusion in WVU Graduate Theses, Dissertations, and Problem Reports collection by an authorized administrator of The Research Repository @ WVU.

For more information, please contact researchrepository@mail.wvu.edu. 


\title{
FATE AND TRANSPORT OF METHAMPHETAMINE AND RELATED COMPOUNDS IN REMEDIATED CLANDESTINE LABORATORIES
}

\author{
Holly A. McCall
}

\author{
Dissertation submitted to the \\ Eberly College of Arts and Sciences \\ at West Virginia University \\ in partial fulfillment of the requirements \\ for the degree of
}

Doctor of Philosophy
in
Chemistry

Suzanne C. Bell, Ph.D., Chair Jonathan Boyd, Ph.D.

Harry Finklea, Ph.D.

Glen Jackson, Ph.D.

Ray Wells, Ph.D.

C. Eugene Bennett Department of Chemistry

Morgantown, West Virginia

2013

Keywords: Clandestine laboratory, DMS, GC/MS, HS-GC/MS, IMS, Methamphetamine, Method validation

Copyright @ 2013 Holly A. McCall 


\title{
ABSTRACT
}

\section{FATE AND TRANSPORT OF METHAMPHETAMINE AND RELATED COMPOUNDS IN REMEDIATED CLANDESTINE LABORATORIES}

\author{
Holly A. McCall
}

Remediation of clandestine laboratories has become a national concern due to health and environmental concerns. To date, remarkably little has been published regarding the fate and transport of methamphetamine in clandestine laboratories, both before and after remediation. The fate and transport of methamphetamine in an indoor air environment is an inherently complex process, where the drug can move as either particulate matter or vapor. The ability to diffuse throughout a building structure increases the need for analysis techniques that can evaluate potential exposure by various means. This research investigated three analytical methods for the detection of methamphetamine: ion mobility spectrometry (IMS), headspace gas chromatography-mass spectrometry (HS-GC/MS), and differential mobility spectrometry (DMS). In post-remediation evaluation of former clandestine laboratories surface wipes are typically analyzed using IMS, followed by confirmation with established $\mathrm{NIOSH}$ instrumental methods. To evaluate the cleaning process, this project established that methamphetamine cleaned with household Simple Green ${ }^{\circledR}$ reduced the concentration of the drug on most nonporous household surfaces while showing little impact on the concentration of porous surfaces. A GC/MS method was validated and a HS-GC/MS method was established to investigate the rate of release of methamphetamine from common household building materials, such as southern yellow pine and gypsum wallboard. It was demonstrated that after a $2 \mathrm{hr}$ analysis at $105^{\circ} \mathrm{C}$ methamphetamine was not released in the gas phase from within the structure of either material, contradicting previously published surface studies. Both the IMS and GC/MS methods evaluated liquid exposure to surfaces. A more realistic approach was made by developing methodology for the detection of methamphetamine in the gas-phase by DMS. DMS analysis confirmed the ability to detect methamphetamine at high concentrations based upon four detection windows. In the final evaluation of all techniques, a vehicle was used to simulate a mobile clandestine laboratory. While DMS results indicate that the airborne methamphetamine concentration was below the detection limit inside the simulated environment, HS and IMS analysis indicate methamphetamine settling onto the surfaces in a car. We hypothesize that even though surface contamination was present, methamphetamine was release was below the limit of detection for the housing materials and was detected at low concentrations in vehicle samples. This finding strongly suggests that methamphetamine may not be the major concern in evaluating former clandestine laboratories for remediation; rather, remediation should focus on the broader range of compounds used in the production of the drug itself. 


\section{DEDICATION}

To my parents (Jean and Bill McCall), my grandparents (Peggy and Al Muir) and my sister (Lyndsey McCall) for their love and support.

You always told me I could do it! 


\section{ACKNOWLEDGEMENTS}

I would like to acknowledge:

Dr. Suzanne Bell, for her laughter, advice and continued faith in me

Members of my committee, Dr. Suzanne Bell, Dr. Jonathan Boyd, Dr. Harry Finklea, Dr. Glen Jackson, and Dr. Ray Wells for taking the time to review this work

Undergraduate assistants, Travis Doria, Kristen Felice, Danylle Knightlinger, Conor Lennon, and Marci Smeltz, for their dumpster diving to find building materials, as well as collecting data (Chapter 2)

Dr. Paul Rauch for quick responses to my many questions, and increasing my understanding of DMS operation (Chapter 4)

The C. Eugene Bennett Department of Chemistry, and Eberly College of Arts and Sciences for acceptance into the Ph.D. program and financial support

Members of the Bell research group, Lucy Oldfield, Stephanie Martindale, Jordan Moran, Corey Nida, Lee Greenawald and Brittany Yeager for always being there to cheer me up when I needed it, celebrate an accomplishment when it happened, offer a helpful hand, and ponder a research question. Without ya'll I never would have made it through!

Past members of the Bell research group, Dr. Rona Nishikawa and Dr.

Xinya Zhang for providing constant friendship, food, laughter, and subtle reminders to "practice."

And my undergraduate professor and friend, Dr. Carol Babyak, for telling me about WVU, and offering continuous encouragement over my many years in chemistry

This material is based upon work supported by the National Institute of Standards and Technology, contract 10-197. 


\section{Table of Contents}

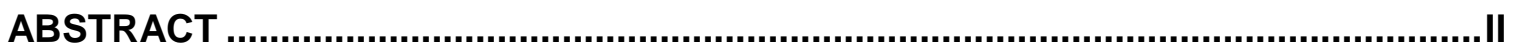

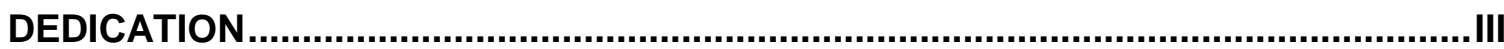

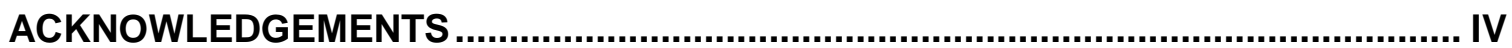

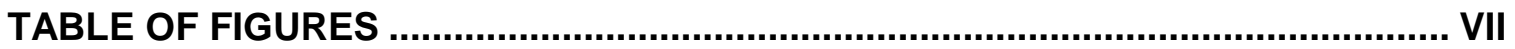

TABLE OF TABLES

LIST OF ABBREVIATIONS, SYMBOLS/NOMENCLATURE...................................... XII

CHAPTER 1: INTRODUCTION TO METHAMPHETAMINE ..........................................

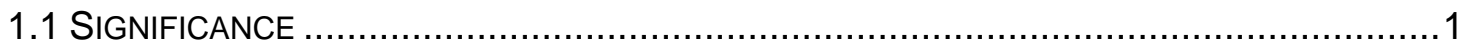

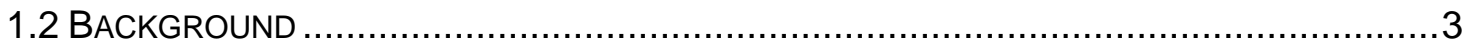

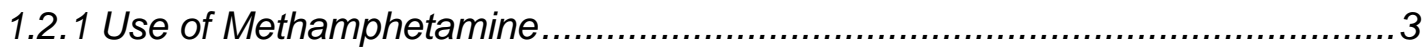

1.2.2 The Chemistry of Methamphetamine ................................................. 4

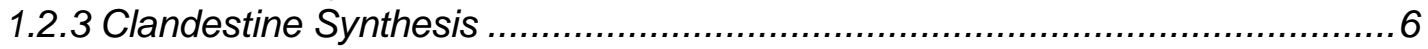

1.2.4 Clandestine Laboratory Analysis...................................................... 12

1.2.5 Methamphetamine in the Indoor Environment...................................... 16

1.2.6 Particulate Matter.......................................................................... 19

1.2.7 Effusion ..................................................... Error! Bookmark not defined.

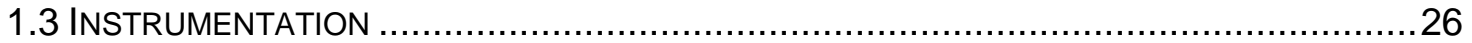

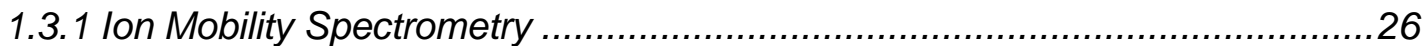

1.3.2 Gas Chromatography - Mass Spectrometry (GC/MS) ..............................29

CHAPTER 2: ION MOBILITY SPECTROMETRY AS A TOOL IN EVALUATING THE EFFICACY OF CLEANING PROTOCOL FOR CLANDESTINE METHAMPHETAMINE

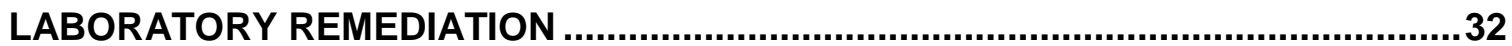

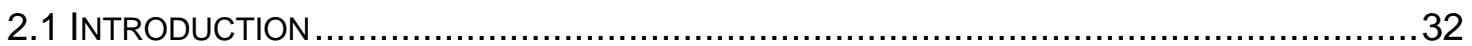

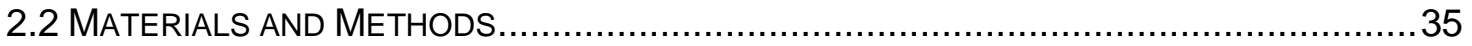

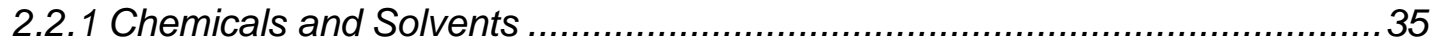

2.2.2 Instrumentation ............................................................................

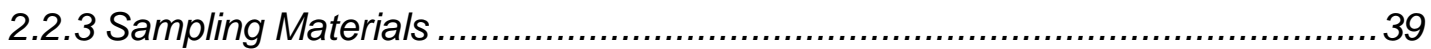

2.2.4 Spikes and Swabbing .....................................................................

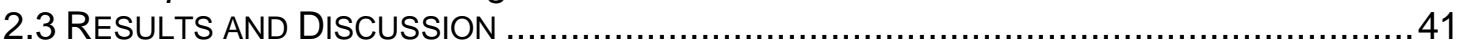

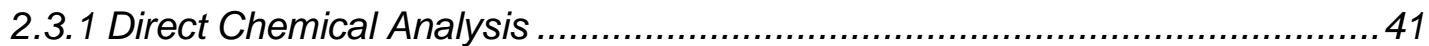

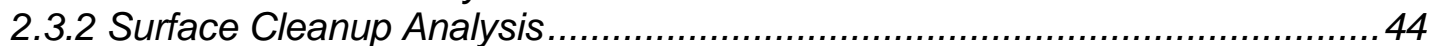

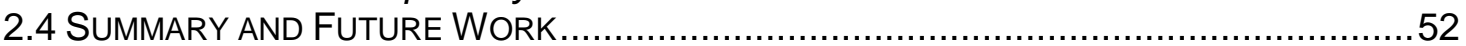

CHAPTER 3: GAS CHROMATOGRAPHY - MASS SPECTROMETRY METHOD

VALIDATION AND APPLICATION TO HEADSPACE DETECTION OF

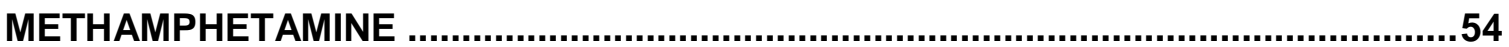

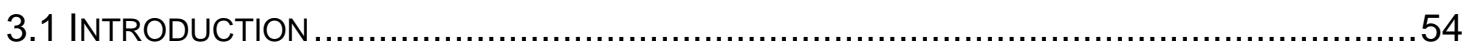

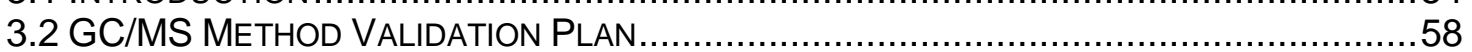

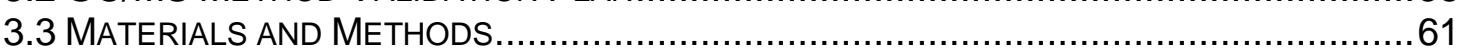

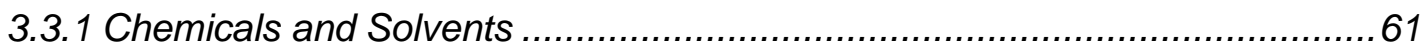

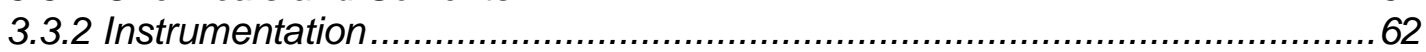

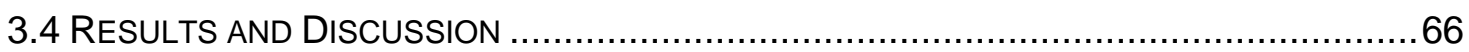

3.4.1 Liquid Injection GC/MS Method Validation ...............................................66

3.4.2 Optimization of Headspace Parameters................................................. 79

3.4.3 Use of an Internal Standard in Headspace Analysis ...................................81

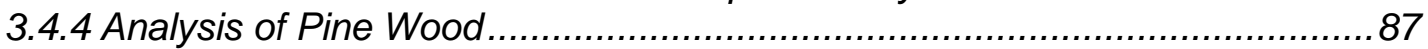

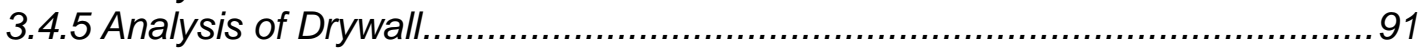

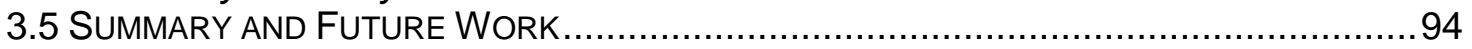


CHAPTER 4: DIFFERENTIAL MOBILITY SPECTROMETRY AS A TOOL IN DETECTING METHAMPHETAMINE IN CLANDESTINE LABORATORIES .................96

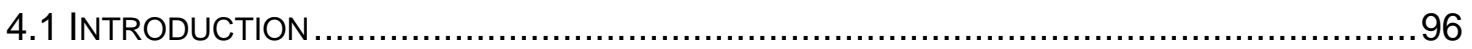

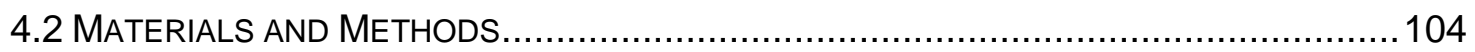

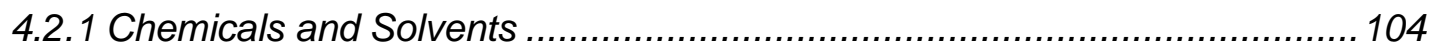

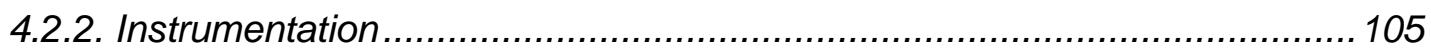

4.2.3 Methamphetamine Detection Optimization.......................................... 105

4.2.4 Data Processing ............................................................................ 107

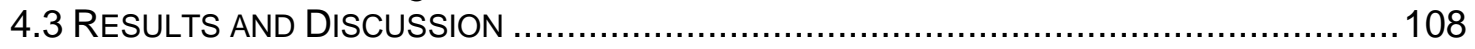

4.3.1 Detection Windows Established ...................................................... 108

4.3.2 Effect of Heating on Sample Detection ............................................... 119

4.3.3 Potential Interferences .................................................................. 123

4.4 SUMMARY AND FUTURE WORK ......................................................... 124

CHAPTER 5: ANALYSIS OF A SIMULATED MOBILE ........................................125

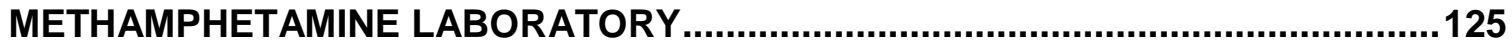

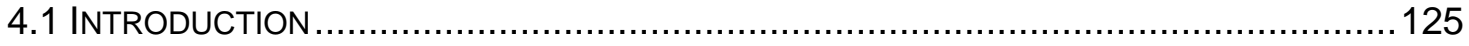

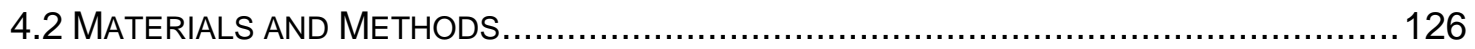

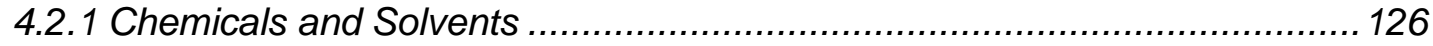

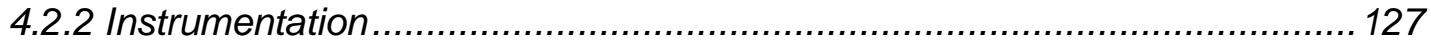

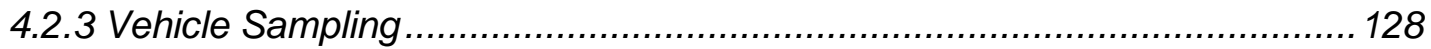

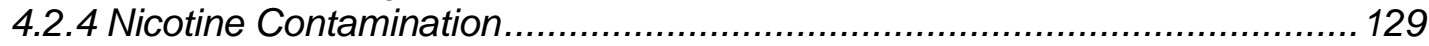

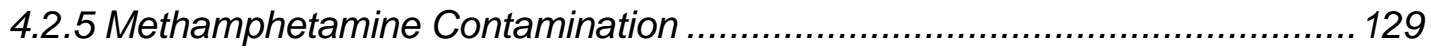

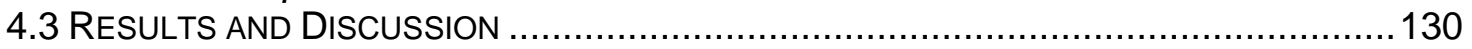

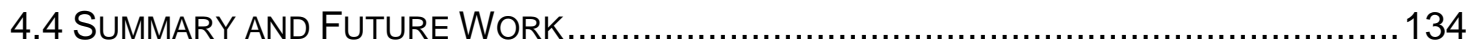

APPENDIX A: ANALYSIS OF CHEMICAL INTERFERENCE BY DMS......................136

APPENDIX B: SAMPLING LOCATIONS FOR THE ANALYSIS OF

METHAMPHETAMINE IN A 1999 DODGE NEON..................................................144

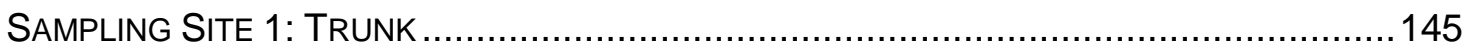

SAMPLING SITE 2: PASSENGER'S SIDE, BACK SEAT - SEAT PADDING .......................... 146

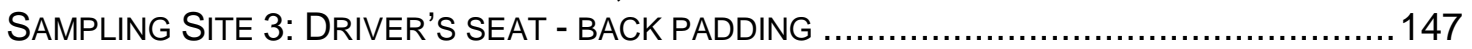

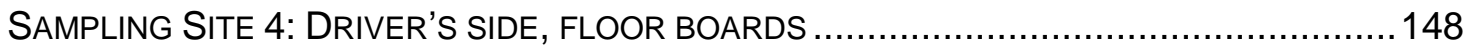

SAMPLING SITE 5: PASSENGER'S SIDE, FRONT SIDE DOOR - GLASS WINDOW ................149

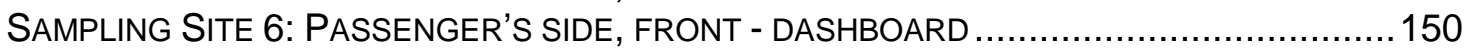

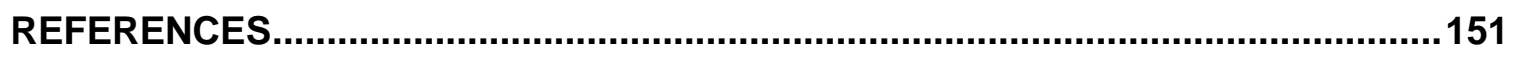




\section{TABLE OF FIGURES}

FIGURE 1.1 GENERIC CONSTRUCTION OF A BUILDING STRUCTURE .............................2

FIGURE 1.2 RED PHOSPHORUS METHOD OF PRODUCTION FOR METHAMPHETAMINE .....10

FIGURE 1.3 NAZI REACTION METHOD OF METHAMPHETAMINE PRODUCTION.................11

FIGURE 1.4 COMPARISON OF CALCULATED DIFFUSION RATES FOR METHAMPHETAMINE IN AIR WITH INCREASING TEMPERATURE, DEMONSTRATING A LINEARLY INCREASING TREND .....................................................ERROR! BOOKMARK NOT DEFINED.

FIGURE 1.5 SCHEMATIC OF AN ION MOBILITY SPECTROMETER ................................27

FIGURE 1.6 SCHEMATIC OF A GAS CHROMATOGRAPHY-MASS SPECTROMETER ............30

FIGURE 2.1 THE SABRE4000 IS SHOWN ALONG WITH SWABS USED FOR ANALYSIS AND A DEMONSTRATION OF THE AREA DESORBED BY THE IMS .33

FIGURE 2.2 PIE CHART DEMONSTRATING THAT SABRETM 4000 MAKES UP 8\% OF THE IMS INSTRUMENTS USED IN THE FIELD, AND AMONGST ION MOBILITY SPECTROMETERS USED FOR DRUG ANALYSIS IT IS ONE OF THE MOST COMMON ${ }^{41} . .34$

FIGURE 2.3 INSTRUMENT CONDITIONS AS SET BY THE SABRE TM 4000 NARCOTICS MODE

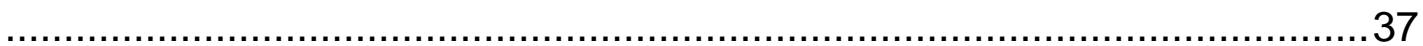

FIGURE 2.4 PEAK AMPLITUDE VERSUS CONCENTRATION OF SWAB IN LOD STUDY .......38

FIGURE 2.5 TYPICAL MOBILITY SPECTRUM OBTAINED IN THE PARTICLE MODE (THERMAL DESORPTION ENGAGED) FOR A BLANK SWAB

FIGURE 2.6 COMBINED MOBILITY SPECTRUM OBTAINED IN THE PARTICLE MODE (THERMAL DESORPTION ENGAGED) FOR METHAMPHETAMINE, SIMPLE GREEN ${ }^{\circledR}$ AND METHAMPHETAMINE COMBINED WITH SIMPLE GREEN ${ }^{\circledR}$....

FIGURE 2.7 BAR CHART OF METHAMPHETAMINE PEAK AMPLITUDES FOR SAMPLES CLASSIFIED AS GLASS

FIGURE 2.8 BAR CHART OF METHAMPHETAMINE PEAK AMPLITUDES FOR SAMPLES CLASSIFIED AS MISCELLANEOUS MATERIALS............................................49

FIGURE 2.9 BAR CHART OF METHAMPHETAMINE PEAK AMPLITUDES FOR SAMPLES CLASSIFIED AS RAW MATERIALS ........................................................5 50

FIGURE 2.10 BAR CHART OF METHAMPHETAMINE PEAK AMPLITUDES FOR SAMPLES CLASSIFIED AS WOOD MATERIALS...........................................................51

FIGURE 3.1 DIAGRAM OF HS SAMPLING ANALYSIS USING A 20-ML HS VIAL................55

FIGURE 3.2 VAPOR PRESSURE CURVE FOR METHAMPHETAMINE ESTABLISHED BASED UPON CLAUSIUS-CLAPEYRON EQUATION ..................................................56

FIGURE 3.3 TOTAL ION CHROMATOGRAPH OF METH-D14 AND METHAMPHETAMINE......63

FIGURE 3.4 MASS SPECTRA RESULTING FROM THE METH-D14 PEAK AT 8.454 MIN......64

FIGURE 3.5 MASS SPECTRA RESULTING FROM THE METHAMPHETAMINE PEAK AT 8.571

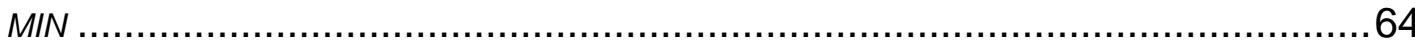

FIGURE 3.6 GC/MS EXTRACTED ION CHROMATOGRAPH OF M/Z $65 \ldots \ldots \ldots \ldots \ldots \ldots \ldots \ldots . . .65$

FIGURE 3.7 GC/MS EXTRACTED ION CHROMATOGRAPH OF M/Z 58 ........................65

FIGURE 3.8 CALIBRATION MODEL OF AVERAGED DATA FROM CERILLIANT ${ }^{\circledR}$ STANDARDS69 FIGURE 3.9 CALIBRATION MODEL OF AVERAGED DATA FROM RESTEK ${ }^{\circledR}$ STANDARDS.....70 FIGURE 3.10 BOX PLOT OF RESTEK ${ }^{\circledR}$ STANDARDS AT 0.0100 NG OF METHAMPHETAMINE ON COLUMN, DEMONSTRATING TWO OUTLIERS IN THE DATA SET, 0.0286 AND 0.0245 
FIGURE 3.11 CALIBRATION MODEL OF AVERAGED DATA FROM SIGMA-ALDRICH ${ }^{\circledR}$ STANDARDS

FIGURE 3.12 BOX PLOT OF SIGMA-ALDRICH ${ }^{\circledR}$ STANDARDS AT 0.0010 NG OF METHAMPHETAMINE ON COLUMN DEMONSTRATING, 0.0469 AS AN OUTLIER IN THE DATA SET.

FIGURE 3.13 CALIBRATION MODEL OF AVERAGED DATA FROM ALL THREE STANDARD MANUFACTURERS, CERILLIANT ${ }^{\circledR}$, RESTEK $^{\Theta}$, AND SIGMA-ALDRICH ${ }^{\circledR}$.....................74

FIGURE 3.14 OPTIMIZATION OF HS GC/MS EQUILIBRATION TIME ...........................81

FIGURE 3.15 HS CALIBRATION CURVE DEVELOPED FROM ABSOLUTE PEAK AREA OF

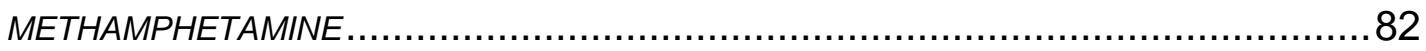

FIGURE 3.16 HS CALIBRATION CURVE DEVELOPED FROM PEAK AREA RATIO METHAMPHETAMINE TO METH-D14.

FIGURE 3.17 GC/MS CHROMATOGRAM OF SOUTHERN YELLOW PINE, BASE SHIFTED TO INCLUDE THREE SAMPLE SETS

FIGURE 3.18 OVERLAY GAS CHROMATOGRAPH OF METHAMPHETAMINE CONTROL AND WOOD SAMPLES ANALYZED OVER FIVE TIME INTERVALS FOR THE RATE OF RELEASE OF METHAMPHETAMINE 90

FIGURE 3.19 OVERLAY GAS CHROMATOGRAPH OF METHAMPHETAMINE CONTROL AND DRYWALL ANALYZED OVER FOUR TIME INTERVALS FOR THE RATE OF RELEASE OF METHAMPHETAMINE.

FIGURE 4.1 PRINCIPLE OF OPERATION FOR A DMS INSTRUMENT..... 98

FIGURE 4.2 RELATIONSHIP BETWEEN ALPHA PARAMETER AND ION TRAJECTORY .........99

FIGURE 4.3 MOBILITY SPECTRUM OF ION CURRENT AS A FUNCTION OF COMPENSATION VOLTAGE.

FIGURE 4.4 FULL SCAN PLOT OF DMS DATA FROM ANALYSIS WITH THE EPC ON IN (A) NEGATIVE MODE AND (B) POSITIVE MODE................................................. 102

FIGURE 4.5 THE JUNO ${ }^{\circledR}$ INSTRUMENT USED FOR ALL DMS EXPERIMENTS, DEMONSTRATING THE IMPORTANT CHARACTERISTICS IN ITS DESIGN..................103

FIGURE 4.6 PHOTOGRAPH OF EXPERIMENTAL SET-UP USING THE JUNO ${ }^{\circledR}$ IN METHAMPHETAMINE CHAMBER, AS WELL AS BLOCK DIAGRAM 106

FIGURE 4.7 TYPICAL DMS OUTPUT FROM METHAMPHETAMINE: (A) FULL SCAN

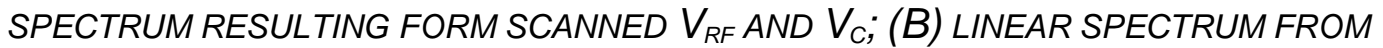
FIXED $V_{R F}$ AND SCANNED $V_{C}$. NOTE, THIS OUTPUT IS DIFFERENT THAN THAT OF TRADITIONAL DRIFT TUBE IMS.

FIGURE 4.8 FULL SCAN SPECTRUM OF METHAMPHETAMINE AND COLOR CODED LINEAR PLOTS FOR THE IDENTIFICATION OF METHAMPHETAMINE SPECIFIC PEAKS...........110

FIGURE 4.9 POLYNOMIAL FIT OF DATA FROM THE $V_{C}$ OF PEAKS DURING $V_{R F} 800$ AGAINST

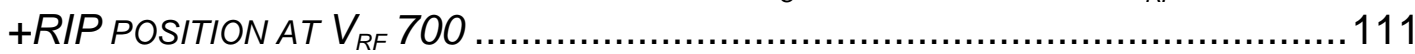

FIGURE 4.10 POLYNOMIAL FIT OF DATA FROM THE $V_{C}$ OF PEAKS DURING $V_{R F} 900$

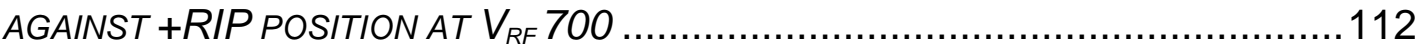

FIGURE 4.11 POLYNOMIAL FIT OF PEAK 1 DATA FROM THE $V_{C}$ OF PEAKS DURING $V_{R F}$

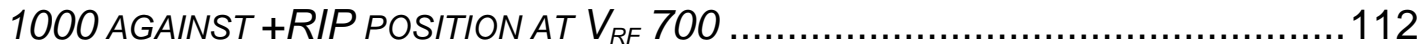

FIGURE 4.12 POLYNOMIAL FIT OF PEAK 2 DATA FROM THE $V_{C}$ OF PEAKS DURING $V_{R F}$

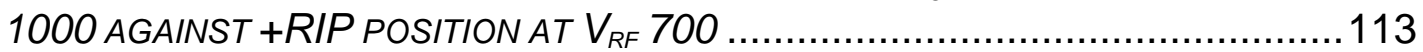

FIGURE 4.13 RESULTS OF FILE PARSING FOR BLANK RUN WITH EPC ON.................117 
FIGURE 4.14 RESULTS OF FILE PARSING FOR METHAMPHETAMINE SAMPLE CONTAINING 0.1 G OF DRU ................................................................................ 118

FIGURE 4.15 FULL SCAN PLOT OF METHAMPHETAMINE CORRESPONDING TO O $0.1 \mathrm{G}$ OF $D R U G$.

FIGURE 4.16 METHAMPHETAMINE PLOTS RESULTING FROM DIFFERENT TEMPERATURES OF THE SOLUTION: (A) $25^{\circ} \mathrm{C}$, (B) $65^{\circ} \mathrm{C}$, AND (C) $85^{\circ} \mathrm{C}$

FIGURE 4.17 LINEAR DMS SPECTRA OF METHAMPHETAMINE IN CASE 1 WITH EXPANSION OF THE PEAK MONITORED DURING THE METH8OO WINDOW 121

FIGURE 4.18 LINEAR DMS SPECTRA OF METHAMPHETAMINE IN CASE 1 WITH EXPANSION OF THE PEAK MONITORED DURING THE METH9OO WINDOW 121

FIGURE 4.19 LINEAR DMS SPECTRA OF METHAMPHETAMINE IN CASE 1 WITH EXPANSION OF THE TWO PEAKS MONITORED DURING THE METH1000 WINDOW .................122

FIGURE 5.1 METHAMPHETAMINE CONTAMINATION OF DODGE NEON ......................130 


\section{TABLE OF TABLES}

TABLE 1.1 ChEMICAL CHARACTERISTICS TABLE FOR METHAMPHETAMINE ${ }^{12} \ldots \ldots \ldots \ldots \ldots . . . . . .6$

TABLE 1.2 ISOMERS OF EPHEDRINE........................................................... 7

TABLE 1.3 FREQUENTLY USED CHEMICALS IN CLANDESTINE METHAMPHETAMINE

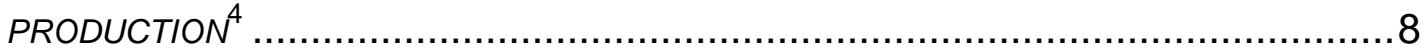

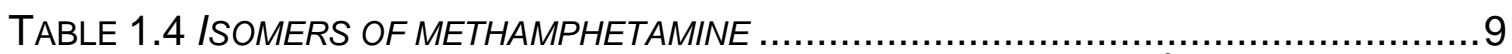

TABLE 1.5 STATE MAXIMUM CONTAMINATION OF METHAMPHETAMINE ${ }^{3 A} \ldots \ldots \ldots \ldots \ldots \ldots . . . . . . . . . .14$

TABLE 1.6 COMPARISON OF THE A- AND B- FORMS OF CALCIUM SULFATE HEMIHYDRATE

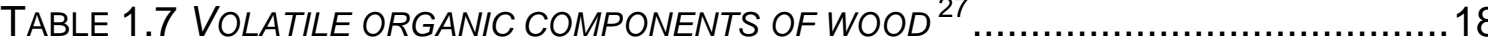

TABLE 1.8 COMPARISON OF METHAMPHETAMINE DOSAGE BASED UPON CALCULATED

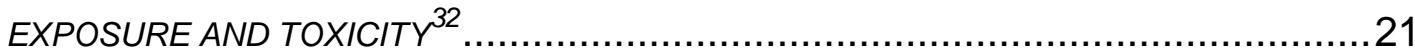

TABLE 1.9 COMPARISON VALUES FOR SPEED DISTRIBUTION ................................24

TABLE 1.10 STRUCTURE AND CHEMICAL CHARACTERISTICS OF NICOTINAMIDE ............28

TABLE 2.1 MASS LOAD OF METHAMPHETAMINE IN LOD/IDL STUDY ..........................38

TABLE 2.2 BUILDING MATERIAL USED FOR ANALYSIS, CATEGORIZED BY APPARENT

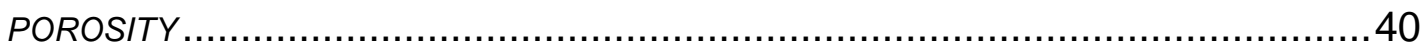

TABLE 2.3 METHAMPHETAMINE PEAK AMPLITUDES FOR SAMPLES CLASSIFIED AS COUNTERTOP MATERIAL AFTER THREE CYCLES OF CLEANING .........................44

TABLE 2.4 METHAMPHETAMINE PEAK AMPLITUDES FOR SAMPLES CLASSIFIED AS FLOORING MATERIAL AFTER THREE CYCLES OF CLEANING ............................46

TABLE 2.5 METHAMPHETAMINE PEAK AMPLITUDES FOR SAMPLES CLASSIFIED AS GLASS MATERIALS AFTER THREE CYCLES OF CLEANING .....................................47

TABLE 2.6 METHAMPHETAMINE PEAK AMPLITUDES FOR SAMPLES CLASSIFIED AS MISCELLANEOUS MATERIALS AFTER THREE CYCLES OF CLEANING .....................48

TABLE 2.7 METHAMPHETAMINE PEAK AMPLITUDES FOR SAMPLES CLASSIFIED AS RAW MATERIALS AFTER THREE CYCLES OF CLEANING ...................................... 50

TABLE 2.8 METHAMPHETAMINE PEAK AMPLITUDES FOR SAMPLES CLASSIFIED AS WOOD MATERIALS AFTER THREE CYCLES OF CLEANING ..................................... 51

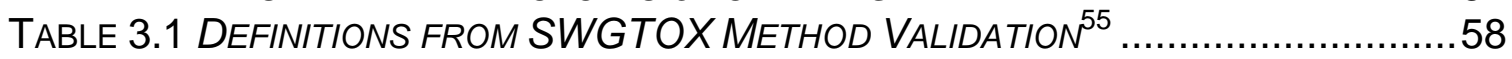

TABLE 3.2 GC/MS CONDITIONS FOR THE ANALYSIS OF METHAMPHETAMINE ..............63

TABLE 3.3 HS-GC/MS CONDITIONS FOR THE ANALYSIS OF METHAMPHETAMINE .........66

TABLE 3.4 CONVERSION OF CONCENTRATION TO MASS OF METHAMPHETAMINE IN GC/MS

TABLE 3.5 CERILLIANT ${ }^{\Theta}$ DATA USED FOR THE FORMATION OF THE CALIBRATION MODEL69

TABLE 3.6 OUTPUT FROM LINEST EQUATION FOR CERILLIANT ${ }^{\circledR}{ }^{\text {DATA } \ldots \ldots \ldots \ldots \ldots \ldots . . . . . . . . . . . . . .69 ~}$

TABLE 3.7 RESTEK ${ }^{\circledR}$ DATA USED FOR THE FORMATION OF THE CALIBRATION MODEL.....70

TABLE 3.8 OUTPUT FROM LINEST EQUATION FOR RESTEK ${ }^{\circledR}$ DATA ........................ 70

TABLE 3.9 SIGMA-ALDRICH ${ }^{\circledR}$ DATA USED FOR THE FORMATION OF THE CALIBRATION

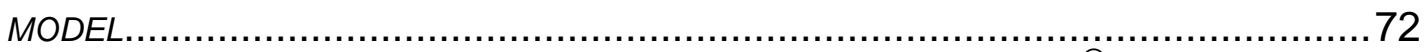

TABLE 3.10 OUTPUT FROM LINEST EQUATION FOR SIGMA-ALDRICH ${ }^{\circledR}$ DATA ...............73

TABLE 3.11 OUTPUT FROM LINEST EQUATION FOR COMBINED DATA....................... 74

TABLE 3.12 ACCURACY EVALUATION OF CERILLIANT ${ }^{\circledR}$ STANDARDS ........................... 75

TABLE 3.13 ACCURACY EVALUATION OF RESTEK ${ }^{\circledR}$ STANDARDS ..............................76

TABLE 3.14 ACCURACY EVALUATION OF SIGMA-ALDRICH ${ }^{\circledR}$ STANDARDS.....................76 
TABLE 3.15 PRECISION RESULTS FOR WITHIN-RUN MEASUREMENTS FOR EACH OF THE MANUFACTURERS REPORTED AS \%CV ...................................................78

TABLE 3.16 PRECISION RESULTS FOR BETWEEN-RUN MEASUREMENTS FOR EACH OF THE MANUFACTURERS CALCULATED FROM THE AVERAGE PEAK AREA RATIO OF METHAMPHETAMINE/METH-D14

TABLE 3.17 COMBINED METHOD PRECISION FOR EACH OF THE MANUFACTURERS CALCULATED FROM THE PEAK AREA RATIO OF METHAMPHETAMINE/METH-D14 ....79

TABLE 3.18 COMPARISON EVALUATION OF METHAMPHETAMINE ANALYSIS ACCOMPLISHED BY HS USING ABSOLUTE PEAK AREA VERSUS PEAK AREA RATIO...86

TABLE 4.1 TERMINOLOGY USED IN ESTABLISHING A DETECTING WINDOW ON JACS SOFTWARE.

TABLE 4.2 RULE WINDOWS FOR PROGRAMMING OF JUNO ${ }^{\Theta}$ ON JACS SOFTWARE IN THE DETECTION OF METHAMPHETAMINE

TABLE 4.3 INTENSITY OF METHAMPHETAMINE SAMPLE FROM CASE 1 UNDER THE FOUR METHAMPHETAMINE RULES MEASURED AT THREE HEAT SETTINGS

TABLE 4.4 POTENTIAL CHEMICAL INTERFERENCES IN THE ANALYSIS OF METHAMPHETAMINE BY JUNO ${ }^{\circledR}$

TABLE 5.1 SAMPLING LOCATIONS IN THE ANALYSIS OF METHAMPHETAMINE IN CONTAMINATED DODGE NEON.

TABLE 5.2 IMS PEAK AMPLITUDES RESULTING FROM POST-CIGARETTE SMOKING ANALYSIS

TABLE 5.3 METHAMPHETAMINE EVALUATION BY IMS IN THE SIMULATED MOBILE CLANDESTINE LABORATORY

TABLE 5.4 METHAMPHETAMINE SPIKED LOCATIONS WITHIN SIMULATED MOBILE CLANDESTINE LABORATORY. 


\section{LIST OF ABBREVIATIONS, SYMBOLS/NOMENCLATURE}

$\alpha$ :

$\lambda$ :

$\mu:$

$\mu \mathrm{g}:$

$\mu L:$

$\mu \mathrm{m}:$

$\mu \mathrm{s}:$

$\Omega:$

${ }^{\circ} \mathrm{C}$ :

$\% \mathrm{CV}:$

$\%$ RSD:

$A_{0}$ :

BP:

$\mathrm{CaSO}_{4} \cdot 1 / 2 \mathrm{H}_{2} \mathrm{O}$ : $\mathrm{CaSO}_{4} \cdot 2 \mathrm{H}_{2} \mathrm{O}$ :

$\mathrm{C}_{\mathrm{G}}$ :

$\mathrm{cm}$ :

CML:

$\mathrm{C}_{\mathrm{s}}$ :

CV:

CWA:

d:

D:

DC:

DEA:

DMS:

E:

El:

EPA:

EPC:

ESI:

eV:

FAIMS:

$\mathrm{ft}$ :

g:

GC:

GC/MS:

$\mathrm{HCl}$ :

$\mathrm{HI}$ :

HS-GC/MS

$\mathrm{HNO}_{3}$ :

$\mathrm{H}_{2} \mathrm{O}$ :

$\mathrm{H}_{3} \mathrm{PO}_{3}$ :

$\mathrm{H}_{3} \mathrm{PO}_{4}$ :
Mobility coefficient describing field dependence

Mean free path

Viscosity of a gas

Microgram

Microliter

Micrometer

Microseconds

Ohm

Degrees celsius

Coefficient of variance

Percent relative standard deviation

Aperature area

Boiling point

Calcium sulfate hemihydrate

Calcium sulfate dihydrate

Concentration of analyte in gas phase

Centimeter

Clandestine methamphetamine laboratory

Concentration of analyte in sample phase

Compensation voltage

Chemical warfare agent

Diameter

Diffusion coefficient

Direct current

U.S. Drug Enforcement Agency

Differential mobility spectrometry

Electric field

Electron Ionization

U.S. Environmental Protection Agency

Environmentally protective cap

Electrospray ionization

Electron volt

Field-asymmetric waveform ion mobility spectrometers

Feet

Gram

Gas Chromatography

Gas Chromatography - Mass Spectrometry

Hydrochloric acid

Hydroiodic acid

Headspace Gas Chromatography - Mass Spectrometry

Nitric acid

Water

Phosphorous acid

Phosphoric acid 


\begin{tabular}{|c|c|}
\hline $\begin{array}{l}\mathrm{H}_{2} \mathrm{SO}_{4}: \\
\mathrm{He}:\end{array}$ & $\begin{array}{l}\text { Sulfuric acid } \\
\text { Helium }\end{array}$ \\
\hline $\begin{array}{l}\text { He: } \\
\text { HEPA: }\end{array}$ & $\begin{array}{l}\text { Helium } \\
\text { High-efficiency particulate air }\end{array}$ \\
\hline HVAC: & Heating, ventilation, and air conditioning \\
\hline IMS: & Ion mobility spectrometry \\
\hline $\mathrm{J}:$ & Joule \\
\hline $\mathrm{k}$ : & Boltzmann constant $\left(1.38065 \mathrm{E}-23 \mathrm{~J} \mathrm{~K}^{-1}\right)$ \\
\hline K: & Kelvin \\
\hline $\mathrm{K}_{\mathrm{pc}}:$ & Partition coefficient \\
\hline $\mathrm{K}_{\mathrm{m}}:$ & Ion mobility \\
\hline $\mathrm{K}_{0}:$ & Reduced mobility constant \\
\hline kg: & Kilogram \\
\hline lbs: & Pounds \\
\hline LCD: & Liquid crystal display \\
\hline LC/MS & Liquid Chromatography - Mass Spectrometry \\
\hline LOD: & Limit of detection \\
\hline LOQ: & Limit of quantification \\
\hline$m:$ & Mass of the molecule \\
\hline m: & Meter \\
\hline $\mathrm{mCi}:$ & Millicuries \\
\hline M: & Molar mass \\
\hline MDA: & 3,4-methylenedioxyamphetamine \\
\hline MDEA: & 3,4-methylenedioxyethylamphetamine \\
\hline MDMA: & 3,4-methylenedioxymethamphetamine \\
\hline $\mathrm{m} / \mathrm{z}:$ & Mass to charge ratio \\
\hline mg: & Milligram \\
\hline $\min :$ & Minute \\
\hline mm: & Millimeter \\
\hline $\mathrm{mmHg}:$ & Millimeters of mercury \\
\hline mol: & Mole \\
\hline MS: & Mass spectrometry \\
\hline$n_{i}:$ & Number of moles present \\
\hline$n_{\text {total }}:$ & Total number of moles present \\
\hline $\mathrm{N}_{\mathrm{A}}:$ & Avogadro's constant (6.02214 E23 $\left.\mathrm{mol}^{-1}\right)$ \\
\hline $\mathrm{NaOH}:$ & Sodium hydroxide \\
\hline ng: & Nanogram \\
\hline$N_{2}(g):$ & Nitrogen gas \\
\hline $\mathrm{nm}:$ & Nanometer \\
\hline NTA: & Nicotinamide \\
\hline P: & Pressure \\
\hline$P_{\text {total: }}$ & Total pressure of the system \\
\hline Pa: & Pascal \\
\hline PFTBA & Perfluorotributylamine \\
\hline $\mathrm{PH}_{3}:$ & Phosphine \\
\hline PM: & Particulate matter \\
\hline ppb: & Parts per billion $\left(\mathrm{ng} \mathrm{mL}^{-1}\right)$ \\
\hline
\end{tabular}




$\begin{array}{ll}\text { ppm: } & \text { Parts per million }\left(\mathrm{ng}^{-1} \mathrm{l}^{-1}\right) \\ \text { R: } & \text { Ideal gas constant }\left(8.31447 \mathrm{~J} \mathrm{~K}^{-1} \mathrm{~mol}^{-1}\right) \\ \text { RH: } & \text { Relative humidity } \\ \text { RIP: } & \text { Reactant ion peak } \\ \text { RF: } & \text { Radio frequency } \\ \text { rpm: } & \text { Revolutions/minute } \\ \text { S: } & \text { Second } \\ \text { SD: } & \text { Standard deviation } \\ \text { SIM: } & \text { Selected ion monitoring } \\ \text { SPME: } & \text { Solid phase microextraction } \\ \text { STP: } & \text { Standard temperature and pressure } \\ \text { SV: } & \text { Separation voltage } \\ \text { SWGTOX } & \text { Scientific Working Group for Forensic Toxicology } \\ \text { SYP: } & \text { Southern yellow pine } \\ t: & \text { Time } \\ \text { T: } & \text { Temperature } \\ \text { Td: } & \text { Townsend } \\ \text { TIC: } & \text { Toxic industrial compounds } \\ \text { TIM: } & \text { Toxic industrial materials } \\ \text { USDA: } & \text { U.S. Department of Agriculture } \\ \bar{v}: & \text { Mean speed } \\ v_{\text {mp }}: & \text { Most probable speed } \\ v_{\text {rel }} & \text { Relative mean speed } \\ V_{\text {rms: }} & \text { Root-means-squared speed } \\ \text { V: } & \text { Volt } \\ \text { Vc: } & \text { Compensation voltage } \\ \text { VOC: } & \text { Volatile organic compounds } \\ \text { Vrf: } & \text { Radio frequency voltage } \\ \text { X: } & \text { mean } \\ \text { XIM: } & \text { Extracted ion monitoring } \\ Z_{c}: & \text { Collisional flux } \\ & \end{array}$




\section{CHAPTER 1: INTRODUCTION}

\subsection{Significance}

Methamphetamine is a Schedule II drug of abuse which is widely produced in the United States. According to the U.S. Drug Enforcement Agency (DEA), 12,033 methamphetamine clandestine laboratory seizure incidents occurred in 2011. ${ }^{1}$ The arrest and prosecution of persons involved in the clandestine production of methamphetamine takes one aspect of this issue into account; however, what is done with the facilities formerly used for production is often overlooked. These facilities include houses, hotel rooms, storage units, automobiles, or outdoor laboratories. ${ }^{2}$ This dissertation focuses on understanding methamphetamine detection in remediated clandestine laboratories.

The U.S. Environmental Protection Agency (EPA) has established voluntary guidelines for methamphetamine laboratory cleanup. The remediation standards set by the EPA assume that a gross removal of contaminants occurs. This is accomplished by removing all bulk chemicals and furniture, appliances, or any building material with obvious stains. The guidelines advise that cleanup begin by reducing volatile organic compounds (VOCs), which is accomplished by simply venting the structure, and should be continued throughout the remediation process. Heating, ventilation, and air conditioning (HVAC) systems should be cleaned and sealed, while all plumbing should be flushed. All surfaces should be vacuumed using a high-efficiency particulate air (HEPA) filter, followed up by a detergent-water solution cleanup. The final step is to encapsulate ceilings, walls 
and floors. Encapsulation is accomplished by adding two layers of oil-based paint to a surface. ${ }^{3}$

This remediation process leaves behind potentially contaminated structural support layers for the building. These materials may serve as sources for significant levels of harmful chemicals in the home over time. ${ }^{4} \mathrm{~A}$ house wall in North America is typically made to contain six layers, as shown in Figure 1.1. If this is assumed, then the wood studs of the home can serve as potentially significant sinks for methamphetamine vapor. This in turn raises the question of what, if any, health hazards result due to transport and release of this absorbed methamphetamine.

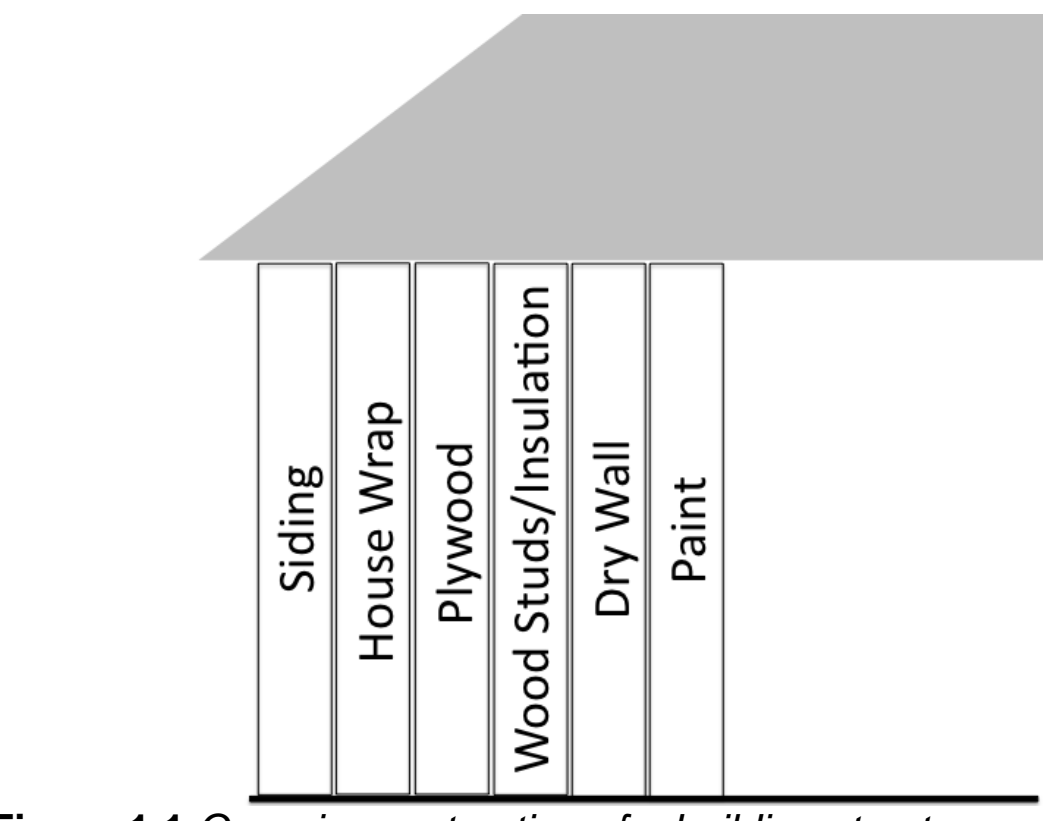

Figure 1.1 Generic construction of a building structure

A study at the National Jewish Medical and Research Center used the red phosphorus method to evaluate the extent of methamphetamine contamination in a house 24 hours after a cook. The report established that traceable levels of airborne methamphetamine remain present for at least this time period. ${ }^{5}$ 
Additionally, a pilot study conducted by Patrick et al. established that even after a site had been decontaminated to state-certified levels, the concentration of semivolatile organic chemicals on surface wipes had increased above the threshold within as little as five days after the decontamination. ${ }^{6}$ This suggests that methamphetamine contamination is more widespread and thus challenging to remediate than is typically assumed.

Congress passed the Methamphetamine Remediation Research Act of 2007 to gain further knowledge on better remediation techniques. In this act, the Federal government has stated there is a "lack of knowledge of how to achieve an effective cleanup." 7 The goal of this project is to address this concern by focused studies on methamphetamine fate and transport in indoor environments.

\subsection{Background}

\subsubsection{Use of Methamphetamine}

Methamphetamine's effect on the brain results in an increase in the level of dopamine. Dopamine is involved in pleasure, motivation, and motor function, such that an increase in dopamine results in an intense euphoria felt by many users of the drug. ${ }^{8}$ With only limited medicinal uses found for methamphetamine, including treatment of narcolepsy, attention deficit disorders, and obesity, it is likely abused due to its pleasurable sensations. ${ }^{9}$

On the street, methamphetamine has many different names, such as crystal, ice, crank, or speed, and is sold at $\$ 140$ - $\$ 190$ per gram according to the

DEA (as of 2007). ${ }^{9}$ Commonly it can be found in pill or powder form, which is normally the hydrochloride salt, and is consumed by swallowing, injecting, 
snorting or smoking. Smoking methamphetamine, often using a glass pipe, results in more rapid absorption; therefore, the effects are felt within seconds. The effects of snorting take 5-20 min before they are felt, while oral ingestion takes as long as 30-60 minutes. These effects vary by dose but typically last for $6-12$ hours. ${ }^{10}$ Due to the metabolism of methamphetamine, roughly $70 \%$ is excreted within 24 hours in the urine as methamphetamine (43\%), 4hydroxymethamphetamine (15\%), and amphetamine (5\%). ${ }^{11}$

As a stimulant, methamphetamine results in symptoms that include increased "wakefulness, increased physical activity, decreased appetite, increased respiration, rapid heart rate, irregular heartbeat, increased blood pressure, and hyperthermia." Consistent use over a long period will often result in extreme weight loss, severe dental problems, anxiety, mood disturbances, insomnia, and violent behavior. ${ }^{8}$

\subsubsection{The Chemistry of Methamphetamine}

Amines are derived from ammonia, where at least one of the hydrogen atoms is replaced with groups generically referred to as "R". The chemistry of amines is dominated by the lone-pair electrons on the nitrogen atom, which make the molecule both basic and nucleophilic. It is this chemistry that allows methamphetamine to undergo $S_{N} 2$ reactions.

Methamphetamine has a $\mathrm{pK}_{\mathrm{a}}$ of 10.38 , meaning that at $\mathrm{pH}$ values below this value, the protonated form will dominate. Methamphetamine undergoes acidbase reactions with atmospheric acids $\left(\mathrm{HCl}, \mathrm{HNO}_{3}, \mathrm{H}_{2} \mathrm{SO}_{4}\right)$ to form solid acid salts. This is of interest here given that particulate matter (PM) that has been 
implicated as a source of many adverse health effects. Certainly other salts can be formed by methamphetamine, but no information or physicochemical data regarding these were found in the literature. ${ }^{12}$

The transport of methamphetamine in air and through surfaces is dependent upon the protonation state of the ionizable amine center on the molecule. While it has been described that transport can occur as particulate matter, transportation can also occur in the vapor phase. The vapor pressure of methamphetamine as the free base (unprotonated) is $19.6 \mathrm{~Pa}(0.147 \mathrm{mmHg})$, suggesting that methamphetamine will vaporize to a significant and detectable extent under typical indoor temperatures and pressures.

While the protonated form is hydrophilic, the free base form is not; this is reflected in the $\log P$ value (Table 1.1). Although the solid salt form of methamphetamine is not appreciably volatile; it can become a constituent of particulate matter, making it mobile in the indoor environment as well. This mobility is governed by the size and settling characteristics of the particulate matter with which it is associated. This dissertation will consider the mobility, chemistry, fate and transport of both acid and base forms of methamphetamine with an emphasis on the gas-phase transport. ${ }^{12}$ 
Table 1.1 Chemical characteristics table for methamphetamine ${ }^{12}$

\begin{tabular}{|l|l|}
\hline \\
\hline Molecular Weight $(\mathrm{g} / \mathrm{mol}):$ & 149.2 \\
\hline pK $\mathrm{a}_{\mathrm{a}}:$ & 10.38 \\
\hline logP: & 2.202 \\
\hline Vapor Pressure $(\mathrm{Pa}):$ & 19.6 \\
\hline $\mathrm{BP}\left({ }^{\circ} \mathrm{C}\right):$ & 215.5 \\
\hline
\end{tabular}

\subsubsection{Clandestine Synthesis}

A key factor in the analysis of a clandestine methamphetamine laboratory $(\mathrm{CML})$ is the method used for production. The two most commonly used "cook" types in the United States are the red phosphorus and the Nazi methods. ${ }^{13}$ The red phosphorus method requires pseudoephedrine or ephedrine (Table 1.2) as a precursor, which is typically extracted from cold medicines. The precursors are reduced using iodine crystals and red phosphorus. A different technique is the Nazi method (also called the Birch method) reportedly used in Germany during World War II which utilizes anhydrous ammonia., ${ }^{4}{ }^{13}$ Both of these techniques for manufacturing methamphetamine involve other potentially harmful and volatile compounds, which should not be ignored. Common components of methamphetamine production for these two methods are listed in Table 1.3. ${ }^{4}$ 
Table 1.2 Isomers of ephedrine

1S, 2S-(+)-pseudoephedrine


Table 1.3 Frequently used chemicals in clandestine methamphetamine production ${ }^{4}$

\begin{tabular}{|c|c|c|c|c|c|c|c|c|}
\hline Chemical & $\begin{array}{l}\text { Common } \\
\text { Legitimate Use }\end{array}$ & Poison & Flammable & $\begin{array}{l}\text { Toxic } \\
\text { Vapors }\end{array}$ & Explosive & Corrosive & $\begin{array}{c}\text { Skin } \\
\text { Absorption }\end{array}$ & Common Health Hazards \\
\hline Acetone & $\begin{array}{l}\text { Finger nail polish remover, } \\
\text { solvents }\end{array}$ & $\mathrm{X}$ & $\mathrm{X}$ & $\mathrm{X}$ & & & $\mathrm{X}$ & Reproductive disorders \\
\hline Anhydrous Ammonia & Disinfectant & $\mathrm{x}$ & & $\mathrm{x}$ & & $\mathrm{x}$ & $\mathrm{x}$ & Blistering, lung damage \\
\hline Benzene & Varnishes, lacquers & $\mathrm{x}$ & $\mathrm{x}$ & $\mathrm{x}$ & $\mathrm{x}$ & $\mathrm{X}$ & $\mathrm{x}$ & Carcinogen, leukemia \\
\hline Ether & Anesthetic, starter fluid & $\mathrm{X}$ & $\mathrm{X}$ & & $\mathrm{X}$ & & & Respiratory failure \\
\hline Freon & Refrigerant, propellants & $\mathrm{x}$ & & $\mathrm{x}$ & & $\mathrm{X}$ & & Frostbite, lung damage \\
\hline Hydriodic Acid & Driveway cleaner & $\mathrm{X}$ & & $\mathrm{X}$ & & $\mathrm{X}$ & $\mathrm{X}$ & Burns, thyroid damage \\
\hline Hydrochloric Acid & Mining industry & $\mathrm{X}$ & & $\mathrm{X}$ & & $\mathrm{X}$ & $\mathrm{X}$ & Respiratory damage, liver damage \\
\hline Iodine Crystals & Antiseptic & $\mathrm{X}$ & $\mathrm{X}$ & & $\mathrm{X}$ & $\mathrm{X}$ & & Birth defects, kidney failure \\
\hline Lithium Metal & Lithium batteries & $\mathrm{X}$ & & & & $\mathrm{X}$ & $\mathrm{X}$ & Burns, pulmonary edema \\
\hline Methanol & Brake cleaner fluid & $\mathrm{X}$ & $\mathrm{X}$ & $\mathrm{X}$ & & & $\mathrm{X}$ & Blindness, eye damage \\
\hline Muriatic Acid & Swimming pool cleaner & $\mathrm{x}$ & & $\mathrm{X}$ & & $\mathrm{x}$ & & Burns, lung damage \\
\hline Phosphine gas & Pesticides & $\mathrm{X}$ & & $\mathrm{x}$ & & & $\mathrm{x}$ & Respiratory failure \\
\hline Pseudophedrine & Cold medicines & $\mathrm{x}$ & & & & & & Heart damage \\
\hline Red Phosphorus & Matches, fireworks & $\mathrm{x}$ & $\mathrm{X}$ & $\mathrm{x}$ & $\mathrm{x}$ & & & Unstable flammable substance \\
\hline Sodium Hydroxide & Drain cleaners, lye & $\mathrm{X}$ & & $\mathrm{X}$ & & $\mathrm{X}$ & $\mathrm{x}$ & Burns, skin ulcers \\
\hline Sulfuric Acid & Battery acid & $\mathrm{x}$ & & $\mathrm{X}$ & & $\mathrm{X}$ & $\mathrm{X}$ & Burns, thyroid damage \\
\hline Toluene & Paint, thinners, solvents & $\mathrm{X}$ & $\mathrm{X}$ & $\mathrm{X}$ & $\mathrm{X}$ & & $\mathrm{X}$ & Fetal damage, pneumonia \\
\hline $\begin{array}{l}\text { Liquid Laboratory } \\
\text { Waste }\end{array}$ & Not applicable & $\mathrm{X}$ & $\mathrm{X}$ & $\mathrm{X}$ & $\mathrm{X}$ & $\mathrm{x}$ & $\mathrm{X}$ & Unknown long-term effects \\
\hline
\end{tabular}


The stereochemistry of the methamphetamine produced in clandestine synthesis also depends on the isomer of ephedrine used. There are four isomers of ephedrine, shown in Table 1.3. ${ }^{13-14}$ The "R" and " $S$ " assignments are given to the two chiral centers on the ephedrine molecule.

These isomers of ephedrine allow for the production of two forms of methamphetamine where the use of either (1R,2S)-(-)-ephedrine or $(1 \mathrm{~S}, 2 \mathrm{~S})-(+)-$ pseudoephedrine will result in the production of $(\mathrm{S})-(+)$-methamphetamine (Table 1.4). Using the isomers, $(1 \mathrm{~S}, 2 \mathrm{R})-(+)$-ephedrine and (1R,2R)-(-)-pseudoephedrine will yield (R)-(-)-methamphetamine. As the more physiologically active form (S)-(+)methamphetamine, also called d-methamphetamine, is typically produced in clandestine laboratories. ${ }^{13}$

Table 1.4 Isomers of methamphetamine

\begin{tabular}{|c|c|}
\hline S-(+)-methamphetamine & R-(-)-methamphetamine \\
\hline
\end{tabular}

The production of methamphetamine can be accomplished by a variety of different methods. Often times these "cooks" are carried out with simple tools and crude apparatuses. ${ }^{15}$ More information regarding these techniques are explained in further sections according to the N.C. State Bureau Drug Chemistry Training Manual. ${ }^{10,13,16}$ 


\subsubsection{Red Phosphorous Method}

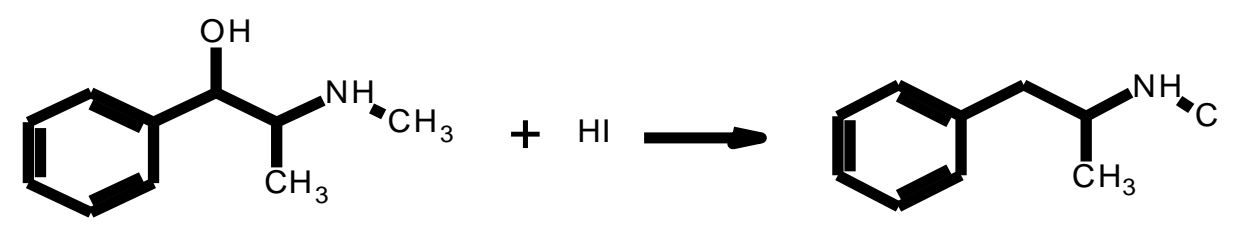

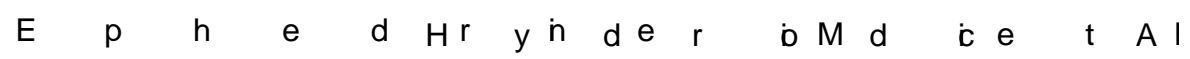

Figure 1.2 Red phosphorus method of production for methamphetamine

The red phosphorus method begins with pseudoephedrine hydrochloride or ephedrine hydrochloride often purchased as cold medicine (Figure 1.2). The tablets are then ground into a fine powder; this can be achieved by using a standard kitchen grinder or blender. The powder is then soaked in a solvent like methanol, often times obtained as brake cleaner. Coffee filters can then be used to remove the insoluble compounds and the filtrate evaporated to leave behind the (pseudo) ephedrine powder. ${ }^{16}$

Red phosphorus (Red P) can then be obtained from soaking matchbook striker plates in isopropyl alcohol to remove the binder and permit the Red $\mathrm{P}$ to be scrapped off the cover. Tincture of iodine, hydrogen peroxide, and a strong acid are typically combined to precipitate iodine, which can then be filtered leaving iodine crystals. The (pseudo) ephedrine, red phosphorus, and iodine crystals are then combined with water and refluxed for roughly 2 hours, yielding an acidic solution containing methamphetamine base. ${ }^{16}$

Hydriodic acid $(\mathrm{HI})$ is thus produced by this step of the reaction using red phosphorus $(\mathrm{P})$ and iodine crystals $\left(\mathrm{I}_{2}\right)$ as seen in this three-step reaction:

$$
\begin{array}{ll}
3 \mathrm{I}_{2}(\mathrm{~s})+2 \mathrm{P}(\mathrm{s})+6 \mathrm{H}_{2} \mathrm{O}(\mathrm{l}) \rightarrow 2 \mathrm{PI}_{3}(\mathrm{~s})+6 \mathrm{H}_{2} \mathrm{O}(\mathrm{I}) & \text { Reaction } 1.1 \\
2 \mathrm{PI}_{3}(\mathrm{~s})+6 \mathrm{H}_{2} \mathrm{O}(\mathrm{l}) \rightarrow \mathrm{HI}(\mathrm{aq})+2 \mathrm{H}_{3} \mathrm{PO}_{3}(\mathrm{aq}) & \text { Reaction } 1.2
\end{array}
$$


$4 \mathrm{H}_{3} \mathrm{PO}_{3}(\mathrm{aq}) \rightarrow 3 \mathrm{H}_{3} \mathrm{PO}_{4}(\mathrm{aq})+\mathrm{PH}_{3}(\mathrm{~g})$

Reaction 1.3

Overheating the reaction mixture can cause the thermally unstable phosphorus acid $\left(\mathrm{H}_{3} \mathrm{PO}_{3}\right)$ to decompose to phosphoric acid $\left(\mathrm{H}_{3} \mathrm{PO}_{4}\right)$ and phosphine $\left(\mathrm{PH}_{3}\right)$ gas shown in Reaction 3. Phosphine gas has a flammability level 4, health level 4, and instability level 2 according to the Hazardous Material Information System and National Fire Protection Association scale. The gas is also very toxic and if inhaled, health effects on lungs, heart, upper respiratory tract, and the central nervous system (CNS) have been shown. ${ }^{17}$ These factors make production of this gas one of the largest hazards in clandestine methamphetamine production.

To the acidic filtrate, a strong base containing $\mathrm{NaOH}$ (such as drain opener, "DrainO") is added to convert the solution to basic $\mathrm{pH}$. Extraction of the methamphetamine occurs by the addition of an organic solvent, such as toluene found in starter fluid. Hydrochloric gas $(\mathrm{HCl})$ is then bubbled through the solvent to convert methamphetamine base to methamphetamine $\mathrm{HCl}$. The $\mathrm{HCl}$ gas can be produced clandestinely by adding rock salt to sulfuric acid $\left(\mathrm{H}_{2} \mathrm{SO}_{4}\right)$, obtained from batteries (Reaction 4). ${ }^{16}$

$2 \mathrm{NaCl}(\mathrm{s})+\mathrm{H}_{2} \mathrm{SO}_{4}(\mathrm{aq}) \rightarrow 2 \mathrm{HCl}(\mathrm{g})+\mathrm{Na}_{2} \mathrm{SO}_{4}(\mathrm{aq}) \quad$ Reaction 1.4

\subsubsection{Nazi (Birch) Method}

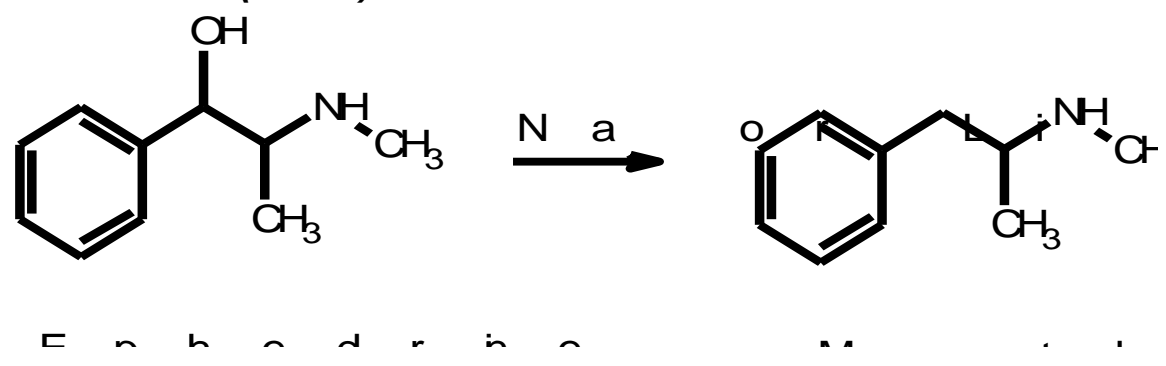

Figure 1.3 Nazi reaction method of methamphetamine production 
Methamphetamine production according to the Nazi method is similar to that of the red phosphorus production, in that (pseudo) ephedrine powder is extracted from cold medicine (Figure 1.3). However, in this method, anhydrous ammonia is cooled and liquefied by placing in an ice bath. Anhydrous ammonia is available as fertilizer for large-scale crop production at agriculture supply stores. The fertilizer is combined with $\mathrm{NaOH}$ and water to produce ammonium gas. ${ }^{16}$

Lithium is then obtained, typically from stripping batteries, and combined with the (pseudo) ephedrine in the cooled vessel with ammonia. When these chemicals are combined the reaction is blue in color. The reaction is allowed to proceed under constant stirring until it turns a gray color. At this point, water is added to quench the remaining lithium. This methamphetamine base is then converted to the acidic form in the same way as outlined in the red phosphorus method. ${ }^{16}$

\subsubsection{Clandestine Laboratory Analysis}

According to the EPA, a clandestine laboratory is defined as "an illicit operation consisting of a sufficient combination of apparatus and chemicals that either has been or could be used in the manufacture or synthesis of controlled substances." Once a clandestine laboratory is identified and police are notified, the DEA seizure process begins. This process usually consists of seven steps, (1) planning; (2) entry; (3) assessment; (4) deactivation; (5) processing; (6) exit; and (7) follow-up. In the planning phase, necessary tactical supports for the seizure are contacted to make entry and remove lab operators. Once the entry is complete, the laboratory is secured and the assessment phase begins. 
Assessment is of particular interest since this is the time at which forensic chemists establish health risks, and help to reduce possible safety hazards. This includes identifying and taking inventory of chemicals and equipment on-site, as well as stopping potential on-going reactions. Once the chemists have finished processing the laboratory, the DEA (or local health department) is responsible for contacting chemical hazard consultants to remove any bulk hazardous waste that was not used as evidence. A final inspection occurs along with the site being secured and prominently labeled with a warning. ${ }^{18}$

Most states require the site to be left in this condition until it has been investigated for residual contamination. It is the responsibility of the property owner to hire a commercial contractor certified as a Clandestine Laboratory Remediation Contractor or Industrial Hygienist. At this point, the need for remediation is assessed. Finally, the department of health must certify that the structure has been properly decontaminated before human habitation is allowed. ${ }^{18}$

A list of locations with formerly identified CMLs is accessible via the DEA website. It is also recommended that the local health department and law enforcement agency certify, or otherwise approve of these contractors. No public funds or grants are currently available to supplement cleanup expenses for CMLs, so the burden remains on the property owner. ${ }^{18}$ The average cost of remediation is between $\$ 5,000-\$ 150,000$ dependent upon the extent of contamination, established by the lab process, quantity, and form of chemicals present. ${ }^{19}$ In some case decontamination is not possible, and demolition is recommended. 
Notably, no standard method of cleanup is established nationwide for CMLs. The EPA and many states recommend that bulk chemicals, furniture, appliances, and other potentially contaminated items be removed from the site in an attempt to reduce contamination levels. According to the 2009 U.S. EPA's Voluntary Guidelines For Methamphetamine Laboratory Cleanup, "current state standards range from $0.05 \mu \mathrm{g} / 100 \mathrm{~cm}^{2}$ to $0.5 \mu \mathrm{g} / 100 \mathrm{~cm}^{2}$, with most common state standard being 0.1 $\mu \mathrm{g} / 100 \mathrm{~cm}^{2 "}$ for surface contamination. ${ }^{3 a}$ The contamination standard set by each state is found in Table 1.5 .

Table 1.5 State maximum contamination of methamphetamine $e^{3 a}$

\begin{tabular}{|c|c|}
\hline Contamination Level & State \\
\hline \multirow[t]{2}{*}{$1.5 \mu \mathrm{g} / 100 \mathrm{~cm}^{2}$} & Kansas \\
\hline & Wyoming \\
\hline \multirow[t]{2}{*}{$0.5 \mu \mathrm{g} / 100 \mathrm{~cm}^{2}$} & Colorado \\
\hline & Michigan \\
\hline $0.11 \mu \mathrm{g} / 100 \mathrm{~cm}^{2}$ & Minnesota \\
\hline \multirow{17}{*}{$0.10 \mu \mathrm{g} / 100 \mathrm{~cm}^{2}$} & Alaska \\
\hline & Arizona \\
\hline & Arkansas \\
\hline & California \\
\hline & Connecticut \\
\hline & Hawaii \\
\hline & Idaho \\
\hline & Minnesota \\
\hline & Montana \\
\hline & Nebraska \\
\hline & New Hampshire \\
\hline & North Carolina \\
\hline & South Dakota \\
\hline & Tennessee \\
\hline & Utah \\
\hline & Washington \\
\hline & West Virginia \\
\hline $0.05 \mu \mathrm{q} / 100 \mathrm{~cm}^{2}$ & Oregon \\
\hline
\end{tabular}


The state level contamination standards have been set based upon sample wipe methodology. The sampling technique is explained in all of the $\mathrm{NIOSH}$ surface methamphetamine methods. ${ }^{20}$ Briefly, the analysis requires a surface area of 100 $\mathrm{cm}^{2}$ (often sampled using a $10 \mathrm{~cm} \times 10 \mathrm{~cm}$ template) be sampled using 12-ply cotton gauze or wipe moistened using methanol or isopropanol wiped by one of the following methods: (1) concentric squares wiping; (2) side-to-side wiping (or blotting). In both the concentric square and side-to-side wipe methods the prewetted gauze is folded in half, and then in half again. The concentric squares method starts at one corner of the surface area and wipes with concentric squares until in the center, where the last fold is reversed and the same area is wiped concentrically again. The side-to-side wipe makes use of the folded gauze passing over the surface area in at least five overlapping side-to-side horizontal passes followed by a reversed fold and re-wipe of the same area. Finally, repeat wiping is used if isopropanol is the solvent, such that two wipes are used for the same sample surface in order to improve the efficiency.

State law throughout much of the United States now dictates that property owners notify prospective purchasers of the presences of a former methamphetamine laboratory on their site. This is due in part, to persons reporting health issues shortly after moving into former CMLs. Chronic exposure has not been studied to any significant degree and no reports on this topic were found in the literature. However, anecdotal evidence suggests that chronic exposure results in a tendency toward migraines and difficulty breathing and even to skin irritations and 
burns. A review in Toxicological Sciences suggests the potential for methamphetamine as a cancer-causing agent. ${ }^{21}$

\subsubsection{Methamphetamine in the Indoor Environment}

In 2001, an average American home contained more than 571 square meters of gypsum wallboard. ${ }^{22}$ This gypsum wallboard is used to establish walls and barriers of buildings, and is often called wallboard, drywall, or plasterboard. The wallboard is constructed from calcium sulfate hemi-hydrate with a sheet of board paper on either side. ${ }^{23}$ Pure gypsum is actually $\mathrm{CaSO}_{4} \cdot 2 \mathrm{H}_{2} \mathrm{O}$ (calcium sulfate dihydrate); however, when it is heated a majority of its water is lost forming the hemihydrate $\left(\mathrm{CaSO}_{4} \bullet 1 / 2 \mathrm{H}_{2} \mathrm{O}\right)$. This dried product is also called plaster of Paris. To make the drywall, the powder is mixed with water to make a paste which when dry will be solid and sturdy. ${ }^{22}$

In the manufacturing process of $\mathrm{CaSO}_{4} \cdot 1 / 2 \mathrm{H}_{2} \mathrm{O}$ the preparation route establishes the crystalline structure that will result. $\alpha-\mathrm{CaSO}_{4} \bullet 1 / 2 \mathrm{H}_{2} \mathrm{O}$ results from heating within the temperature range of $120-160{ }^{\circ} \mathrm{C}$ and up to 8 bar (hydrothermal conditions), while $\beta$ - $\mathrm{CaSO}_{4} \cdot 1 / 2 \mathrm{H}_{2} \mathrm{O}$ is obtained from heating at $120-180{ }^{\circ} \mathrm{C}$ (dry heat conditions). Due to differences in their specific surface area (SSA) it is believed that the hemi-hydrates result in crystals of different particle sizes. ${ }^{24}$

Table 1.6 Comparison of the $\alpha$ - and $\beta$-forms of calcium sulfate hemihydrate

\begin{tabular}{|c|c|c|}
\hline & $\alpha-\mathrm{CaSO}_{4} \cdot 1 / 2 \mathrm{H}_{2} \mathrm{O}$ & $\beta-\mathrm{CaSO}_{4} \bullet 1 / 2 \mathrm{H}_{2} \mathrm{O}$ \\
\hline Preparation Temperature $\left({ }^{\circ} \mathrm{C}\right)$ & $120-160$ & $120-180$ \\
\hline Specific Surface Area $\left(\mathrm{m}^{2} \mathrm{~g}^{-1}\right)$ & $\sim 1$ & $\sim 10$ \\
\hline Density $\left(\mathrm{g} \mathrm{cm}^{-1}\right)$ & 2.74 & 2.73 \\
\hline Crystal Structure & 1121 (monoclinic) & $\mathrm{P} 3_{1}$ (trigonal) \\
\hline
\end{tabular}


While the crystalline structures of the $\alpha$ - and $\beta$ - forms have been debated, a consensus has been reached showing differences in the basic structure. Yet both structures demonstrate water channels, which allow for the potential to trap gas phase or particulate methamphetamine. It is also possible that the methamphetamine will pass easily through with little resistance due to the gaps within the structure.

A study conducted by Martyny verifies the potential for methamphetamine to cross the gypsum boundary. This study at the National Jewish Medical and Research Center discussed the presence of methamphetamine on both the front and back paper that surrounds the wallboard, suggesting that the methamphetamine has travelled around the surface instead of through the material. This is because their primary means of investigation was the analysis of surface wipes. ${ }^{25}$ Methamphetamine in the vapor phase can settle onto the material and may diffuse through channel openings in the material as well as transport throughout an open-air environment.

Since painted drywall is typically removed upon cleaning a CML, the wooden framing studs are a reservoir of potential contamination. Wood studs typically utilize 2" x 4" pine boards, due to their low cost and structural strength. Yellow pine, also termed southern yellow pine (SYP), describes a class of pines that are most commonly used in indoor framing construction. The southern yellow pine is considered to be a heavy wood, with a density around $537-626 \mathrm{~kg} \mathrm{~m}^{-3}$, and is one of the hardest woods used in construction with a Janka hardness rating of $690 .{ }^{26}$ 
The volatile organic constituents of wood will vary based upon a number of factors; however, the main constituents are considered to be terpenes and terpenoids, aliphatic compounds, and phenols. The most volatile of these components are terpenes, more specifically monoterpenes. Terpenes have the chemical formula $\left(\mathrm{C}_{5} \mathrm{H}_{8}\right)_{n}$, where $n \geq 2$, such that their base structure comes from isoprene. Examples of the main volatile constituents of wood are shown in Table $1.7 .^{26}$

Table 1.7 Volatile organic components of wood ${ }^{27}$

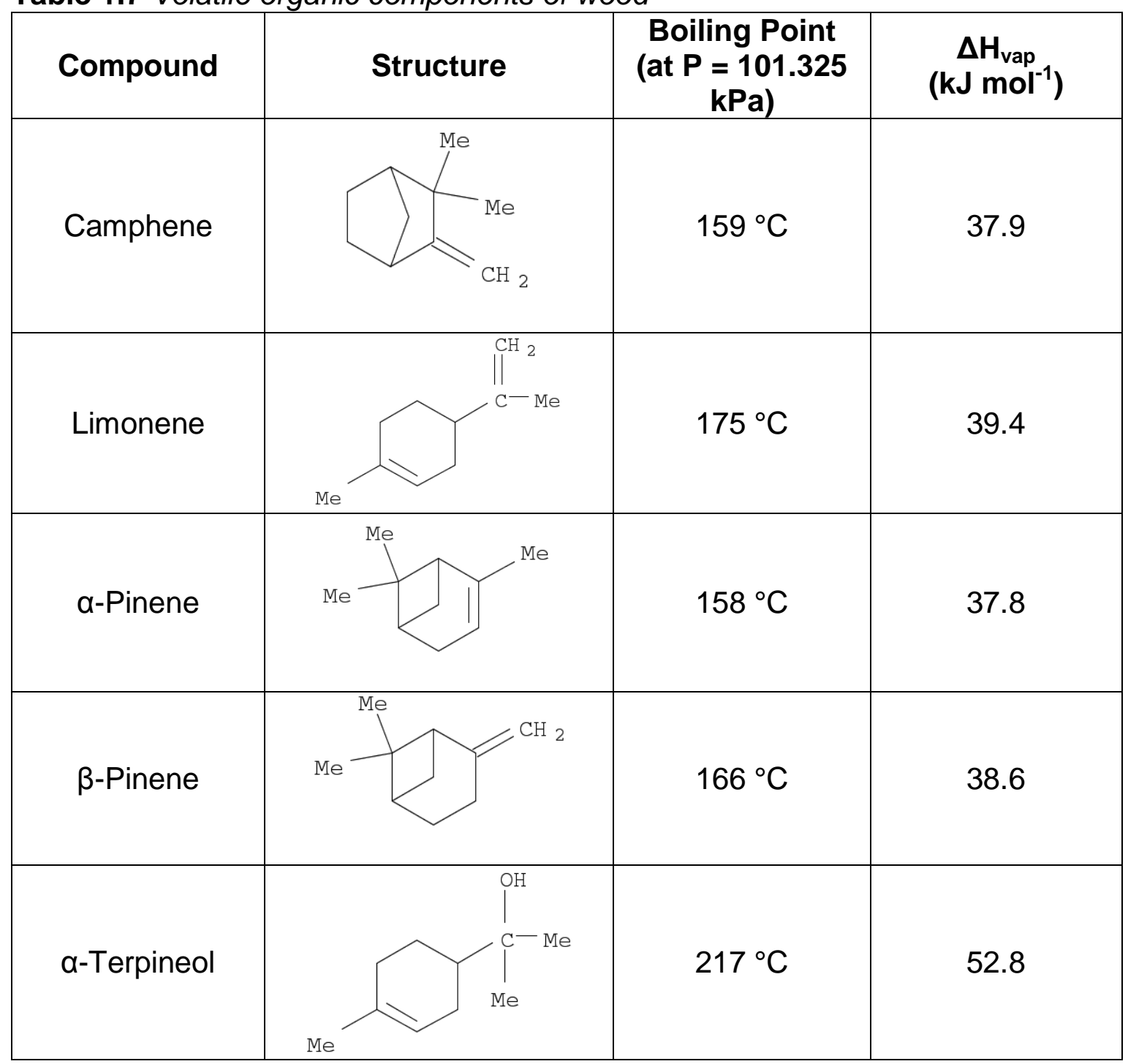




\subsubsection{Particulate Matter}

Aerosols are known to consist of either solid or liquids, in small amounts, which are temporarily suspended in air. In cases where a liquid is being suspended the term droplet is used, while particulate matter is used to refer to either a solid or liquid particle. ${ }^{28}$ These particles vary by size, shape, and composition; however, all can be described by their diameter. While it is well established that these particles are often times not spherical in shape, they are typically modeled as such. Particles of a diameter less than $2.5 \mu \mathrm{m}$ are called fine (or PM2.5), while particles of diameter $2.5-10 \mu \mathrm{m}$ are known as coarse (or PM10). ${ }^{29}$

Airborne particulate matter represents a complex mixture of organic and inorganic substances. There are four typical methods by which particulate matter can be formed: (1) physical attrition; (2) combustion particle burnout; (3) homogenous or heterogeneous nucleation; and (4) droplet evaporation. When two surfaces rub together producing particulate of the same composition and density as the parent particle, this is termed physical attrition. Combustion particulates are the product of fuel entering hot furnace combustion. Nucleation converts vapor phase material to particulate, and droplet evaporation occurs as small particles are produced from evaporation of analyte. Physical and combustion methods produce particulate in the range of $1-1,000 \mu \mathrm{m}$ in size, while homogeneous and heterogeneous nucleation, and drop evaporation produce a particulate that is smaller than $1 \mu \mathrm{m}$ in diameter. ${ }^{30}$

According to a study conducted by Martyny, methamphetamine was found to exist most commonly as a respirable particle of size less than $1.0 \mu \mathrm{m} .{ }^{5}$ These 
particles likely come in the form of methamphetamine-loaded dust. The health risks imposed on persons exposed to methamphetamine, vapor and particulates, are of concern. Once a particle enters the lungs, deposition and removal are dependent upon the chemical and physical characteristics of that particle as well as the individual exposed to the chemical. Differences in breathing patterns and route of exposure, nose or mouth, will also influence particle deposition in individuals. Children are often at a greater risk as they breathe a relatively greater volume of air than adults due to their higher metabolism. ${ }^{31}$

Hairs within the nasal cavity, and impaction in the nasal turbinates filter particles inhaled through the nose. The turbinates operate by changing the direction of the inhaled air, such that particles once suspended in the air are unable to change direction at the same rate thus resulting in collisions with the mucus layer. Once the particles are trapped within the mucus coating they are transported by the cilia to the pharynx, where they are swallowed. Inhalation through the nose is highly efficient in removing particles greater than $5 \mu \mathrm{m}$ in diameter. ${ }^{31}$

The mouth is an important entry site into the respiratory tract, where particles can be passed through the trachea and into the lungs for deposition by impaction, sedimentation, and/or diffusion. Similar to the nasal cavity, impaction is the major route of removal for particles greater than $5 \mu \mathrm{m}$ in diameter. Methamphetamine deposition most likely results from sedimentation and diffusion within the lower respiratory tract, which is most common for particles $0.1-1 \mu \mathrm{m}$ in diameter. ${ }^{31}$

Inhalation and ingestion of methamphetamine-loaded dust is one route of exposure; however, dermal contact with methamphetamine-contaminated surfaces 
should not be ignored. Estimated doses for methamphetamine by dermal exposure, based upon $10 \%$ dermal absorption fraction, were accomplished by the Colorado Department of Public Health and Environment in 2005 (Table 1.8). ${ }^{32}$

Table 1.8 Comparison of methamphetamine dosage based upon calculated exposure and toxicity ${ }^{32}$

\begin{tabular}{|c|l|}
\hline $\begin{array}{c}\text { Dose } \\
\left(\mathbf{m g ~ k g}^{-1} \mathbf{d a y}^{-1}\right)\end{array}$ & \multicolumn{1}{c|}{ Basis } \\
\hline $4 \times 10^{-5}$ & $\begin{array}{l}\text { Calculated dose to an infant exposed at } \\
0.05 \mu \mathrm{g} / 100 \mathrm{~cm}^{2} \text { wipe concentration }\end{array}$ \\
\hline $8 \times 10^{-5}$ & $\begin{array}{l}\text { Calculated dose to an infant exposed at } \\
0.1 \mu \mathrm{g} / 100 \mathrm{~cm}^{2} \text { wipe concentration }\end{array}$ \\
\hline $4 \times 10^{-4}$ & $\begin{array}{l}\text { Calculated dose to an infant exposed at } \\
0.5 \mu \mathrm{g} / 100 \mathrm{~cm}^{2} \text { wipe concentration }\end{array}$ \\
\hline $4 \times 10^{-3}$ & $\begin{array}{l}\text { Calculated RfD based on reproductive } \\
\text { endpoints }\end{array}$ \\
\hline $5 \times 10^{-3}$ & $\begin{array}{l}\text { Calculated RfD based on neurotoxicity } \\
\text { endpoints }\end{array}$ \\
\hline $7 \times 10^{-3}$ & $\begin{array}{l}\text { Calculated RfD based on postnatal } \\
\text { development endpoints }\end{array}$ \\
\hline $1 \times 10^{-2}$ & $\begin{array}{l}\text { Lowest therapeutic level assuming } \\
5 \text { mg dose for a 70 kg adult }\end{array}$ \\
\hline 2.14 & $\begin{array}{l}\text { Illicit usage assuming a 150 mg daily } \\
\text { dose for a 70 kg adult }\end{array}$ \\
\hline
\end{tabular}

The daily dose calculations are an upper limit of the total potential dose as a result of both hand-to-mouth oral exposure and direct dermal absorption. The reference dosage $(R f D)$ values were established from laboratory studies on neurotoxicity and developmental toxicity of animals dosed with methamphetamine. To date, established toxicity values for methamphetamine are not available through the EPA for any route of exposure. ${ }^{32}$

The average exposure to methamphetamine occurring in a day due to surface contamination, estimated from Martyny's established average surface concentration, was equal to $0.41 \mathrm{mg} \mathrm{kg}^{-1} \mathrm{day}^{-1}(499 \mu \mathrm{g} / \mathrm{sample}) .{ }^{32}$ The health hazards associated 
with chronic exposure to these low concentrations are not presented in the literature; however, these levels are well below the median lethal dose $\left(L D_{50}\right)$ for methamphetamine. In intraperitoneal studies using mice, $\mathrm{LD}_{50}$ were found to range from $67.8-119.6 \mathrm{mg} \mathrm{kg}^{-1}$. It should be noted that animal studies demonstrated the loss of the life at concentrations much lower than that of the $\mathrm{LD}_{50}\left(9 \mathrm{mg} \mathrm{kg}^{-1}\right)$ when room temperature was increased. It is believed that methamphetamine induces brain hyperthermia leading to the breakdown of the blood-brain barrier, likely contributing to loss of brain function and neurodegeneration. ${ }^{33}$

\subsubsection{Diffusion}

The first understandings of particulate motion began in 1827 with the observations of Brownian motion by Robert Brown. Brown observed the irregular wiggling motion of pollen grains in water, which resulted from randomized interactions of a gas/liquid against a particle. Einstein then went on to characterize the movements in the 1900s. Diffusion can therefore be described as the net transport of particles as a result of a concentration gradient. ${ }^{28}$

The transport, or molecular motion, of methamphetamine can be predicted by modeling, as well as measured through experimentation. As the primary means by which small particles $(<0.1 \mu \mathrm{m})$ travel, diffusion will first be considered. The diffusion coefficient, $D\left(\mathrm{~m}^{2} \mathrm{~s}^{-1}\right)$, can be calculated by: ${ }^{34}$

$$
D=\frac{1}{3} \lambda \bar{v}
$$

Where $\lambda$ is the mean free path $(\mathrm{m})$; and $\bar{v}$ is the mean speed $\left(\mathrm{m} \mathrm{s}^{-1}\right)$. Upon substitution: ${ }^{34}$ 
$D=\frac{1}{3}\left(\frac{v^{2}}{z}\right)$

Further simplification of this equation yielded:

$D=\frac{8}{3}\left(\frac{T}{\pi d}\right)^{2}\left(\frac{R k}{\bar{v}_{r e l} M P}\right)$

Where $T$ is temperature $(K)$; $d$ is the diameter $(m)$; $R$ is the ideal gas constant $(8.314$ $\left.47 \mathrm{~J} \mathrm{~K}^{-1} \mathrm{~mol}^{-1}\right) ; \mathrm{k}$ is Boltzmann constant $\left(1.38065 \mathrm{E}-23 \mathrm{~J} \mathrm{~K}^{-1}\right) ; \mathrm{V}_{\text {rel }}$ is the relative mean speed, $V_{\text {rel }}=2^{1 / 2} v$ (also called the most probable speed, $\mathrm{m} \mathrm{s}^{-1}$ ); and $\mathrm{P}$ is pressure (Pa). With this knowledge, the diffusion coefficient for methamphetamine can then be estimated using typical room pressure of $101.325 \mathrm{kPa}$.

The diameter of the methamphetamine molecule, $d$, was determined to be $0.86 \mathrm{~nm}$ using HyperChem ${ }^{\odot}$ (Hypercube, Inc) modeling software, which geometrically optimizes the structure according to bond lengths. Martyny's study found that methamphetamine existed in the air environment as particles smaller than $1 \mu \mathrm{m}$ in diameter. ${ }^{5}$ This suggests that, whereas the molecular diameter usually underestimates the collisional cross-section, it can be used as a representative model of the minimum collision rate. Using the model diameter, the average methamphetamine diffusion at room temperatures is $1.18 \times 10^{-6} \mathrm{~m}^{2} \mathrm{~s}^{-1}$. It is expected that the measured results from experimentation would result in lower diffusion rates due in part to adsorption to surfaces, thus making diffusion an almost negligible process in the transport of methamphetamine in the environment. 


\subsubsection{Molecular Speed}

The Maxwell distribution shows the probability of a molecule having a speed between $v$ and $v+d v$. These particle speeds are often compared as most probable speed, mean speed, and root-mean-squared speed. ${ }^{35}$ The speed variables used throughout the calculations follow the text, Atkins' Physical Chemistry; ${ }^{34}$ however, the values for root-mean-squared speed and most probable speed have been presented for comparison. As the calculations for most probable and mean speed have been shown above, root-mean-squared speed, $\mathrm{v}_{\mathrm{rms}}\left(\mathrm{m} \mathrm{s}^{-1}\right)$, is: $:^{34-35}$

$$
v_{r m s}=\left(\frac{3 R T}{M}\right)^{1 / 2}
$$

Where, $\mathrm{R}$ is the ideal gas constant $\left(8.31447 \mathrm{~J} \mathrm{~K}^{-1} \mathrm{~mol}^{-1}\right)$; $\mathrm{T}$ is temperature $(\mathrm{K})$; $\mathrm{M}$ is the molar mass $\left(\mathrm{kg} \mathrm{mol}^{-1}\right)$. The most probable speed, $\mathrm{v}_{\mathrm{mp}}\left(\mathrm{m} \mathrm{s}^{-1}\right)$, is: ${ }^{34-}$ ${ }^{35} v_{m p}=\left(\frac{2 R T}{M}\right)^{1 / 2}$

These three speeds have been calculated over the temperature range of analysis and are presented in the table below (Table 1.9).

Table 1.9 Comparison values for speed distribution

\begin{tabular}{|c|c|c|c|}
\hline $\begin{array}{c}\text { Temp } \\
\text { (-) }\end{array}$ & $\begin{array}{c}\text { Most probable speed } \\
\left(\mathbf{m ~ s}^{-1}\right)\end{array}$ & $\begin{array}{c}\text { Mean speed } \\
\left(\mathbf{m ~ s}^{-1}\right)\end{array}$ & $\begin{array}{c}\text { Root-mean-squared } \\
\text { speed }\left(\mathbf{m ~ s}^{-1}\right)\end{array}$ \\
\hline-10 & 171.4 & 193.4 & 209.9 \\
\hline-5 & 173.0 & 195.3 & 211.9 \\
\hline 0 & 174.6 & 197.1 & 213.8 \\
\hline 5 & 176.2 & 198.9 & 215.8 \\
\hline 10 & 177.8 & 200.6 & 217.7 \\
\hline 15 & 179.3 & 202.4 & 219.6 \\
\hline 20 & 180.9 & 204.2 & 221.5 \\
\hline 25 & 182.4 & 205.9 & 223.4 \\
\hline 30 & 183.9 & 207.6 & 225.3 \\
\hline 35 & 185.4 & 209.3 & 227.1 \\
\hline
\end{tabular}




\subsubsection{Effusion}

There is clearly a possibility that methamphetamine will deposit on a surface. The vapor can simply condense on a surface or effuse through possible pores in the material. Effusion is the means by which a gas passes through an opening, or pore, often summarized by Graham's law of effusion. This states that the rate of effusion is inversely proportional to the square root of the molar mass, which is described by the collisional flux, $\mathrm{Z}_{\mathrm{c}}\left(\mathrm{m}^{-2} \mathrm{~s}^{-1}\right)$, in the equation: ${ }^{35}$

$$
Z_{C}=\frac{P}{(2 \pi m k T)^{1 / 2}}=P\left(\frac{N_{A}}{2 \pi k t M}\right)^{1 / 2}
$$

where $m$ is the mass of the molecules, such that $M=m N_{A}$, where $N_{A}$ is Avogadro's constant $\left(6.02214 \times 10^{23} \mathrm{~mol}^{-1}\right), \mathrm{k}$ is the Boltzmann constant $\left(1.38065 \times 10^{-23} \mathrm{~J} \mathrm{~K}^{-1}\right), \mathrm{T}$ is temperature $(\mathrm{K})$, and $\mathrm{P}$ is pressure $(\mathrm{Pa})$. It is predicted that at room pressure $(101.325 \mathrm{kPa})$ and temperature, methamphetamine will result in collisional flux value of $1.292 \times 10^{27} \mathrm{~m}^{-2} \mathrm{~s}^{-1} \cdot 35$

The rate of effusion is the rate of escape of molecules; this is equal to the rate at which they strike the aperture area. Such that for a given aperture area, $A_{0}: 34-35$

Rate of effusion $=Z_{c} A_{0}=\frac{P A_{0}}{(2 \pi m k T)^{1 / 2}}$

These effusion rates, demonstrate that greater pore size and lower temperatures will result in more molecules exiting through the pore in a given period. Effusion is an important for porous surfaces, where methamphetamine on the surface can be reduced to effusion into the bulk of the material. Pore sizes for wood are on the micron scale, such that the effusion rate for a pore of $100 \mu \mathrm{m}$, at room temperature, is $1.29 \times 10^{22} \mathrm{~s}^{-1}$. 
As demonstrated, methamphetamine has a significant potential for diffusion, and thus contamination, throughout the area surrounding a cook. Its toxic nature, and ability to effuse through building materials make it of particular concern. This dissertation will focus on the detection of methamphetamine using three detection methods, ion mobility spectrometry, headspace-gas chromatography-mass spectrometry, and differential mobility spectrometry.

\subsection{Instrumentation}

\subsubsection{Ion Mobility Spectrometry}

Ion mobility spectrometry (IMS, Figure 1.5) is currently used as the main method of analysis in CML remediation due to its portability, reasonable reliability, and ease of use. These portable IMS instruments are pre-programmed with alarms, which allow for detection according to drift time and reduced mobility for selected molecules. These established detection windows are typical for field analysis, as demonstrated by the IMS and differential mobility spectrometry (DMS) evaluations. IMS instruments operate under ambient conditions of temperature and pressure, a distinct advantage for field instrumentation. Often times, the IMS is normally described as gas-phase electrophoresis because ions are separate according to their size-to-charge ratio. 


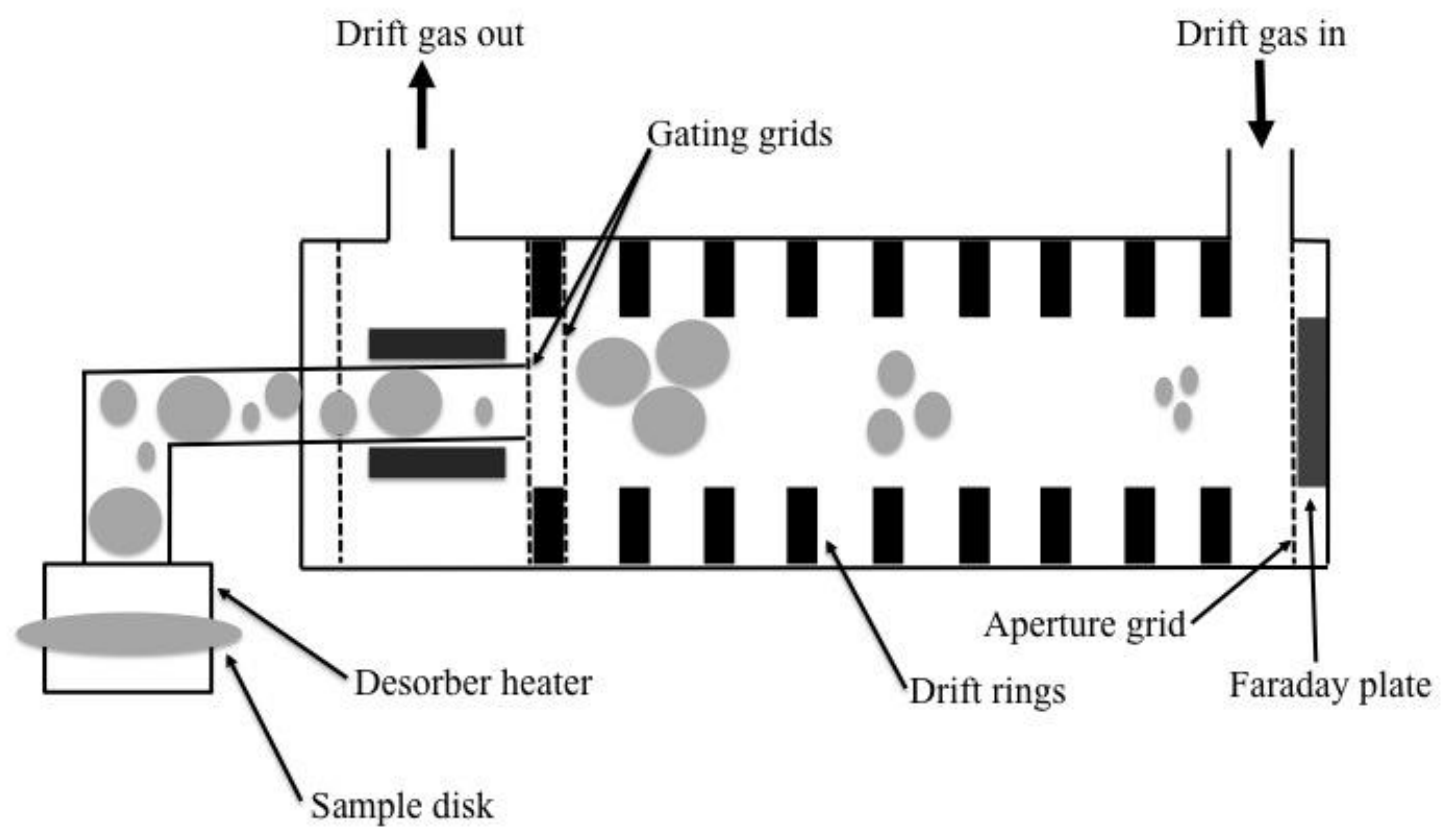

Figure 1.4 Schematic of an Ion mobility spectrometer

Ionization occurs when the drift gas and the sample interact with thermal electrons emitted by a ${ }^{63} \mathrm{Ni}$ source. The drift gas is typically air and in the design used throughout this study contains a nicotinamide (NTA) dopant/calibrant. The drift gas runs countercurrent to the sample such that, when operated in positive mode used for the analysis of drugs, NTA will be ionized by the $\beta$-particles which then protonate the sample molecule. The structure of NTA is shown in Table $1.10{ }^{36}$ 
Table 1.10 Structure and chemical characteristics of nicotinamide

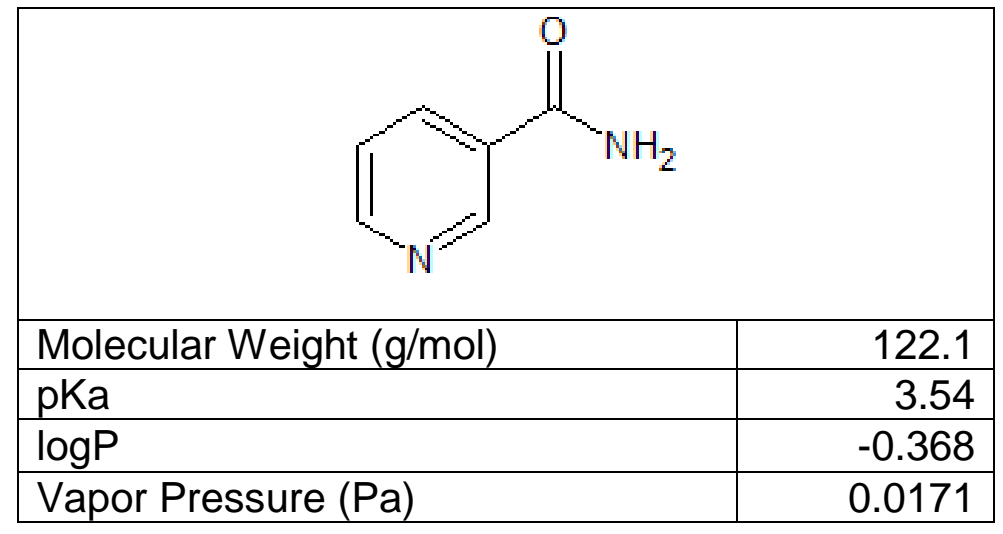

Analysis begins when a $\sim 250 \mu \mathrm{s}$ voltage pulse is applied to the ion gate allowing a packet of ions to enter the drift tube. lons traverse the drift region against the drift gas flow due to a potential difference applied to the drift rings. The rate at which an ion will reach the detector is related to the electric field and ion mobility $\left(K_{m}\right)$, such that smaller ions will reach the detector first due to their greater mobility. The ion mobility constant can be calculated according to Equation 1.13:

$$
K_{m}=\frac{d}{t E}
$$

Where $d$ is the distance an ion will travel in the measured time $(t)$ under an electric field $(E)$. Since variations in ambient temperature and pressure are possible with atmospheric pressure instrumentation, the reduced mobility constant $\left(K_{0}, \mathrm{~cm}^{2} \mathrm{~V}^{-1} \mathrm{~s}^{-1}\right)$ is used to compensate for these factors.

$$
\left.K_{0}=K_{m}\left\lfloor\frac{273}{T}\right\rfloor \frac{P}{760}\right\rfloor
$$

Where $K_{m}$ is the ion mobility constant, $T$ is the temperature of the buffer gas $(\mathrm{K})$, and $P$ is the pressure in the drift region (Torr). To ensure an accurate determination of a peak in the mobility spectrum, the mobility constant must be reproducible relative to 
the internal standard. In the Smiths' design, the drift time of nicotinamide is used as the mobility reference standard in the positive ion mode.

A mobility spectrum is a plot of current intensity at the detector as a function of drift time. Depending on instrument design, drift times are usually in the range of 2-20 milliseconds. Whereas IMS is not a quantitative technique, it is reasonably categorized as a semi-quantitative method. Mobility peak height and area are proportional to that of the number of ions present; the primary limitation is the available ion "pool" from which charge exchange can occur. ${ }^{36}$

Ion mobility spectrometers are widely deployed at airport security checkpoints, as well as with military and civil defense personnel. They offer the advantage of being simple to operate as well as easy to transport (with many handheld devices on the market today) with their lightweight and low power consumption. However, IMS instruments, as with any field detection method, are subject to false positive signals. This is because a given drift times are not unique to specific compounds.

\subsubsection{Gas Chromatography - Mass Spectrometry (GC/MS)}

In addition to IMS analysis, a standard confirmatory technique for qualitative and quantitative data was used for methamphetamine characterizations. Gas chromatography-mass spectrometry (GC/MS) is a widely used confirmatory testing method within forensic laboratories. As the analyte travels through the capillary column, separation occurs via analyte partitioning between the stationary and mobile phases. Equilibrium must be established between the phases before the analyte 
comes off the column. This time is established as the retention time, which is a factor of time spent between the mobile and stationary phases.

The basic components of a GC/MS system, as shown in Figure 1.6, are a gas cylinder, flow regulators, sample injection system, thermostatted oven (containing the capillary column) and a detector. Specific parameters are discussed by experiment, presented in future chapters. The detector used for all GC analysis was a quadrupole mass spectrometer.

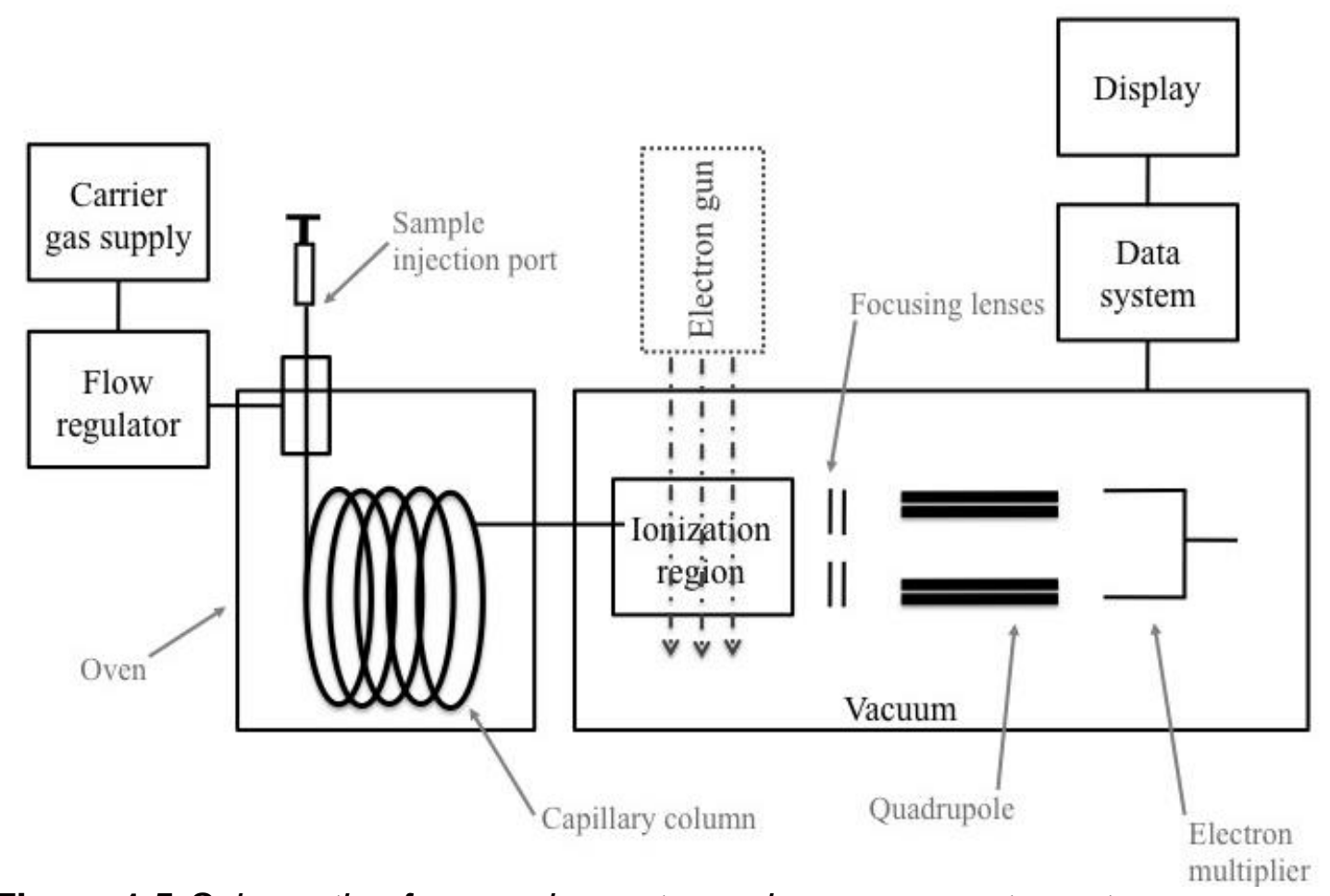

Figure 1.5 Schematic of a gas chromatography-mass spectrometer.

The main components of a mass spectrometer are the ionization source, mass analyzer and transducer. A typical GC/MS system uses an electron ionization source, which bombards the gaseous analyte with a $70 \mathrm{eV}$ beam of electrons. A molecular ion is produced when the target molecule loses an electron due to interactions with the high-energy electron. Further fragmentation can occur as a 
result of collisions, if a sufficient amount of electron energy is present; thereby, producing a mass spectrum. This spectrum provides structural information about the analyte. Use of this ionization source allows for comparison with widely established libraries of mass spectra within books and computer databases.

An applied potential at the repeller plate of the ion source causes the ions to move toward the mass analyzer. This beam is then further focused using an ion focus plate with a small potential applied, which forces the ions to enter the second region of the mass spectrometer, the mass analyzer. In this dissertation a quadrupole mass analyzer was used, typical of forensic laboratories. A single quadrupole is made up four parallel cylindrical rods, situated in a square array, to which direct current (DC) and radio frequency (RF) voltages are applied. Opposite poles have the same charge, such that one pair is attached to the positive side of the variable DC source and the other the negative. This is also true of the RF voltages, which are $180^{\circ}$ out of phase. lons are accelerated in the area between the poles by a potential difference, while RF and DC voltages are increased simultaneously. This allows for only ions of certain $\mathrm{m} / \mathrm{z}$ value to reach the transducer, while others strike the rods and are neutralized. ${ }^{37}$

An electron multiplier is typically used in combination with these systems for detection. As ions reach the cathode, made up of $\mathrm{Cu}$-Be surface, a burst of electrons is emitted. A cascade then begins as the electrons strike a series of dynodes. This causes amplification of the number of electrons up to $\sim 10^{5}$ at the anode where the current is read. ${ }^{36-37}$ 


\section{CHAPTER 2: ION MOBILITY SPECTROMETRY AS A TOOL IN EVALUATING THE EFFICACY OF CLEANING PROTOCOL FOR CLANDESTINE METHAMPHETAMINE LABORATORY REMEDIATION}

This chapter is derived from the published article in the Journal of Occupational and Environmental Hygiene (JOEH) in January 2013.

\subsection{Introduction}

As discussed in Chapter 1, CMLs often exist in structures such as houses, hotel rooms, storage units, and even automobiles. ${ }^{38}$ In these "cooks," it is not only the person performing the "cook" that is exposed to methamphetamine, but so are other occupants and the facility itself. Therefore, state law throughout much of the United States now dictates that property owners notify prospective purchasers of the presences of a former CML on their site. ${ }^{39}$

In 2009, the Environmental Protection Agency published their recommendation for the extent of remediation necessary for these CMLs in Voluntary Guidelines for Methamphetamine Laboratory Cleanup. Although there are many other potentially harmful chemicals used in CMLs, the EPA only considers remediation in regards to the concentration of methamphetamine ${ }^{4} \mathrm{~A}$ detergentwater solution is recommended on any surface or item not discarded. Commercially available Simple Green ${ }^{\circledR}$ is typically used to make the detergent-water solution, which is mainly composed of water (78\%), and about $5 \%$ of each of 2-butoxyethanol, ethoxylated alcohol, and tetrapotassium pyrophosphate. ${ }^{40}$ The EPA recommends that cleaning products such as bleach, trisodium phosphate, methanol, and peroxide-based proprietary cleaners be avoided due to a lack of research on the resulting by-products. ${ }^{41}$ 
The EPA suggests that cleaning according to these methods will help to lower surface contamination of methamphetamine. As discussed in Chapter 1, residual contamination, existing post-cleaning, is typically evaluated by portable IMS. Portable IMS instruments offer the advantage of rapid analysis, good sensitivity, and simple operation. ${ }^{42}$ Samples can be obtained using direct air sampling ("sniffing"), or through thermal desorption of a substrate that has been used to collect particulate sample. When thermal desorption is utilized, it is important to note that the whole swab does not get desorbed. Only particular portion of the swab is desorbed, demonstrated as the circle in Figure 2.1.

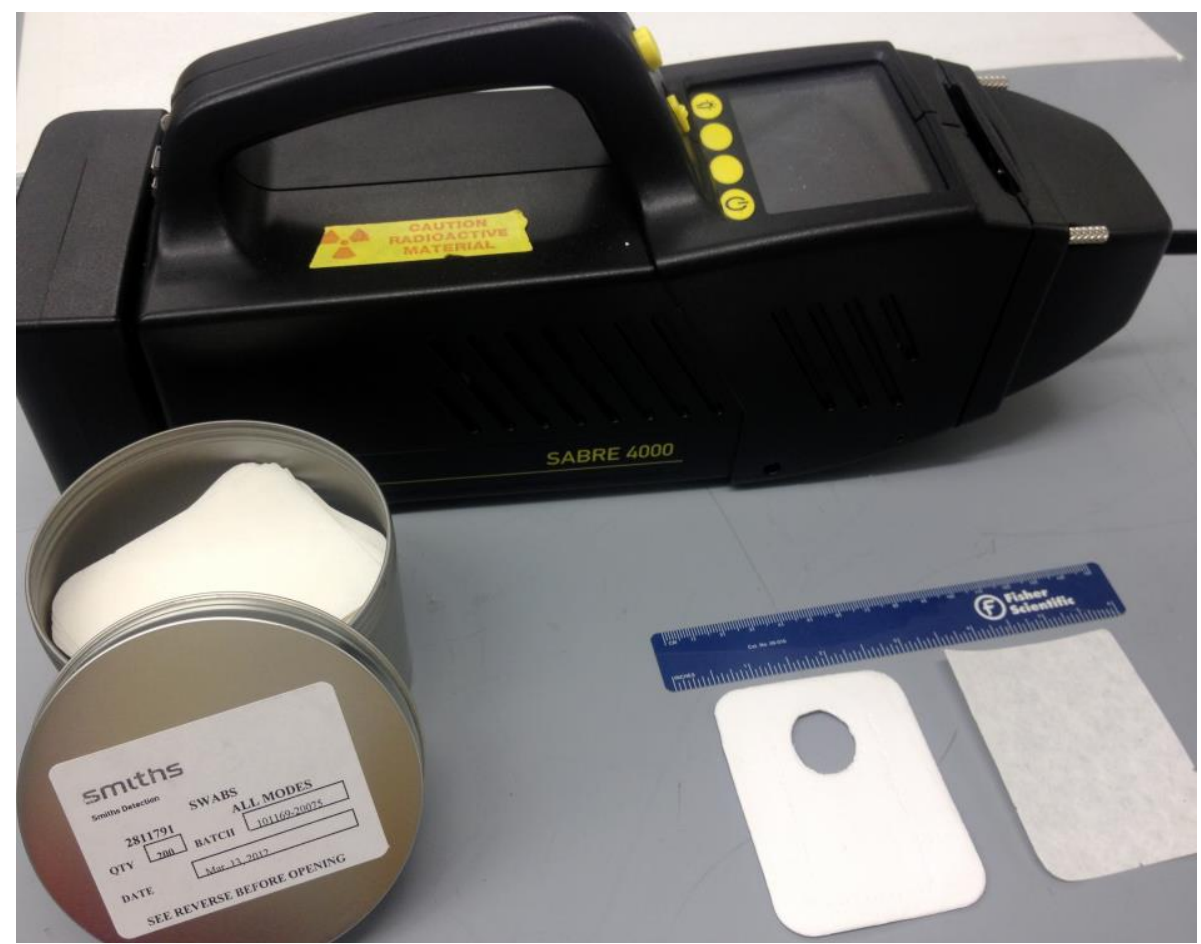

Figure 2.1 The Sabre4000 is shown along with swabs used for analysis and a demonstration of the area desorbed by the IMS

The Sabre ${ }^{\mathrm{TM}} 4000$ (Smiths Detection) makes up 8\% of the use of IMS instruments in field studies, making it the third most common model of IMS owned by government agencies. Figure 2.2 shows the established field usages for a 
variety of different manufacturers. However, the Sabre 4000 is one of the most common models of IMS for illicit drug analysis ${ }^{43}$, compared to that of the more common field IMS instruments.

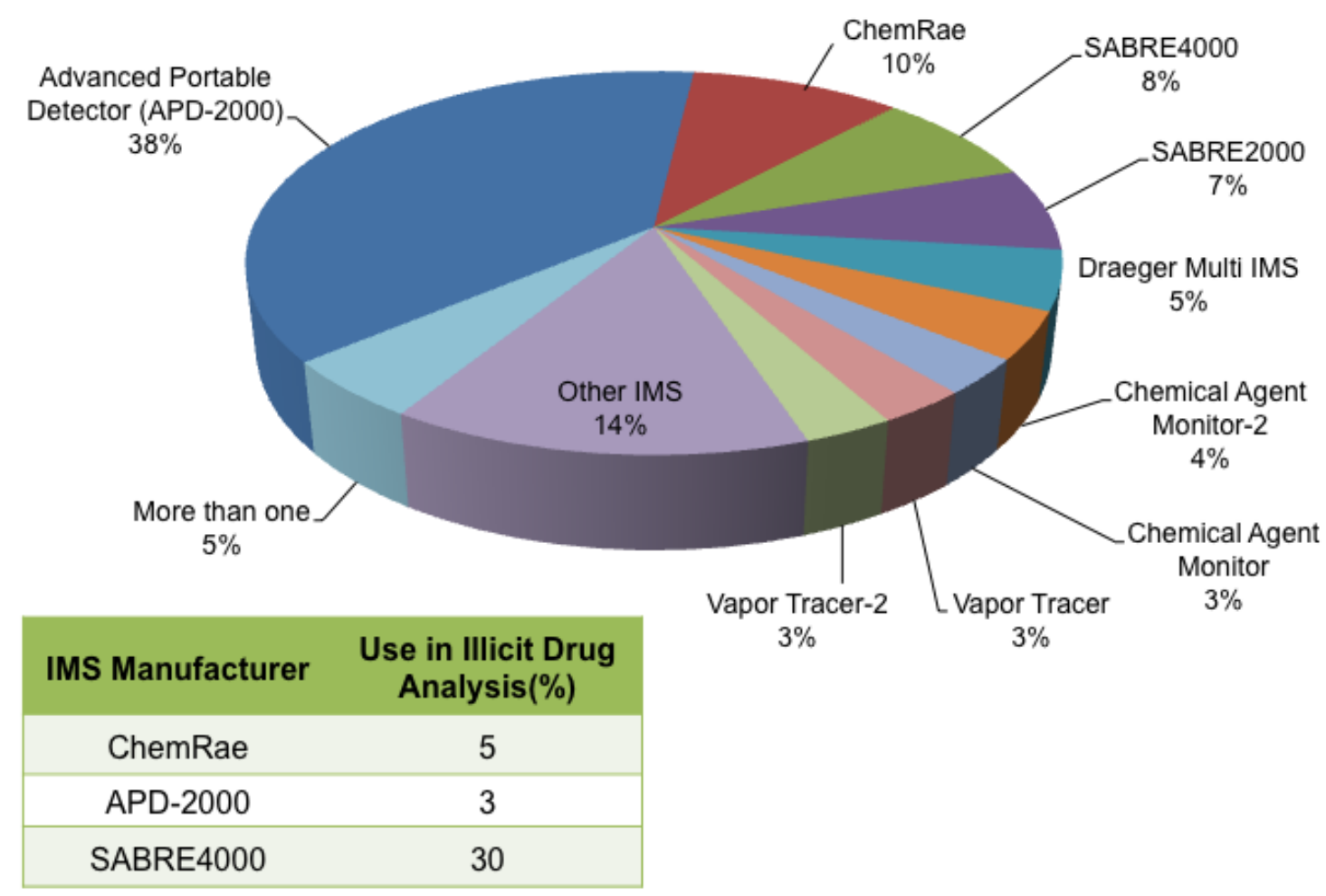

Figure 2.2 Pie chart demonstrating that Sabre ${ }^{\mathrm{TM}} 4000$ makes up $8 \%$ of the IMS instruments used in the field. Amongst ion mobility spectrometers used for drug analysis, it is one of the most common ${ }^{43}$

In the field, the success of the remediation cannot be judged solely by IMS; lack of a mobility response does not imply absence of methamphetamine. Rather, it means methamphetamine, if present, is below the limit of detection (LOD) of the IMS unit or that an interfering substance is responsible for a false negative. Laboratory analysis of swabs using recommended methods must be used to confirm the ultimate success of the remediation. The National Institute for Occupational Safety and Health (NIOSH) lists three laboratory methods for establishing the success of a 
clandestine lab cleanup. These methods use wipes extracted by liquid-liquid extraction with gas chromatography-mass spectrometry (GC/MS) analysis (NIOSH 9106), solid-phase extraction and GC/MS (NIOSH 9109) and liquid chromatographytandem mass spectrometry (LC/MS/MS) (NIOSH 9111). ${ }^{41,44}$ Therefore, a typical scenario for post-remediation analysis involves screening with IMS, followed by cleaning until IMS demonstrates a minimal methamphetamine peak. Once clean, samples are then sent for analysis in the laboratory for confirmation. IMS results dictate when a site is designated as "clean" for laboratory confirmation, and as such is a critical screening step which to date has not been evaluated in a realistic setting.

The goal of this project was to use ion mobility spectrometry to analyze CML cleaning profiles on typical materials associated with housing structures. By doing so, profiles can characteristically evaluate problematic surface materials of housing structures in regards to methamphetamine decontamination. Furthermore, the overall goal of this research is to aid in the development of a standard operating procedure (SOP) for CML remediation with analysis by IMS as called for by the passing of the Methamphetamine Remediation Research Act of $2007 .{ }^{45}$ Funding for this project came from the National Institute of Standards and Technology (NIST).

\subsection{Materials and Methods}

\subsubsection{Chemicals and Solvents}

For sample preparation, methamphetamine $\mathrm{HCl}$ standard (Sigma-Aldrich, St. Louis MO), and LC/MS-grade methanol (Fluka/Sigma-Aldrich, St. Louis MO) were used. The methamphetamine was obtained from Sigma-Aldrich as a solid and stock solutions prepared from the solid. A working stock solution was made at $100 \mathrm{ppm}$ 
$(\mathrm{mg} / \mathrm{L})$ and stored in Mininert ${ }^{\mathrm{TM}}$ vials, which are airtight and can be sampled without exposing the solution to atmosphere or evaporative loss of solvent or analyte. For swabbing, anhydrous reagent alcohol was used (ACS grade, EMD Scientific, Rockland MA). This alcohol mixture consists of $89-92 \%$ ethanol, $3.5-5.5 \%$ methanol, and $4-6 \%$ isopropyl alcohol, which is reasonably representative of solvents used in the field. Simple Green ${ }^{\circledR}$ was used in all cleaning studies and diluted 1:10 in water (All-Purpose Cleaner, Sunshine Makers, Inc., Huntington Beach, CA). Swabs were purchased from Smiths Detection. Building materials were found from various sources, of which some were new while others were obtained from demolition projects.

\subsubsection{Instrumentation}

A Smiths Detection Sabre ${ }^{\mathrm{TM}}$ 4000, as described earlier, was used for this work. The principal parameters of the IMS instrument were set using the instrument's "Narcotics" setting since this is how the instrument is used in the field. No laboratory optimization took place, since the manufacturer's Narcotics mode is optimized for methamphetamine as well as cocaine, heroin and THC (Figure 2.3). Users in the field will only use the pre-programmed settings and detection windows; however, it is possible that the optimal conditions for methamphetamine detection in a CML setting may not correspond with default settings. To ensure readiness of the instrument for daily project use, the IMS was programmed to perform a four-hour bake-out cycle each night. 


\section{smiths}

Title: Sabre_Optimize GSR

\section{Miscellaneous Parameters}

TEMPERATURE AND MOISTURE SETTINGS
\begin{tabular}{|l|r|}
\hline Drift heater $\left({ }^{\circ} \mathrm{C}\right)$ & 150 \\
\hline Inlet heater $\left({ }^{\circ} \mathrm{C}\right)$ & 145 \\
\hline Desorber heater $\left({ }^{\circ} \mathrm{C}\right)$ & 125 \\
\hline Min. vapour sample time $(\mathbf{s})$ & 10 \\
\hline Max. vapour sample time $(\mathrm{s})$ & 20 \\
\hline Calibrant block heater $\left({ }^{\circ} \mathrm{C}\right)$ & 70 \\
\hline Bake-out drift heater $\left({ }^{\circ} \mathrm{C}\right)$ & 200 \\
\hline Bake-out inlet heater $\left({ }^{\circ} \mathrm{C}\right)$ & 200 \\
\hline
\end{tabular}

FLOW RATES AND BAKE-OUT SETTINGS
\begin{tabular}{|l|r|}
\hline Drift flow (cc/min) & 200 \\
\hline Bake-out drift flow (cc/min) & 500 \\
\hline Bake-out time (min) & 480 \\
\hline Bake-out recovery time (min) & 60 \\
\hline Bake-out cal. threshold (d.u.) & 100 \\
\hline Timed auto bake-out at (hh:mm) & $00: 05$ \\
\hline Purge count & 2 \\
\hline Purge on time (ms) & 2000 \\
\hline Purge off time (ms) & 10000 \\
\hline Clean count & 2 \\
\hline
\end{tabular}

Particle Data Acquisition Parameters

$\bigotimes$ Synchronize PC display and instrument sampling algorithm (recommended)

\begin{tabular}{|l|r|}
\hline Analysis delay (s) following start of desorption & 0.500 \\
\hline Scan period (ms) & 25 \\
\hline Shutter grid width (ms) & 0.300 \\
\hline
\end{tabular}

\begin{tabular}{|l|r|r|}
\hline & Instrument Alg & PC Display \\
\hline Maximum analysis duration (s) & 26.250 & 26.250 \\
\hline Maximum number of segments per analysis & 30 & 30 \\
\hline Number of co-added scans per segment & 35 & 35 \\
\hline Analysis duration (s) & 20.000 & 20.000 \\
\hline Number of segments per analysis & 23 & 23 \\
\hline Delay (ms) before start of sampling for each scan & 1.000 & 1.000 \\
\hline Sampling period $(\mu$ s) & 50.0 & 25.0 \\
\hline Number of sample points per scan & 478 & 955 \\
\hline Delay (ms) to start of background reference & 5.000 & 5.000 \\
\hline Duration (ms) of background reference & 0.300 & 0.300 \\
\hline
\end{tabular}

Figure 2.3 Instrument conditions as set by the Sabre ${ }^{\mathrm{TM}} 4000$ narcotics mode

Using the default settings, detection limits comparable to state recommended guidelines were obtained. The LOD was established by performing an experiment in which nine analysts spiked $10 \mu \mathrm{L}$ of methamphetamine solution at $1,5,10,25,50$, and $100 \mathrm{ppm}$ onto a sample swab. These swabs were then allowed to dry and analyzed. In the case of the 1,5 , and $10 \mathrm{ppm}$ solution no detectable peak resulted. A discernible peak was defined as one in which the peak allowed for integration using the Gaussian fit algorithm established by the software. Discernible peaks were 
present for the solution at 25,50 , and $100 \mathrm{ppm}$. In this case the LOD was established as $25 \mathrm{ppm}\left(0.25 \mu \mathrm{g} / 100 \mathrm{~cm}^{2}\right.$, Table 2.1$)$.

Table 2.1 Mass load of methamphetamine in LOD/IDL study

\begin{tabular}{|c|c|c|}
\hline $\begin{array}{c}\text { Concentration of } \\
\text { solution (ppm) }\end{array}$ & $\begin{array}{c}\text { Mass of } \\
\text { methamphetamine } \\
\text { delivered }(\boldsymbol{\mu g})\end{array}$ & $\begin{array}{c}\text { Number of positive } \\
\text { detections }(\mathbf{n}=\mathbf{9})\end{array}$ \\
\hline 1 & 0.010 & 0 \\
\hline 5 & 0.050 & 0 \\
\hline 10 & 0.10 & 0 \\
\hline 25 & 0.25 & 3 \\
\hline 50 & 0.50 & 8 \\
\hline 100 & 1.0 & 9 \\
\hline
\end{tabular}

After plotting the averaged intensity of the peaks for each concentration a linear relationship was used to fit the data (Figure 2.4). The instrumental detection limit (IDL) was estimated from the lowest reliable peak amplitude over the multimonth analysis ( $n=1369)$. In this case, methamphetamine was detected 49 times at less than 15 digital units ( $\mathrm{dU}$, corresponding to voltage at the Faraday plate), and thus the corresponding concentration was assigned as the IDL, here $22 \mathrm{ppm}$.

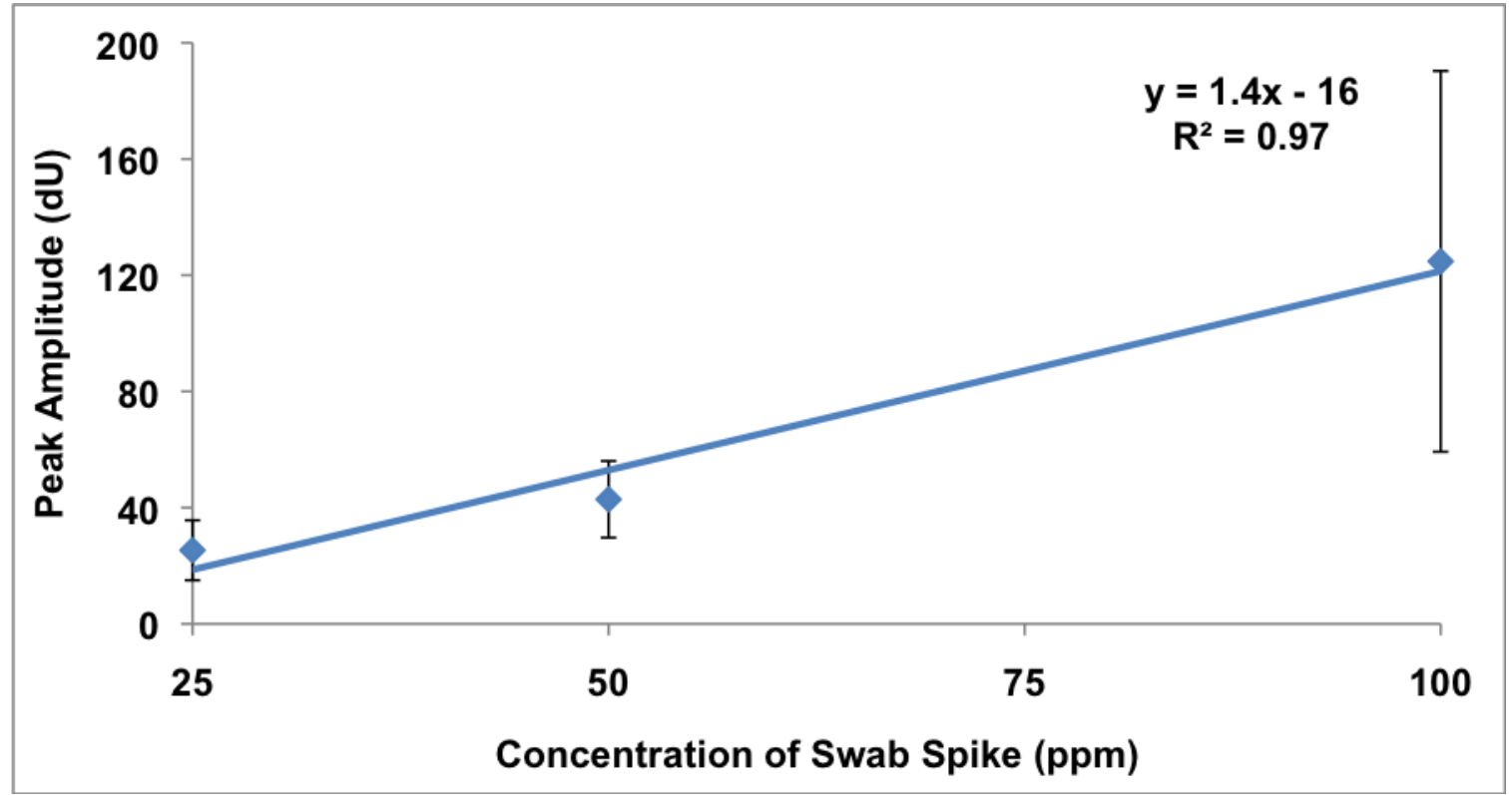

Figure 2.4 Peak amplitude versus concentration of swab in LOD study 


\subsubsection{Sampling Materials}

A variety of building materials were collected for analysis and are listed in Table 2.2. The samples were visually divided into the following categories: countertop (C1-C4), flooring (F1-F10), glass (G1-G4), miscellaneous (M1-M15), raw (R1-R11), and wood-plywood (W1-W3). Each of these sampling surfaces was then grouped visually based upon porosity. Porosity was gauged by a general understanding of building materials, and not determined quantitatively. Porosity labels of porous (P), moderately porous (MP), and non-porous (NP) were given to each material. For example, unfinished wood was expected to be porous; while polymeric surfaces, such as glass, were expected to be non-porous. These categorizations were relatively subjective, and used for broad classification purposes only. 
Table 2.2 Building material used for analysis, categorized by apparent porosity

\begin{tabular}{|c|c|c|}
\hline ID & Description & Porosity \\
\hline C1 & Laminated countertop type 1 & $\mathrm{NP}$ \\
\hline $\mathrm{C} 2$ & Laminated countertop type 2 & NP \\
\hline C3 & Laminated countertop type 3 & NP \\
\hline $\mathrm{C} 4$ & Laminated countertop type 4 & NP \\
\hline F1a & Wood laminate floor boards ( 1 of 3 ) & NP \\
\hline $\mathrm{F} 1 \mathrm{~b}$ & Wood laminate floor boards ( 2 of 3 ) & NP \\
\hline F1c & Wood laminate floor boards ( 3 of 3 ) & NP \\
\hline F2 & Tan floor tile, adhesive on back & NP \\
\hline F3 & Green floor tile, cracked in corner & NP \\
\hline F4 & Tan floor tile, adhesive on back & NP \\
\hline F5 & Linoleum floor tile & NP \\
\hline F6a & Ceramic floor tile ( 1 of 4 ) & NP \\
\hline F6b & Ceramic floor tile (2 of 4$)$ & NP \\
\hline F6c & Ceramic floor tile (3 of 4 ) & NP \\
\hline F6d & Ceramic floor tile ( 4 of 4 ) & NP \\
\hline F7 & Linoleum floor tile & NP \\
\hline F8 & Shower stall liner & NP \\
\hline F9 & Finished baseboard & MP \\
\hline F10 & Interior wood (old), multiple layers of paint & MP \\
\hline G1 & Plexiglas & NP \\
\hline G2 & Single-paned window & NP \\
\hline G3 & Plexiglass from a lab hood & NP \\
\hline G4 & Plexiglass & NP \\
\hline M1 & Light bulb & NP \\
\hline M2 & Smoke detector & NP \\
\hline M3 & Seat cushion & $\mathrm{P}$ \\
\hline M4 & Motor for a heater & NP \\
\hline M5 & Latex cleaning gloves & NP \\
\hline M7 & Ceiling tile & $\mathrm{P}$ \\
\hline M8 & Window blinds (white) & NP \\
\hline M9 & Bolt lock & NP \\
\hline M10 & Electrical outlet & NP \\
\hline M11 & PVC pipe & NP \\
\hline M12 & PVC pipe & NP \\
\hline M13 & Light switch cover & NP \\
\hline M14 & Outlet cover & NP \\
\hline M15 & PVC pipe & NP \\
\hline $\mathrm{R} 1$ & Sheet rock & $\mathrm{P}$ \\
\hline R2 & Untreated wood & $P$ \\
\hline R3 & Wood & $P$ \\
\hline R4 & Interior wood (sanded) & $P$ \\
\hline R5 & Untreated wood & $\mathrm{P}$ \\
\hline R6 & Composite wood mimic - material unknown & NP \\
\hline $\mathrm{R} 7$ & Painted baseboard & MP \\
\hline W1 & OSB particle board & $\mathrm{P}$ \\
\hline W2 & Oak plywood & $\mathrm{P}$ \\
\hline W3 & Birch plywood & $\mathrm{P}$ \\
\hline
\end{tabular}




\subsubsection{Spikes and Swabbing}

Each surface was cleaned with reagent alcohol prior to spiking. Once the alcohol had dried, the surface was then spiked (in the center of the $10 \times 10 \mathrm{~cm}^{2}$ area) using a glass syringe with a $20 \mu \mathrm{L}$ aliquot of $100 \mathrm{ppm}$ methamphetamine stock solution and allowed to dry in open air. While methamphetamine as a contaminant during clandestine production is not typically in the liquid form, spiking of the liquid onto the surface was deemed a reasonable and practical method of inoculation for this project. The surfaces were each sprayed with Simple Green ${ }^{\circledR}$, then wiped and analyzed by desorption IMS. This process was repeated two more times for a total of three cleanings. If the data resulted in two consecutive negative methamphetamine readings, the cleaning was stopped.

A surface area of $100 \mathrm{~cm}^{2}$, using a $10 \times 10 \mathrm{~cm}^{2}$ template as per typical field practice, was sampled with a NIST paper swab moistened using reagent alcohol. Each substrate was wiped using the NIOSH method described in Chapter 1, Section 1.2.4. For some building materials it was not possible to swab a $10 \times 10 \mathrm{~cm}^{2}$ square area. In these circumstances all of the potentially exposed area was wiped with the swab in the manner described above. Some materials were large enough to allow for multiple sampling points of $10 \times 10 \mathrm{~cm}^{2}$. As many sampling areas as possible were used for each building material.

\subsection{Results and Discussion}

\subsubsection{Direct Chemical Analysis}

To ensure that the responses for Simple Green ${ }^{\circledR}$ and methamphetamine did not interfere with one another, mobility spectra were obtained for each chemical in 
particle mode. In this type of IMS, two types of interference are possible. First, a compound could have the same drift time as methamphetamine, which would cause a false positive. Second, competitive ion exchange mechanisms can produce a variety of responses with more than one active analyte present. This exchange can lead to false negatives, peak shifts, and other artifacts that will defeat the field detection algorithms.

As the first step, a blank was obtained to insure a clean background, with a calibrant (nicotinamide) peak at approximately $11.708 \mathrm{~ms}$ (Figure 2.5). Potential shifts in the drift time of the calibrant may occur as a result of differences in temperature and pressure in the area in which analysis occurs; however, identification was based upon the $\mathrm{K}_{0}$ value, calculated in equation 1.14 , which takes into account these variations. A peak was also detected with a drift time before the reactant ion peak, likely due to a contamination present in the air during the day of sampling. This air contaminant did not interfere with peak identification.

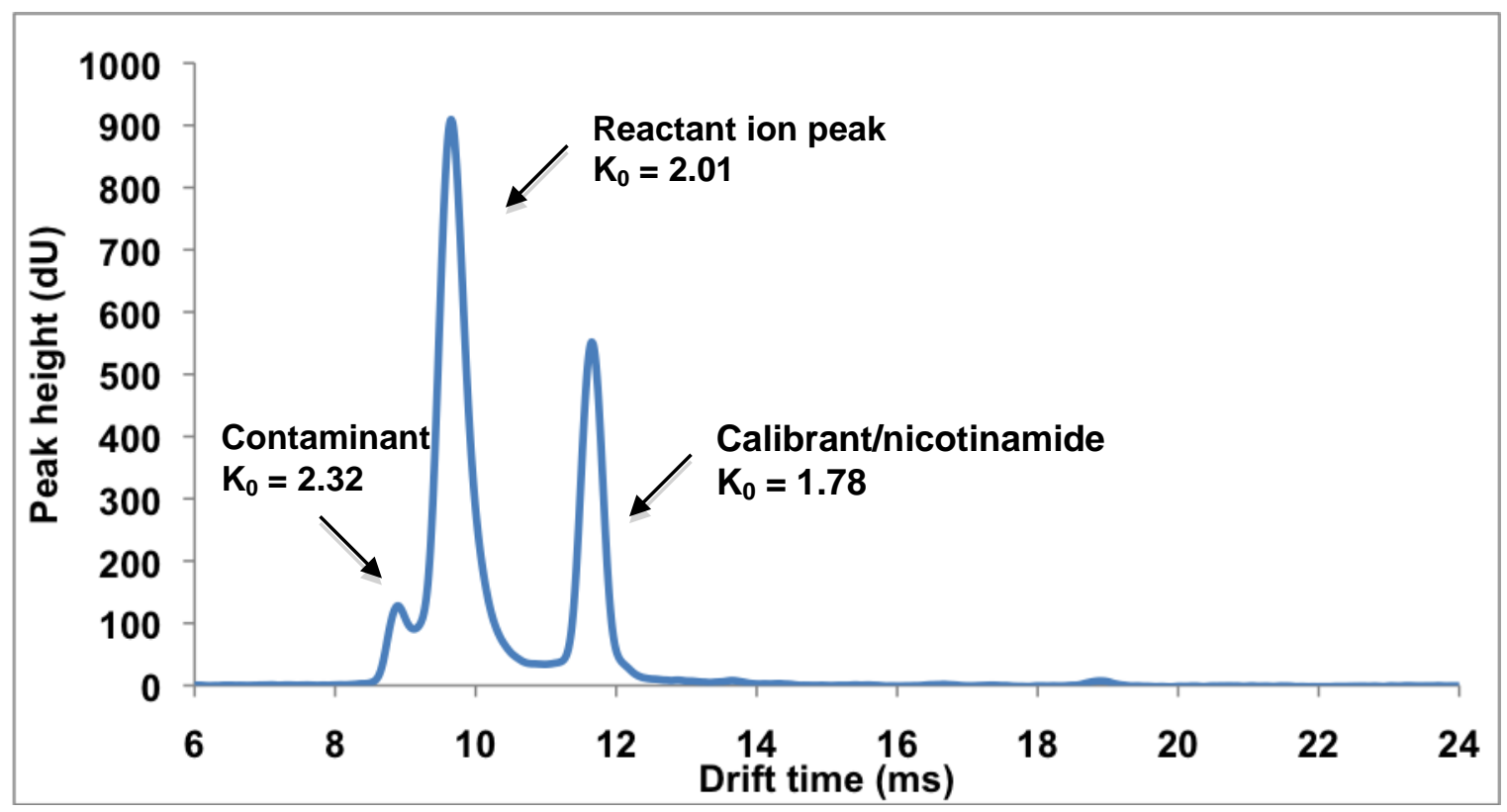

Figure 2.5 Typical mobility spectrum obtained in the particle mode (thermal desorption engaged) for a blank swab 
A methamphetamine solution was placed directly on the sample swab producing a significant peak on the mobility spectrum at $12.868 \mathrm{~ms}$ (Figure 2.6). The reduced mobility constant for methamphetamine is $1.6 \mathrm{~cm}^{2} \mathrm{~V}^{-1} \mathrm{~s}^{-1}$, and was verified by the software for the peak produced at that time. ${ }^{46}$ All further monitoring of methamphetamine was accomplished by meeting both the criteria of a similar mobility constant and drift time.

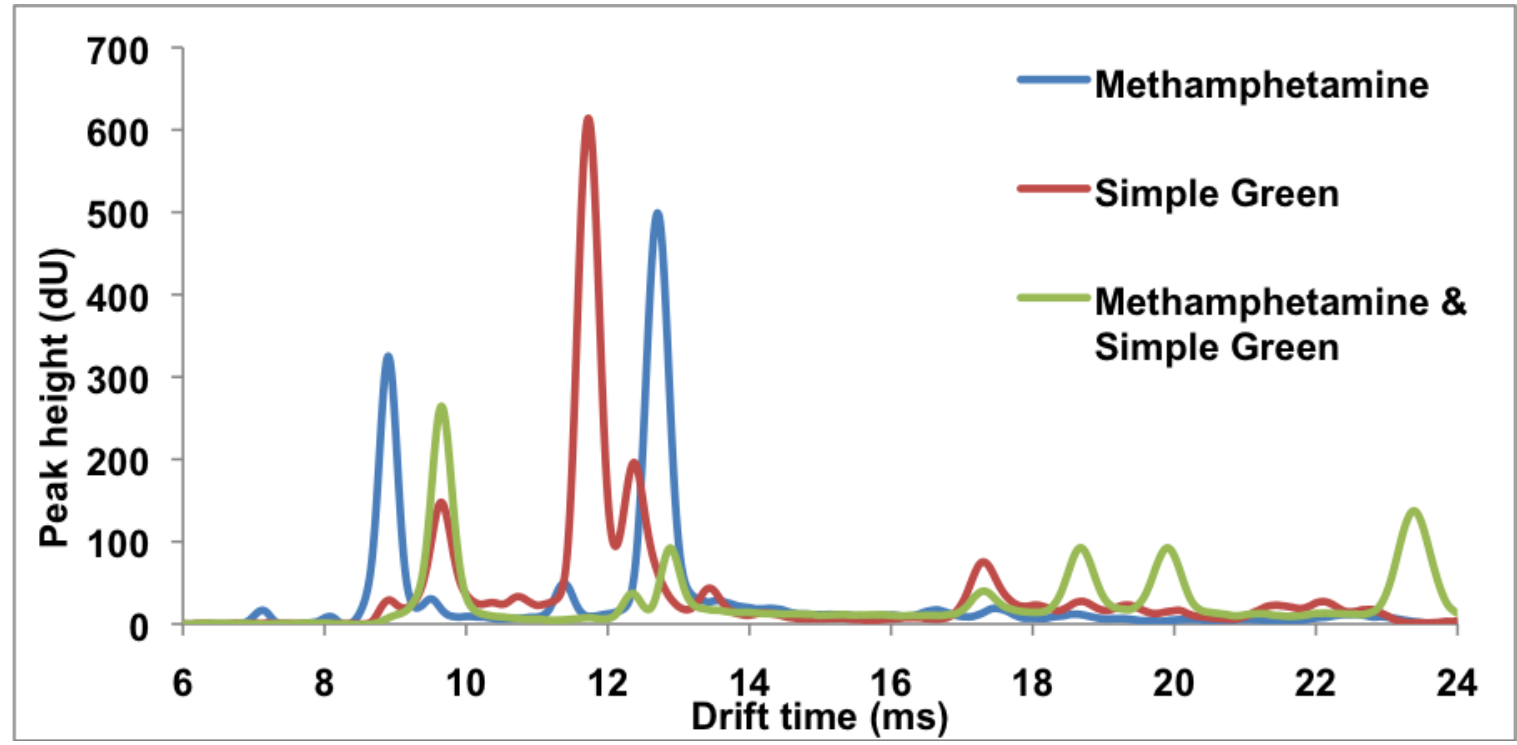

Figure 2.6 Combined mobility spectrum obtained in the particle mode (thermal desorption engaged) for methamphetamine, Simple Green ${ }^{\circledR}$ and methamphetamine combined with Simple Green ${ }^{\circledR}$

When Simple Green ${ }^{\circledR}$ and methamphetamine were run together by applying the two solutions to the IMS swab, they produced peaks at $11.708,12.302$, and $12.868 \mathrm{~ms}$ for the calibrant, Simple Green $^{\circledR}$, and methamphetamine respectively; however, this plot also introduces several other peaks after $16 \mathrm{~ms}$ that are only observed in the mixture (Figure 2.6). One possibility for the identifying of the peaks after $16 \mathrm{~ms}$ is that the 2-butoxyethanol in the cleaner formed a dimer or possibly a hetero-dimer with methamphetamine that would have longer drift times than either 
monomer. Another possibility is a reaction product between the two compounds that yielded a new compound with a larger collisional cross-section and thus a longer drift time than the reagents.

A literature review produced little evidence to suggest that methamphetamine and Simple Green ${ }^{\circledR}$ would react on a surface. The potential does exist for $\mathrm{S}_{\mathrm{N}} 2$ reactions between the ether and alcohol groups of 2-butoxyethanol with that of the amine group in methamphetamine; however, this reaction is not expected to occur without an additional driving force, -such as high temperature - because $-\mathrm{NH}_{2}$ is considered to be very poor leaving group. Without the presence of a catalyst or reflux conditions, reactions between the two compounds are unlikely. Therefore, the reduction in methamphetamine peak height is more likely the result of dilution by Simple Green ${ }^{\circledR}$ solution and broader/deeper dispersion and penetration of methamphetamine into a surface

\subsubsection{Surface Cleanup Analysis}

All building materials gathered were classified by type, as either a countertop (C1-C4); flooring (F1-F10); glass (G1-G4); miscellaneous (M1-M15); raw (R1-R11); and wood-plywood (W1-W3) material. To ensure that the materials would not present contamination from environmental factors, all surfaces were cleaned with methanol before a background sample was taken. Additionally, surface blanks were created whenever possible. To create a surface blank, a portion of the building material that was not spiked with methamphetamine was swabbed and analyzed. This ensured that positive methamphetamine signals in sampled areas were not the result of accidental transfer. 
Laminated countertop made up all of the items within the "countertop" category; while the manufacturers of the materials are unknown, each appeared to be different in regards to appearance and source. Many of the countertop items (C1C4) did not have detectable methamphetamine peaks (Table 2.3). Whereas C1 demonstrated no peak after the first cleaning, the second and third cleanings did produce signal. For this sample, it was found that a decrease in amplitude did result from cleaning a third time. However, C4 produced methamphetamine peaks, which were inconsistent since a detectable signal occurred immediately after the first cleaning and in the third sampling. No detectable signal was present after the second cleaning for this material.

Table 2.3 Methamphetamine peak amplitudes for samples classified as countertop material after three cycles of cleaning

\begin{tabular}{clll}
\hline Item & After Cleaning 1 & After Cleaning 2 & After Cleaning 3 \\
\hline C1 & ND, ND & ND, 27.8 $\left(27.8^{*}\right)$ & ND, 25.8 $\left(25.8^{\star}\right)$ \\
C2 & ND, ND & ND, ND & ND, ND \\
C3 & ND, ND & ND, ND & ND, ND \\
C4 & $34.4,31.4(32.9)$ & ND, ND & 29.9, ND $\left(29.9^{\star}\right)$ \\
\hline
\end{tabular}

ND: Not detected

*value reported not a result of averaging due to multiple ND samples

Those items classified as flooring were made of many different materials including multiple pieces of wood laminant, baseboard, and ceramic and linoleum tiles. Several of the flooring items (F1a-F10) did not show recovery of methamphetamine after the third cleaning (Table 2.4). This could be due to the impermeability of these surfaces suggesting that most of the methamphetamine was removed after the first cleaning occurred. This was not the case for materials F4, F8, F9, and F10. While F4 and F8 were also considered to be non-porous tile floor panel, they demonstrated recovery after 3 cleanings. There is likely structural 
variation between the surfaces that accounts for this difference, as well as differences in the coating materials. F9 and F10 were judged to be slightly porous due to visual differences in structure. F10 did behave as expected with decreased methamphetamine peak amplitudes over the cleaning periods.

Table 2.4 Methamphetamine peak amplitudes for samples classified as flooring material after three cycles of cleaning

\begin{tabular}{clll}
\hline Item & \multicolumn{1}{c}{ After Cleaning 1 } & After Cleaning 2 & After Cleaning 3 \\
\hline F1a & ND, 26.7 (26.7*) & ND, ND & ND, ND \\
F1b & ND, ND & ND, 21.5 (21.5*) & ND, ND \\
F1c & $21.0, N D\left(21.0^{*}\right)$ & $47.5,38.1(43.0)$ & ND, ND \\
F2 & ND, ND & ND, ND & ND, ND \\
F3 & ND, ND & ND, ND & ND, ND \\
F4 & $13.8,22.5,22.6$ & $25.0,13.3,40.4$ & $29.2,23.6,25.1$ \\
F5 & $(19.6 \pm 5.1)$ & $(26.2 \pm 13.6)$ & $(26.0 \pm 2.9)$ \\
F6 & ND,$~ N D$ & ND & ND \\
F7 & ND, ND, ND & ND, ND & ND, ND \\
F8 & $15.4,14.5,26.2$ & $9.9,9.7,11.6$ & ND, ND, ND \\
F9 & $(18.7 \pm 6.5)$ & $(10.4 \pm 1.0)$ & $(22.3 \pm 2.0)$ \\
F10 & 21.2 & 13.2 & 28.8 \\
& $20.7,14.7,17.8$ & $11.4,23.9,12.1$ & ND, ND, 13.9 \\
\hline
\end{tabular}

ND: Not detected

*value reported not a result of averaging due to multiple ND samples

Plexiglas from multiple different sources and a windowpane made up the analysis of glass building materials. The glass surfaces (G1-G4) were all considered to be non-porous and generally exhibited a decrease in the amount of methamphetamine recovered after each clean (Table 2.5 and Figure 2.7). Yet the G2 surface was an exception with decreased detection after the second cleaning. While G1 and G3-G4 were Plexiglas samples, G2 was a plane of glass from a window, effectively demonstrating that some difference exists between these two surfaces. 
Table 2.5 Methamphetamine peak amplitudes for samples classified as glass materials after three cycles of cleaning

\begin{tabular}{clll}
\hline Item & After Cleaning 1 & \multicolumn{1}{c}{ After Cleaning 2 } & \multicolumn{1}{c}{ After Cleaning 3 } \\
\hline G1 & $23.4,19.2,16.4$ & $17.3,18.9,12.4$ & $9.9, \mathrm{ND}, 11.9$ \\
& $(19.7 \pm 3.5)$ & $(16.2 \pm 3.4)$ & $(10.9 \pm 1.4)$ \\
G2 & $25.2,17.0,35.8$ & $17.8,14.7,27.1$ & $19.7,24.6,22.5$ \\
G3 & $(26.0 \pm 9.4)$ & $(19.9 \pm 6.5)$ & $(22.3 \pm 2.5)$ \\
G4 & 39.9 & 33.9 & 15.0 \\
& $(27.7 \pm 16.17 .1,19.5$ & $19.7, \mathrm{ND}, 19.0$ & $8.3,13.1,13.6$ \\
\hline
\end{tabular}

ND: Not detected

*value reported not a result of averaging due to multiple ND samples

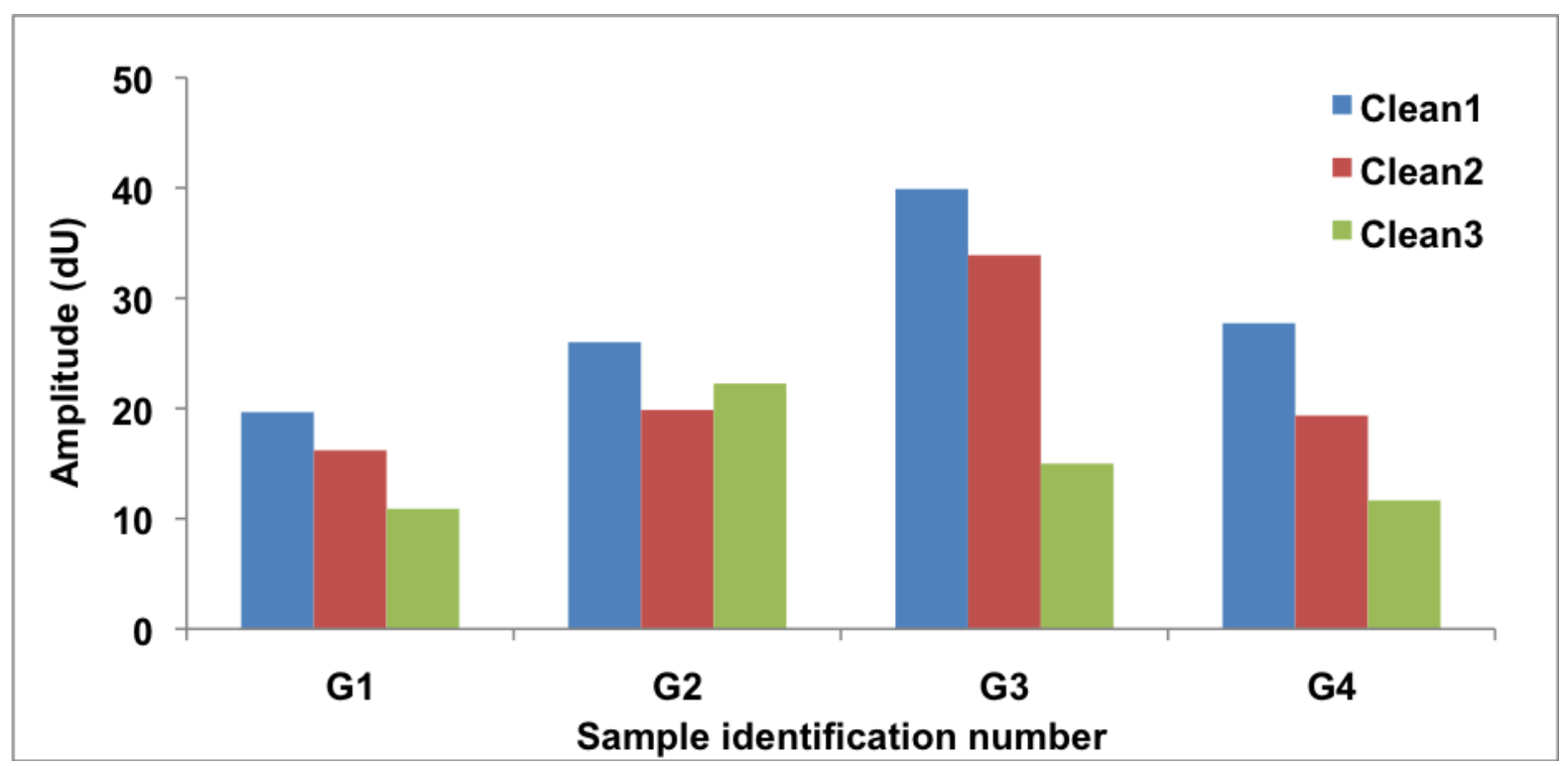

Figure 2.7 Bar chart of methamphetamine peak amplitudes for glass

Materials such as a light bulb, PVC pipes, electrical outlet covers, and a ceiling tile were categorized as miscellaneous (M1- M15) and contain items considered porous (M3 and M7) as well as non-porous (M1-M2, M4-M6, M8-M15). The non-porous objects typically exhibited a decrease in the amount of methamphetamine present after each clean (Table 2.6 and Figure 2.8). Additionally, M3 revealed a decrease in the amount of methamphetamine present after each clean. However M7, which was also thought to be porous, resulted in a steady increase in methamphetamine detection. This increased detection could be due to 
methamphetamine that has penetrated below the surface being drawn out due to contact with the solvent.

Table 2.6 Methamphetamine peak amplitudes for samples classified as miscellaneous materials after three cycles of cleaning

\begin{tabular}{clll}
\hline Item & After Cleaning 1 & After Cleaning 2 & After Cleaning 3 \\
\hline M1 & 11.3 & 7.8 & ND \\
M2 & ND & 12.7 & ND \\
M3 & $22.0,18.7,23.7$ & $16,18.6, \mathrm{ND}$ & $17.3,16.3,9.2$ \\
M4 & $(21.5 \pm 2.5)$ & $(17.3)$ & $(14.3 \pm 4.4)$ \\
M5 & 26.1 & 19.9 & 12.5 \\
M6 & 97.4 & 79.0 & 156.1 \\
M7 & 14.8 & 29.0 & 30.7 \\
& $(16.9 \pm 2.4)$ & $(23.6 \pm 4.9)$ & $32.5,27.1,14.1$ \\
M8 & ND, 18.9, ND & ND, 21.2, 11.6 & $(24.6 \pm 9.5)$ \\
M9 & $\left(18.9^{*}\right)$ & $(16.4)$ & $(7.5)$ \\
M10 & ND & 54.0 & 22.4 \\
M11 & 28.6 & 43.8 & ND \\
M12 & 21.0 & 16.2 & ND \\
M13 & 19.7 & 10.6 & ND \\
M14 & ND.2 & ND & ND \\
M15 & 18.2 & ND & ND \\
\hline
\end{tabular}

ND: Not detected

*value reported not a result of averaging due to multiple ND samples 


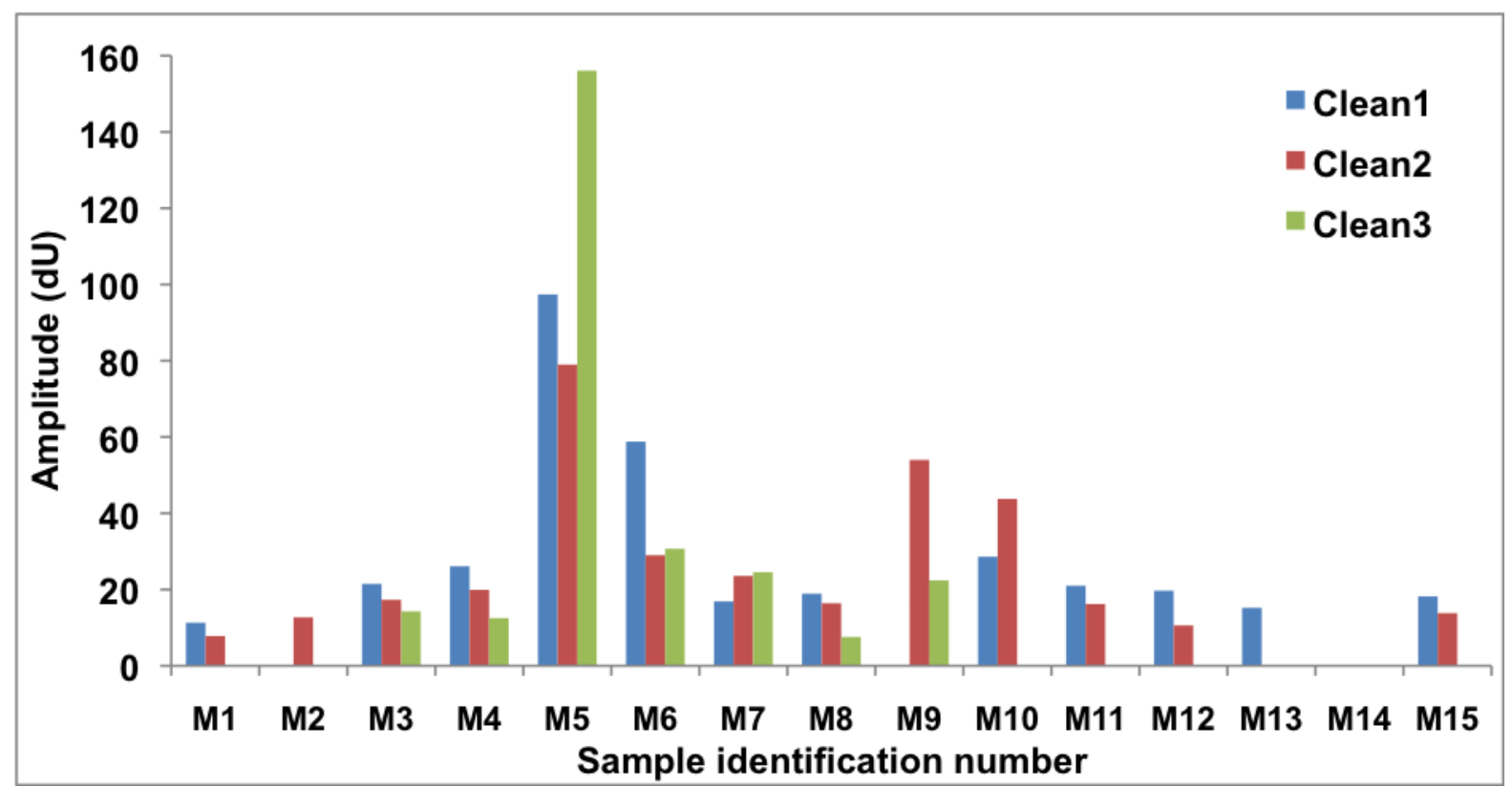

Figure 2.8 Bar chart of methamphetamine peak amplitudes for samples classified as miscellaneous materials

Raw materials produced recovery after every clean (Table 2.7 and Figure 2.9) suggesting that additional cleanings would be required to reduce methamphetamine concentration below the detectable limit. This can be attributed to the porous substrate (sheet rock and different untreated woods) onto which the methamphetamine was deposited. It is also important to note that the paint on the center of each sampling area wore away by the last sampling. Thus exposed wood was visible after the last cleaning. This likely affected the recovery, but would be typical of this form of cleaning. 
Table 2.7 Methamphetamine peak amplitudes for samples classified as raw materials after three cycles of cleaning

\begin{tabular}{clll}
\hline Item & \multicolumn{1}{c}{ After Cleaning 1 } & \multicolumn{1}{c}{ After Cleaning 2 } & \multicolumn{1}{c}{ After Cleaning 3 } \\
\hline R1 & $30.8,32.4,24.2$ & $31.8,33.2,28.5$ & $24.7,29.7,8.2$ \\
R2 & $(29.1 \pm 4.3)$ & $(31.2 \pm 2.4)$ & $(20.9 \pm 11.2)$ \\
R3 & $32.0,39.0(35.5)$ & $18.5,27.7(23.1)$ & $23.1,17.8(20.5)$ \\
R4 & 35.0 & 14.5 & 12.9 \\
R5 & 32.0 & 26.0 & 17.1 \\
R6 & $(35.6 \pm 3.1)$ & $(22.6 \pm 2.6)$ & $(21.1 \pm 1.7)$ \\
R7 & 18.1 & 29.4 & 18.3 \\
\end{tabular}

ND: Not detected

*value reported not a result of averaging due to multiple ND samples

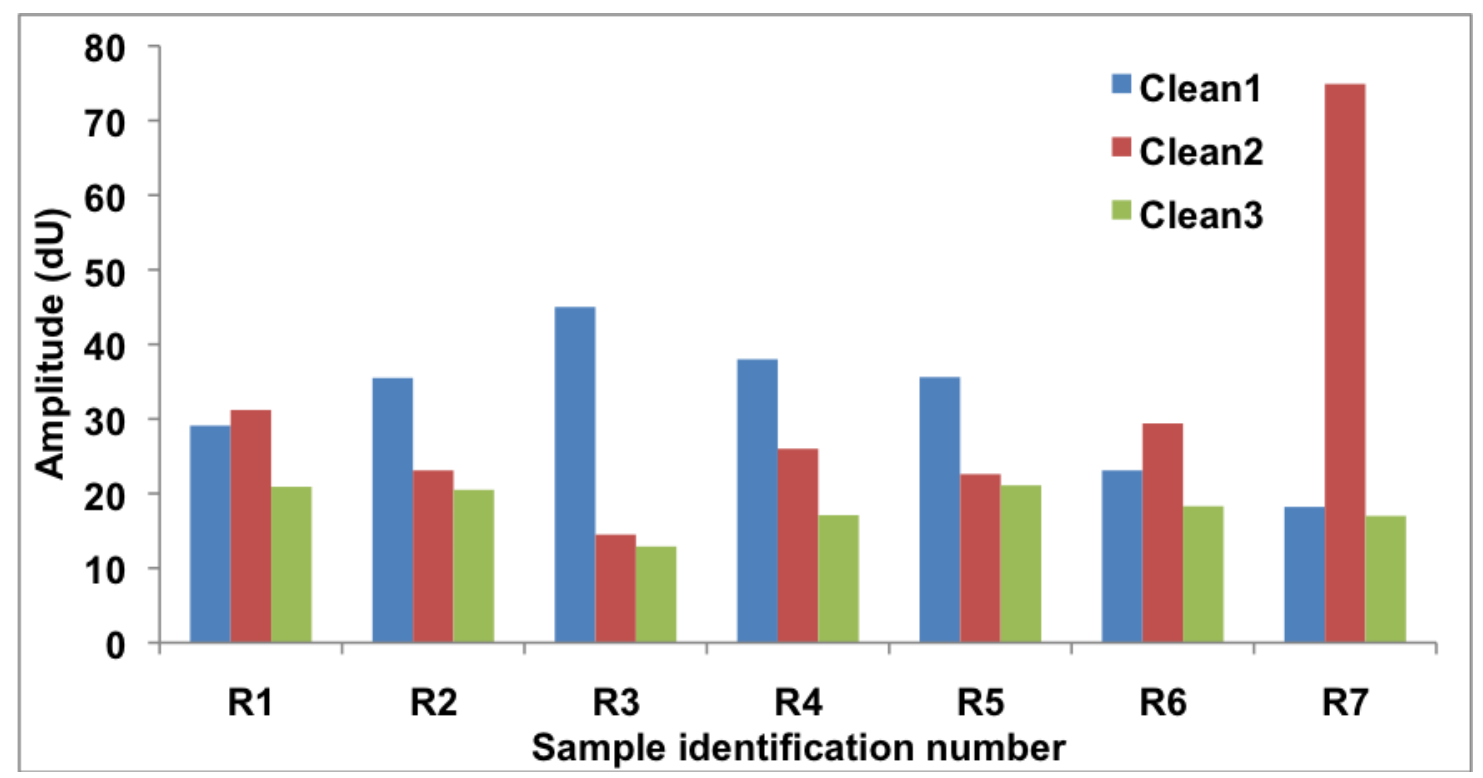

Figure 2.9 Bar chart of methamphetamine peak amplitudes for samples classified as raw materials

Finally, the wood-plywood (W1-W3) samples revealed mixed data (Table 2.8 and Figure 2.10). All of the plywood samples were considered to be porous. In the analysis of W1, data showed a spike in amplitude during the second cleaning resulting in greater amplitude after the final clean than Clean 1. In the W2 evaluation, a steadily increasing methamphetamine content resulted. Similarly W3 produced significantly larger amplitude in Clean 3 than the previous cleans. This 
suggests that methamphetamine has the potential to build up on porous surfaces such as wood. This is an important realization since the methamphetamine clandestine remediation typically calls for the stripping down of the building to its interior wooden supports.

Table 2.8 Methamphetamine peak amplitudes for samples classified as wood materials after three cycles of cleaning

\begin{tabular}{cccc}
\hline Item & After Cleaning 1 & After Cleaning 2 & After Cleaning 3 \\
\hline W1 & $56.7,22.0(39.4)$ & $93.1,28.1(60.6)$ & $69.3,22.0(45.7)$ \\
W2 & $64.0,25.8(44.9)$ & $61.3,70.0(65.7)$ & $76.9,82.3(79.6)$ \\
W3 & 20.3, ND $\left(20.3^{*}\right)$ & $23.1,19.5(21.3)$ & $77.3,68.1(72.7)$ \\
\hline
\end{tabular}

ND: Not detected

*value reported not a result of averaging due to multiple ND samples

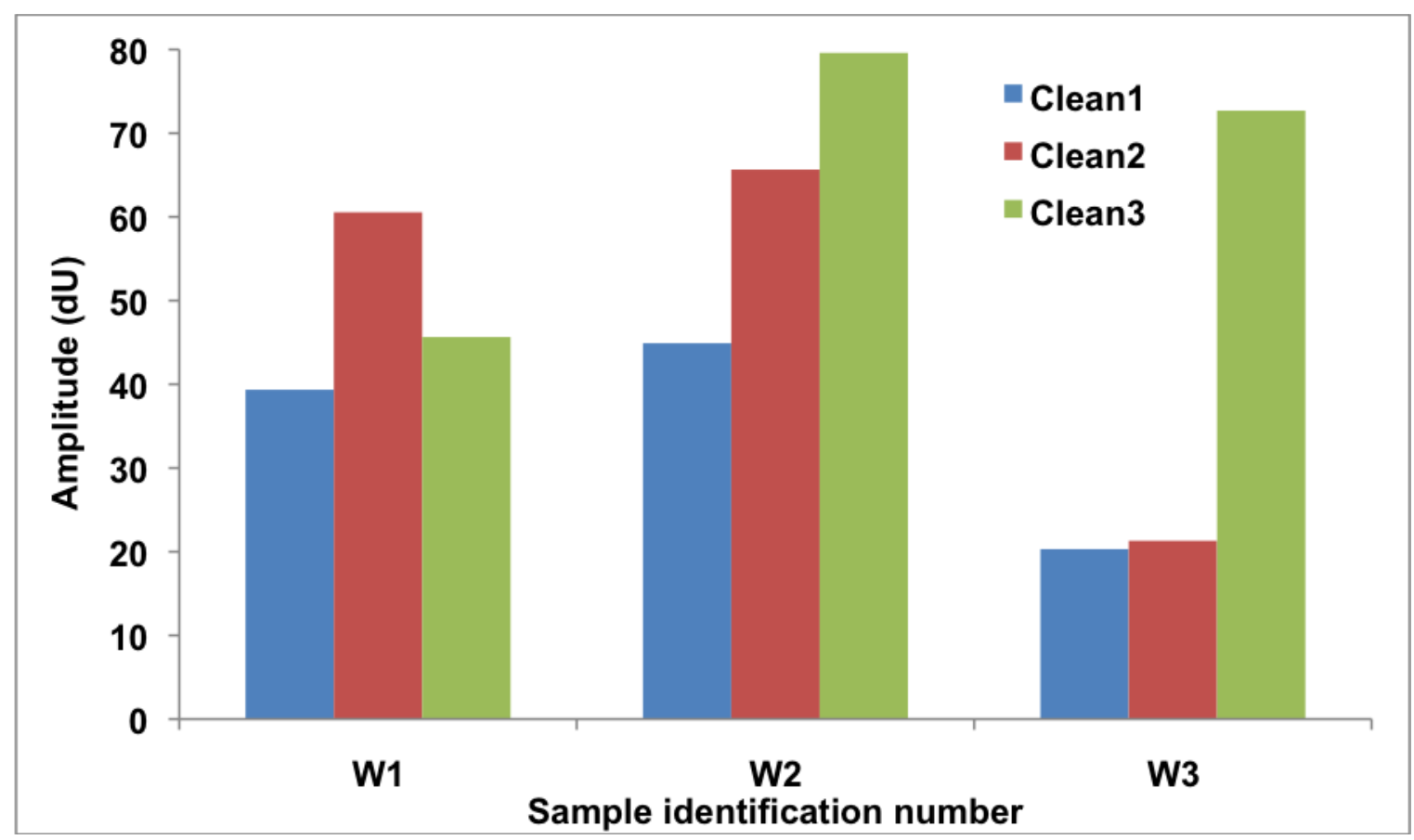

Figure 2.10 Bar chart of methamphetamine peak amplitudes for samples classified as wood materials

CML remediation efforts can be very costly and in some cases it is more costeffective to demolish an entire residence rather than replace counters, walls, flooring, etc. However, in cases where demolition is not possible, effective cleaning SOP must be followed. IMS is an inexpensive and simple technique to evaluate 
cleaning efficiency. The IMS analysis on these building materials has highlighted interesting cleaning profiles that are indicative of the porosity and absorption characteristics of methamphetamine. Typically, glossed ceramics and sealed materials had drastically minimized methamphetamine levels after the clean cycles. The relatively non-porous materials show that CML remediation according to the EPA recommended can work but that efficacy is as much a function of substrate as it is of procedure. Results here demonstrate that texturized and porous materials will need a more extensive cleaning process than recommended in the guidelines.

\subsection{Summary and Future Work}

The work in this chapter evaluated the efficacy of the EPA recommended cleaning procedures for former clandestine laboratories. It was found that materials, which appeared as relatively non-porous resulted in more significant reductions of methamphetamine from the surface when cleaned with Simple Green ${ }^{\circledR}$. The mechanism by which this reduction occurs is primarily through liquid extraction; such that upon addition of Simple Green ${ }^{\circledR}$ to a contaminated surface, methamphetamine is solublized allowing for abstraction onto a cleaning towel. In the case of a more porous material, the addition of Simple Green $^{\circledR}$ allows for partitioning of methamphetamine on the surfaces, as well as further penetration into the bulk of the material. Therefore, as the concentration increases within the pores of the bulk, diffusion will drive methamphetamine to the surface over time.

The reduction of methamphetamine surface contamination by liquid extraction with a traditional household cleaner, such as Simple Green ${ }^{\circledR}$, appears to be an inefficient means for removal. Further research should focus on establishing a 
method by which methamphetamine concentration is reduced due to reactions with a surface cleaner producing a compound with known low toxicity. Hypochloritecontaining bleaches would react with the amine group of methamphetamine to form chloramines and water through well-characterized processes. ${ }^{47}$ Another potential cleaning mechanism would be the use of an ozone generator, which was demonstrated by Crystal Forester et al to break down methamphetamine. ${ }^{48}$

Potential future work in this area should include the use of more replicates on a single material, followed by quantitative extraction of the sample wipe using the $\mathrm{NIOSH}$ recommended procedures for GC/MS, or LC/MS evaluation. Additionally, it should be recognized that methamphetamine is not the only contaminant in clandestine laboratories, and may not be the cause of illness in persons living in former CMLs. Table 1.3 presents a variety of chemicals that have demonstrated the ability to be absorbed by the skin, and their removal should be evaluated during the cleaning process as well. 


\section{CHAPTER 3: GAS CHROMATOGRAPHY - MASS SPECTROMETRY METHOD VALIDATION AND APPLICATION TO HEADSPACE DETECTION OF METHAMPHETAMINE}

\subsection{Introduction}

As described in Chapter 1, methamphetamine has the potential to contaminate surfaces, as well as circulate in the air environment of clandestine laboratories. The goal of this chapter is to gain a better understanding of methamphetamine evolution from surfaces by analyzing the rate at which methamphetamine is released from pinewood and drywall surfaces that have been previously exposed to methamphetamine. When a sample is placed into a vial and sealed, volatile components will diffuse from the sample (liquid or solid) phase into the gas phase. This will continue until equilibrium is established between the two phases contained within the sample vial. Headspace (HS) analysis is the method by which the vapor phase, or HS, above the sample phase is analyzed.

Three common techniques exist amongst HS systems which are (1) gas-tight syringe, (2) balanced pressure, and (3) pressure loop. ${ }^{49,50}$ The gas-tight syringe technique makes use of a thermostatted oven for the heating of a sample vial at a given temperature and established time, allowing for equilibrium to be reached. Next, a sample aliquot is taken from the HS by a gas-tight syringe. To transfer the sample to the GC injector, with minimal possible condensation of the analyte on the syringe, a heated syringe assembly is used. The sample is then introduced to the GC system (Figure 3.1). The disadvantage of a gas-tight syringe system is the possibility that sample loss may occur as a result of changing pressures between vial and atmosphere. The balanced pressure and pressure loop systems allow for 
the sample vial to reach equilibrium before a pressurization of the vial occurs, where the pressure is then used to force sample into the injector. The major difference between these two systems is that the balanced pressure systems allows for a continuous flow of analyte through the injector, whereas pressure-loop systems inject a given volume. ${ }^{49}$

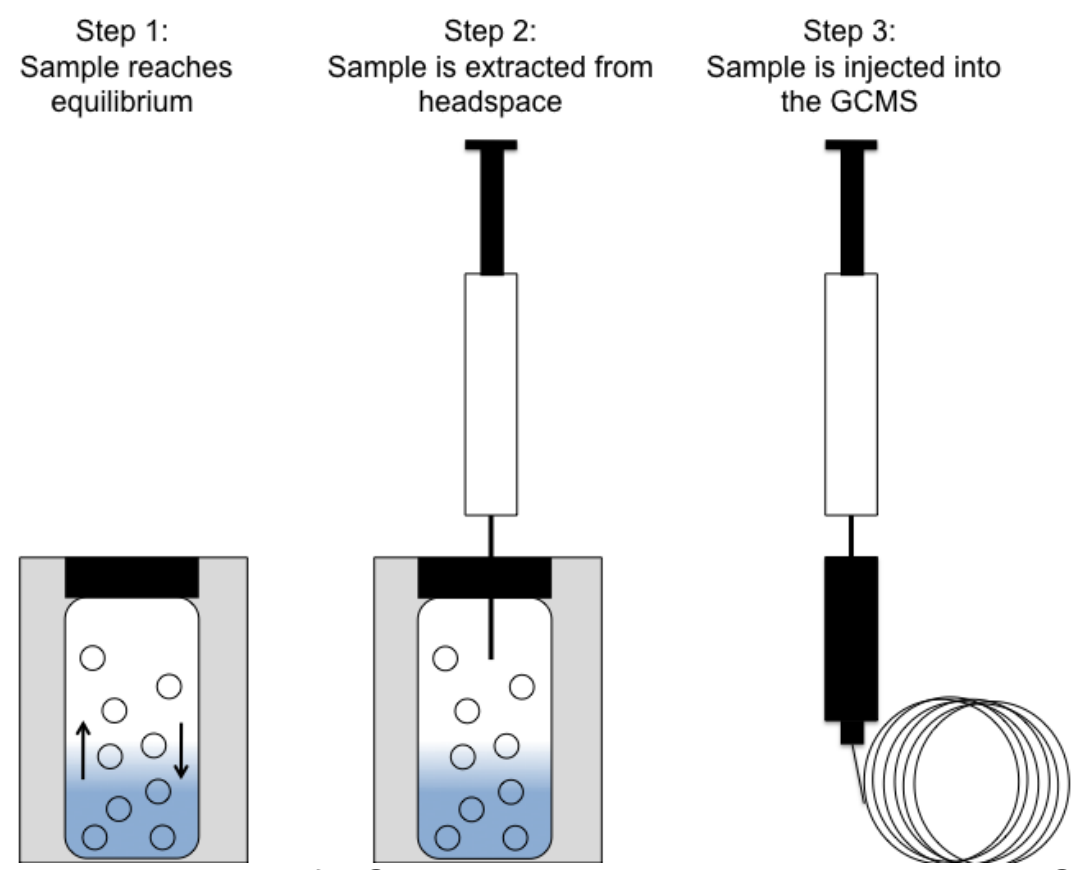

Figure 3.1 Diagram of HS sampling analysis using a 20-mL HS vial

The difference between traditional GC/MS and HS-GC/MS is the sample introduction system. Rather than the liquid being directly injected, the vapor above a sample is quantitatively sampled and delivered to the injector port. In the case of HS sampling, the amount of analyte delivered is a function of how effectively the analyte is vaporized from the sample. This in turn depends on many factors such as vapor pressure and interactions with the sample matrix.

Since the vapor pressure for methamphetamine is $19.6 \mathrm{~Pa}$, increasing vapor pressure is favorable in that it will decrease the partition coefficient. This can be 
accomplished by increasing the temperature at which the sample vial is held during the equilibration time. This relationship is derived from the Clausius-Clapeyron equation, which is written as follows: ${ }^{51}$

$\ln \left(\frac{P_{T 1}}{P_{T 2}}\right)=\frac{\Delta H_{v a p}}{R}\left(\frac{1}{T_{2}}-\frac{1}{T_{1}}\right)$

Where $\mathrm{P}_{\mathrm{T} 1}$ is the pressure at initial temperature; $\mathrm{P}_{\mathrm{T} 2}$ is the pressure at the final temperature; $\Delta \mathrm{H}_{\text {vap }}$ is the enthalpy of vaporization (for methamphetamine, $\Delta \mathrm{H}_{\text {vap }}=$ $\left.4.519 \times 10^{4} \mathrm{~J} \mathrm{~mol}^{-1}\right) ; \mathrm{R}$ is the gas constant $\left(8.314 \mathrm{~J} \mathrm{~K}^{-1} \mathrm{~mol}^{-1}\right) ; \mathrm{T}_{1}$ is initial temperature $(\mathrm{K})$, and $\mathrm{T}_{2}$ final temperature $(\mathrm{K})$. Figure 3.2 demonstrates the result of increasing temperature during incubation in HS analysis of methamphetamine.

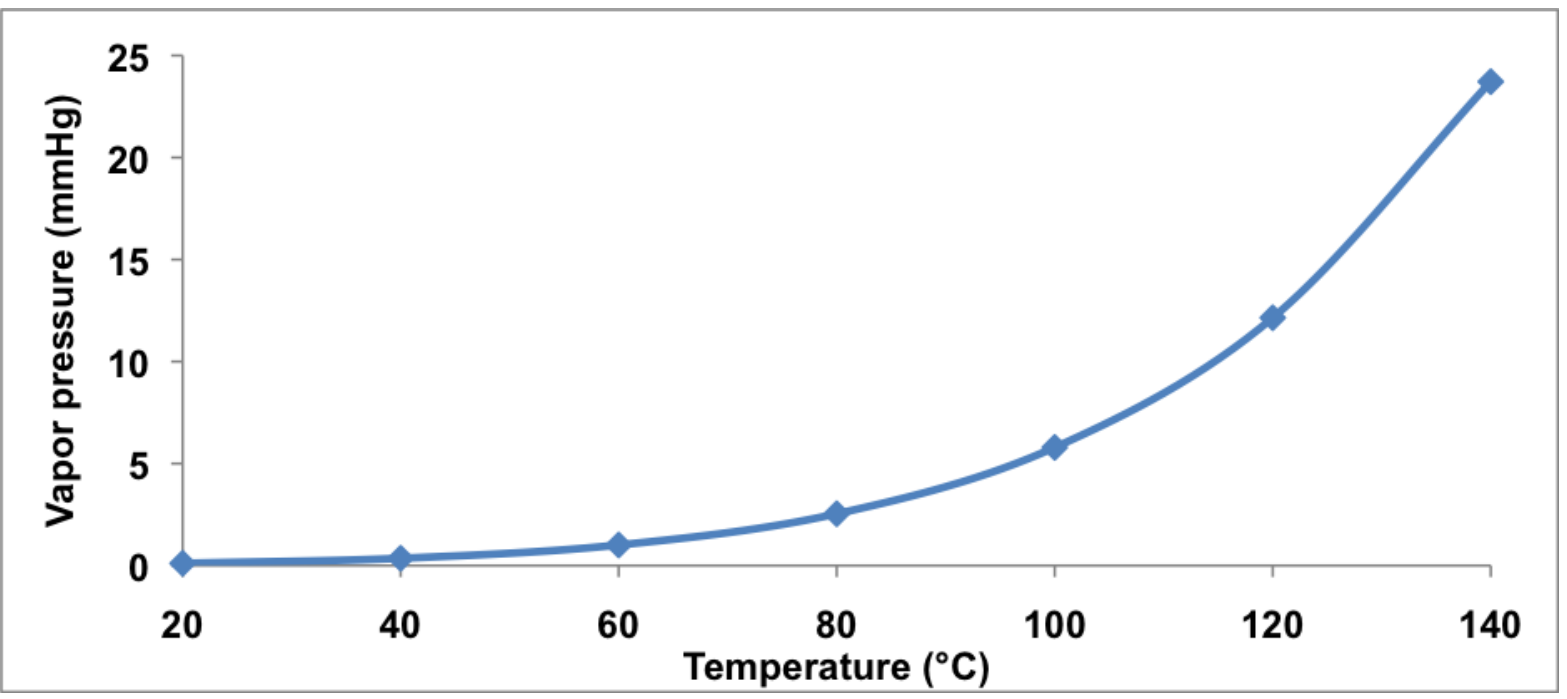

Figure 3.2 Vapor pressure curve for methamphetamine established based upon Clausius-Clapeyron equation.

A method validation was first performed with liquid-injection. HS analysis was used as a comparison to the liquid-injection method, under a non-validated analysis. Detection of methamphetamine in the HS without derivatization has not been commonly reported throughout the literature due to the reasonably low volatility, and 
difficulties with efficiency. Since derivatization of gas-phase samples collected could not be performed, the author elected not to derivatize standards in establishing the calibration.

To avoid this dilemma, current research has moved away from the use of static HS analysis in the detection of methamphetamine, and towards solid-phase microextraction (SPME). SPME aids in the pre-concentration of the analyte on the fiber while also allowing for gas-phase derivatization. Methods for methamphetamine detection in serum, hair and urine by HS-SPME-GC/MS with derivatization have been reported in the literature..$^{52,53,54}$ However, SPME fibers remain reasonably high priced, and as such were not used in this project.

Fundamentally, any method validation must first be fit-for-purpose, meaning that the method and its validation should meet the goals and application of the analytical method. Second, any method validation protocol should be reasonable and defensible in the context that it will be utilized. For this application, the parameters given by the 2012 Scientific Working Group for Forensic Toxicology's (SWGTOX) DRAFT of Standard Practices for Method Validation in Forensic Toxicology have been chosen. It should be noted that these parameters remain in draft form, but are useful as they capture concepts of method validation, which are important in forensic chemistry. These requirements target figures of merit (defined in Table 3.1), which include: (1) accuracy; (2) calibration model; (3) carryover; (4) interference studies; (5) limit of detection; (6) limit of quantification; and (7) precision. An evaluation of each of these parameters proves that the method developed is 
sufficient for its intended purpose ${ }^{55}$ It should be noted that a non-traditional definition of limit of quantitation was used in this study.

Table 3.1 Definitions from SWGTOX Method Validation ${ }^{55}$

\begin{tabular}{|c|l|}
\hline Accuracy & $\begin{array}{l}\text { The closeness of agreement between a measured } \\
\text { quantity value and a true quantity value of a measurand. } \\
\text { Usually reported as a percent difference. The term bias } \\
\text { may also be used to describe accuracy. }\end{array}$ \\
\hline Calibration Model & $\begin{array}{l}\text { The mathematical model that demonstrates the } \\
\text { relationship between the concentration of analyte and } \\
\text { the corresponding instrument response. }\end{array}$ \\
\hline Carryover & $\begin{array}{l}\text { The appearance of unintended analyte signal in } \\
\text { samples after the analysis of a positive sample. }\end{array}$ \\
\hline Interferences & $\begin{array}{l}\text { Non-targeted analytes, which may impact the ability to } \\
\text { detect, identify, or quantitate a targeted analyte. }\end{array}$ \\
\hline Limit of Detection & $\begin{array}{l}\text { An estimate of the lowest concentration of an analyte in } \\
\text { a sample that can be reliably detected or identified but } \\
\text { not necessarily quantitated by the analytical method. }\end{array}$ \\
\hline Quantification & $\begin{array}{l}\text { An estimate of the lowest concentration of an analyte in } \\
\text { a sample that can be reliably differentiated from blank } \\
\text { matrix and measured with acceptable precision and } \\
\text { accuracy. }\end{array}$ \\
\hline Precision & $\begin{array}{l}\text { The measure of the closeness of agreement between a } \\
\text { series of measurements obtained from multiple } \\
\text { samplings of the same homogenous sample. It is } \\
\text { expressed numerically as imprecision. }\end{array}$ \\
\hline
\end{tabular}

\subsection{GC/MS Method Validation Plan}

During the methamphetamine analysis of this project, two sample introduction techniques were used: direct injection and HS. Liquid injection analyses were performed first to validate the direct injection method. This was done to ensure better detection limits for the analysis, due to an inability to derivatize methamphetamine for this work. Once all parameters of method validation were completed, HS analysis conditions were optimized. All method validation parameters were reported as a mass loaded onto the column to allow for comparison of the two sample introduction methods. 
Methamphetamine was purchased from three different manufacturers for this study: Cerilliant $^{\circledR}$, Sigma-Aldrich ${ }^{\circledR}$, and Restek ${ }^{\circledR}$. The criteria for validation are presented separately as well as combined for the various manufactured methamphetamine standards. The use of multiple manufacturers allowed for the evaluation of an additional figure of merit not addressed by SWGTOX, robustness. According to International Conference on Harmonization (ICH), "robustness/ruggedness of an analytical procedure is a measure of its capacity to remain unaffected by small, but deliberated variations." Since street drug compositions are known to vary, ideally the robustness of this method ensures method validity under various conditions with the potential that different forms of methamphetamine may be produced. From a practical perspective, characterizing the robustness in this manner allowed for the use of any of these commercial standards without necessitating re-validation.

Using an internal standard helps account for potential variation in instrumental response; therefore, reported values make use of peak area ratios of methamphetamine to the internal standard. Methamphetamine-D14 (meth-D14) was chosen as the internal standard due to its structural similarity, and separation from methamphetamine in the chromatography. Choosing a deuterated internal standard ensures that the internal standard peak is not a component of the analyte itself.

While selected ion monitoring (SIM) affords the lowest detection limit, it lacks information about the background that has the potential of being significant. Extracted ion chromatographs (XIC) allows for the selection of a specific ion post- 
run; therefore, all useful information is collected with integration that results in increased signal to noise ratios.

In this method validation, a calibration model was established by first injecting various concentration solutions to determine roughly the low and high end of the calibration range. Due to difficulties with peak splitting at high concentrations, the range for methamphetamine throughout this study was 0.0100 to $0.400 \mathrm{ng}$ on column. The linear regression will be demonstrated along this calibration range for all manufacturers.

The LOD and LOQ were established by SWGTOX guidelines rather than traditional signal-to-noise ratios. Data processing did not allow for the collection of raw data, due to the use of software thresholding. Thresholding is the elimination of all signals below a certain level and occurred in all XIC chromatograms. ${ }^{56}$ As such, it was established that the LOQ was the lowest calibrant possessing both accuracy and precision. The LOD was said to be less than that of the LOQ, due to an inability to establish signal-to-noise ratio estimates, and inaccurate estimates based upon the calibration curves.

Accuracy and precision (within and between-run) measurements were run concurrently with the establishment of the calibration model. These parameters were evaluated as percent difference and percent coefficient of variance $(\% \mathrm{CV})$. A deviation of less than $20 \%$ CV was established to be acceptable under both conditions.

To ensure minimal sample carryover, two procedures were put into place. While the analyte was detected within the first 10 min of the temperature ramp, an 
additional 6 min was used to raise the temperature and hold it for several minutes. Additionally, the programming of multiple syringe rinse steps aided in the reduction of carryover. Carryover was evaluated by running methanol blanks after high concentration samples, with adjustments to the GC method until no analyte signal was detectable in the blank runs.

Finally, the interference study was accomplished by examining the peaks of methamphetamine and the internal standard separately, as well as together in a run. These peaks were then evaluated to ensure that co-elution did not occur, and that the deuterated internal standard would have no effect on the signal intensity of the analyte. A matrix study was not utilized since methamphetamine and meth-D14 were evaluated as a part of the interference study, and were the only components of the system.

Having established a validated method, the injection system was changed to HS sampling. Temperature and equilibration time were optimized for the HS method in an effort to achieve the lowest \%RSD. At this point, the method was optimized and validated for the detection of methamphetamine by GC/MS, with the ability to analyze both liquid and gas-phase samples.

\subsection{Materials and Methods}

\subsubsection{Chemicals and Solvents}

Methamphetamine was obtained from Cerilliant $^{\circledR}(( \pm)$-methamphetamine, 99\%), Restek ${ }^{\circledR}\left((+)\right.$-methamphetamine standard, 99\%) and Sigma-Aldrich ${ }^{\circledR}((+)-$ methamphetamine hydrochloride). The internal standard (IS) used in all models was meth-D14 (Cerilliant $\left.{ }^{\circledR}\right)$. Cerilliant ${ }^{\circledR}$ and Restek $^{\circledR}$ standards were purchased at a 1,000 
ppm in methanol, and a stock solution at the same concentration was made from the Sigma-Aldrich $^{\circledR}$ solid in LC/MS grade methanol (Fluka/Sigma-Aldrich, St. Louis MO). For each manufacturer, working solutions were produced at 10 and $100 \mathrm{ppm}$. Working solutions were promptly diluted to calibration concentrations of $10,5,1,0.5$, and $0.25 \mathrm{ppm}$ with methanol and stored in $1.5-\mathrm{mL} \mathrm{GC/MS}$ vials at $4{ }^{\circ} \mathrm{C}$.

Headspace analysis was performed using the gas-tight syringe method, and 20-mL HS vials. HS analysis of Sigma-Aldrich ${ }^{\circledR}$ and Cerilliant ${ }^{\circledR}$ standards for methamphetamine were prepared from 1,000 ppm and diluted using methanol. Southern yellow pine (SYP) wood chips were acquired from a local wood shop.

\subsubsection{Instrumentation}

Conditions of the optimized GC/MS method using the Shimadzu GC-2010 equipped with GC/MS-QP2010S quadrupole mass spectrometer, and AOC 5000 autosampler (Shimadzu Scientific Instruments, Columbia, MD) are shown in Table 3.2. An Rxi-5Sil MS column ( $30 \mathrm{~m}, 0.25 \mathrm{~mm}$ i.d., $0.50 \mu \mathrm{m}$ film thickness; Restek ${ }^{\circledR}$, Bellefont, PA) was used for the separation of target analytes. The GC oven was operated under a temperature-ramping program (Table 3.2). 
Table 3.2 GC/MS conditions for the analysis of methamphetamine

\begin{tabular}{|c|c|}
\hline \multicolumn{2}{|c|}{ Chromatographic Conditions } \\
\hline Temperature program & $\begin{array}{l}\text { Start at } 80^{\circ} \mathrm{C}(1 \mathrm{~min}), 10^{\circ} \mathrm{C} / \mathrm{min} \rightarrow 180^{\circ} \mathrm{C}(1 \\
\mathrm{min}), 50^{\circ} \mathrm{C} / \mathrm{min} \rightarrow 280^{\circ} \mathrm{C}(3 \mathrm{~min})\end{array}$ \\
\hline Injection volume & $1 \mu \mathrm{L}$ \\
\hline Injection temperature & $280^{\circ} \mathrm{C}$ \\
\hline Gas & $\mathrm{He}(1 \mathrm{~mL} / \mathrm{min})$ \\
\hline Mode & Split (25:1) \\
\hline Column & Rxi-5Sil MS w/ Integra-Guard \\
\hline \multicolumn{2}{|c|}{ Mass Spectrometer Conditions } \\
\hline GC interface temperature & $280^{\circ} \mathrm{C}$ \\
\hline Ion source temperature & $260^{\circ} \mathrm{C}$ \\
\hline Electron ionization (EI) & $70 \mathrm{eV}$ \\
\hline Mass spec mode & $\begin{aligned} \text { XIM: } & m / z 58 \text { methamphetamine } \\
& m / z 65 \text { methamphetamine-d14 }\end{aligned}$ \\
\hline
\end{tabular}

Optimization of retention times and chromatographic resolution was based upon the total ion chromatogram (Figure 3.3). Two chromatographically resolved peaks resulted at 8.454 and $8.571 \mathrm{~min}$, for meth-D14 and methamphetamine respectively. These peaks were identified based upon their mass spectrum (Figure 3.4 and 3.5).

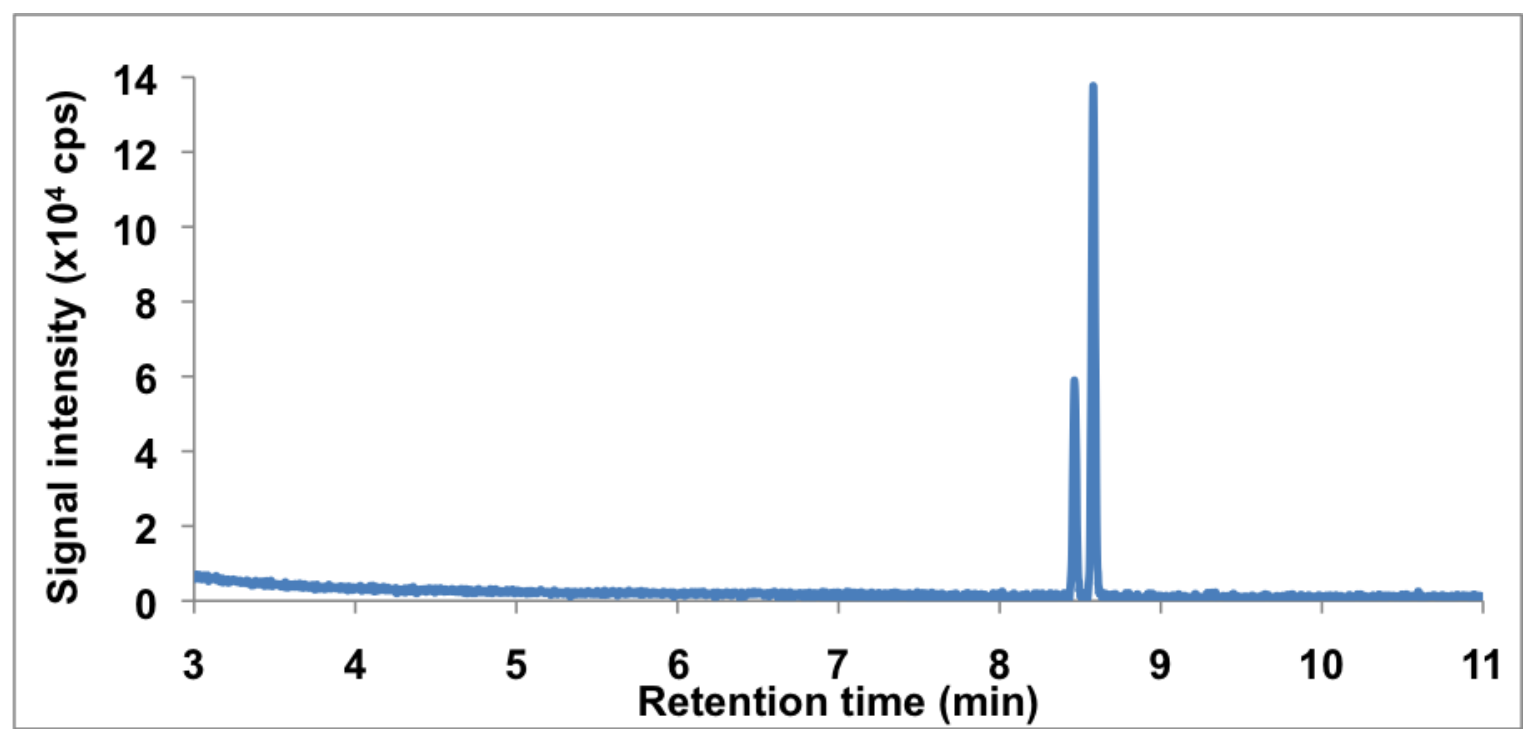

Figure 3.3 GC/MS total ion chromatograph of meth-D14 (8.454 min) and methamphetamine (8.571 $\mathrm{min})$ 


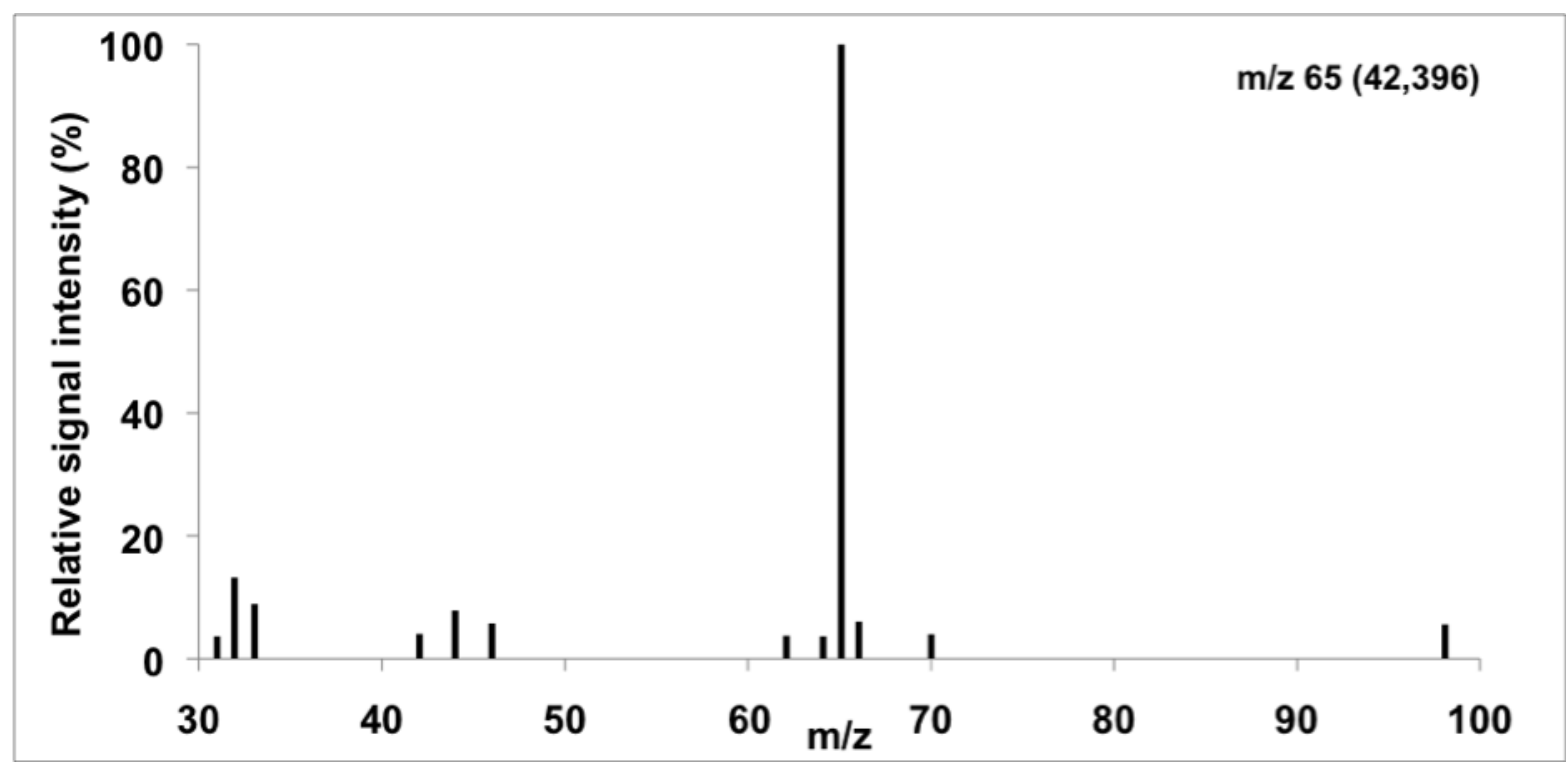

Figure 3.4 Mass spectrum resulting from the meth-D14 peak at 8.454 min

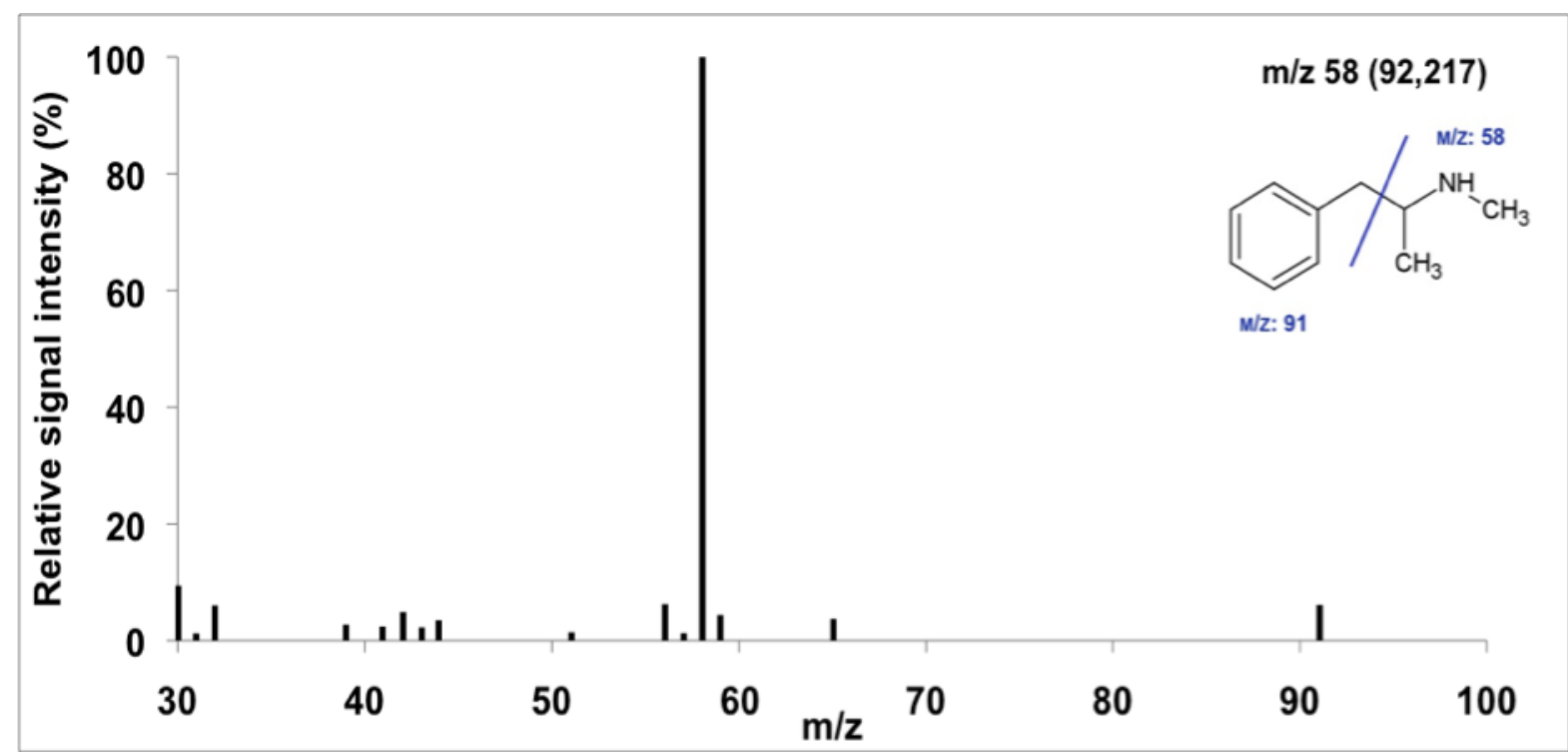

Figure 3.5 Mass spectrum resulting from the methamphetamine peak at $8.571 \mathrm{~min}$

Quantification was conducted by performing extracted ion chromatography (XIC) with specific ions for each target compound. The mass-to-charge ratio of 65 for meth-D14, and $\mathrm{m} / \mathrm{z} 58$ for methamphetamine were chosen for monitoring due to their high abundance. Figure 3.6, XIC of $\mathrm{m} / \mathrm{z} 65$, produced two chromatographic peaks; however, the peak eluting at 8.454 min, was monitored as meth-D14. The 
second peak in the figure is a result of the ionization of methamphetamine, which produces a minor fragment at $m / z 65$. Due to chromatographic separation, only the area of the peak at 8.454 min was used for quantification of $\mathrm{m} / \mathrm{z} 65$. The XIC of $\mathrm{m} / \mathrm{z}$ 58, shown in Figure 3.7, produced only a single peak.

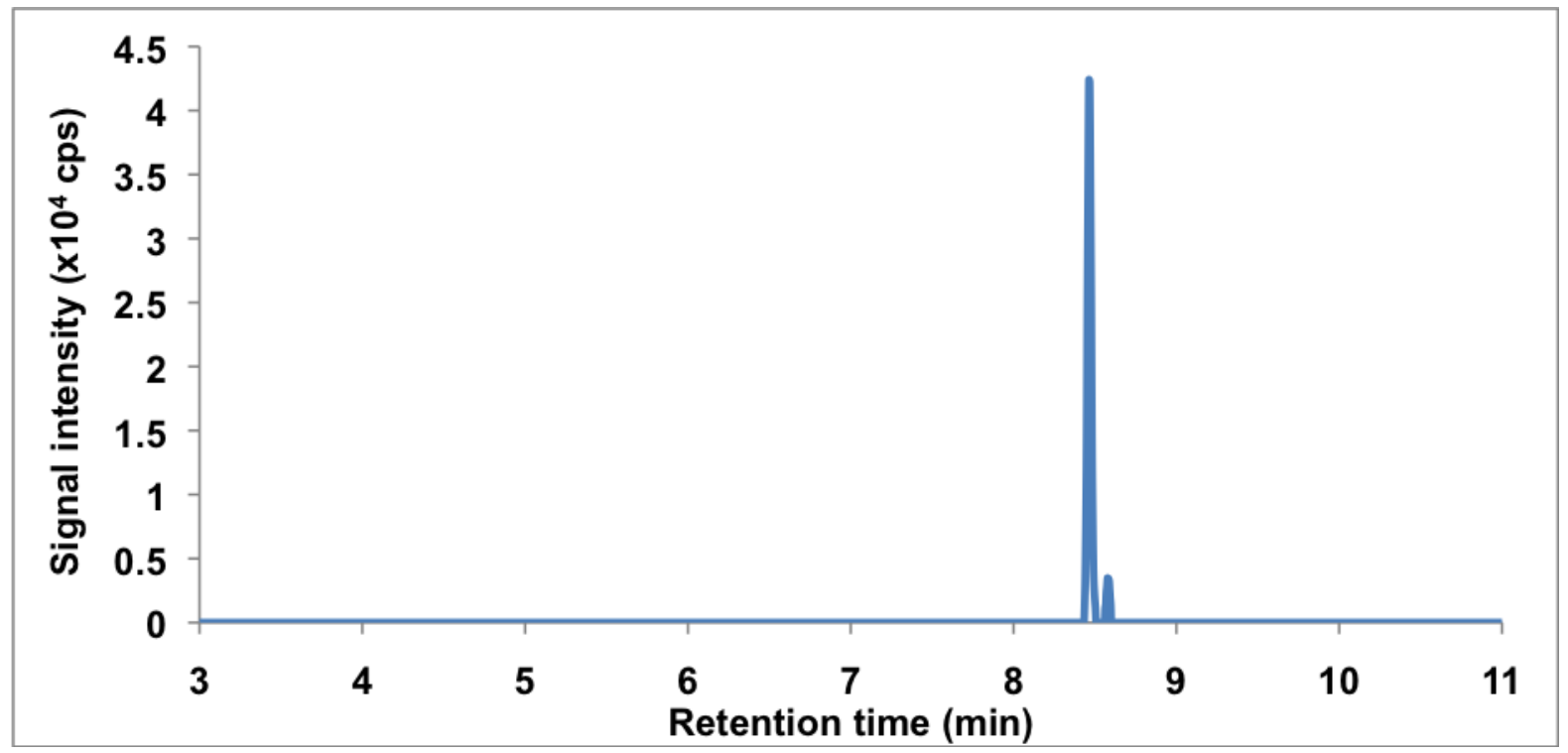

Figure 3.6 GC/MS extracted ion chromatograph of $\mathrm{m} / \mathrm{z} 65$

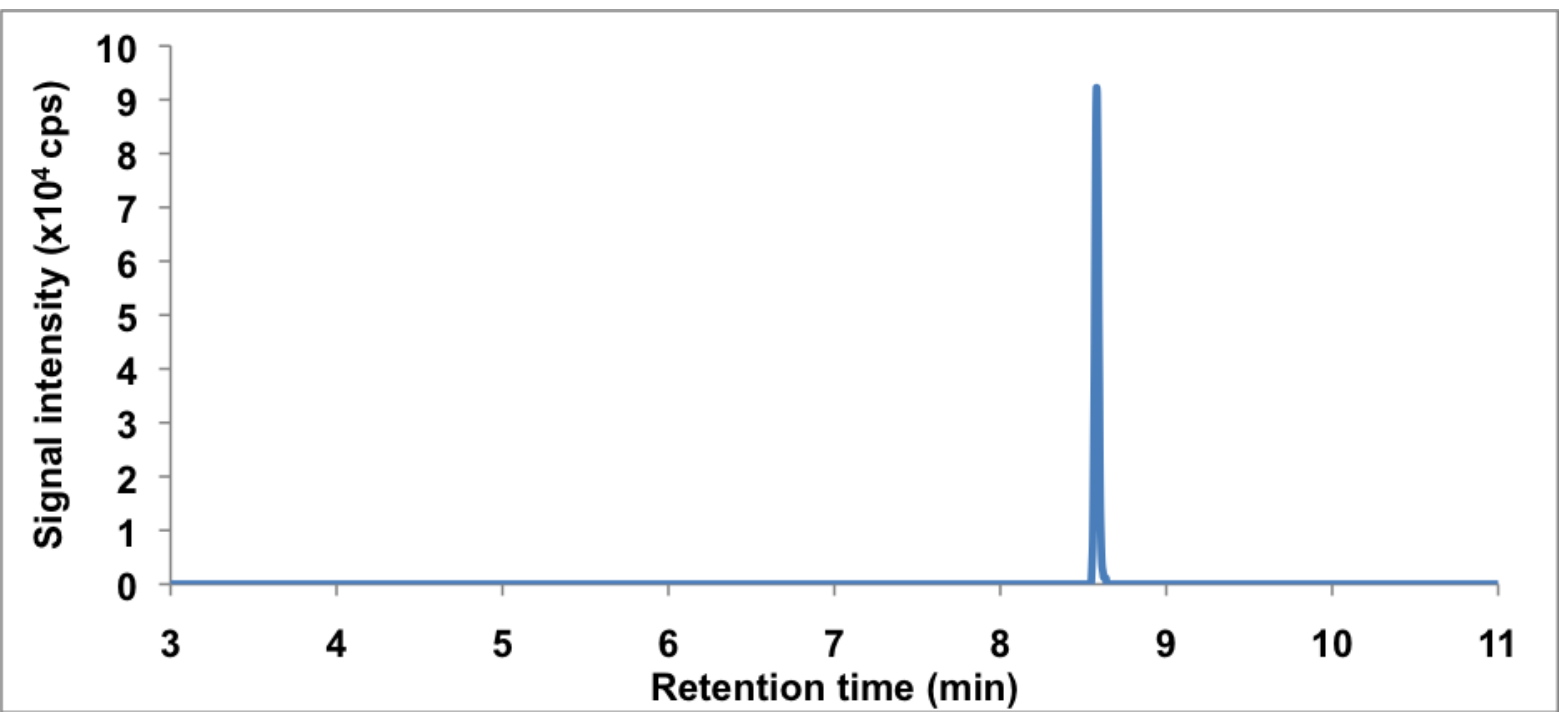

Figure 3.7 GC/MS extracted ion chromatograph of $\mathrm{m} / \mathrm{z} 58$ 
In the HS analysis, both the $2.5-\mathrm{mL}$ gas-tight syringe and sample vial were heated to $105{ }^{\circ} \mathrm{C}$. The vial was held within the thermostatted oven for $30 \mathrm{~min}$ and agitated at $500 \mathrm{rpm}$ during that time period. The optimized conditions were established experimentally as discussed in Section 3.4.2. The GC/MS method remained the same as used for liquid samples (Table 3.3).

Table 3.3 HS-GC/MS conditions for the analysis of methamphetamine

\begin{tabular}{ll}
\hline Headspace Conditions & \\
\hline Incubation Temperature & $105^{\circ} \mathrm{C}$ \\
\hline Incubation Time & $30 \mathrm{~min}$ \\
\hline Syringe Temperature & $105^{\circ} \mathrm{C}$ \\
\hline Agitator speed & $500 \mathrm{rpm}$ \\
\hline \multicolumn{2}{l}{ Chromatographic Conditions } \\
\hline Temperature program & Start at $80^{\circ} \mathrm{C}(1 \mathrm{~min}), 10^{\circ} \mathrm{C} / \mathrm{min} \rightarrow 180^{\circ} \mathrm{C}$ \\
\hline Injection volume & $(1 \mathrm{~min}), 50^{\circ} \mathrm{C} / \mathrm{min} \rightarrow 280^{\circ} \mathrm{C}(3 \mathrm{~min})$ \\
\hline Injection temperature & $2.50 \mathrm{~mL}$ \\
\hline Gas & $280^{\circ} \mathrm{C}$ \\
\hline Mode & $\mathrm{He}(1 \mathrm{~mL} / \mathrm{min})$ \\
\hline Column & $\mathrm{Split}(25: 1)$ \\
\hline Mass Spectrometer Conditions \\
\hline GC interface temperature & $280^{\circ} \mathrm{C}$ \\
\hline lon source temperature & $260^{\circ} \mathrm{C}$ \\
\hline Electron ionization (EI) & $70 \mathrm{eV}$ \\
\hline Mass spec mode & $\mathrm{XIM:} \mathrm{m} / \mathrm{z} 58$ methamphetamine \\
\end{tabular}

\subsection{Results and Discussion}

\subsubsection{Liquid Injection GC/MS Method Validation}

\subsubsection{Calibration Model}

A calibration model is established by first determining the concentration range over which analyte signal will need to be detected for sample analysis. ${ }^{55}$ For this project, this was determined by evaluating the low and high ends of instrument 
detection. A range of $0.25 \mathrm{ppm}$ to $10 \mathrm{ppm}$ was chosen. Three separate calibration models have been established for this method to compare differences in methamphetamine manufacturing.

Five calibration points were used as these aptly span the calibration range: $0.25,0.5,1,5$, and $10 \mathrm{ppm}$. Samples were diluted from the respective $1,000 \mathrm{ppm}$ standard to obtain working solutions at 100 and $10 \mathrm{ppm}$, which were used to prepare the calibration standard. Meth-D14 internal standard was spiked at $5 \mathrm{ppm}$ into each calibration standard. Calibration solutions were prepared once for all evaluations and stored at $4{ }^{\circ} \mathrm{C}$ between analysis days. Before GC/MS evaluation, calibration standards were removed from refrigeration and allowed to reach room temperature.

Concentrations were then converted to nanograms (ng) on column, to establish a relationship that could be compared with HS sampling. An example calculation is shown here for the $10 \mathrm{ppm}$ solution. The units of ppm are equivalent to that of nanograms per microliter.

$10 \mathrm{ppm}=\frac{10 \mathrm{ng}}{1 \mu L}$

In which $1 \mu \mathrm{L}$ of the sample is the injection volume into the GC/MS, establishing that $10 \mathrm{ng}$ are put into the system.

$$
\frac{10 n g}{1 \mu L} \bullet 1 \mu L=10 n g_{I n j}
$$

Due to the $25: 1$ split on the instrument, only $4 \%$ of the sample makes it onto the GC/MS column.

$$
10 n g\left\lfloor\frac{1}{25}\right\rfloor=0.40 n g_{\text {column }}
$$


Therefore, for a $10 \mathrm{ppm}$ solution with a $1 \mu \mathrm{L}$ injection volume and a split of $25: 1$, only $0.400 \mathrm{ng}$ of methamphetamine enters the GC/MS column. These converted concentrations are shown in the Table 3.4.

Table 3.4 Conversion of concentration to mass of methamphetamine in GC/MS

\begin{tabular}{|c|c|}
\hline $\begin{array}{c}\text { Concentration of solution injected } \\
\text { (ppm) }\end{array}$ & $\begin{array}{c}\text { Mass on column } \\
\text { (ng) }\end{array}$ \\
\hline 0.250 & 0.0100 \\
\hline 0.500 & 0.0200 \\
\hline 1.00 & 0.0400 \\
\hline 5.00 & 0.200 \\
\hline 10.0 & 0.400 \\
\hline
\end{tabular}

A calibration model plots the peak area ratio of methamphetamine to methD14 versus nanograms (ng) on column of methamphetamine. For each manufacturer, the calibration standards were analyzed over three days. The calibration models established use the least squares method as recommended for the best approach to establishing a linear relationship. The linear regression was established using the LINEST function of Microsoft Excel ${ }^{\circledR}$ to define the slope and yintercept of the best-fit line.

The calibration model presented in Figure 3.8 is a result of calibration standards from Cerilliant. The nine determinations of a single day were averaged and the percent relative standard deviations (\%RSD) established for the overall analysis of a Cerilliant ${ }^{\circledR}$ calibration standard. It was found that at all concentrations the RSD's for Cerilliant ${ }^{\circledR}$ standards were below $8 \%$. 


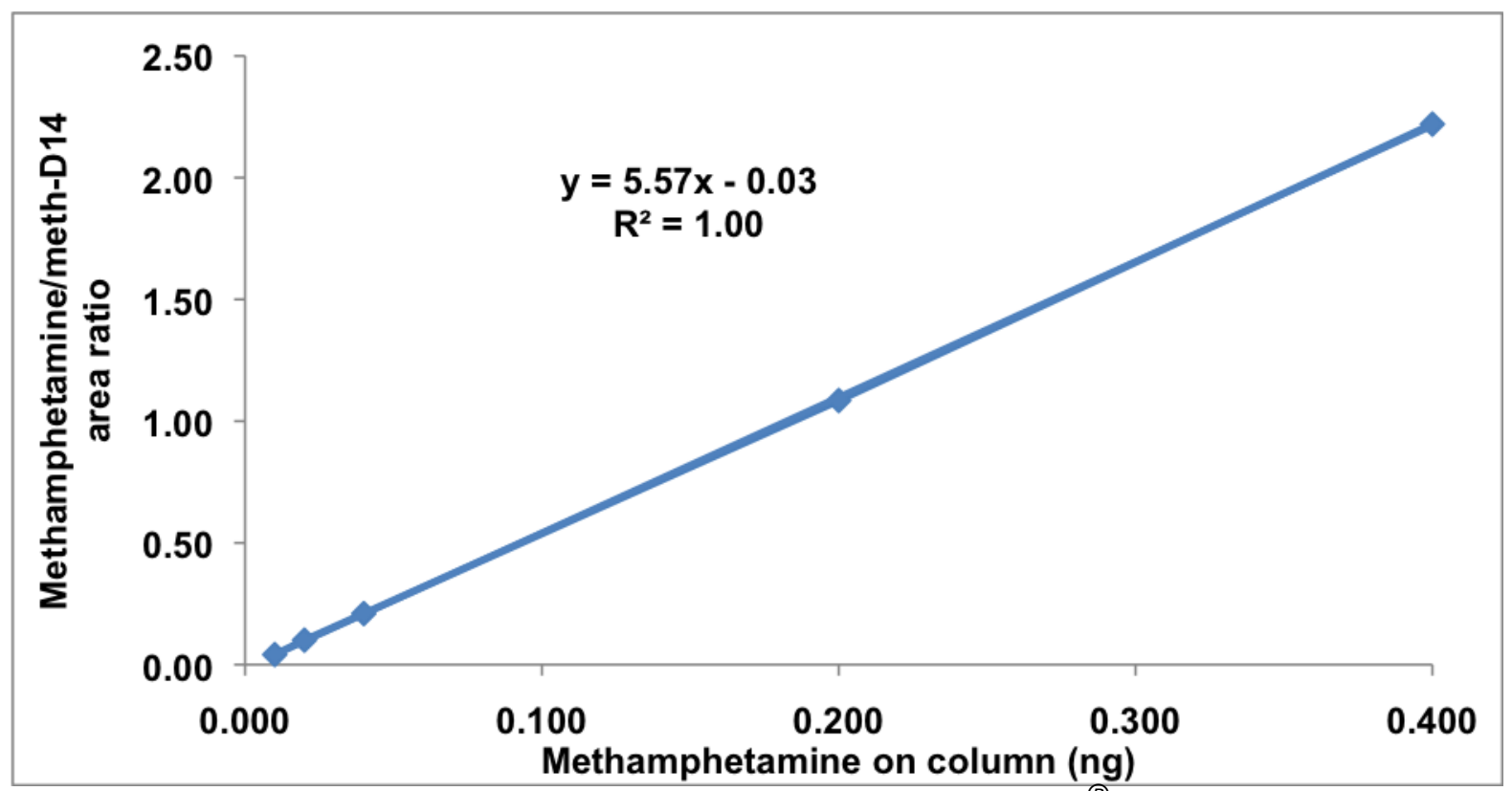

Figure 3.8 Calibration model of averaged data from Cerilliant $^{(\Theta)}$ standards

Table 3.5 Cerilliant $t^{\circledast}$ data used for the formation of the calibration model

\begin{tabular}{|l|c|r|r|r|r|}
\hline & \multicolumn{5}{|c|}{ Methamphetamine on Column (ng) } \\
\hline Analysis Day & $\mathbf{0 . 0 1 0 0}$ & $\mathbf{0 . 0 2 0 0}$ & $\mathbf{0 . 0 4 0 0}$ & $\mathbf{0 . 2 0 0}$ & $\mathbf{0 . 4 0 0}$ \\
\hline Day 1 Average & 0.041 & 0.100 & 0.211 & 1.08 & 2.22 \\
\hline Day 2 Average & 0.042 & 0.101 & 0.207 & 1.08 & 2.20 \\
\hline Day 3 Average & 0.041 & 0.101 & 0.212 & 1.10 & 2.23 \\
\hline AVERAGE & 0.041 & 0.101 & 0.210 & 1.08 & 2.22 \\
\hline SD & 0.003 & 0.005 & 0.006 & 0.02 & 0.09 \\
\hline \%RSD & $8 \%$ & $5 \%$ & $3 \%$ & $2 \%$ & $4 \%$ \\
\hline
\end{tabular}

Table 3.6 Output from LINEST equation for Cerilliant $^{\oplus}$ data

\begin{tabular}{|c|c|c|}
\hline & Slope & Intercept \\
\hline Parameter & 5.57 & -0.015 \\
\hline SD & 0.03 & 0.006 \\
\hline $\mathrm{R}^{2}$ & 1.00 & 0.01 \\
\hline
\end{tabular}

Upon analysis of the Restek ${ }^{\circledR}$ standards, a calibration curve was produced (Figure 3.9). Data points were considered to be outliers based upon diagramming as a modified box-and-whisker plot of the methamphetamine to meth-D14 ratio. Modified box-and-whisker plots do not include outliers as part of the box-and- 
whisker, but instead plot them as an individual point. This allows for the dispersion of data to be represented more accurately. An outlier is established as any point that lies more than 1.5 times the length of the box from either end of the box. Two data points, measured at $0.0100 \mathrm{ng}$ of methamphetamine, were removed from the Restek $^{\circledR}$ data set based upon modified box-and-whisker analysis (Figure 3.10).

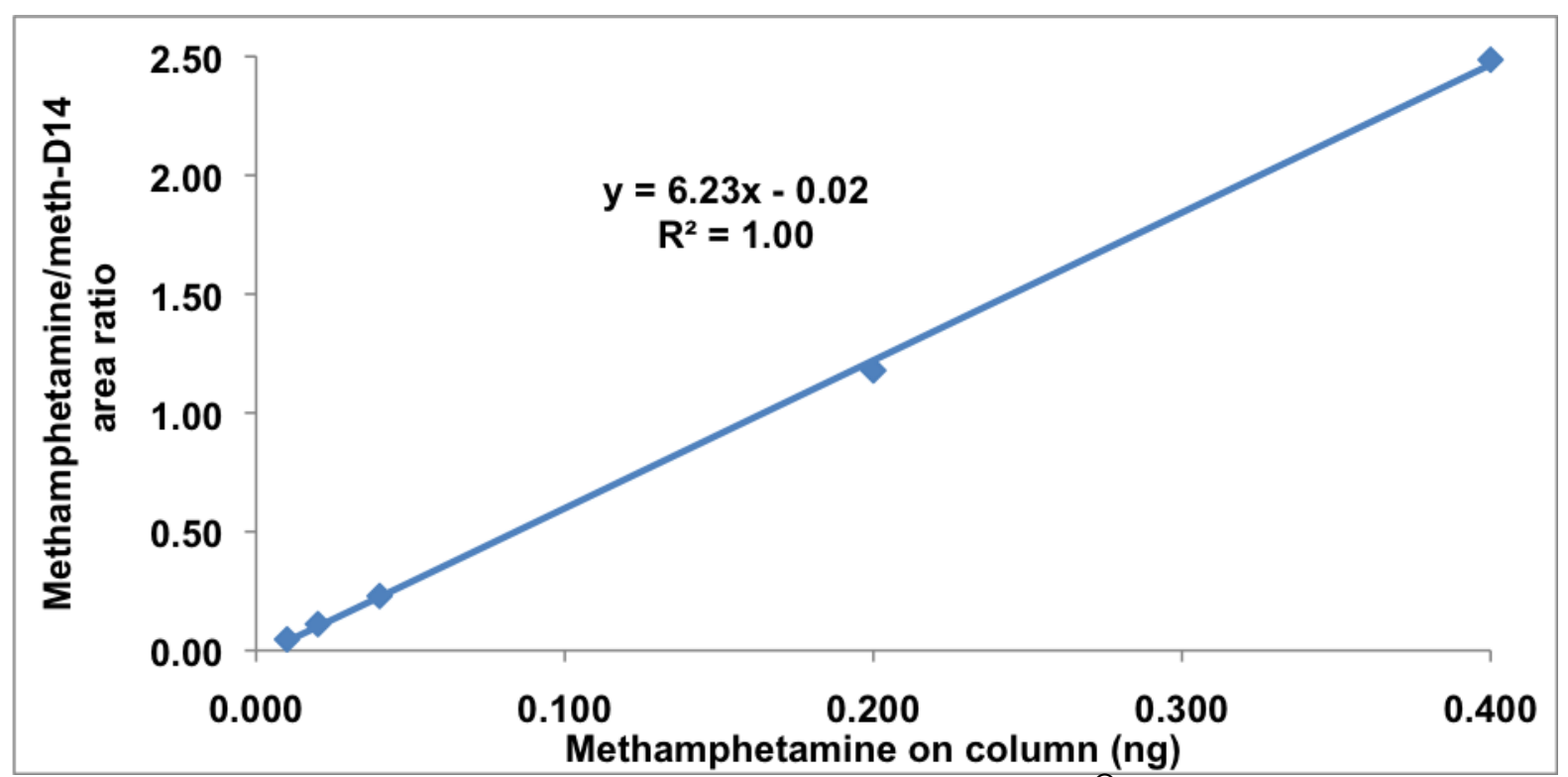

Figure 3.9 Calibration model of averaged data from Restek ${ }^{\circledR}$ standards

Table 3.7 Restek ${ }^{\circledR}$ data used for the formation of the calibration model

\begin{tabular}{|l|c|r|r|r|r|}
\hline & \multicolumn{6}{|c|}{ Methamphetamine on Column (ng) } \\
\hline Analysis Day & $\mathbf{0 . 0 1 0 0}$ & $\mathbf{0 . 0 2 0 0}$ & $\mathbf{0 . 0 4 0 0}$ & $\mathbf{0 . 2 0 0}$ & $\mathbf{0 . 4 0 0}$ \\
\hline Day 1 Average & 0.046 & 0.110 & 0.23 & 1.18 & 2.49 \\
\hline Day 2 Average & 0.045 & 0.110 & 0.23 & 1.18 & 2.48 \\
\hline Day 3 Average & 0.049 & 0.113 & 0.23 & 1.28 & 2.49 \\
\hline AVERAGE & 0.047 & 0.111 & 0.23 & 1.18 & 2.49 \\
\hline SD & 0.005 & 0.005 & 0.01 & 0.05 & 0.07 \\
\hline \%RSD & $10 \%$ & $4 \%$ & $5 \%$ & $4 \%$ & $3 \%$ \\
\hline
\end{tabular}

Table 3.8 Output from LINEST equation for Restek ${ }^{\circledR}$ data

\begin{tabular}{|c|c|c|}
\hline & Slope & Intercept \\
\hline Parameter & 6.23 & -0.02 \\
\hline SD & 0.08 & 0.02 \\
\hline $\mathrm{R}^{2}$ & 1.00 & 0.03 \\
\hline
\end{tabular}




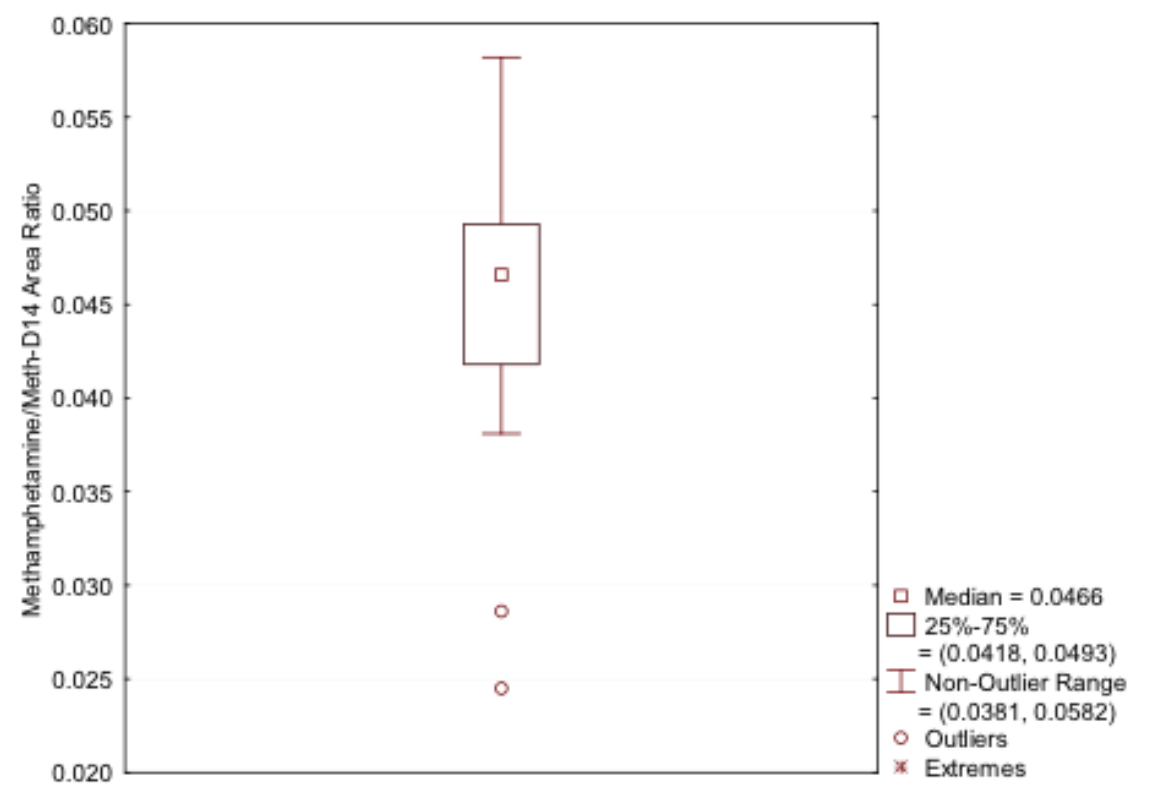

Figure 3.10 Box plot of Restek ${ }^{\circledR}$ standards at $0.0100 \mathrm{ng}$ of methamphetamine on column, demonstrating two outliers in the data set, 0.0286 and 0.0245

The methamphetamine/meth-D14 peak area ratios found within the Restek ${ }^{\circledR}$ samples produced a greater relative standard deviation (\%RSD) between the replicates than that of the Cerilliant ${ }^{\circledR}$ standards in most cases. In the analysis of 0.0200 and $0.400 \mathrm{ng}$ on column methamphetamine, a smaller relative standard deviation occurred versus Cerilliant ${ }^{\circledR}$. For the three other concentrations, Restek ${ }^{\circledR}$ values of $\%$ RSD were $2 \%$ greater.

The third calibration model established from this data set was that of the Sigma-Aldrich ${ }^{\circledR}$ methamphetamine product which was obtained in solid form and made up in methanol for the given concentrations (Figure 3.11). A solid sample was chosen because it evaluates differences in sample preparation technique. One point was removed from this study as an outlier as evaluated by box-and-whisker plots (Figure 3.12). The point was removed from the $0.0100 \mathrm{ng}$ on column analysis in this case. 
The curve produced from the solids demonstrated the lowest \%RSD among the three curves for that of the $0.400 \mathrm{ng}$ on column data, while also yielding an $\mathrm{R}^{2}$ value of 1 . It was expected that the calibration standards made from solids would have greater variance than that of the two liquid standards since an additional preparation step was involved; yet the data demonstrates that the Sigma-Aldrich ${ }^{\circledR}$ standard is reproducible with RSD values less than $10 \%$.

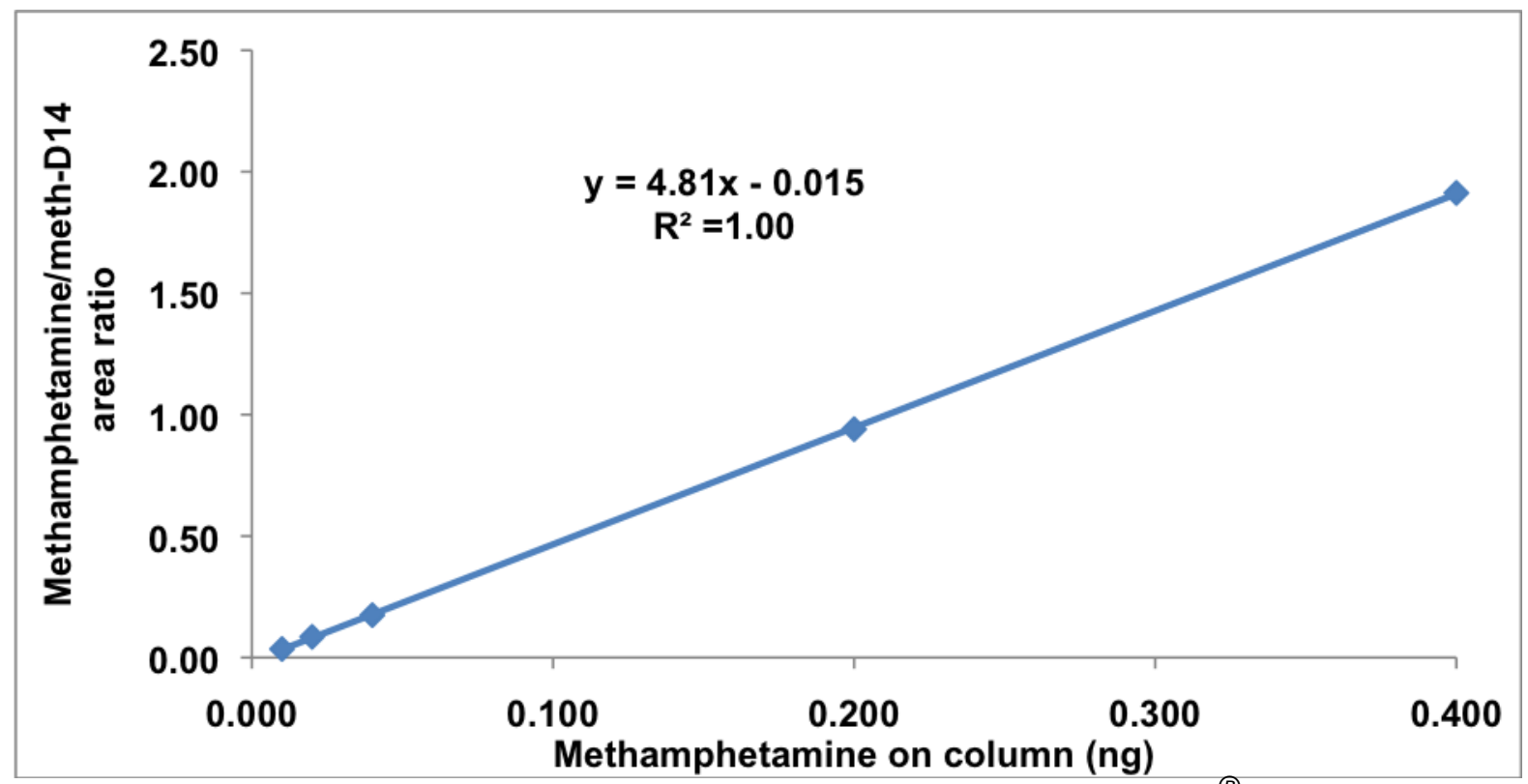

Figure 3.11 Calibration model of averaged data from Sigma-Aldrich ${ }^{\circledast}$ standards

Table 3.9 Sigma-Aldrich ${ }^{\circledast}$ data used for the formation of the calibration model

\begin{tabular}{|l|c|r|r|r|r|}
\hline & \multicolumn{6}{|c|}{ Methamphetamine on column (ng) } \\
\hline Analysis Day & $\mathbf{0 . 0 1 0 0}$ & $\mathbf{0 . 0 2 0 0}$ & $\mathbf{0 . 0 4 0 0}$ & $\mathbf{0 . 2 0 0}$ & $\mathbf{0 . 4 0 0}$ \\
\hline Day 1 Average & 0.036 & 0.086 & 0.18 & 0.94 & 1.94 \\
\hline Day 2 Average & 0.036 & 0.084 & 0.16 & 0.94 & 1.91 \\
\hline Day 3 Average & 0.033 & 0.085 & 0.18 & 0.94 & 1.90 \\
\hline AVERAGE & 0.035 & 0.085 & 0.18 & 0.94 & 1.91 \\
\hline SD & 0.003 & 0.004 & 0.01 & 0.02 & 0.04 \\
\hline \%RSD & $10 \%$ & $5 \%$ & $6 \%$ & $2 \%$ & $2 \%$ \\
\hline
\end{tabular}


Table 3.10 Output from LINEST equation for Sigma-Aldrich ${ }^{\circledR}$ data

\begin{tabular}{|l|r|r|}
\hline & \multicolumn{1}{|c|}{ Slope } & \multicolumn{1}{c|}{ Intercept } \\
\hline Parameter & 4.81 & -0.015 \\
\hline SD & 0.02 & 0.003 \\
\hline$R^{2}$ & 1.00 & 0.005 \\
\hline
\end{tabular}

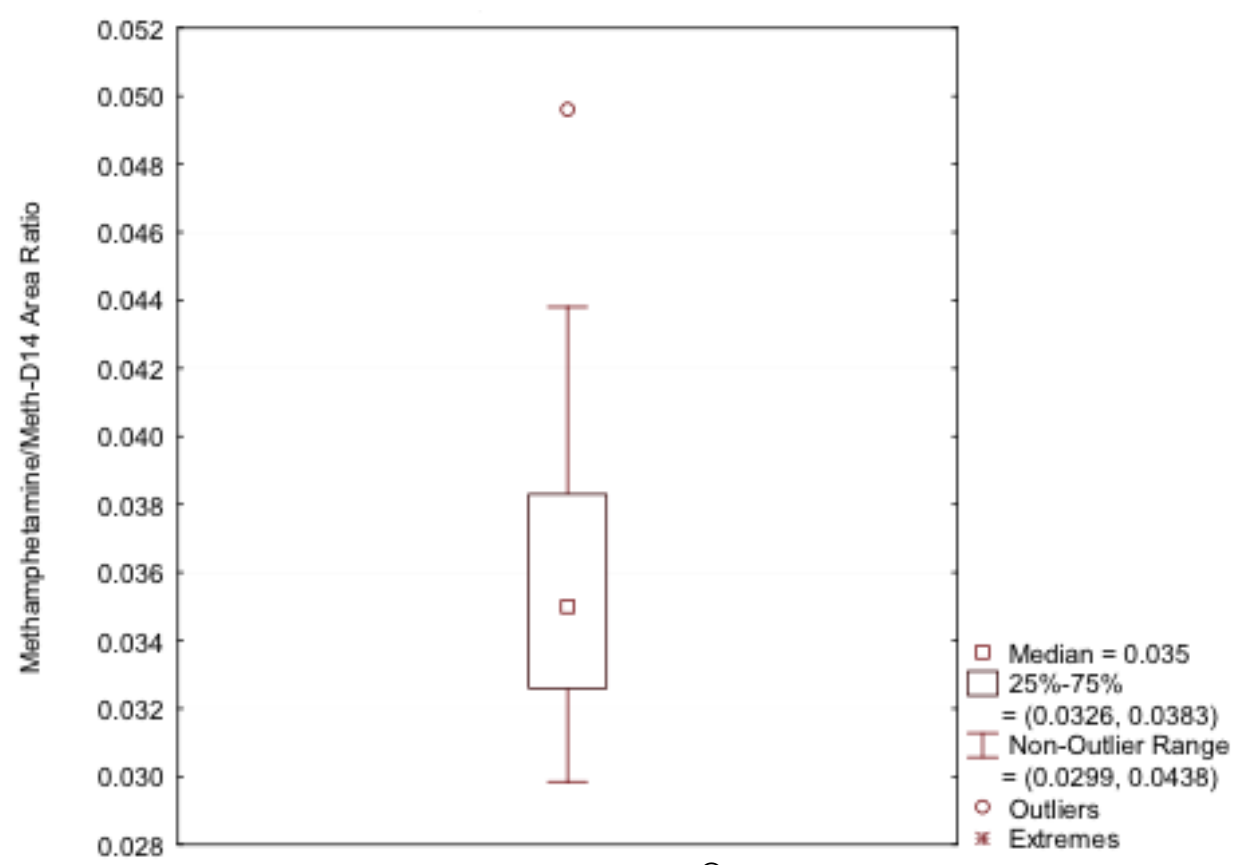

Figure 3.12 Box plot of Sigma-Aldrich ${ }^{\circledR}$ standards at 0.0010 ng of methamphetamine on column demonstrating, 0.0469 as an outlier in the data set

Finally, a combined calibration model was established (Figure 3.13). This calibration curve was created from the averaged values for all methamphetamine standards analyzed $\left(\right.$ Cerilliant $^{\circledR}$, Restek $^{\circledR}$, and Sigma-Aldrich ${ }^{\circledR}$ ). In this model, all calibrants were found to have a \%RSD of $14 \%$ or less, thus demonstrating this method is likely not dependent upon the manufacturer of the drug.

Whereas the slopes of the calibration curves for each manufacturer were expected to be similar, if not exact, they did vary between manufacturers. Since the methamphetamine standards were all purchased at purity of $99 \%$, this is likely not a factor contributing to the overall difference. New calibration solutions were not 
prepared daily and consequently, it is likely that changes in the slope are a result of the preparation on a single day. All standards were considered to have been prepared in a similar fashion, thus the preparation of the internal standard was investigated. Upon evaluation of the internal standard, it was found that fluctuations in the peak area occurred between sample batchers; therefore, changes in slope were due to slight differences in the concentration of the internal standard. Regardless, by validating across all three standards, the method can be used with any of the three standards.

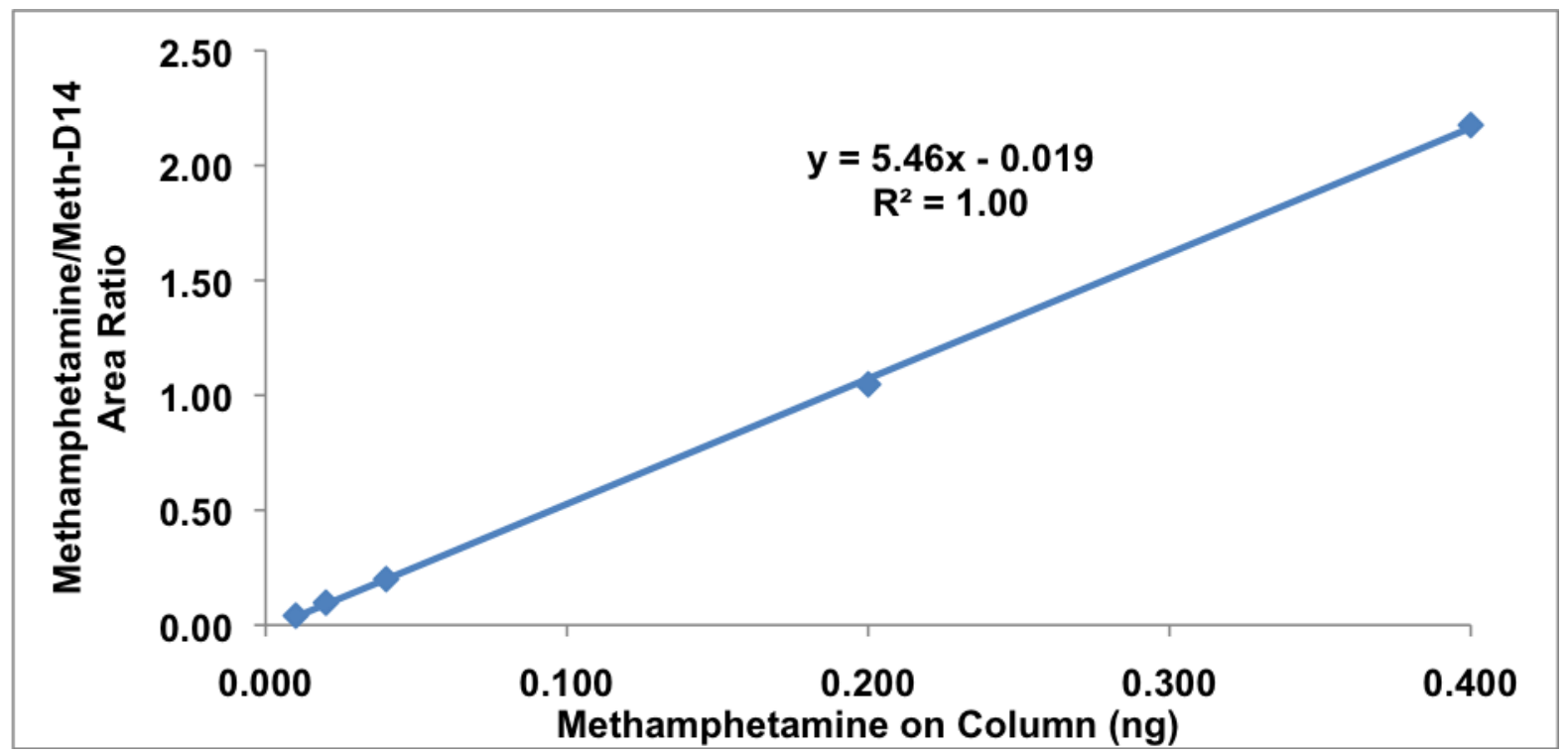

Figure 3.13 Calibration model of averaged data from all three standard manufacturers, Cerilliant ${ }^{\circledR}$, Restek $^{\circledR}$, and Sigma-Aldrich ${ }^{\circledR}$

Table 3.11 Output from LINEST equation for combined data

\begin{tabular}{|c|c|c|}
\hline & Slope & Intercept \\
\hline Parameter & 5.46 & -0.019 \\
\hline SD & 0.05 & 0.010 \\
\hline $\mathrm{R}^{2}$ & 1.00 & 0.017 \\
\hline
\end{tabular}




\subsubsection{Accuracy}

Accuracy for the GC/MS method was evaluated by nine injections of each of the calibration mass loads $(0.0100,0.0200,0.0400,0.200$, and $0.400 \mathrm{ng}$ ). Calibration was repeated for three different sources of methamphetamine. The ratio of methamphetamine to the internal standard (meth-D14) is reported in Tables 3.12,

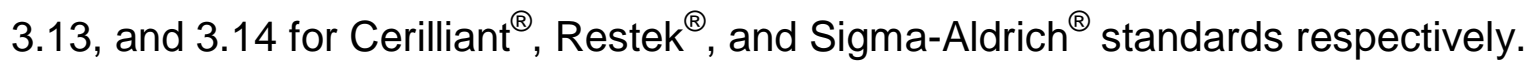

The accuracy of the concentration was then calculated according to equation:

$\%$ Difference $=\left\lfloor\frac{\text { actual }- \text { theoretical }}{\text { theoretical }}\right\rfloor \cdot 100$

Where the actual value was established from the linear regression of the calibration curve, and theoretical considered to be the mass load on column as previously stated.

SWGTOX establishes a minimum acceptable accuracy to be $20 \%$ for each level of evaluation. ${ }^{55}$ These levels of acceptability are likely due to the complex biological matrices commonly analyzed using SWGTOX guidelines. Tables 3.12, $3.13,3.14$ demonstrate that for all of the manufactured methamphetamine standards used in this project, the percent difference was less than or equal to $13 \%$.

Table 3.12 Accuracy evaluation of Cerilliant ${ }^{\Theta}$ standards

\begin{tabular}{|r|r|r|}
\hline \multicolumn{1}{|c|}{ Actual } & Theoretical & \% Difference \\
\hline $0.010_{2}$ & 0.0100 & 1.7 \\
\hline $0.020_{8}$ & 0.0200 & 4.0 \\
\hline $0.040_{4}$ & 0.0400 & 0.99 \\
\hline $0.19_{8}$ & 0.200 & 1.3 \\
\hline $0.40_{1}$ & 0.400 & 0.30 \\
\hline
\end{tabular}


Table 3.13 Accuracy evaluation of Restek ${ }^{\circledR}$ standards

\begin{tabular}{|r|r|r|}
\hline \multicolumn{1}{|c|}{ Actual } & Theoretical & \% Difference \\
\hline $0.011_{3}$ & 0.0100 & 13 \\
\hline $0.021_{6}$ & 0.0200 & 8.2 \\
\hline $0.040_{7}$ & 0.0400 & 1.6 \\
\hline $0.19_{3}$ & 0.200 & 3.4 \\
\hline $0.40_{3}$ & 0.400 & 0.81 \\
\hline
\end{tabular}

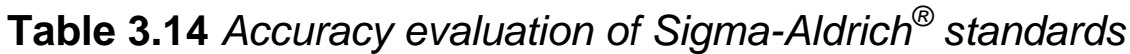

\begin{tabular}{|c|r|r|}
\hline Actual & Theoretical & \% Difference \\
\hline $0.010_{4}$ & 0.0100 & 4.3 \\
\hline $0.020_{9}$ & 0.0200 & 4.3 \\
\hline $0.039_{4}$ & 0.0400 & 1.5 \\
\hline $0.19_{86}$ & 0.200 & 0.72 \\
\hline $0.40_{07}$ & 0.400 & 0.18 \\
\hline
\end{tabular}

\subsubsection{Carryover}

It is important to ensure that sample carryover does not occur, as this could potentially affect the subsequent measurements by enhancing the signal. With this in mind several experiments were performed and the method optimized to reduce sample carryover to a non-detectable amount. The analyte itself is detected at $\sim 8.3$ minutes; however, the run time has been extended and the temperature ramps to $280{ }^{\circ} \mathrm{C}$ at a rate of $50{ }^{\circ} \mathrm{C} / \mathrm{min}$ and then holds for 3 minutes to ensure that, even at maximum concentration, sample carryover is not observed. This was confirmed to be true by triplicate measurements of $0.400 \mathrm{ng}$ on column methamphetamine solution, followed by a methanol blank.

\subsubsection{Interference Studies}

In methods using a stable-isotope internal standard it is necessary to ensure that the internal standard signal is not interfering with that of the analyte. A methanol blank was spiked with the highest concentration of the calibration curve $(0.400 \mathrm{ng}$ 
methamphetamine on column) and the peak monitored. This was followed by an experiment in which a blank was spiked with internal standard $(0.200 \mathrm{ng}$ meth-D14 on column) and the peak was monitored. It was found from these experiments that the ion monitored for Meth-D14 $(\mathrm{m} / \mathrm{z} 65)$ did produce a peak at the elution time of the methamphetamine $(\mathrm{m} / \mathrm{z}$ 58). However, since each of these peaks were integrated based upon their specific mass-to-charge ratio at the given retention time, it is believed that no interference occurs between methamphetamine and the internal standard.

\subsubsection{Limit of Detection}

The LOD can be evaluated for method validation by several different means. However, it is most important to choose the means which is reasonable for a particular project. In this case, the author was not looking to exceed the limit of quantitation; therefore, LOD was not essential to this project and was considered to be less than the limit of quantitation.

\subsubsection{Limit of Quantitation}

The limit of quantitation (LOQ) was chosen as the lowest non-zero calibrator, $0.0100 \mathrm{ng}$ of methamphetamine on column. This selection was confirmed by meeting the accuracy and precision criteria established in this method validation.

\subsubsection{Precision}

Precision analysis was accomplished concurrently with the accuracy studies discussed above. Nine measurements over three replicates were checked for \%CV at all concentrations $(0.0100,0.0200,0.0400,0.200$, and $0.400 \mathrm{ng}$ on column). The $\% C V$ was calculated as: 
$\% C V=\frac{S D}{x} \bullet 100$

Where SD is the standard deviation of the values, and $\mathrm{x}$ is the mean. ${ }^{55}$ According to the SWGTOX guideline entitled Precision of Quantitative Procedures, a \%CV must not exceed $20 \%$ for any concentration level. For each manufacturer, the within-run precision was evaluated as \%CV for a single day of analysis (Table 3.15), and the between-run precision is the total \%CV for all three days of the analysis (Table 3.16). For each day of analysis, nine points exist for every calibration standard. All within-run precision measurements were below $12 \%$, while all between-run precision measurements were less than $7 \%$. In four of the five calibration points, Restek $^{\circledR}$ and Sigma-Aldrich ${ }^{\circledR}$ produced greater imprecision during between-run analysis than the Cerilliant ${ }^{\circledR}$ standards. The Sigma-Aldrich ${ }^{\circledR}$ standard produced the most precise measurement in the evaluation of $0.400 \mathrm{ng}$ on column.

Table 3.15 Precision results for within-run measurements for each of the manufacturers reported as \% CV

\begin{tabular}{|c|c|c|c|c|c|c|}
\hline \multirow{2}{*}{$\%$ CV } & \multirow{2}{*}{ Day } & \multicolumn{6}{|c|}{ Mass on Column (ng) } \\
\cline { 2 - 7 } & & $\mathbf{0 . 0 1 0 0}$ & $\mathbf{0 . 0 2 0 0}$ & $\mathbf{0 . 0 4 0 0}$ & $\mathbf{0 . 2 0 0}$ & $\mathbf{0 . 4 0 0}$ \\
\hline \multirow{3}{*}{ Cerilliant $^{\circledR}$} & 1 & 7 & 4 & 2 & 2 & 4 \\
\cline { 2 - 7 } & 2 & 5 & 6 & 3 & 1 & 5 \\
\cline { 2 - 7 } & 3 & 9 & 4 & 3 & 2 & 4 \\
\hline \multirow{3}{*}{ Restek $^{\circledR}$} & 1 & 6 & 3 & 5 & 3 & 2 \\
\cline { 2 - 7 } & 2 & 10 & 2 & 4 & 4 & 3 \\
\cline { 2 - 7 } & 3 & 7 & 6 & 5 & 6 & 4 \\
\hline \multirow{3}{*}{ Sigma-Aldrich $^{\circledR}$} & 1 & 8 & 4 & 6 & 3 & 2 \\
\cline { 2 - 7 } & 2 & 12 & 6 & 6 & 2 & 2 \\
\cline { 2 - 7 } & 3 & 5 & 5 & 6 & 2 & 2 \\
\hline
\end{tabular}


Table 3.16 Precision results for between-run measurements for each of the manufacturers calculated from the average peak area ratio of methamphetamine/meth-D14

\begin{tabular}{|c|r|r|c|c|c|c|}
\hline \multirow{2}{*}{ Manufacturer } & \multirow{2}{*}{ Parameter } & \multicolumn{6}{|c|}{ Mass on Column (ng) } \\
\cline { 2 - 7 } & & $\mathbf{0 . 0 1 0 0}$ & $\mathbf{0 . 0 2 0 0}$ & $\mathbf{0 . 0 4 0 0}$ & $\mathbf{0 . 2 0 0}$ & $\mathbf{0 . 4 0 0}$ \\
\hline \multirow{3}{*}{ Cerilliant $^{\circledR}$} & Average & 0.0413 & 0.0101 & 0.210 & 1.08 & 2.2 \\
\cline { 2 - 7 } & SD & 0.0009 & 0.004 & 0.005 & 0.02 & 0.1 \\
\cline { 2 - 7 } & \%CV & 2 & 4 & 3 & 2 & 5 \\
\hline \multirow{3}{*}{ Restek $^{\circledR}$} & Average & 0.047 & 0.111 & 0.23 & 1.18 & 2.49 \\
\cline { 2 - 7 } & SD & 0.003 & 0.004 & 0.02 & 0.05 & 0.08 \\
\cline { 2 - 7 } & \%CV & 7 & 4 & 5 & 5 & 3 \\
\hline \multirow{3}{*}{ Sigma-Aldrich $^{\circledR}$} & Average & 0.035 & 0.085 & 0.17 & 0.94 & 1.91 \\
\cline { 2 - 7 } & SD & 0.002 & 0.004 & 0.01 & 0.03 & 0.02 \\
\cline { 2 - 7 } & \%CV & 6 & 5 & 6 & 3 & 1 \\
\hline
\end{tabular}

As a final evaluation of the combined method, the precisions between all three manufacturers of the methamphetamine standard were evaluated (Table 3.17). A coefficient of variance less than $14 \%$ occurred for all calibration concentrations. This demonstrates that this method is both precise and accurate for the measurement of methamphetamine on column for Cerilliant ${ }^{\circledR}$, Restek ${ }^{\circledR}$ and SigmaAldrich ${ }^{\circledR}$ manufactured methamphetamine products.

Table 3.17 Combined method precision for each of the manufacturers calculated from the peak area ratio of methamphetamine/meth-D14

\begin{tabular}{|c|c|c|r|r|r|}
\hline & \multicolumn{7}{|c|}{ Methamphetamine on Column (ng) } \\
\hline Manufacturer & $\mathbf{0 . 0 1 0 0}$ & $\mathbf{0 . 0 2 0 0}$ & $\mathbf{0 . 0 4 0 0}$ & $\mathbf{0 . 2 0 0}$ & $\mathbf{0 . 4 0 0}$ \\
\hline Cerilliant $^{\Theta}$ & 0.041 & 0.10 & 0.21 & 1.08 & 2.2 \\
\hline Restek $^{\circledR}$ & 0.047 & 0.11 & 0.23 & 1.18 & 2.5 \\
\hline Sigma-Aldrich $^{\Theta}$ & 0.035 & 0.09 & 0.17 & 0.94 & 1.9 \\
\hline Average & 0.041 & 0.10 & 0.20 & 1.05 & 2.2 \\
\hline SD & 0.006 & 0.01 & 0.02 & 0.09 & 0.2 \\
\hline \%CV & $14 \%$ & $11 \%$ & $11 \%$ & $9 \%$ & $11 \%$ \\
\hline
\end{tabular}

\subsubsection{Optimization of Headspace Parameters}

To assure the methamphetamine sample was being completely volatilized, two parameters were assessed for the headspace mode. These established the 
optimal temperature for the heat block and syringe (in all experiments, the temperature used for the heat block was the same as that used for the syringe), and the time it takes for the sample to reach equilibrium. In this case, an effort was made to push the entire sample into the HS leaving as little as possible in the liquid phase.

\subsubsection{Incubation Temperature}

The temperature of the incubation chamber and syringe were optimized for the autosampler system (AOC-5000). Both were maintained at the same set temperature to reduce the potential for methamphetamine to condense within the syringe before injection (resulting in increased sample carryover). In order to increase the vapor pressure to the greatest extent, the system was operated at its maximum potential temperature. While the AOC-5000 allows for the incubation chamber and syringe to reach temperatures of up to $140{ }^{\circ} \mathrm{C}$, the HS syringe purchased for use in the system has plunger stability up to only $110^{\circ} \mathrm{C}$. With this reasoning, an incubation temperature for both the syringe and vial was chosen to be $105^{\circ} \mathrm{C}$.

\subsubsection{Equilibration Time}

The time it takes for a sample to equilibrate is also an important factor in analysis using HS. The AOC-5000 allows for a given sample to be agitated and heated to a specific temperature for a given period of time. The agitation of the incubation chamber remained consistent for all experiments at $500 \mathrm{rpm}$. Once the temperature setting had been optimized at $105^{\circ} \mathrm{C}$, a series of analyses took place over five equilibration times. A $20-\mathrm{mL}$ HS vial was spiked with $10 \mu \mathrm{L}$ of $500 \mathrm{ppm}$ methamphetamine solution, and $10 \mu \mathrm{L}$ of $1000 \mathrm{ppm}$ meth-D14. These were then 
analyzed in triplicate at equilibration times of $30 \mathrm{~s}, 30 \mathrm{~min}, 60 \mathrm{~min}, 90 \mathrm{~min}$ and 120 min. Since this method was developed for the rate of release study, which would not allow for the use of internal standard due to potential differences in release rates, the equilibration time was established based upon absolute peak area for methamphetamine, and not peak area ratios. Figure 3.14 shows the resulting peak area over time for both methamphetamine and meth-D14. The equilibration time with the lowest \%RSD was 30 minutes, which yielded peak areas of roughly double of the $30 \mathrm{~s}$ analysis.

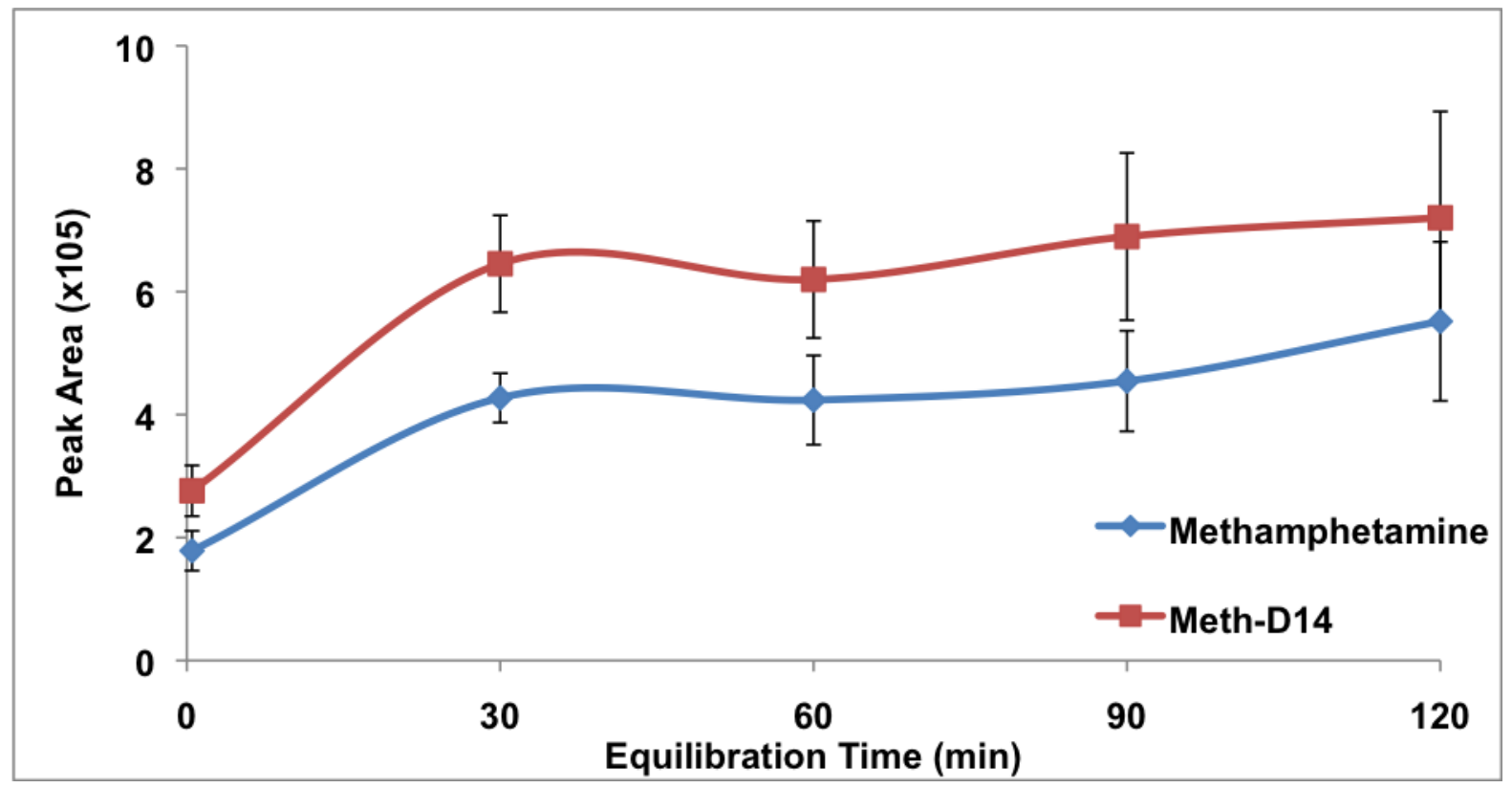

Figure 3.14 Optimization of HS GC/MS equilibration time for methamphetamine analysis

\subsubsection{Use of an Internal Standard in Headspace Analysis}

Internal standards serve a significant purpose in analysis accomplished by HS due to challenging reproducibility in this technique. A HS calibration curve was established using Cerilliant ${ }^{\circledR}$ standard methamphetamine and internal standard, meth-D14. $10 \mu \mathrm{L}$ of each solution $(100,250,400,550,700,850$, and $1000 \mathrm{ppm})$ was 
added to a HS vial. Additionally, each vial was spiked with $10 \mu \mathrm{L}$ of $1000 \mathrm{ppm}$ methD14. Analysis was performed in triplicate and two calibration curves were created from the data. The first calibration curve was established based upon the absolute peak area of methamphetamine, while in the second calibration curve the peak area ratio of methamphetamine to meth-D14 was used along the y-axis (Figure 3.15 and 3.16).

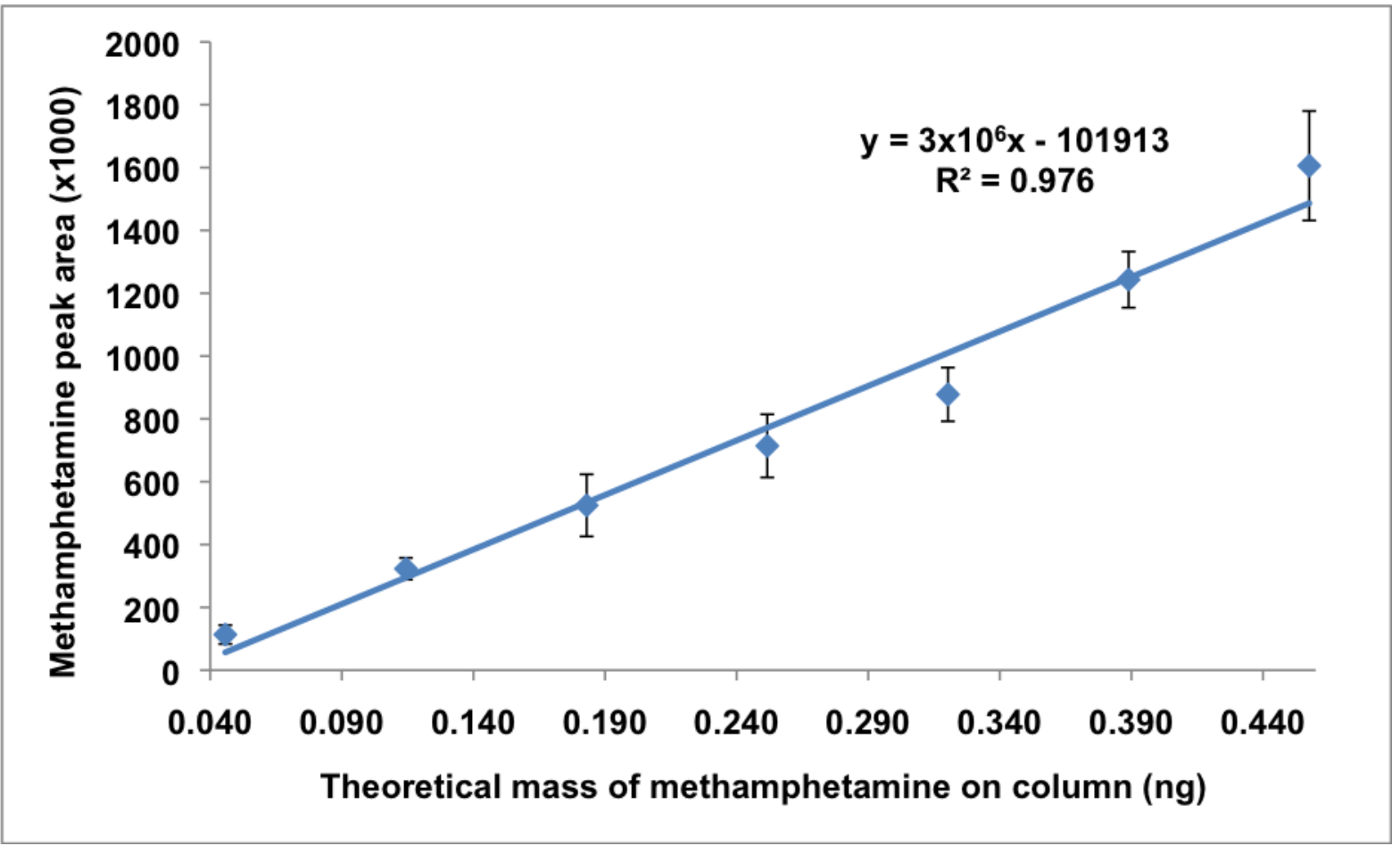

Figure 3.15 HS calibration curve developed from absolute peak area of methamphetamine. The theoretical mass on column assumes equilibrium headspace concentration at $105^{\circ} \mathrm{C}$ and $100 \%$ collection efficiency. 


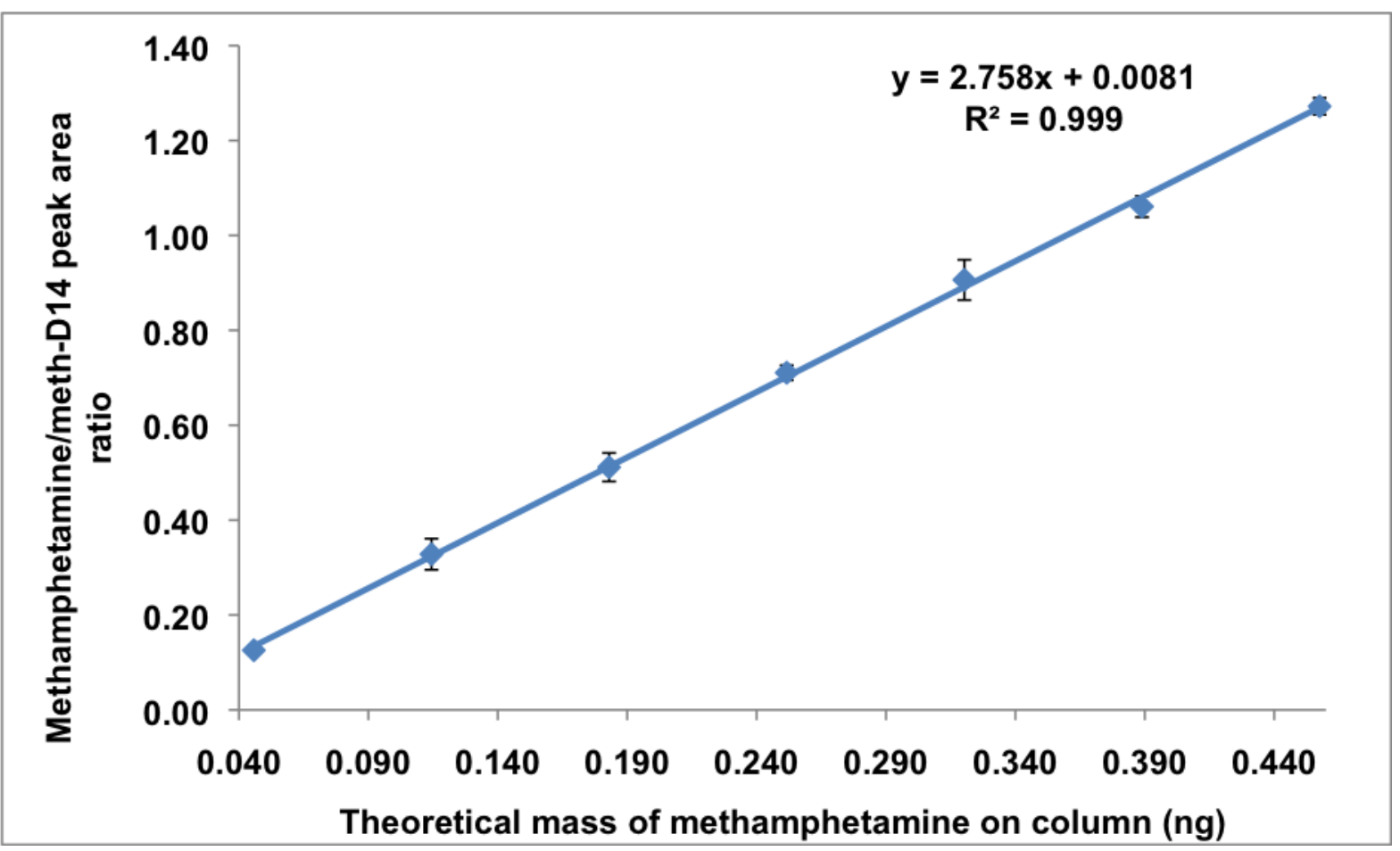

Figure 3.16 HS calibration curve developed from peak area ratio methamphetamine to meth-D14. The theoretical mass on column assumes equilibrium headspace concentration at $105^{\circ} \mathrm{C}$ and $100 \%$ collection efficiency.

Calculated values of methamphetamine concentration on the column come from a combined understanding of Dalton's and Raoult's laws which allow for the derivation of the equation:

$$
K_{p c}=\frac{C_{s}}{C_{G}}=\frac{x_{s}}{x_{G}}=\frac{P_{\text {total }}}{P_{i}^{*} \gamma_{i}}
$$

Where $\mathrm{K}_{\mathrm{pc}}$ is the partition coefficient; $\mathrm{C}_{\mathrm{s}}$ is the concentration of the analyte in the sample phase; $C_{G}$ is the concentration of the analyte in the gas phase; $x_{s}$ is the mole fraction of the sample; $x_{G}$ is the mole fraction of the gas phase; $P_{\text {total }}$ is the total pressure; $p_{i}^{*}$ is the vapor pressure of the pure components; and $\gamma_{i}$ is the activity coefficient. The partition coefficient is utilized to determine the concentration in the gas phase based upon vapor pressure. If the vapor pressure is known for a 
particular temperature (Figure 3.2), and an assumption made that the activity coefficient is equal to 1 , then partition coefficient at $105^{\circ} \mathrm{C}$ is calculated as:

$K_{p c}=\frac{P_{\text {total }}}{p_{i}^{*}}=\frac{760 \mathrm{mmHg}}{6.95 \mathrm{mmHg}}=109$

Based upon this value, the portion of methamphetamine contributing to the HS concentration can be calculated for the analysis of $10 \mu \mathrm{L}$ of a $100 \mathrm{ppm}$ solution:

$C_{G}=\frac{C_{S}}{K_{p c}}=\frac{[(100 p p m)(10.0 \mu L)]}{109}=9.15$

With analysis accomplished using 20-mL HS vials, and sample injection volumes being $2.50 \mathrm{~mL}$ :

$9.15 n g\left\lfloor\frac{2.50 m L}{20.0 m L}\right\rfloor=1.14 n g$

Making use of a 25:1 split:

$1.14 n g\left\lfloor\frac{1}{25}\right\rfloor=0.458 n g$

Therefore, in the analysis of a $100 \mathrm{ppm}$ sample, only $0.458 \mathrm{ng}$ of methamphetamine is expected to make it on the column. These values are shown on the x-axis of the calibration curves in Figures 3.13 and 3.14.

Error bars have been added to these curves in order to represent the standard deviation in the triplicate measurements. Comparing the $R^{2}$ value for the trend line fitted using the meth-D14 resulted in a correlation of 0.999 , while analysis of data neglecting the internal standard had an $R^{2}$ of 0.976 .

If the \%RSDs for the calibration measurements were examined then, in the calibration without internal standard, the highest \%RSD resulted from the analysis of the lowest concentration and the lowest \%RSD during the analysis of the $850 \mathrm{ppm}$ 
solution. In comparing to the analysis using internal standard, the largest \%RSD is $10 \%$, which occurred during the $250 \mathrm{ppm}$ sample analysis, and the lowest \%RSD for the $1000 \mathrm{ppm}$ solution. These values are compared in Table 3.18. With a method validated and a HS method prepared, methamphetamine samples could be analyzed. 
Table 3.18 Comparison evaluation of methamphetamine analysis accomplished by HS using absolute peak area versus peak area ratio

\begin{tabular}{|r|r|r|r|r|r|}
\hline $\begin{array}{c}\text { Concentration } \\
\text { of solution } \\
\text { (ppm) }\end{array}$ & $\begin{array}{c}\text { Theoretical Mass } \\
\text { of } \\
\text { Methamphetamine } \\
\text { on column } \\
\text { (ng) }\end{array}$ & $\begin{array}{c}\text { Average } \\
\text { Peak Area: } \\
\text { Meth }\end{array}$ & $\begin{array}{c}\text { Average } \\
\text { \%RSD: } \\
\text { Peak Area }\end{array}$ & $\begin{array}{c}\text { Peak Area: } \\
\text { Meth/Meth-D14 }\end{array}$ & $\begin{array}{c}\text { \%RSD: } \\
\text { Area ratio }\end{array}$ \\
\hline 100 & 0.0458 & 113403 & 26 & 0.13 & 4.3 \\
\hline 250 & 0.114 & 322916 & 11 & 0.33 & 10 \\
\hline 400 & 0.183 & 524708 & 19 & 0.51 & 5.9 \\
\hline 550 & 0.252 & 714019 & 10 & 0.71 & 2.2 \\
\hline 700 & 0.320 & 877873 & 7.2 & 1.06 & \\
\hline 850 & 0.389 & 1243337 & 11 & 1.27 & \\
\hline 1000 & 0.458 & 1605905 & & & \\
\hline
\end{tabular}




\subsubsection{Analysis of Pine Wood}

\subsubsection{Background Evaluation of Pine samples}

Southern yellow pine (SYP) chips were used in this rate of release study. Volatile components within the SYP were evaluated to ensure no co-elution occurred at a retention time of $\sim 8.3$ minutes, matching $\mathrm{m} / \mathrm{z} 58$, for methamphetamine. This was accomplished by placing 3 wood chips of roughly $1 \mathrm{~cm} \times 1 \mathrm{~cm} \times 0.1 \mathrm{~cm}$ inside a single $20-\mathrm{mL}$ HS vial, and replicating this three times. A profile of the volatile components of wood was then established and the lack of $\mathrm{m} / \mathrm{z} 58$ verified. A base shifted chromatograph of these three samples is shown in Figure 3.17. Standards were run for the identification of $\alpha$-pinene, $\beta$-pinene, and limonene. Whereas various peaks were unable to be identified using standards, a library search of the NIST 05 Database resulted in potential identification of some of the peaks. The database suggests that peaks at $5.132,5.758$, and $8.489 \mathrm{~min}$ are a result of camphene $(79 \%$ match), verbenone (64\%), and a-terpineol (78\%), respectively. Since these three chemicals are terpenes, it is likely they would exist within the pine wood samples analyzed. 


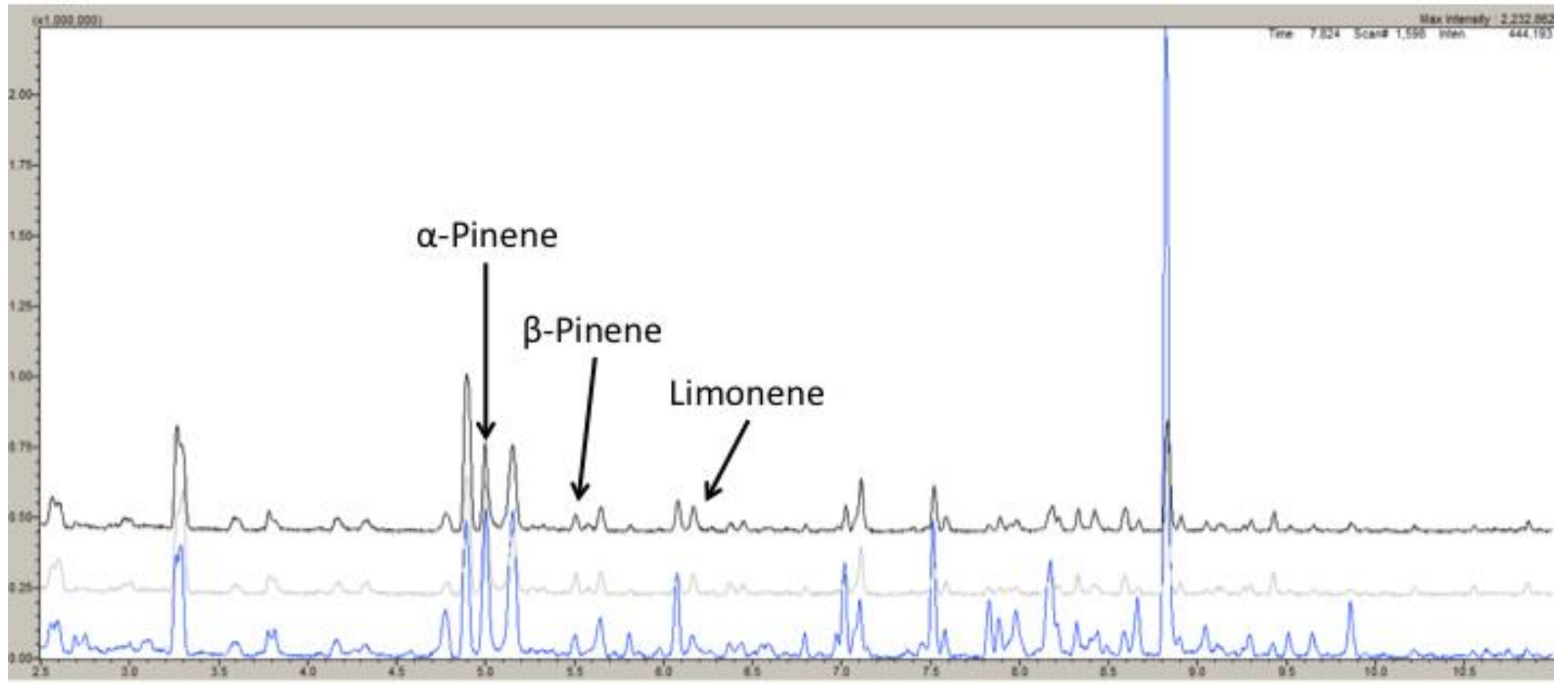

Figure 3.17 GC/MS chromatogram of southern yellow pine, base shifted to include three sample sets 


\subsubsection{Rate of Release from Methamphetamine Contaminated Pine}

A rate of release experiment was undertaken to establish how quickly methamphetamine is released in the vapor phase from SYP wood. Based on the results described in Chapter 2, it was expected that methamphetamine would penetrate into the bulk of the wood sample where it would remain. This was tested by dispensing $10 \mu \mathrm{L}$ aliquots of $500 \mathrm{ppm}$ methamphetamine to the surface of a single SYP chip. The wood chips were then analyzed over five equilibration times in triplicate for a total of 15 samples: $30 \mathrm{~s}, 30 \mathrm{~min}, 60 \mathrm{~min}, 90 \mathrm{~min}$, and $120 \mathrm{~min}$. A control was run in order to establish the effect of increasing equilibration time on peak area, in which only the methamphetamine was placed within the $20-\mathrm{mL} H S$ vial. These control samples were demonstrated previously in Table 3.19.

A temperature of $105{ }^{\circ} \mathrm{C}$ (that of the incubation chamber) is unrealistic for a housing structure; however, elevating the temperature within a house during the remediation process is recommended in several state guidelines. This heating, or "baking" of the house is said to aid in the volatilization of the contaminants, but it should be noted that the EPA does not recommend "baking." "Baking" a structure could potentially redistribute chemicals, according to the EPA, and further research is needed. Yet, in this analysis, all samples analyzed as controls produced significant peak areas, while none of the 15 SYP surface spikes yielded a quantifiable peak (Figure 3.18) for identification of methamphetamine. This suggests that "baking" is not useful for clearing methamphetamine that has penetrated the surface of a material. 


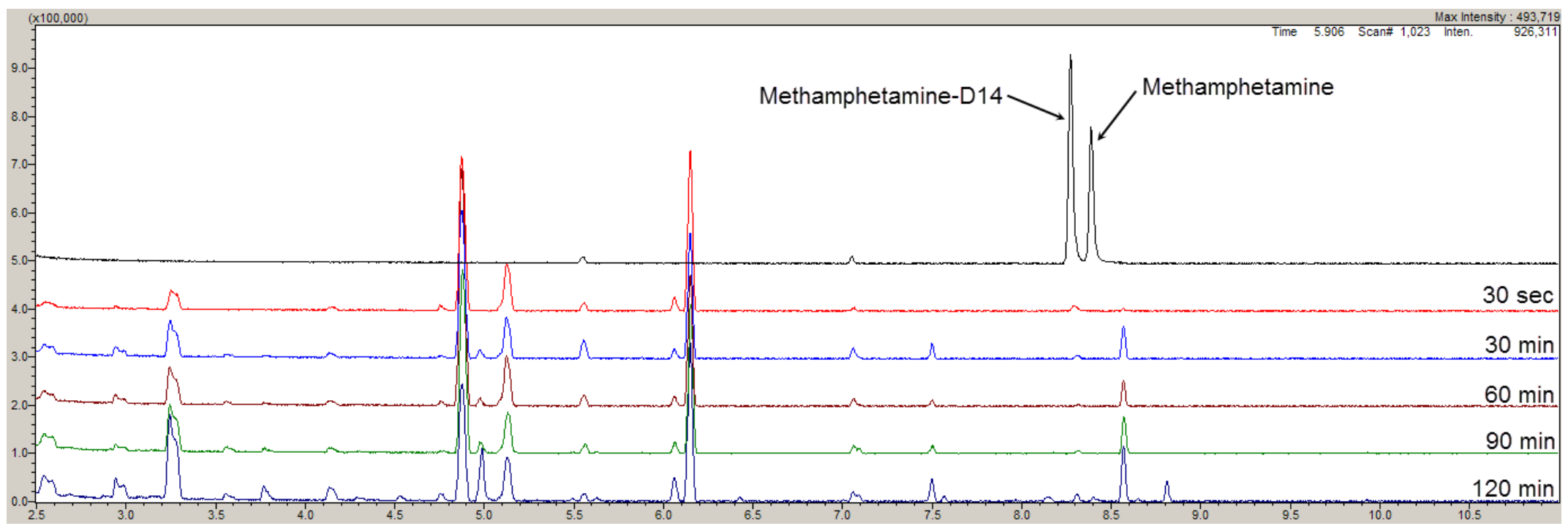

Figure 3.18 Overlay gas chromatograph of methamphetamine control and wood samples analyzed over five time intervals for the rate of release of methamphetamine 


\subsubsection{Analysis of Drywall}

\subsubsection{Background Evaluation of Drywall}

A sheet of drywall was obtained and used in this rate of release study. Volatile components within the drywall were evaluated in the same manner as the SYP chips. Based on the results described in Chapter 2 for drywall analysis, it was expected that methamphetamine would be retained within the material. Drywall was described in Section 1.2.5 as containing two layers, paper and calcium sulfate. Calcium sulfate is commonly used as a drying agent, and would be expected to retain any methamphetamine that passed through the paper layer. The analysis in Chapter 2 confirms this, since the material demonstrated decreasing surface concentrations as the cleaning proceeded. These results are not consistent with the literature, which reports that at high temperatures methamphetamine will become more volatile.

Since methamphetamine must first penetrate the paper layer of drywall before exposure to gypsum, the top paper layer was cut from the drywall sheet for analysis. Using a razor blade, $1 \times 1 \mathrm{~cm}^{2}$ blocks were cut from the paper. Whereas some gypsum remained attached to the back of the drywall paper exposure occurred on the paper itself. A single drywall sample was placed in a 20-mL HS vial, and analysis replicated for three samples. A profile of the volatile components of drywall was then established, confirming that ions with $\mathrm{m} / \mathrm{z} 58$ were not present in the sample at $\sim 8.3 \mathrm{~min}$. 


\subsubsection{Rate of Release from Methamphetamine Contaminated Drywall}

To gain a better understanding of how building materials will respond to methamphetamine contamination, drywall was also evaluated in a rate of release study. This was accomplished by dispensing $10 \mu \mathrm{L}$ aliquots of $500 \mathrm{ppm}$ methamphetamine to the surface of a single drywall sample. The drywall samples were then analyzed over four equilibration times in triplicate: $30 \mathrm{~s}, 30 \mathrm{~min}, 60 \mathrm{~min}$, and 90 minutes. These were then compared to the control samples run for the SYP chips. Analysis of all drywall samples provided no response to methamphetamine spikes (Figure 3.19), suggesting that the methamphetamine is retained within the drywall to a significant extent. These results are in agreement with the hypothesis developed from Chapter 2; however, they do not agree with statements made in the EPA remediation guidelines. 


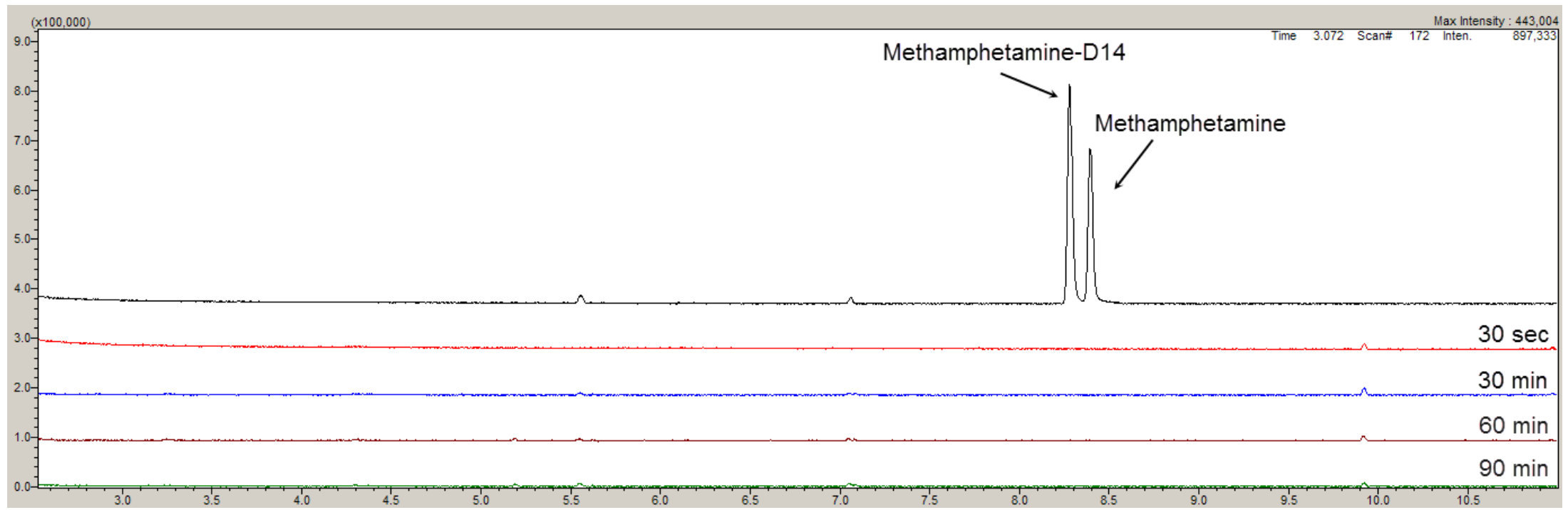

Figure 3.19 Overlay gas chromatograph of methamphetamine control and drywall analyzed over four time intervals for the rate of release of methamphetamine 


\subsection{Summary and Future Work}

The focus of this chapter was to establish the potential for methamphetamine volatilization off a surface using a quantitative technique; however, it was found that methamphetamine does not readily off-gas from the surface of a material, as previously believed. In this case, methamphetamine is retained on the surface as a result of adsorption; which is described as either physisorption or chemisorption. Chemisorption results in the formation of a covalent bond between the surface and adsorbate by exothermic reaction. However, physisorption is much more likely for methamphetamine interactions, as it is a result of non-covalent interactions such as van der Waals forces.

Wood, as well as drywall paper, is mainly composed of cellulose, hemicellulose, and lignin. Polar $\mathrm{OH}$ groups are present in both materials, as the structural framework of cellulose and the water content of gypsum. The interaction between pyridine adsorbed on gypsum by ATR-FTIR by Destaillats et al were classified as Bronsted-type acidic surface sites, in which the $\mathrm{OH}$ group from the surface interacted with the amine group of the molecule. ${ }^{57}$ This evidence suggests that methamphetamine will be held to the surface by hydrogen bonds.

Additional experiments should be performed to evaluate the presence of the methamphetamine on the wood. Extraction techniques followed by GC/MS evaluation, would provide evidence that methamphetamine remained sorbed to the sample.

As described previously, a multitude of materials are exposed to methamphetamine when found inside a clandestine laboratory. However, this 
research suggests that the focus of remediation and detection within clandestine analysis should no longer be on the detection of methamphetamine alone, as this is likely to be retained within, and not released into the environment as initially hypothesized. There are many potentially hazardous chemicals used in the production of methamphetamine that are likely to be the source of the health hazards reported by persons living in former CMLs. Further research would focus on the detection of high levels of contamination presented in Table 1.3 in the air, and their release from structural materials over time. 


\section{CHAPTER 4: DIFFERENTIAL MOBILITY SPECTROMETRY AS A TOOL IN DETECTING METHAMPHETAMINE IN CLANDESTINE LABORATORIES}

\subsection{Introduction}

Traditional IMS was introduced in the 1970s, followed shortly after by the introduction of differential mobility spectrometry (DMS). The former Soviet Union began developing DMS in the 1990s, which was subsequently brought to North America by the mid-1990s for further development. These instruments are frequently termed high field-asymmetric waveform ion mobility spectrometers (FAIMS); however, this typically refers to a specific configuration of the instrument. DMS does not differ greatly from ion mobility spectrometry (IMS); both make use of a drift gas at/around atmospheric pressure and applied electric fields for the separation of ions. ${ }^{58,59,60}$

Similar to that of IMS, DMS uses a series of reactions with high-energy electrons, with an average of $17 \mathrm{keV}$, from the ${ }^{63} \mathrm{Ni}$ source to produce reactant ions. In positive mode, the high-energy electron collides with nitrogen molecules in the atmosphere, which produces $\mathrm{N}_{2}^{+}$by the loss of a secondary electron. The formation of the $\mathrm{N}_{2}{ }^{+}$ions will continue until all primary and secondary electrons are below the ionization potential of air. A sequence of reactions then occurs between $\mathrm{N}_{2}{ }^{+}$and ambient air:

$$
\begin{array}{ll}
\mathrm{N}_{2}{ }^{+}+2 \mathrm{~N}_{2} \rightarrow \mathrm{N}_{4}{ }^{+}+\mathrm{N}_{2} & \text { Reaction 4.1 } \\
\mathrm{N}_{4}^{+}+\mathrm{H}_{2} \mathrm{O} \rightarrow 2 \mathrm{~N}_{2}+\mathrm{H}_{2} \mathrm{O}^{+} & \text {Reaction 4.2 } \\
\mathrm{H}_{2} \mathrm{O}^{+}+\mathrm{H}_{2} \mathrm{O} \rightarrow \mathrm{H}_{3} \mathrm{O}^{+}+\mathrm{OH} & \text { Reaction 4.3 } \\
\mathrm{H}_{3} \mathrm{O}^{+}+\mathrm{H}_{2} \mathrm{O}+\mathrm{N}_{2} \rightarrow \mathrm{H}^{+}\left(\mathrm{H}_{2} \mathrm{O}\right)_{2}+\mathrm{N}_{2} & \text { Reaction 4.4 }
\end{array}
$$


$\mathrm{H}^{+}\left(\mathrm{H}_{2} \mathrm{O}\right)_{2}+\mathrm{H}_{2} \mathrm{O}+\mathrm{N}_{2} \rightarrow \mathrm{H}^{+}\left(\mathrm{H}_{2} \mathrm{O}\right)_{3}+\mathrm{N}_{2}$

Reaction 4.5

Since the hydrated protons dominate, these are often referred to as the reactant ion.

The spectral peak that results from the presence of a reactant ion is called the reactant ion peak or RIP. To form the product ion, the hydrated proton reacts with the analyte molecule:

$\mathrm{H}^{+}\left(\mathrm{H}_{2} \mathrm{O}\right)_{n}+\mathrm{M} \rightarrow \mathrm{MH}^{+}\left(\mathrm{H}_{2} \mathrm{O}\right)_{n-1}+\mathrm{H}_{2} \mathrm{O}$

Reaction 4.6

Thus forming the protonated monomer by the displacement of a water molecule. Protonated dimers can also be formed, which exist as $\mathrm{M}_{2} \mathrm{H}^{+}\left(\mathrm{H}_{2} \mathrm{O}\right){ }^{61}$

Whereas IMS and DMS are based on related principles of gas-phase mobility, DMS separates analyte molecules through a different mechanism than does IMS. In IMS, the drift gas typically runs countercurrent to that of the sample, resulting in collisions that aid in the separation of analytes according to size-to-charge ratio. Ions migrate down the drift region due to an applied potential for IMS, whereas ions in DMS transport through the drift region due to the flow of the drift gas in the direction of the detector. Separation of ions in DMS is the result of applied potentials perpendicular to the drift gas flow, planar electrodes (Figure 4.1). The separation mechanism is different from IMS, in that IMS uses only low field potentials to drive the ion movement and DMS uses both high and low field potentials. 


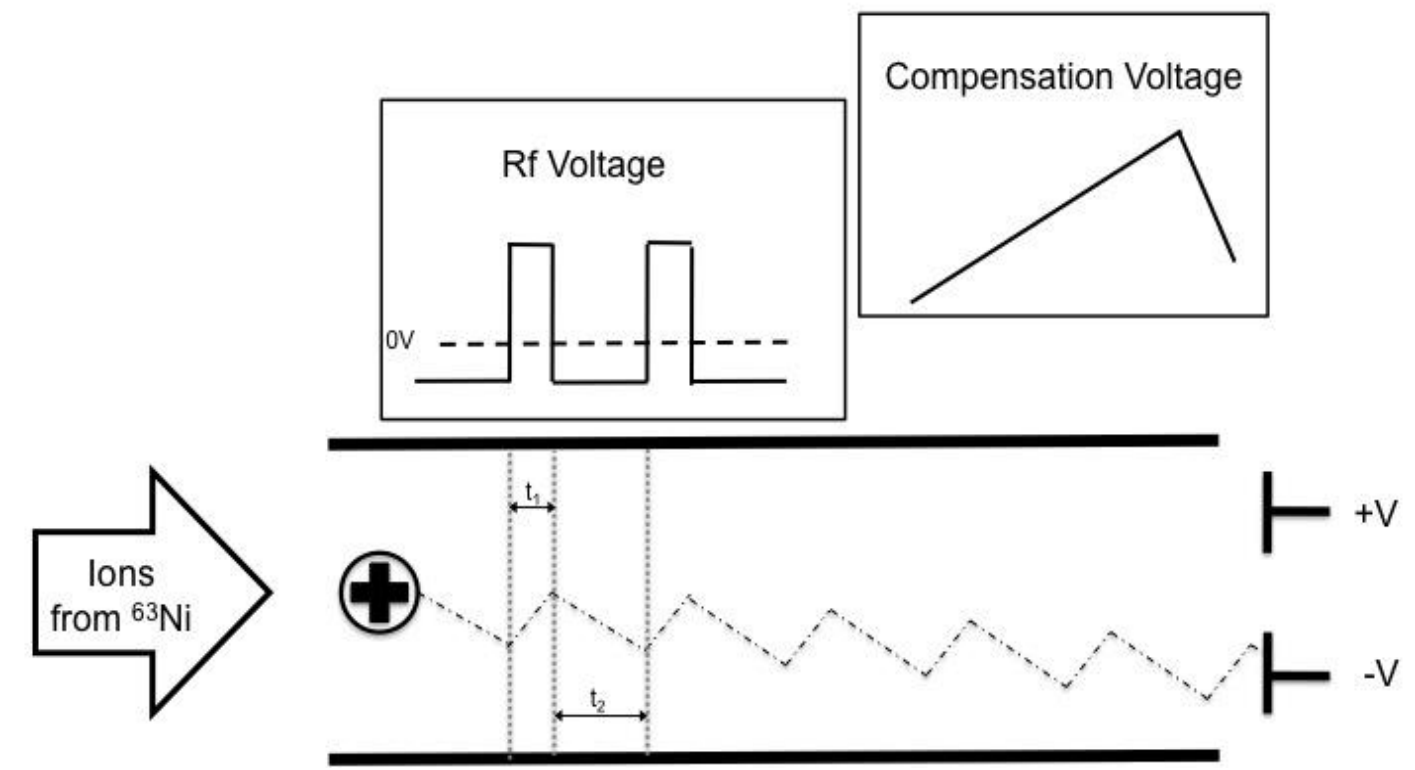

Figure 4.1 Principle of operation for a DMS instrument

While one of the planar electrodes is held at ground potential, an asymmetric waveform is applied to the other. A $1.5 \mathrm{MHz}$ waveform produces shorter periods of high-electric field $\left(\sim 20,000 \mathrm{~V} \mathrm{~cm}^{-1}\right)$ strength followed by a longer period of lowelectric field $\left(\sim 1,000 \mathrm{~V} \mathrm{~cm}^{-1}\right)$. This field is applied perpendicular to the drift gas flow and is referred to as the separation voltage (or RF voltage, $V_{\mathrm{rf}}$ ). As a result of the separation voltage, ions will oscillate between the plates, and have a net displacement toward one of the electrodes or ions of the right mobility will pass between the electrodes striking one of the detector plates.

Net displacement of ions toward a DMS electrode is related to the changing tendency of cluster formation as the system oscillates between high and low fields. In a high field, ions travel faster and an increased number of collisions occur; this produces a greater local temperature, resulting in de-clustering and thereby increasing mobility for ions. In the presence of a low field, these ions will travel 
slower due to a decrease in effective temperatures and clusters are more likely to reform.

The relationship between mobility and electric field is non-linear, and described by the following equation for DMS: ${ }^{62}$

$$
K\left(\frac{E}{N}\right)=K_{0}\left\lfloor 1+\alpha\left(\frac{E}{N}\right)\right\rfloor
$$

Where $\mathrm{K}_{0}$ is the mobility coefficient under low field conditions, $\alpha$ is the relative deviation of $\mathrm{K}$ from its low field mobility, $\mathrm{N}$ is the gas density, and $\mathrm{E}$ is the electric field. The ratio of E/N is most often expressed in the unit of Townsend $(\mathrm{Td}, 1 \mathrm{Td}=$ $10^{-17} \mathrm{~V} \mathrm{~cm}^{-2}$ ). Alpha is a term typically used to describe the ratio of mobility in the low field to that in the high field, given as:

$$
\alpha(E)=\left(K(E)-\left(K_{0}\right)\right) / K_{0}
$$

Where $\mathrm{K}(\mathrm{E})$ is the high field mobility and $\mathrm{K}_{0}$ is the low field mobility. Therefore, for ions experiencing an increased mobility in the high field, $\alpha$ is positive $(\alpha>0)$. In the case of ions with negative alpha parameters $(\alpha<0)$, their mobility decreases with increased field strength. The difference in the alpha parameter is demonstrated in Figure 4.2.

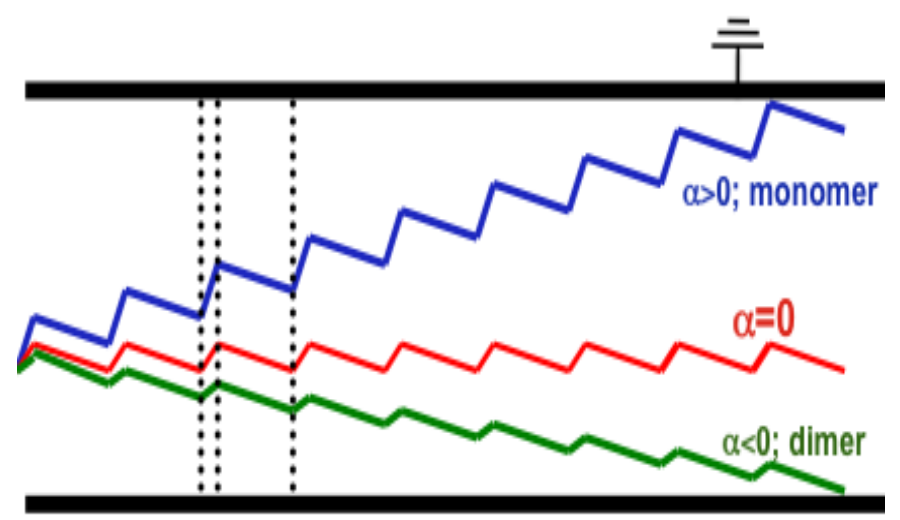

Figure 4.2 Relationship between alpha parameter and ion trajectory 
The alpha value of the proton-bound dimer shows a negative alpha function, suggesting that in the high field mobility is decreased; therefore, the movement of the ion is slower at high field. This slowed motion is a result of the increased collision frequency, due to increased temperature, without significant reduction in collision cross-section as compared to monomers. This relationship is demonstrated by the Mason-McDaniel equation:

$K=\left(\frac{3 e}{16 N}\right)\left[\frac{2 \pi}{\mu k T_{e f f}}\right]^{1 / 2}\left[\frac{1}{\Omega_{D}}\right]$

Where $\mathrm{e}$ is the charge of an electron; $\mathrm{N}$ is the number density of neutral gas molecules; $\mu$ is the reduced mass of the ion and gas; $k$ is Boltzmann constant; $T_{\text {eff }}$ is the effective temperature of the ion determined by thermal energy; and $\Omega_{d}$ is the effective collision cross section of the ion.

To correct for deviations of alpha parameter, a compensation voltage $\left(V_{c}\right)$ is superimposed along the asymmetric waveform. This allows specified ions to traverse the electric field channels without neutralization against the analyzer walls (Figure 4.1). For monomers, with a tendency to have positive alpha values, the $V_{c}$ potential will be negative value; whereas dimers will require a positive $V_{c}$ potential. This is demonstrated in Figure 4.3, which shows a 2-dimensional mobility spectra resulting from a scan of compensation voltage. ${ }^{58}$ 


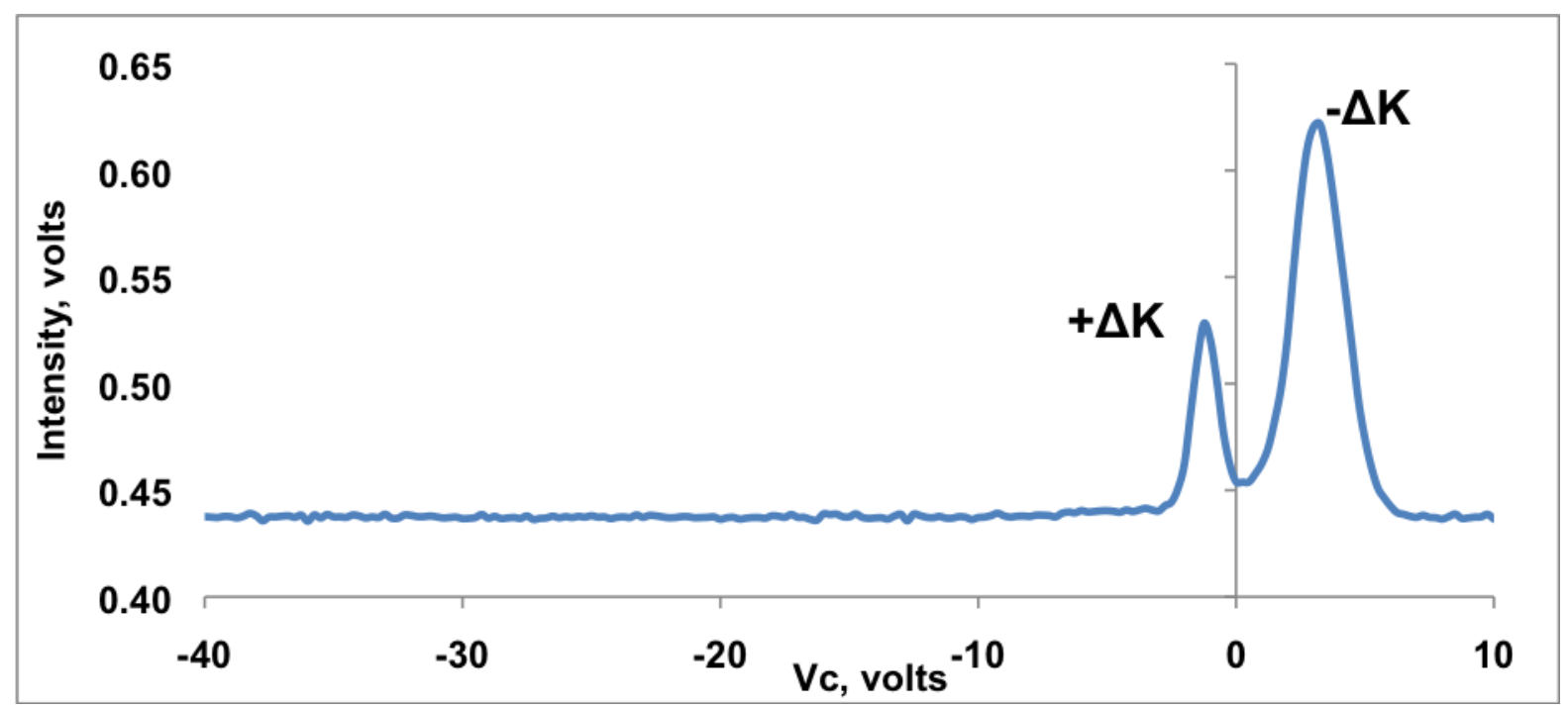

Figure 4.3 Mobility spectrum of ion current as a function of compensation voltage

DMS instruments typically consist of two Faraday cups (Figure 4.1) that can monitor the positive and negative ion species simultaneously. By doing this, selectivity is improved such that the presence or absence of peaks in positive and negative mode provides identifying characteristics for a given compound. The output of a DMS full-scan is a topographical plot that plots the RF field strength versus the compensation voltage (along the $\mathrm{x}$ - and $\mathrm{y}$-axes), and color density to represent the peak intensity (z-axis) ${ }^{63}$ Figure 4.4 demonstrates a dispersion plot as a result of only reactant ions, $\mathrm{H}^{+}\left(\mathrm{H}_{2} \mathrm{O}\right)_{3}$. Note that this output is significantly different than that obtained from an IMS, as described in Chapters 1 and 2. In DMS, there is no reduced mobility value. It is the pattern as a function of compensation voltage that is used to distinguish one compound from another. 

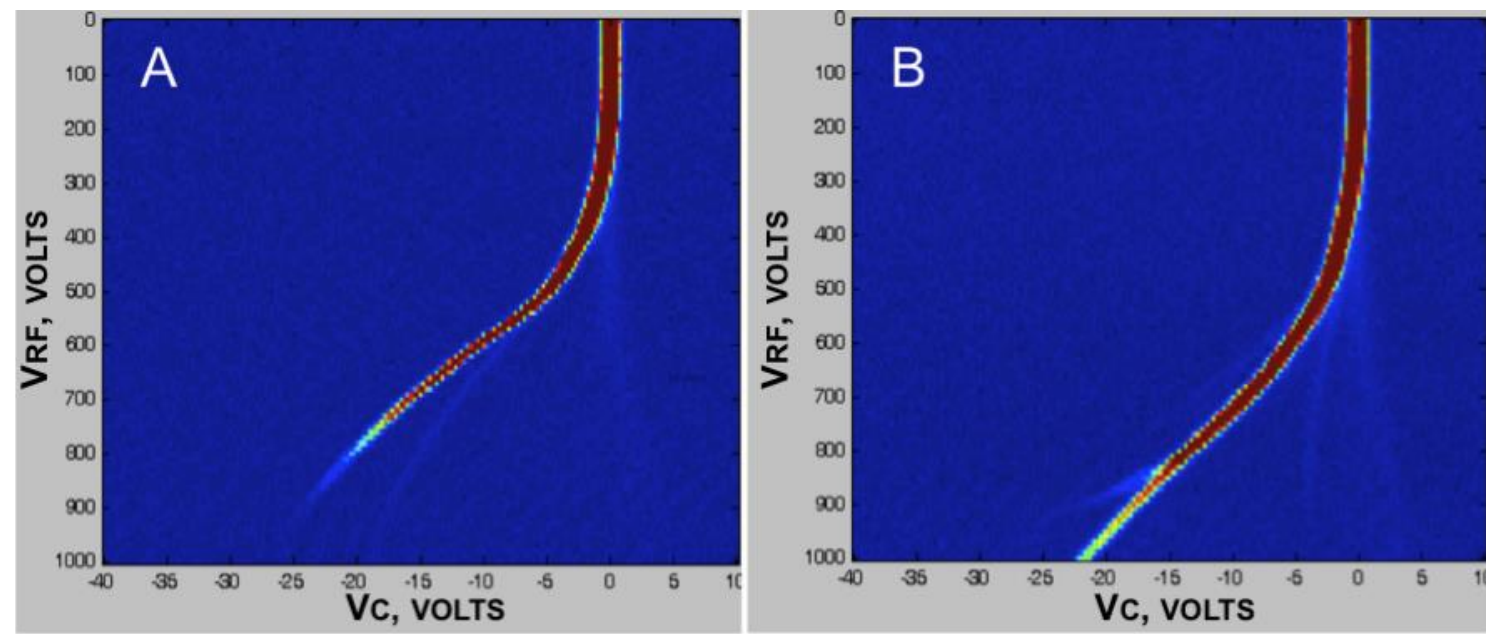

Figure 4.4 Full scan plot of DMS data from analysis with the Environmentally Protective Cap on in $(A)$ negative mode and $(B)$ positive mode

$\mathrm{JUNO}^{\circledR}$ is a planar DMS with continuous air sampling capabilities developed by Chemring Detection Systems (Figure 4.5). It is a rugged, field portable instrument that is lightweight (at only $2 \mathrm{lbs}$ ) and small in size (4" W $\times 2.4$ " D $\times 8.3^{\prime \prime} \mathrm{L}$ ). JUNO ${ }^{\circledR}$ has the capability to be programmed for the detection of various substances. The detection program is based upon pattern matching of specified detection windows. When used in the field, JUNO ${ }^{\circledR}$ will collect data, process it against the rule detection set, and report the results on the user interface. This is similar to that of the Smiths Detection Sabre $^{\mathrm{TM}} 4000$ discussed in Section 1.3.1 and 2.2.2; however, the Sabre ${ }^{\mathrm{TM}}$ uses drift time and $\mathrm{K}_{0}$ value for positive identification while $\mathrm{JUNO}^{\circledR}$ evaluates data based upon ion current over specified electric field. 


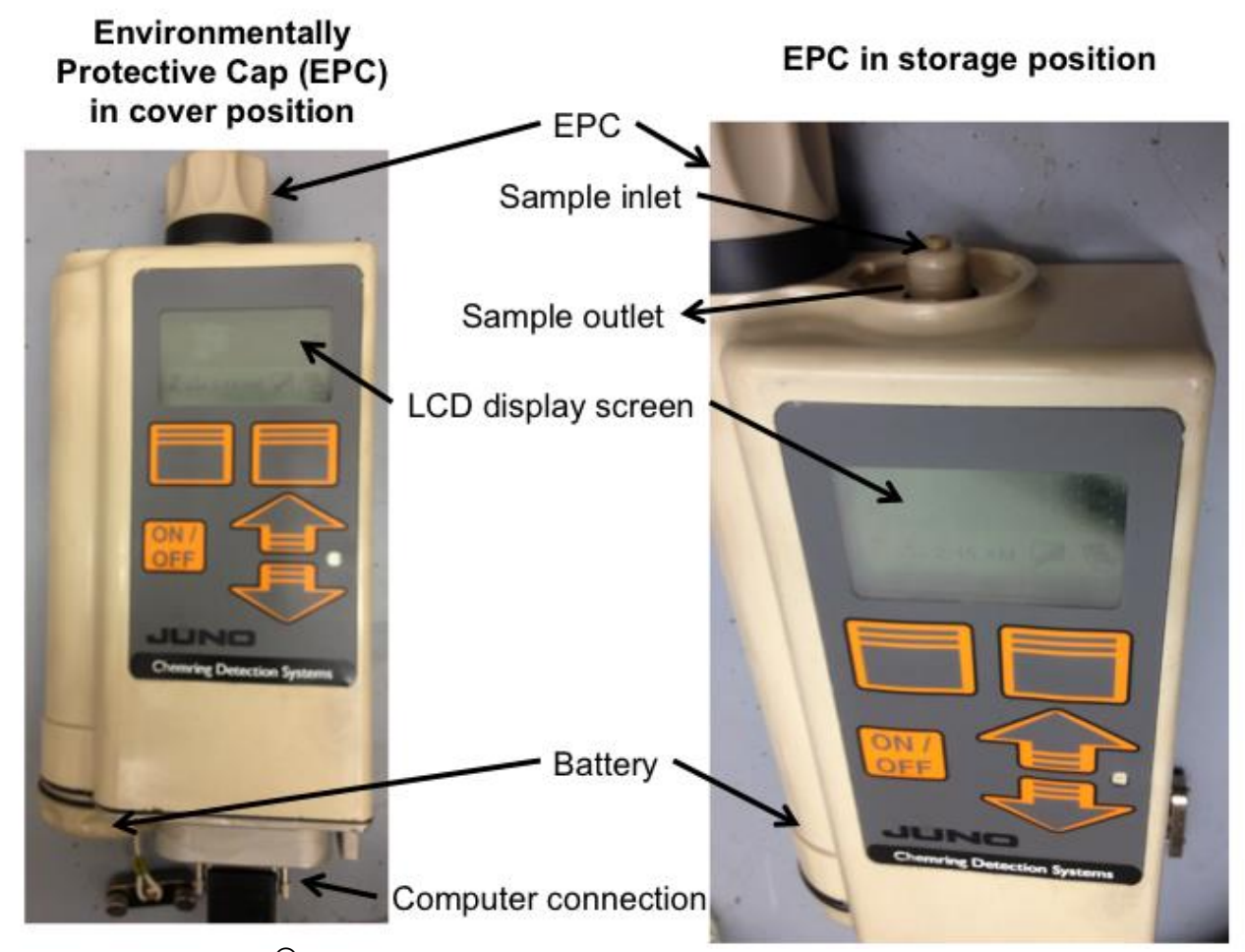

Figure 4.5 The JUNO ${ }^{\circledR}$ instrument used for all DMS experiments, demonstrating the important characteristics in its design

Currently, methods exist for the detection of chemical warfare agents (CWAs), toxic industrial compounds (TICs), and toxic industrial materials (TIMs) using $\mathrm{JUNO}^{\circledR}{ }^{\circledR 63,59}$ A review of the literature found that field portable detection of illicit drugs has not been performed using DMS. There have been few reports regarding the use of DMS instruments in the evaluation of gas-phase drugs of abuse throughout the literature. Much of the research requires the addition of an electrospray ionization source (ESI) for the vaporization of liquid samples. In 2002, McCooeye et al. discussed the analysis of recreational drugs, including amphetamine, methamphetamine, MDA, MDMA, and MDEA, in urine samples by SPME-ESI-DMS-MS. ${ }^{64}$ Separation of cocaine and common cutting agents was accomplished in 2012, using nano-ESI-DMS-MS. Developed as a potential 
technique to reduce laboratory backlog by improving sample through-put, analysis could be accomplished within $30 \mathrm{~s}{ }^{65}$ Pyrolysis-GC/MS of methamphetamine has been accomplished by this $1 a b,{ }^{66}$ and further research suggests the potential to couple pyrolysis-GC-DMS for more rapid analysis. ${ }^{67,68}$

With a fast response time and easy portability, DMS instruments are optimal for forensic applications where vapor detection is the primary objective. ${ }^{65}$ In this project, JUNO ${ }^{\circledR}$ was investigated as an alternative to IMS for gas-phase sampling of methamphetamine in clandestine synthesis. The easy-to-use interface makes it suitable such that police agencies and department of health representatives could use $\mathrm{JUNO}^{\circledR}$ in preliminary screening of seized clandestine laboratories.

\subsection{Materials and Methods}

\subsubsection{Chemicals and Solvents}

For sample preparation, methamphetamine $\mathrm{HCl}$ standard (Sigma-Aldrich, St. Louis MO), sodium hydroxide and hexane were used. Sodium hydroxide $(\mathrm{NaOH})$ pellets, purchased from Fisher Scientific (Fair Lawn, NJ), and hexane, from Sigma Aldrich (St. Louis, MO), were utilized in the liquid-liquid extraction (LLE) procedure. A $0.1 \mathrm{M}$ solution of $\mathrm{NaOH}$ was prepared using $18 \Omega$ deionized (DI) water. A $2 \mathrm{~mL}$ portion of $\mathrm{NaOH}$ and methamphetamine was doubly extracted with $5 \mathrm{~mL}$ portions of hexane. The organic layer was transferred to a $20-\mathrm{mL}$ disposable glass scintillation vial and solvent was allowed to evaporate in open air. In the testing of potential interferences, acetone (VWR, West Chester PA), methanol (Sigma-Aldrich ${ }^{\circledR}$ ), and pentane, 2-propanol, and toluene from Fisher Scientific ${ }^{\circledR}$ were used. 


\subsubsection{Instrumentation}

Experiments were performed using a differential mobility spectrometer, JUNO $^{\circledR}$ (Chemring Detection Systems, Charlotte, NC), which was loaned to the

research group. JUNO ${ }^{\circledR}$ uses a ${ }^{63} \mathrm{Ni}$ ionization source $(5 \mathrm{mCi})$. Scanning separation voltages from 0 to $1000 \mathrm{~V}$, and compensation voltages from -40 to $+10 \mathrm{~V}$ optimized the DMS. In this work, both positive and negative ion mode data were collected. However, analysis of methamphetamine was accomplished using the positive mode only.

\subsubsection{Methamphetamine Detection Optimization}

A Plexiglas box, that was known to be water tight (thus assumed to be reasonably airtight), was made for the analysis of vaporized methamphetamine sample. The box was placed within a chemical hood to minimize exposure to the methamphetamine vapor. The chamber (Figure 4.6, $30.5 \times 30.5 \times 61.0 \mathrm{~cm}^{3}$ ) had a removable lid, as well as a window through which a sample could be added to the chamber. Inside the box were two hot plates, one for the sample (contained within a 20-mL scintillation vial) and one for water heating during humidity analysis. The $\mathrm{JUNO}^{\circledR}$ instrument was strategically placed approximately $5 \mathrm{~cm}$ above the lid of the scintillation vial. Spectra were collected as samples were at room temperature (25 ${ }^{\circ} \mathrm{C}$ ), or heated to 65 or $85^{\circ} \mathrm{C}$ for analysis. 

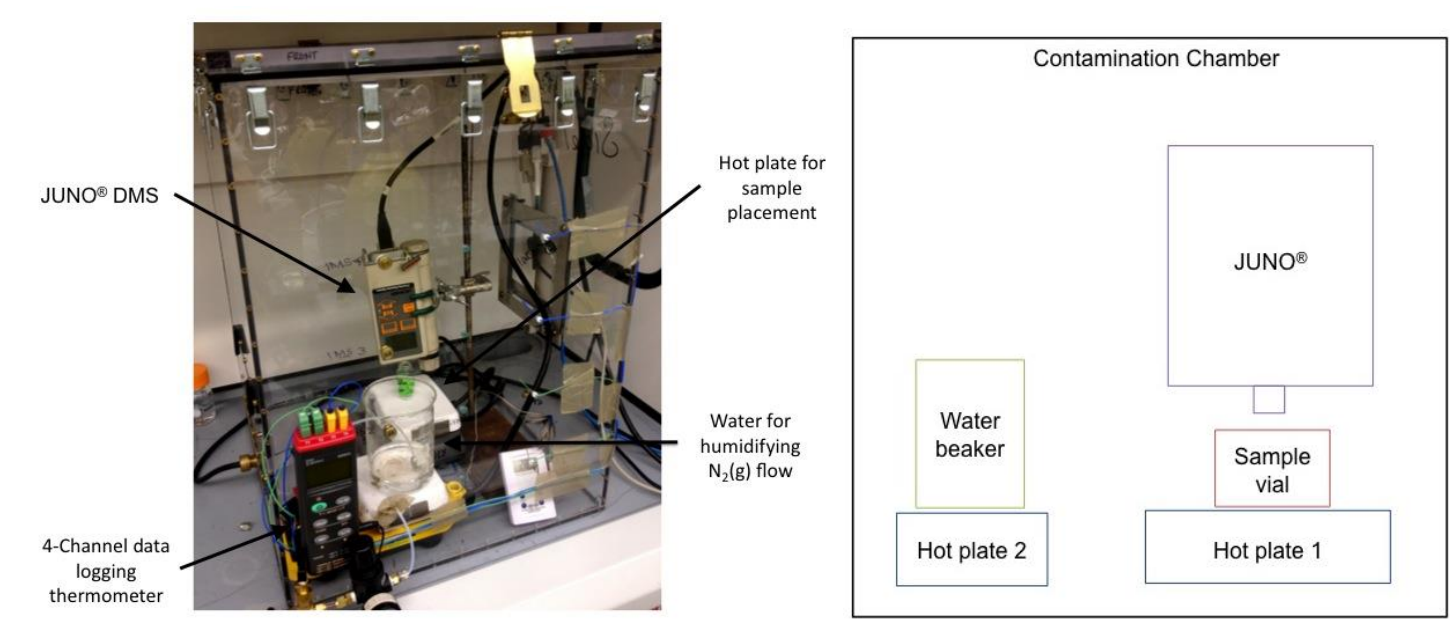

Figure 4.6 Photograph of experimental set-up using the JUNO ${ }^{\circledR}$ in methamphetamine chamber, as well as block diagram

For each day of analysis, a DMS spectrum was first collected with the environmentally protective cap (EPC) in place over the inlet nozzle, to ensure cleanliness of the system. A clean spectrum was noted as the presence of the reactant ion peak only. This was followed by samples of the background, which included analysis within the chemical hood, as well as samples within the box chamber. All background samples produced a small peak; which was later determined to be the result of contamination within the chamber. The JUNO ${ }^{\circledR}$ was not to be used for quantitative measurements, and so trace contamination was not of concern.

Three sample preparations of methamphetamine were used for the development of the detection method: methamphetamine $\mathrm{HCl}$ (solid), methamphetamine dissolved in methanol, and methamphetamine base oil. Methamphetamine base oil samples were prepared by performing liquid-liquid extraction of methamphetamine $\mathrm{HCl}$ into $\mathrm{NaOH}$ and hexane. The organic layer was then removed and allowed to evaporate in the chemical hood, until only the 
methamphetamine base oil remained. It was later found that all sample preparation method produced similar DMS spectra.

To produce a humid environment within the chamber, three approximate humidity levels were used: (1) 50\%, (2) 75\% and (3) 100\% relative humidity. Without a device to measure exact humidity, visual comparisons were made to establish a range, which was based upon a shift in +RIP position. Samples taken under standard room conditions were considered to be at $50 \% \mathrm{RH}$, while samples taken at $75 \% \mathrm{RH}$ had water introduced in the system. In this process, a beaker of water was added on top of hot plate inside of the methamphetamine chamber. $\mathrm{N}_{2}(\mathrm{~g})$ was then bubbled through the heated water, while the chamber lid remained partially off. In the high humidity experiments $(100 \% \mathrm{RH})$ a similar set-up was used, but the added beaker of water was allowed to boil (no additional gas flow was used) and the chamber lid was locked in place.

\subsubsection{Data Processing}

After using $\mathrm{JUNO}^{\circledR}$, JACS 3.0 (LabVIEW 2010, National Instruments Austin TX) virtual instrument software program was used to analyze the data, which was saved as an Excel $^{\circledR}$ file (Microsoft, Redman WA). The data was read by MATLAB 2012 version (The MathWorks Inc., Natick, MA) and stored as a data matrix. Data was further analyzed using JACS Data Helper (LabVIEW 2010, National Instruments Austin TX).

$\mathrm{JUNO}^{\circledR}$ allows for operation in two different modes: 1) when $\mathrm{V}_{\mathrm{rf}}$ is fixed and $\mathrm{V}_{\mathrm{c}}$ is scanned, a linear DMS spectrum is recorded; 2) a full differential mobility scan can 
be recorded when $V_{\text {rf }}$ and $V_{c}$ are both synchronized and scanned. All 3-dimensional plots were produced using MATLAB software.

\subsection{Results and Discussion}

\subsubsection{Detection Windows Established}

Initial screening of methamphetamine occurred by scanning both the separation voltage and compensation voltage, and is viewed as the method development phase of the DMS analysis. Once a useful combination of $V_{r f}$ and $V_{c}$ are established, then the rapid nature of the technique can be exploited. As such, $\mathrm{JUNO}^{\circledR}$ was placed directly above the sample containing scintillation vial, and the air above the vial was continuously sampled. As the air was sampled, DMS full scan spectra were collected with the $V_{\text {rf }}$ potential scanned from 0 to $1000 \mathrm{~V}$, and the $V_{c}$ from -40 to $+10 \mathrm{~V}$. A full differential mobility scan was collected within 5 minutes.

Figure 4.7A demonstrates a typical full differential mobility spectrum for methamphetamine. The reactant ion peak can still be seen; however, an additional branch has formed around the $\mathrm{V}_{\mathrm{c}}$ of 0 . If a 2-dimensional slice of this spectrum is taken, holding $\mathrm{V}_{\mathrm{rf}}$ constant at $800 \mathrm{~V}$, three distinct peaks can be noted (Figure 4.7 B). Based on the previous discussion of the mechanism of ion motion in the DMS, monomer peaks typically will appear at negative $V_{c}$ potentials, and dimers at positive $V_{c}$ potentials. We believe that both species are present in this analysis. A series of methamphetamine samples were then prepared and analyzed for consistent detection of branching. 


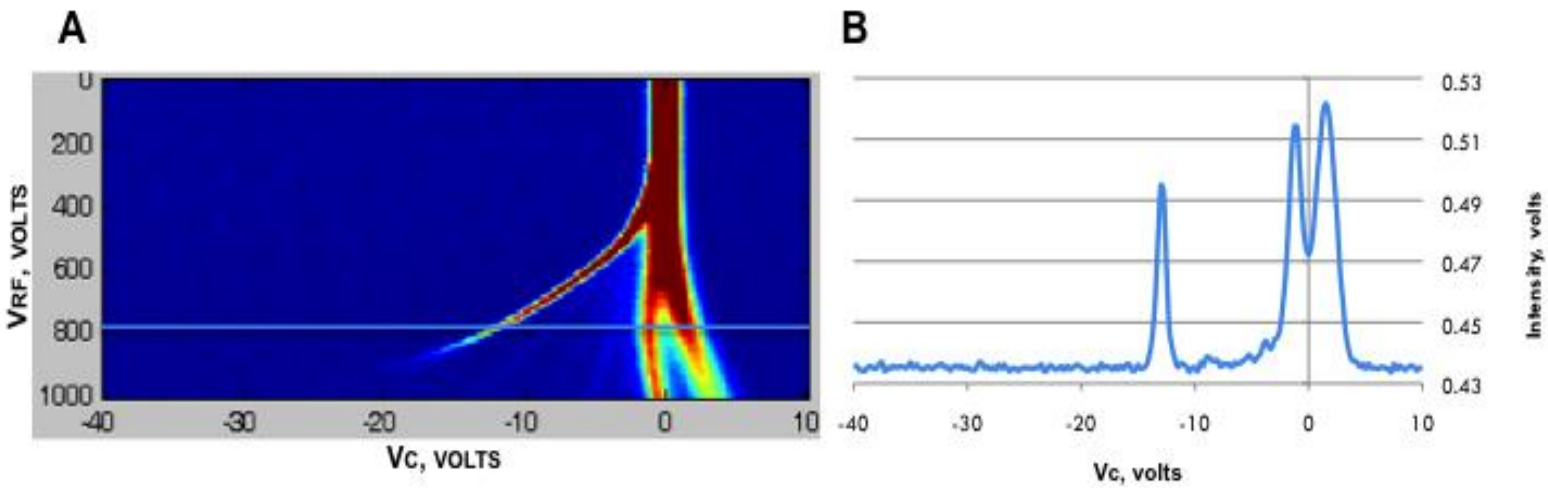

Figure 4.7 Typical DMS output from methamphetamine: (A) full scan spectrum resulting from scanned $V_{\text {rf }}$ and $V_{c}$; $(B)$ linear spectrum from fixed $V_{r f}$ and scanned $V_{c}$. Note, this output is different than that of traditional drift tube IMS and cannot be directly compared to it.

After obtaining consistent results from DMS full spectrum collection, the added parameter of humidity was evaluated. It is known that the moisture content within the DMS will cause peak shifting due to changes in mobility. This is a result of increases in water concentration, which affects formation of the reactant ion peak as well as cluster formation for both the monomer and the dimer. As these molecules become more positively charged due to increased clustering, a more negative compensation voltage is required to pass the analyte ion through to the detector. However, the dimer requires a more positive potential as demonstrated previously in Figure 4.2. Since various field applications and locations may result in different levels of moisture, it was also important to establish a model which would compensate for these changes. By monitoring the position of the RIP, as well as the analyte peak under humid conditions, an algorithm can be established which will best approximate the peak position under a range of humidities. ${ }^{69}$

After collecting spectra at various concentrations and humidities, a visual comparison was made to establish patterns unique to methamphetamine. The 
patterns were based upon the branching that occurred upon the addition of methamphetamine to the chamber; these distinct regions appeared to occur around $\mathrm{V}_{\text {rf }}=800,900$, and 1000 V. Figure 4.8 shows a full scan spectrum for methamphetamine, and the linear spectra resulting from that spectrum at the three $\mathrm{V}_{\mathrm{rf}}$ 's discussed. Additionally, $700 \mathrm{~V}$ is shown which was used to monitor the +RIP position (a measure of humidity in the DMS system); a star marks the + RIP in each linear spectrum.
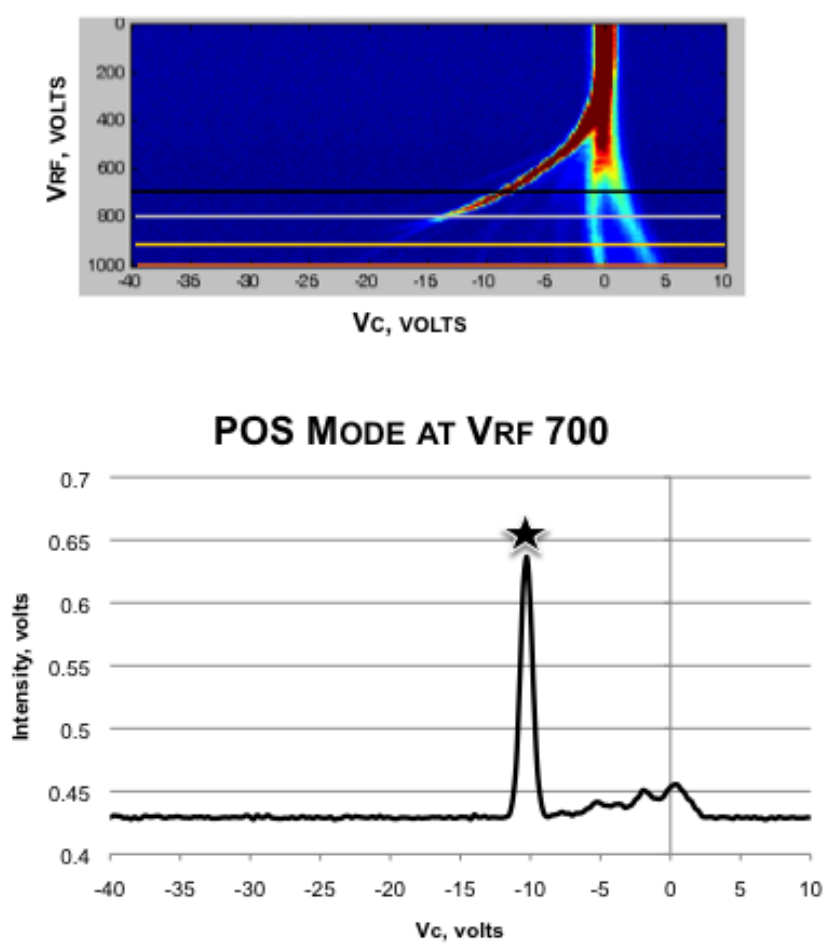
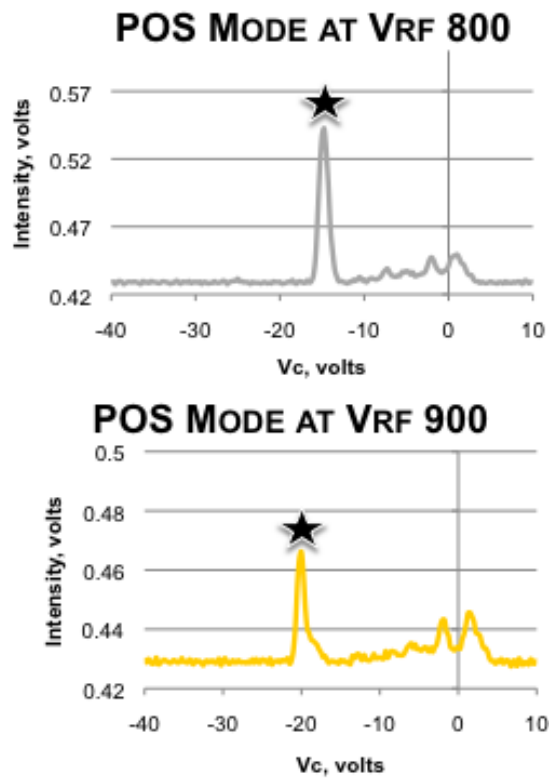

POS MODE AT VRF 1000

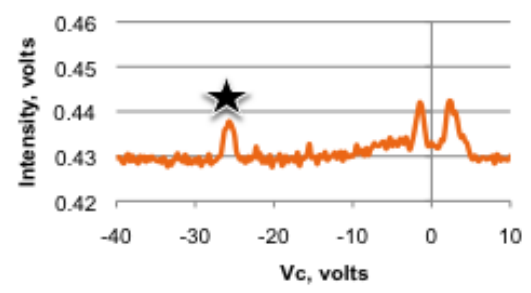

Figure 4.8 Full scan spectrum of methamphetamine and color-coded linear plots for the identification of methamphetamine specific peaks

To establish the algorithm for detection using $\mathrm{JUNO}^{\circledR}$ software, a polynomial relationship was developed between peak positions for methamphetamine and that 
of the + RIP. The monomer was monitored for its position at 800 and $900 \mathrm{~V}$, while both monomer and the dimer were chosen for the $1000 \mathrm{~V}$ detection window. These relationships are demonstrated in Figure 4.9 - 4.12, in which the +RIP shifted during experiments accomplished at higher humidity levels. The + RIP position at $700 \mathrm{~V}$ was plotted along the x-axis based upon the software requirements of the instrument.

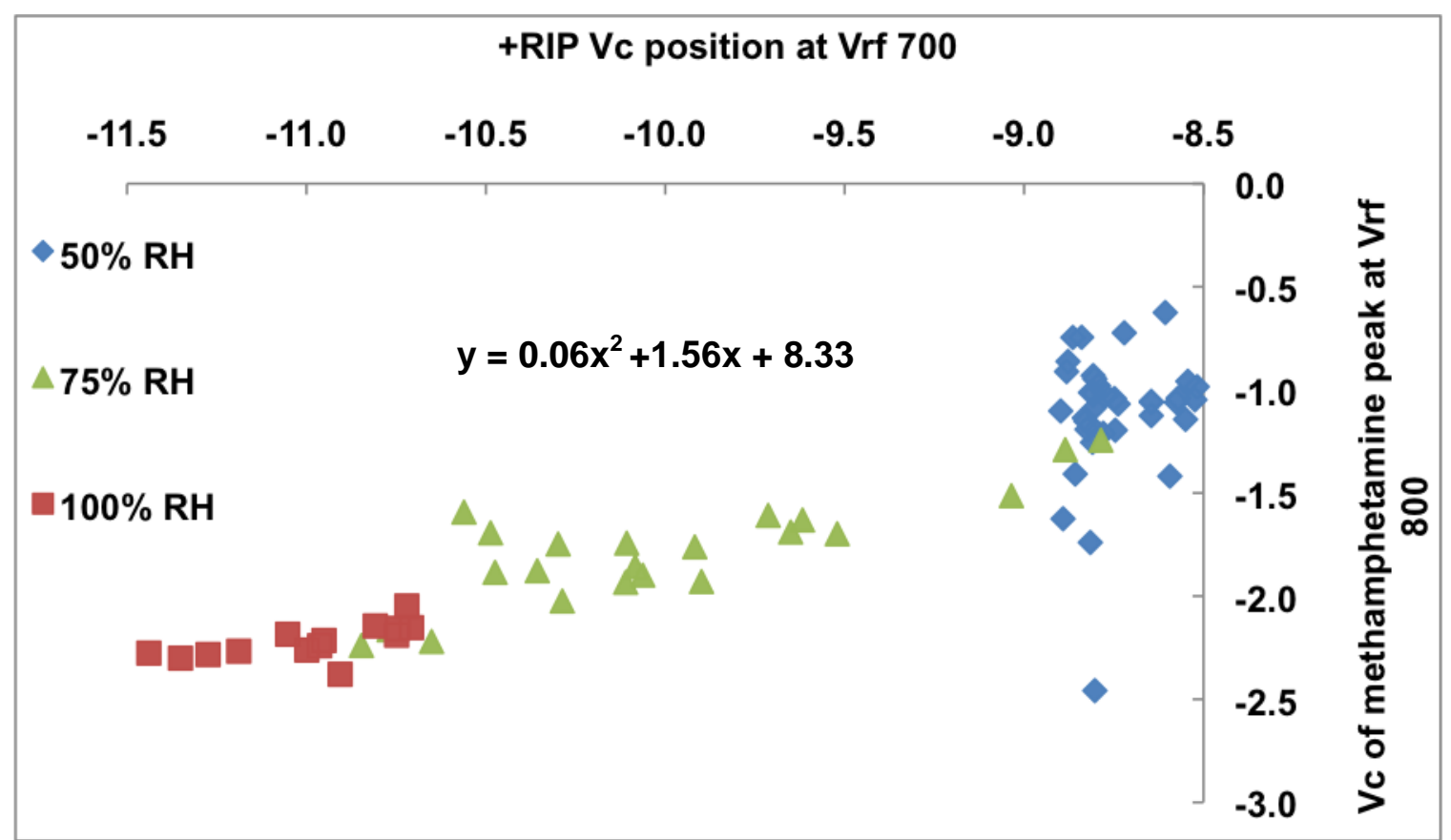

Figure 4.9 Polynomial fit of data from the $V_{c}$ of peaks during $V_{r f} 800$ against $+R I P$ position at $V_{r f} 700$ 


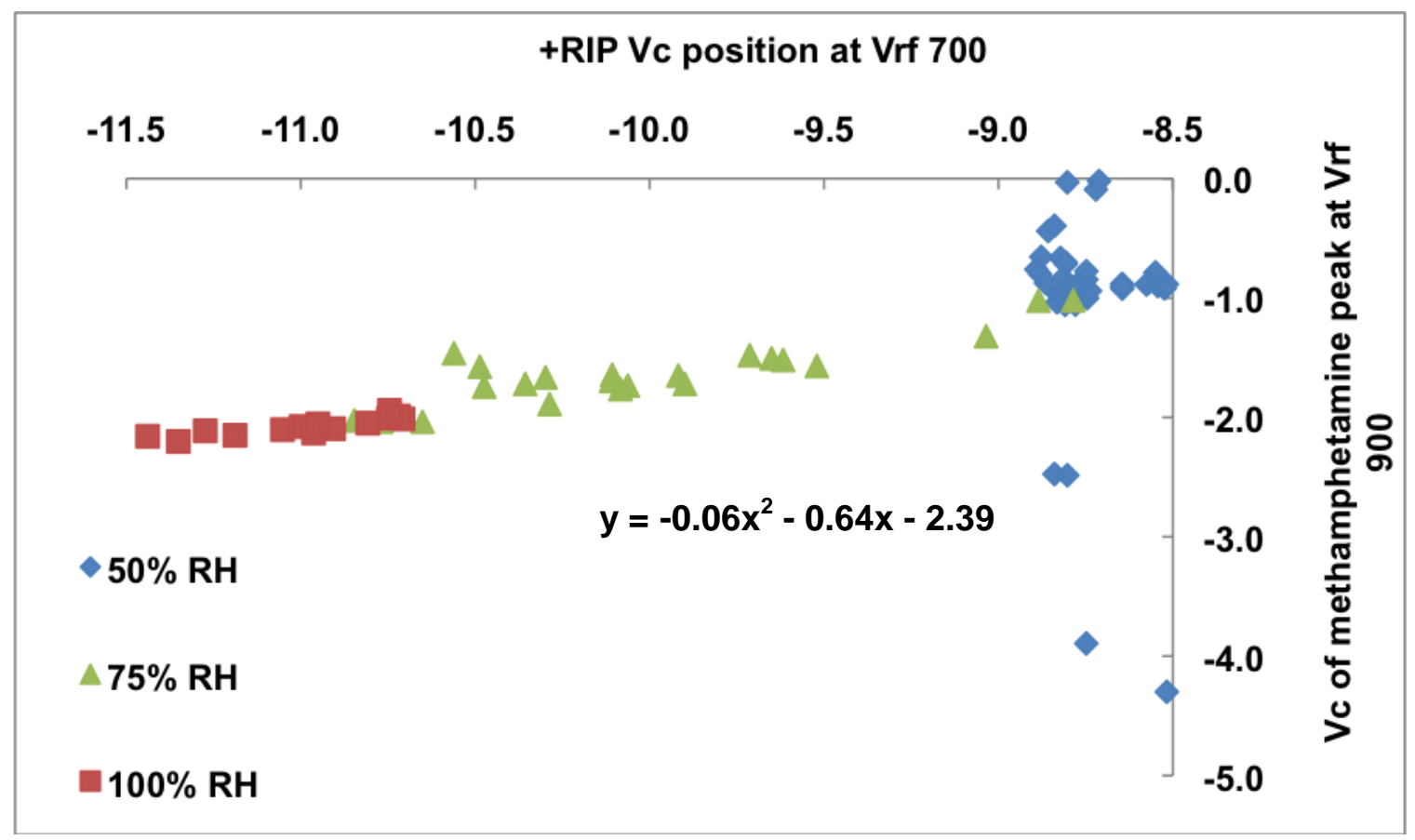

Figure 4.10 Polynomial fit of data from the $V_{c}$ of peaks during $V_{\text {rf }} 900$ against $+R I P$ position at $V_{r f} 700$

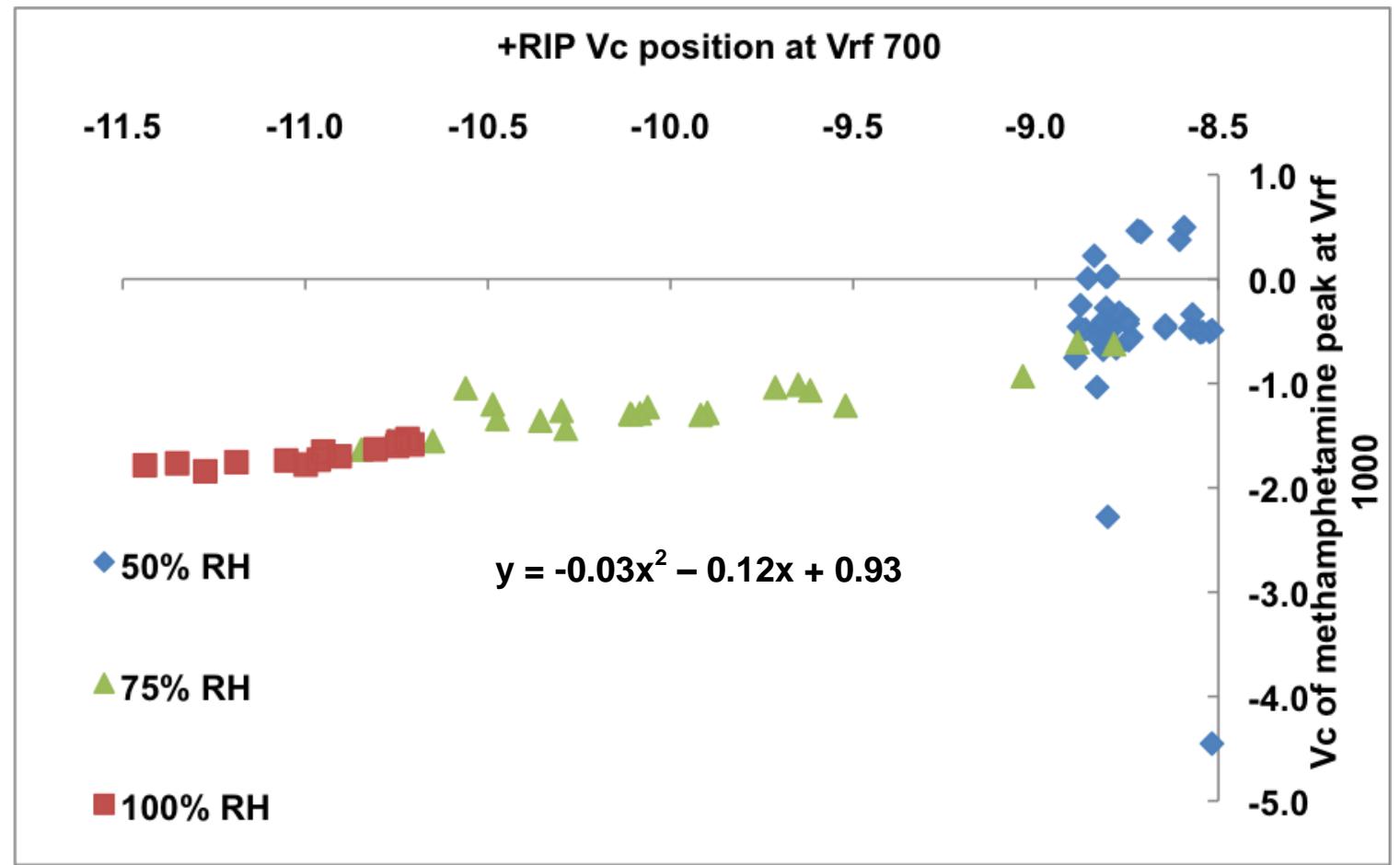

Figure 4.11 Polynomial fit of peak 1 data from the $V_{c}$ of peaks during $V_{r f} 1000$ against $+R I P$ position at $V_{r f} 700$ 


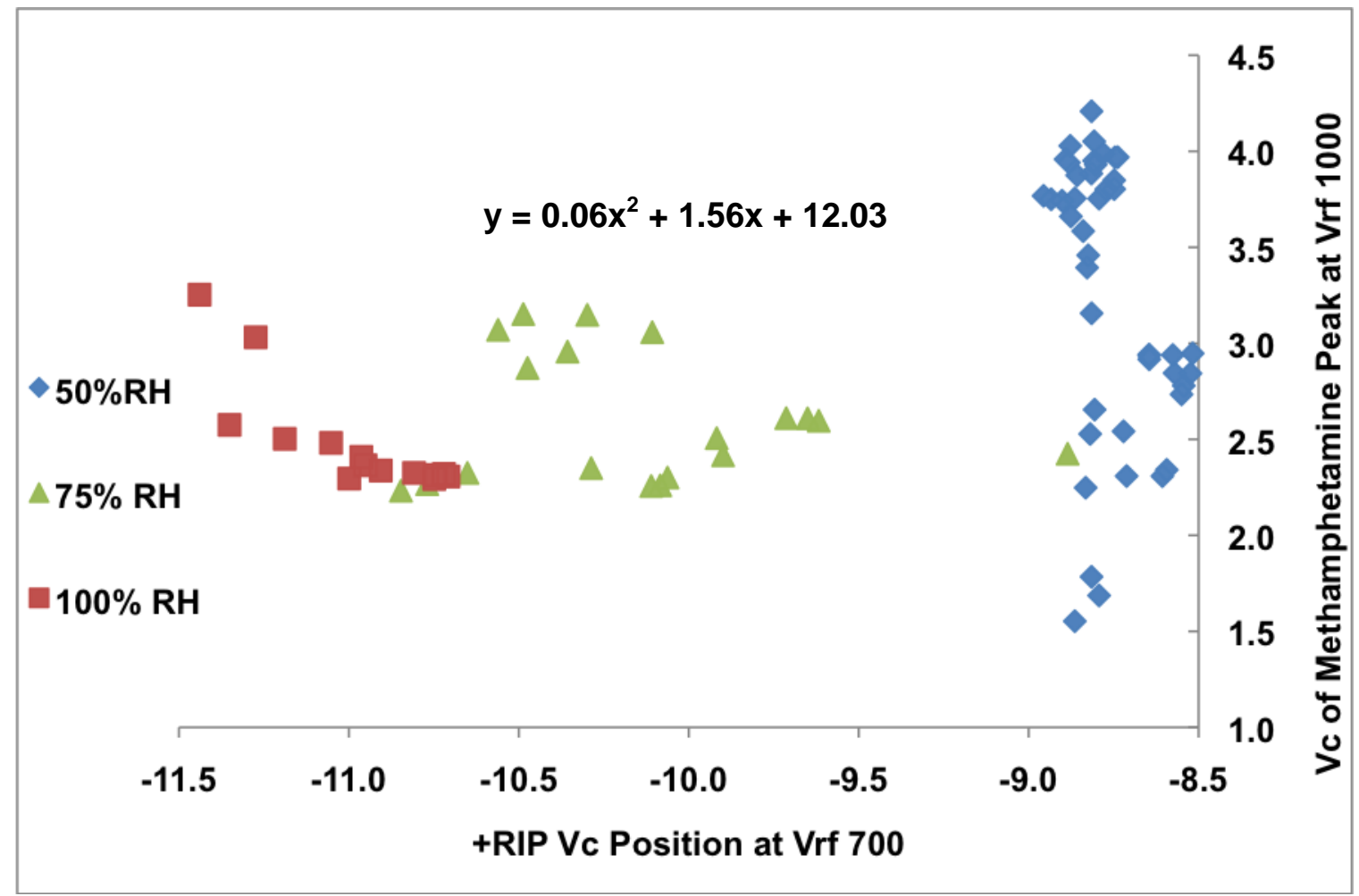

Figure 4.12 Polynomial fit of peak 2 data from the $V_{c}$ of peaks during $V_{\text {rf }} 1000$ against $+R I P$ position at $V_{\text {rf }} 700$

From each polynomial equation, the software coding (used in JACS) for the detection of methamphetamine developed a specific set of rules. The parameters necessary for the creation of a rule are shown in Table 4.1.

Table 4.1 Terminology used in establishing a detecting window on JACS software

\begin{tabular}{|c|l|}
\hline $\mathbf{V}_{\mathbf{r f}}$ & Separation voltage of interest \\
\hline Polarity & Positive or negative mode scan \\
\hline a, b and c & $\begin{array}{l}\text { Coefficients from the polynomial equation established for the } \\
\text { regression at a specific } \mathrm{V}_{\text {rf }}\end{array}$ \\
\hline D & $\begin{array}{l}\text { Width of the detection window. Established from the spread of data } \\
\text { in the polynomial equation }\end{array}$ \\
\hline ID & A name given to the window that identifies the compound of interest \\
\hline Min & Minimum peak height used for positive detection (mV) \\
\hline Label & A name given as a unique identifier for a specific window \\
\hline
\end{tabular}

For the detection of methamphetamine, four rules were established, all of which occurred in the positive mode of scanning. The detection window width was 
developed based upon the distribution of the peaks around the fitted quadratic, and a minimum established such that any peak exceeding a given intensity (volts) would cause the system to alarm. The minimum was evaluated by peak intensities during background scans. These rules appear as loaded in the software, in Table 4.2. Two additional parameters were added for monitoring purposes; these appear as WIN files in the ID category. Under WIN ID, the windows for the +RIP and -RIP were monitored. However, the WIN rules had no effect on the alarm of the system but were used to verify the instrument was operating properly. 
Table 4.2 Rule windows for programming of JUNO ${ }^{\circledR}$ on JACS software in the detection of methamphetamine

\begin{tabular}{|c|c|c|c|c|c|c|c|c|}
\hline Vrf & Polarity & $\mathbf{a}$ & $\mathbf{b}$ & $\mathbf{c}$ & $\mathbf{d}$ & ID & Min & Label \\
\hline 800 & POS & 0.0549 & 1.5614 & 8.3348 & 0.200 & METH & 15 & METH800 \\
\hline 900 & POS & -0.0552 & -0.6351 & -2.392 & 0.334 & METH & 16 & METH900 \\
\hline 1000 & POS & -0.0321 & -0.1149 & 0.9251 & 0.334 & METH & 11 & METH1000 (1) \\
\hline 1000 & POS & 0.0634 & 1.5615 & 12.025 & 0.417 & METH & 13 & METH1000 (2) \\
\hline 700 & POS & 0 & 1 & 0 & 1 & WIN-RIP & 10 & RIP Pos \\
\hline 700 & NEG & 0 & 1.25 & -4.5 & 1 & WIN-RIP & 10 & RIP Neg \\
\hline
\end{tabular}


The four-methamphetamine detection rules were then tested against data gathered previously, in the development phase of understanding methamphetamine branching. The software was set to identify positively the $+R I P$, allowing for further identification of the analyte based upon the given relationships (Figure $4.9-4.12$ ). The software then displayed a "Yes" in the "Alarm?" field if a peak above a certain intensity threshold (Min) was present, within the correct window of the $\mathrm{V}_{\mathrm{rf}}$.

The screen shot in Figure 4.13 demonstrates the appropriate response for the $\mathrm{JUNO}^{\circledR}$ system with the EPC on, resulting in a "No" alarm for the four methamphetamine rules. The system also responds with a "Yes" alarm for the two monitored windows of the +RIP and - RIP, which demonstrates that the system is functioning properly. In Figure 4.14, a methamphetamine sample produces a "Yes" alarm for all six rules, including the four methamphetamine and two +RIP windows. The corresponding full scan spectrum for this sample is shown in Figure 4.15, along with the linear spectra for the sample. It should be noted that although a full spectrum was collected in this analysis, only the detection windows would be scanned during field analysis. The need to only scan selected voltages would allow for a very rapid response to signals. 


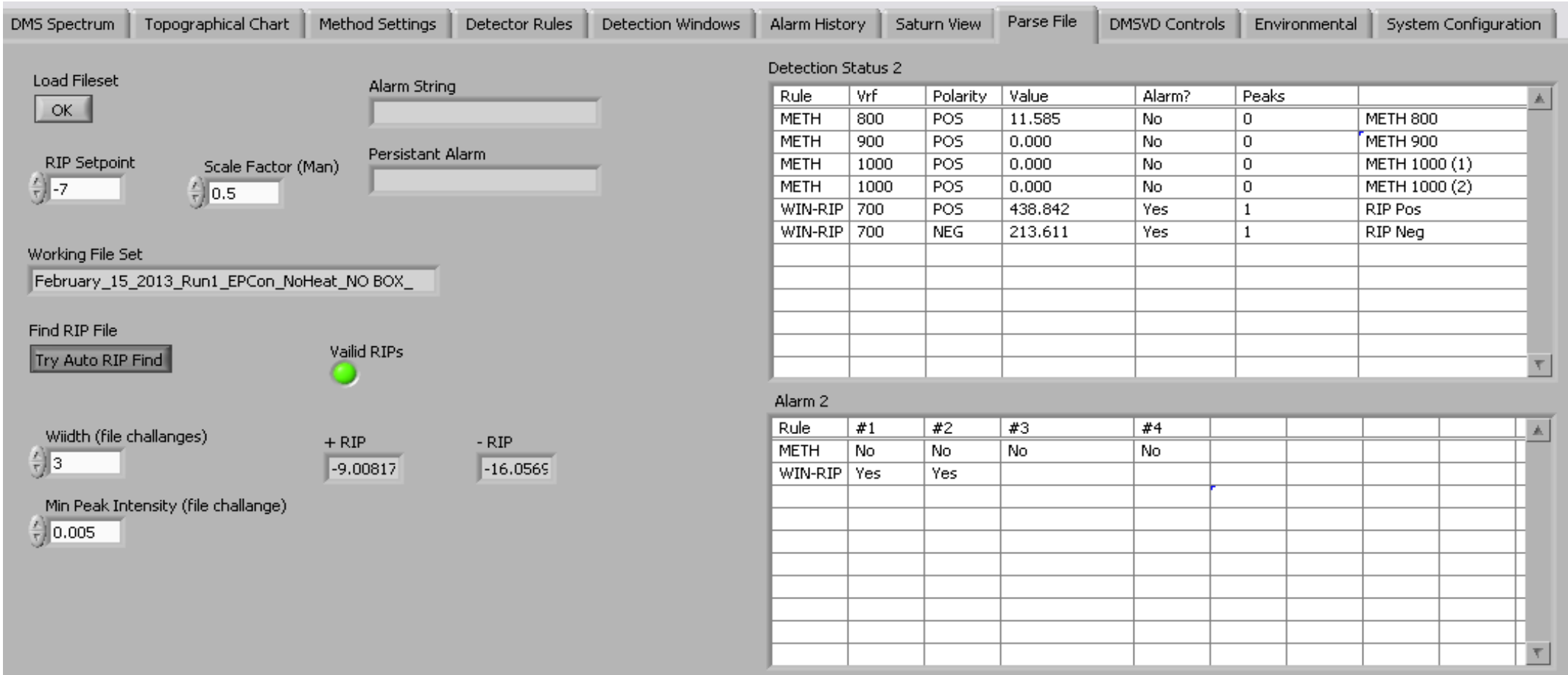

Figure 4.13 Results of file parsing for blank run with EPC on 


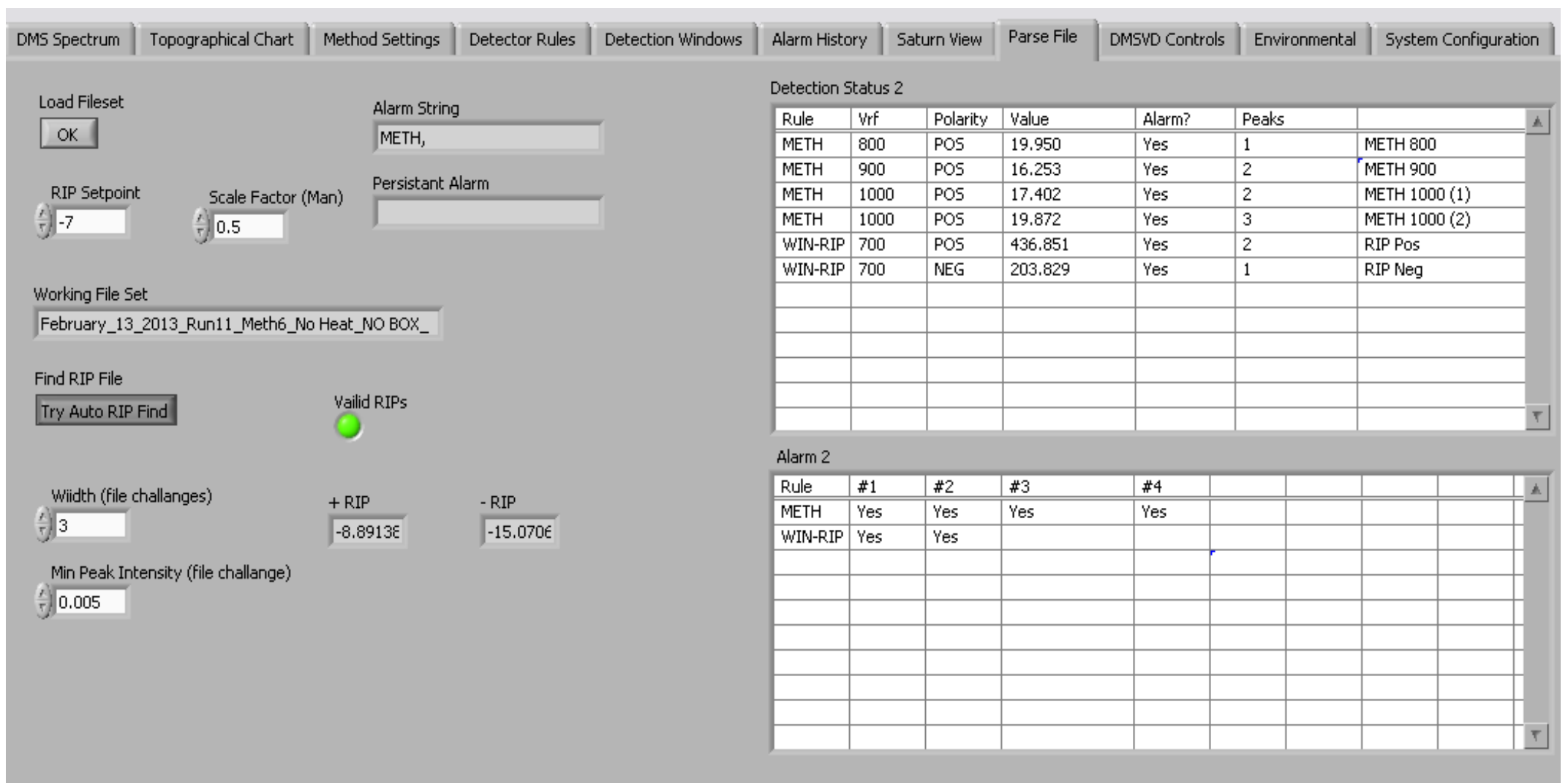

Figure 4.14 Results of file parsing for methamphetamine sample containing $\sim 0.1 \mathrm{~g}$ of drug 

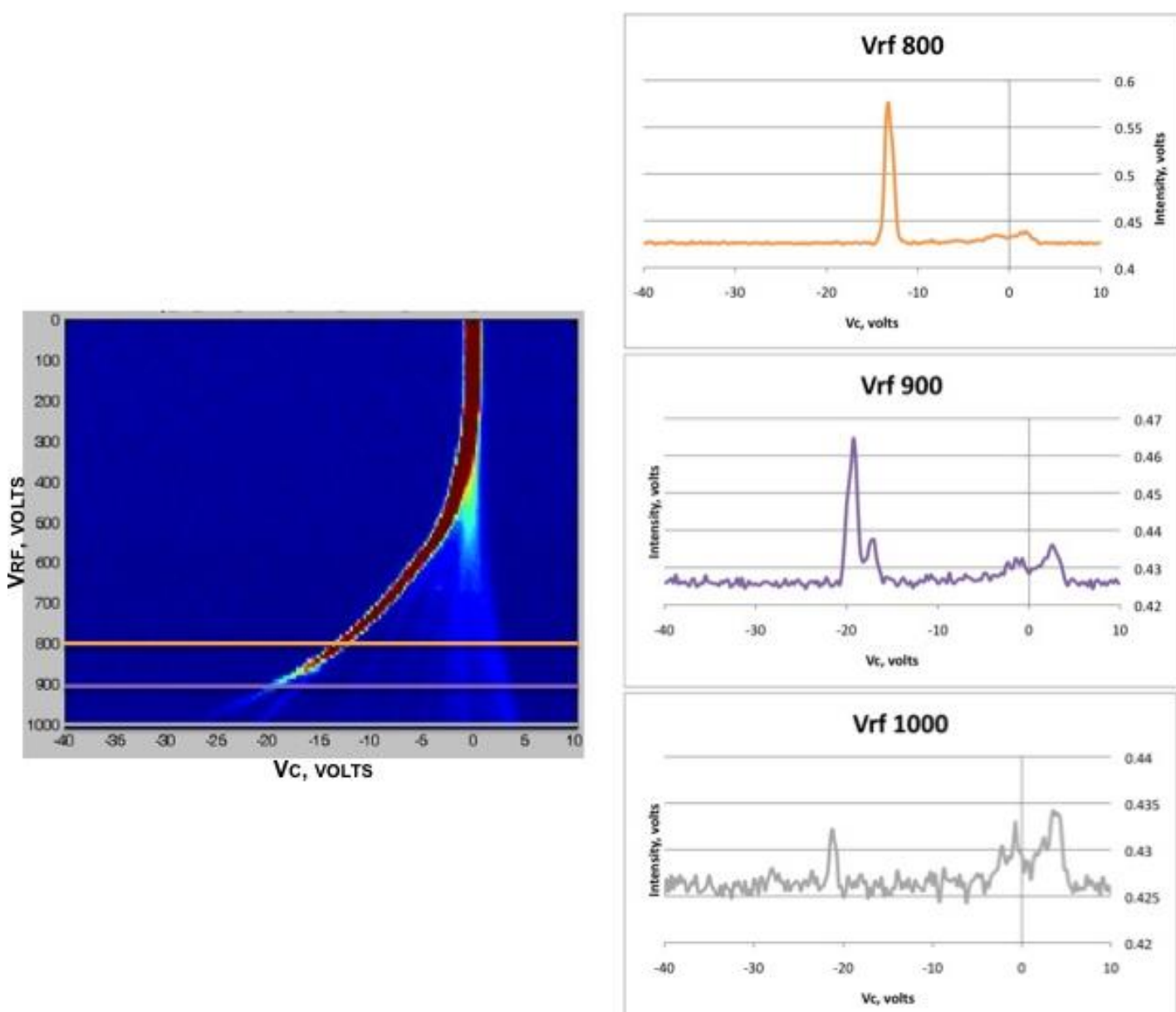

Figure 4.15 Full scan plot of methamphetamine corresponding to $\sim 0.1 \mathrm{~g}$ of drug

\subsubsection{Effect of Heating on Sample Detection}

A hot plate inside the methamphetamine chamber allowed for the addition of heat to the various samples of methamphetamine drug. Figure 4.16 shows the positive mode full scans for three different heating methods. In this figure, we can see the progressive growth in intensity of the methamphetamine branch, which demonstrate the increasing concentration of methamphetamine within the box chamber. 

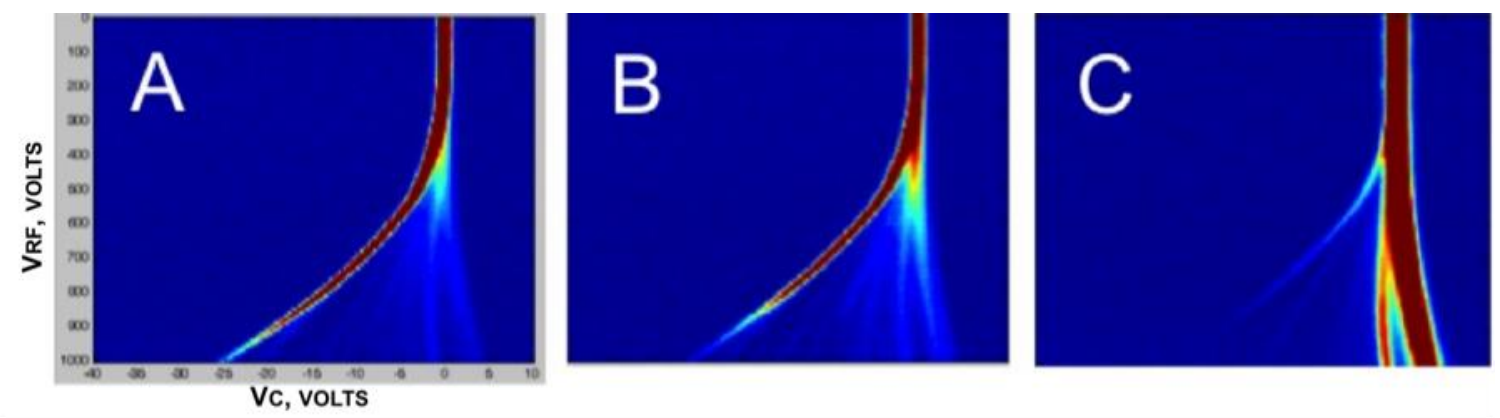

Figure 4.16 Methamphetamine plots resulting from different temperatures of the solution: $(A) 25^{\circ} \mathrm{C},(B) 65^{\circ} \mathrm{C}$, and $(C) 85^{\circ} \mathrm{C}$

Figures $4.17\left(\mathrm{~V}_{\mathrm{rf}} 800\right), 4.18\left(\mathrm{~V}_{\mathrm{rf}} 900\right)$, and $4.19\left(\mathrm{~V}_{\mathrm{rf}} 1000\right)$ show the linear methamphetamine spectra with overlays of the different heat settings. Here it can be observed that, with no heat $\left(25^{\circ} \mathrm{C}\right)$ applied to the samples there is a much lower signal than that of the sample at a high heat $\left(85^{\circ} \mathrm{C}\right)$ setting. However, under all three conditions, a methamphetamine peak was distinguishable from the baseline. When the methamphetamine concentration was too high for the system, depletion of the RIP current was almost absent. This is demonstrated in the case of Figure 4.6C, as well as the corresponding one-dimensional spectra.

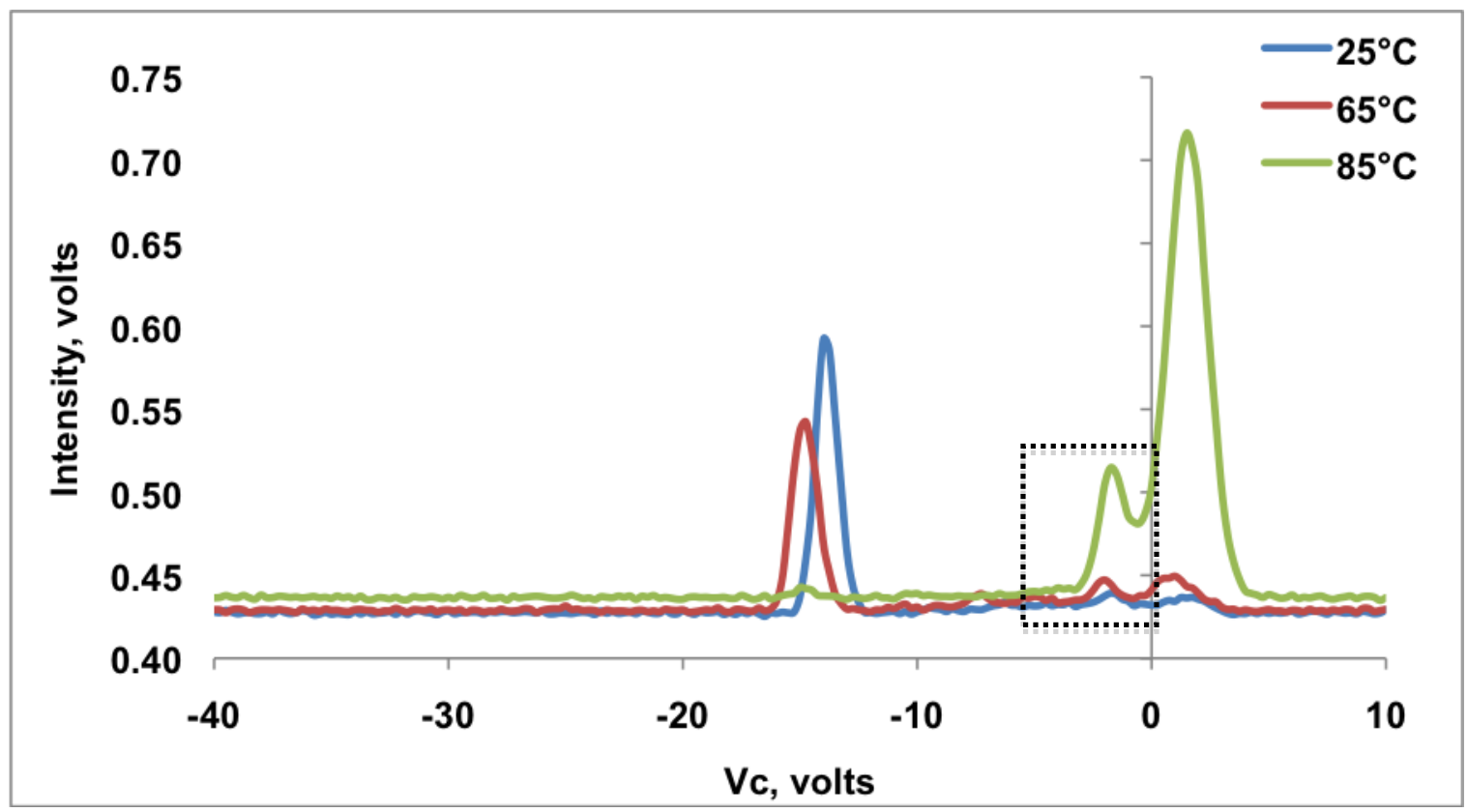


Figure 4.17 One-dimensional DMS spectra of methamphetamine in Case 1 with expansion of the peak monitored during the METH800 window

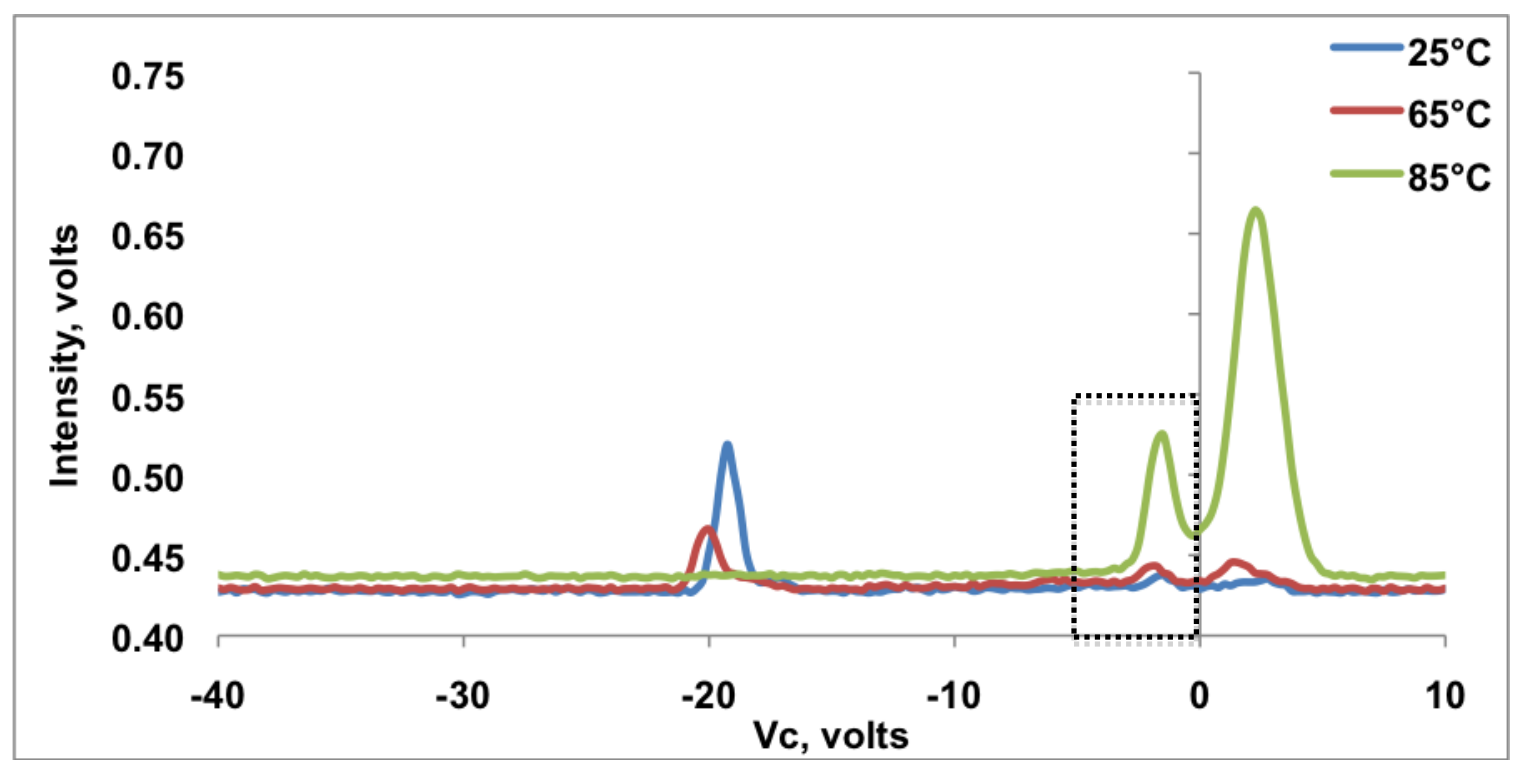

Figure 4.18 One-dimensional DMS spectra of methamphetamine in Case 1 with expansion of the peak monitored during the METH900 window 


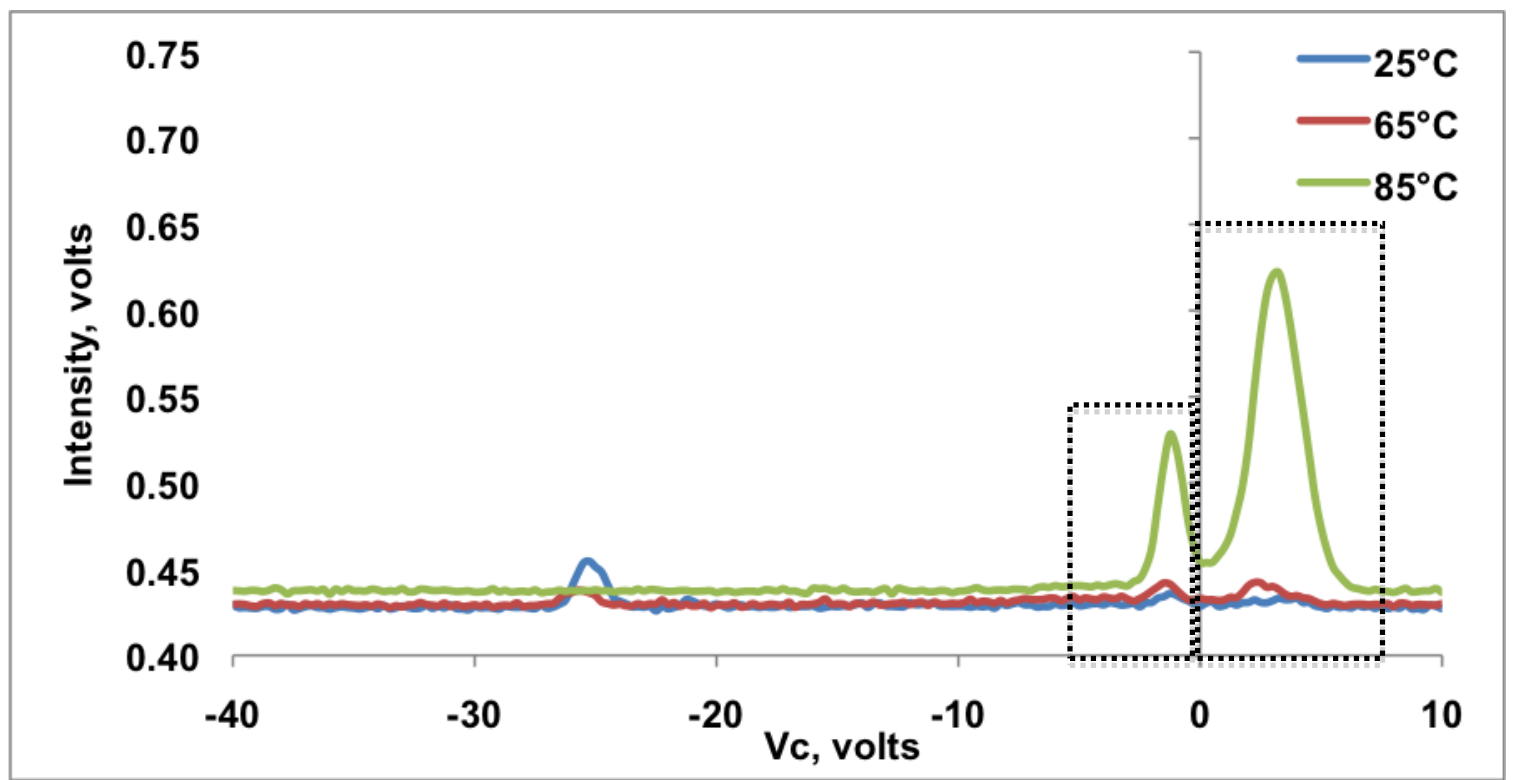

Figure 4.19 One-dimensional DMS spectra of methamphetamine in Case 1 with expansion of the two peaks monitored during the METH1000 window

The values in Table 4.3 demonstrate an increasing trend for each methamphetamine detection window when the temperature of the solution is increased. This establishes the potential for methamphetamine to be calibrated for quantitation on the $\mathrm{JUNO}^{\circledR}$. An understanding of the concentration of methamphetamine in the air would allow for this unit to be of even greater use to remediation contractors and department of health workers who have to enter these sites. 
Table 4.3 Intensity of methamphetamine sample from Case 1 under the four methamphetamine rules measured at three heat settings

\begin{tabular}{|c|c|c|c|c|}
\hline & METH 800 & METH 900 & METH1000 (1) & METH1000 (2) \\
\hline $25{ }^{\circ} \mathrm{C}$ & 28 & 24 & 20 & 15 \\
\hline $65^{\circ} \mathrm{C}$ & 39 & 32 & 29 & 30 \\
\hline $8^{\circ} \mathrm{C}$ & 160 & 182 & 186 & 375 \\
\hline
\end{tabular}

\subsubsection{Potential Interferences}

Common chemical solvents were analyzed against the established four detection windows set for methamphetamine. These solvents, all of which were known to have high vapor pressures, were chosen as typical components in the methamphetamine production process. Simple Green ${ }^{\circledR}$ was also tested due to its frequent use in the clandestine laboratory clean up processes. The primary nonwater ingredient in Simple Green ${ }^{\circledR}$ is 2-butoxyethanol, hence its vapor pressure is reported in Table 4.4.

Table 4.4 Potential chemical interferences in the analysis of methamphetamine by JUNO ${ }^{\circledR}$

\begin{tabular}{|c|c|}
\hline Potential Chemical Interference & Vapor Pressure (Torr, at $\mathbf{2 5}{ }^{\mathbf{}} \mathbf{C}$ ) \\
\hline Acetone & 348 \\
\hline Benzene & 101 \\
\hline Hexane & 150 \\
\hline Methanol & 265 \\
\hline Pentane & 516 \\
\hline 2-Propanol & 81.3 \\
\hline Toluene & 27.7 \\
\hline Simple Green ${ }^{\circledR}$ (2-butoxyethanol) & 1.74 \\
\hline
\end{tabular}


A false positive for methamphetamine would meet the parameters of all four detection rules. In the analysis of these eight potential chemical interferences, none tested positive in all detections windows. The full scan spectra for each of the interferences are shown in Appendix A, along with the detected value for each parameter. All of the spectra were collected in the same manner as those of the methamphetamine; however, in some instances a software glitch did produce peak shifting as seen in Appendix A. Of the eight potential interferences analyzed, six of the chemicals detected peaks above the threshold value during the window for detection at $V_{\text {rf }} 800$. While METH900 produced a positive detection only once, METH1000 (1) and METH1000 (2) yielded three positive results.

\subsection{Summary and Future Work}

After programming $\mathrm{JUNO}^{\circledR}$ with four specific detection windows for methamphetamine, the system demonstrated significant potential for the detection of the drug in air. Methamphetamine detection produced increasing peak intensities as the sample was heated as expected. Methamphetamine vapor concentration increases with rapidly increasing temperatures, as demonstrated in the glass controls used in Chapter 3 . Thus, potential exists that the $\mathrm{JUNO}^{\circledR}$ system could be used to make semi-quantitative measurements of methamphetamine in a clandestine laboratory. Therefore, the $\mathrm{JUNO}^{\circledR}$ could be used by police officers and first responders to evaluate the risk of the responder to the contaminated air environment in less than 5 minutes. 


\section{CHAPTER 5: ANALYSIS OF A SIMULATED MOBILE METHAMPHETAMINE LABORATORY}

\subsection{Introduction}

With significant limitations set on the sales of methamphetamine precursors, illicit production has turned to a new method called the 'shake ' $n$ ' bake' or one-pot cook. This method is considered to be extremely dangerous to the manufacturer as it combines anhydrous ammonia, pseudoephedrine tablets, water, and reactive lithium metal in a single container, typically a $2-\mathrm{L}$ soda bottle. $^{70}$ The shake ' $n$ ' bake method is described as taking only about 40 minutes to complete, leaving only a few dirty bottles behind, and producing up to $8 \mathrm{~g}$ of methamphetamine. Cooks of this type tend to work in cars, dumping bottles in an effort to destroy evidence and evade police.

News media have reported that over $80 \%$ of the labs busted since 2010 are a result of shake ' $n$ ' bake cooks. The degree of to which contamination of methamphetamine in the air resulting during these cooks is not yet known; however, these one-pot methods are considered to be extremely dangerous with a chance of an explosion. Therefore, sites previously used for the production of methamphetamine by this method should be investigated for demolition and/or remediation by the EPA guidelines.

Smoking methamphetamine can also produce airborne drug which is released into the environment resulting in contamination. Smoking methamphetamine has been found to result in $50 \%$ of the methamphetamine remaining in the pipe, while $67-90 \%$ of the aerosolized methamphetamine is absorbed by the body. ${ }^{71,72}$ The remaining methamphetamine is thus expected to 
settle in the surrounding areas. A study by Martyny et al demonstrated the potential contamination by performing a simulated "smoke" of $100 \mathrm{mg}(91 \%$ purity) of methamphetamine in a pipe. ${ }^{73}$ The findings showed that methamphetamine airborne concentrations, calculated for the presence of a smoker, ranged from 37-131 $\mathrm{\mu g} \mathrm{m}^{-3}$, while surface analysis produced levels from $0.02-0.08 \mu \mathrm{g} / 100 \mathrm{~cm}^{2}$ for a single smoke.

With increasing tendency toward one-pot cooks, methamphetamine production is becoming mobile. These mobile clandestine laboratories are typically producing small quantities of drug in order to fulfill the needs of the person synthesizing them. With the ability to move from site-to-site the cooks are often able evade police officers; however, it is not yet understood what to do with the confiscated vehicle housing the clandestine laboratory. Further investigation of the effects of methamphetamine smoking and spills is required to understand the potential of contamination. This research is intended to increase the knowledge in the detection of methamphetamine within a contaminated vehicle.

\subsection{Materials and Methods}

\subsubsection{Chemicals and Solvents}

Methamphetamine $\mathrm{HCl}$ standard (Sigma-Aldrich, St. Louis $\mathrm{MO}$ ), and LC/MS-grade methanol (Fluka/Sigma-Aldrich, St. Louis MO) were used. The methamphetamine was obtained as a solid and a stock solution prepared at $1,000 \mathrm{ppm}$. The solution was stored in a $20-\mathrm{mL}$ scintillation vial at $4{ }^{\circ} \mathrm{C}$. For swabbing, reagent alcohol was used (ACS grade, EMD Scientific, Rockland MA). 
Smiths Detection swabs were purchased for desorption in ion mobility spectrometry analysis.

\subsubsection{Instrumentation}

When DMS is operated in the field, full scan spectra cannot be collected. Instead, the samples taken are scanned against the established rules for the instrument. This is common practice for field portable detection, and produces rapid response for detection of the analyte. It is important to note that DMS is still considered a screening technique; therefore, a secondary analysis should be used to confirm the presence of an analyte. In this analysis, HS-GC/MS was used for confirmatory analysis. IMS evaluation was also used, since it is standard practice in clandestine laboratory remediation procedures to evaluate by sample swab as screening technique.

Chemring Detection Systems' JUNO ${ }^{\circledR}$ DMS instrument was programmed for the detection of methamphetamine. Four detection rules were established to evaluate the presence of methamphetamine and two additional rules used to evaluate the presence of the reactant ion peak. In order to produce a positive signal, a response for methamphetamine must occur above threshold value during each of the four-methamphetamine specific windows. These detection windows were established and described in Section 4.3.1.

Smiths' Detection Sabre ${ }^{\mathrm{TM}} 4000$ with a radioactive ${ }^{63} \mathrm{Ni}$ ionization source was used in "Narcotics" mode, as this is typical of field operation. Under this positive detection mode, sample analyte was desorbed off the swab for ionization 
and separation with positive identification occurring for methamphetamine as having a $\mathrm{K}_{0}$ value of $1.61 \mathrm{~cm}^{2} \mathrm{~V}^{-1} \mathrm{~s}^{-1}$.

HS-GC/MS was used as a quantitative technique for the detection of methamphetamine. Conditions were optimized for this analysis in Section 3.4.2, which are shown in brief in Table 3.3.

\subsubsection{Vehicle Sampling}

A 1999 Dodge Neon was used to simulate the contamination of a mobile clandestine laboratory. Specific locations within the vehicle were marked for analysis. The sites used are described in brief in Table 5.1, while Appendix B provides photographs of these locations. Sites 1-4 were used for HS-GC/MS analysis and were taken as plugs of the fabric. All six sites were used for IMS evaluation by swabbing a $10 \times 10 \mathrm{~cm}^{2}$ area. As an air-sampling unit, the DMS instrument was placed in car at 3 different times: (1) before any contamination, (2) during cigarette smoking, and (3) after exposure to methamphetamine. Background samples were also obtained before any contamination occurred within the vehicle. For both HS and IMS, these blank samples yielded no response for methamphetamine. 
Table 5.1 Sampling locations in the analysis of methamphetamine in contaminated Dodge Neon

\begin{tabular}{|c|c|c|}
\hline $\begin{array}{c}\text { Sampling } \\
\text { Site \# }\end{array}$ & Location within Vehicle & $\begin{array}{c}\text { Analysis } \\
\text { Technique }\end{array}$ \\
\hline 1 & Trunk & HS, IMS \\
\hline 2 & Passenger's side, back seat - seat padding & HS, IMS \\
\hline 3 & Driver's seat - back padding & HS, IMS \\
\hline 4 & Driver's side, floor boards & HS, IMS \\
\hline 5 & Passenger's side, front side door - glass window & IMS \\
\hline 6 & Passenger's side, front - dashboard & IMS \\
\hline
\end{tabular}

\subsubsection{Nicotine Contamination}

It has been previously reported that methamphetamine detection in the presence of nicotine using IMS yields ambiguous results due to similarities in charge affinity and ion mobility $\left(\mathrm{K}_{0}\right.$, methamphetamine: $1.61 \mathrm{~cm}^{2} \mathrm{~V}^{-1} \mathrm{~s}^{-1}$, and nicotine: $\left.1.54 \mathrm{~cm}^{2} \mathrm{~V}^{-1} \mathrm{~s}^{-1}\right) \cdot{ }^{46}$ However, no reports in the literature discuss the behavior of DMS in the presence of the two compounds. In an attempt to evaluate the effectiveness of DMS in the separation of nicotine and methamphetamine, nicotine was introduced to the vehicle. A volunteer smoked two cigarettes (Virginia Slim Ultra Light Menthol 120's, Altria, Richmond, VA), exhaling into the car over the course of $30 \mathrm{~min}$, throughout which time the $\mathrm{JUNO}^{\circledR}$ instrument was collecting data within the vehicle. After the smoking event, the $\mathrm{JUNO}^{\circledR}$ was removed and the vehicle closed for five days before samples were collected.

\subsubsection{Methamphetamine Contamination}

After samples for nicotine background had been obtained, methamphetamine was introduced to the vehicle. For each of the four locations for HS analysis and six sites for IMS evaluation, $2 \mathrm{~mL}$ of methamphetamine $(1,000 \mathrm{ppm}$ in methanol) were spiked on the surface. After surface spikes, $\sim 1 \mathrm{~g}$ 
of methamphetamine dissolved in $10 \mathrm{~mL}$ of methanol which was heated to $65{ }^{\circ} \mathrm{C}$ using a hotplate in the floorboard of the passenger's side. The heating process was continued for 30 minutes, at which point the car was visibly filled with vapor (Figure 5.1). The car was left closed for 68 hours, parked outside at a temperature of $\sim 10^{\circ} \mathrm{C}$, before entry was made and sample collection occurred.

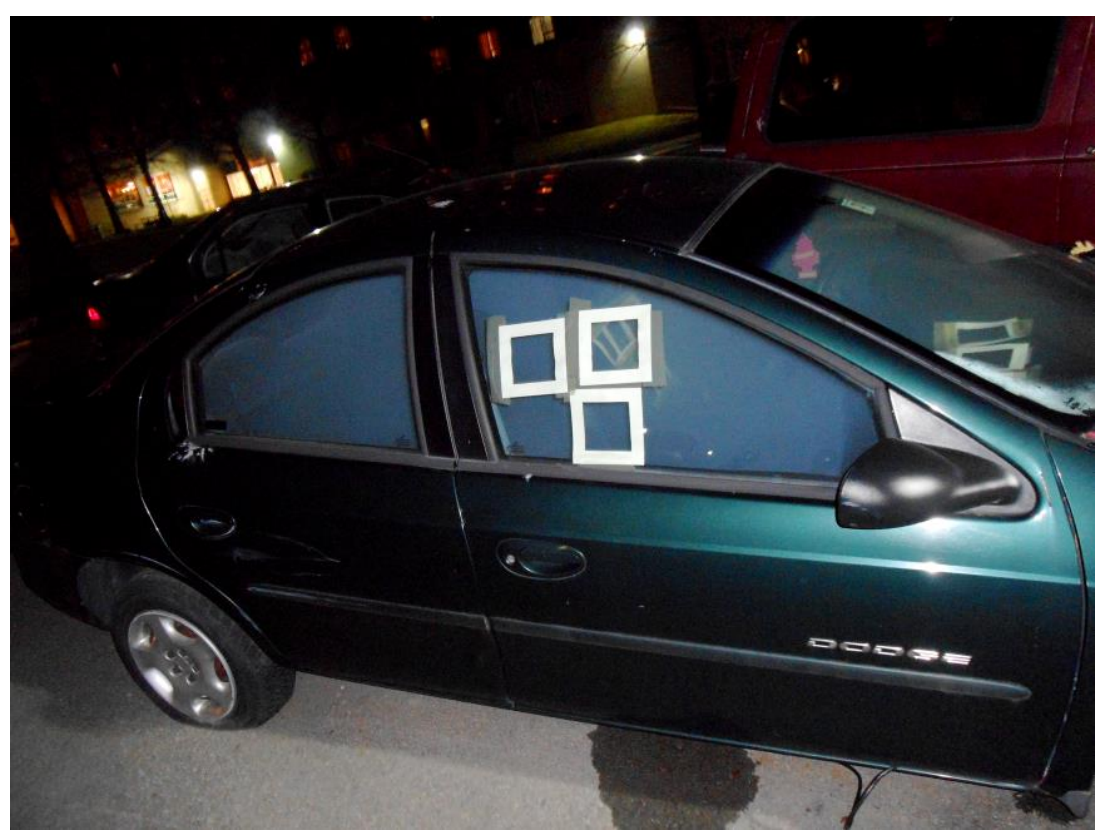

Figure 5.1 Methamphetamine contamination of Dodge Neon

\subsection{Results and Discussion}

After the cigarettes were smoked and 68 hours had passed, four HSGC/MS and six sample swabs for IMS were obtained and stored in glass vials, which were taken back to the laboratory for analysis. In the case of the HS samples, no signal was produced as interference for methamphetamine. However, when the IMS swabs were analyzed, a peak was produced at low amplitudes as a false positive for methamphetamine (Table 5.2). 
Table 5.2 IMS peak amplitudes resulting from post-cigarette smoking analysis

\begin{tabular}{|l|l|}
\hline Site & Amplitude (dU) \\
\hline 1 & 20.2 \\
\hline 2 & 67.5 \\
\hline 3 & 153 \\
\hline 4 & 137 \\
\hline 5 & 75.2 \\
\hline 6 & 147 \\
\hline
\end{tabular}

The results demonstrate that in the areas closest to the smoking (front of the vehicle), nicotine contamination was at the highest. It was expected that only low levels of nicotine would reach the trunk space of the vehicle, and this was demonstrated by peak amplitude of $20.2 \mathrm{dU}$.

$\mathrm{JUNO}^{\circledR}$ was placed in the vehicle during the smoking time, and did not result in an "alarm" during the analysis. However, it should be noted that the instrument did result in an "error." This was likely due to the high concentration of cigarette smoke in the air environment overloading the system and depleting the RIP. If the system is unable to detect the reactant ion, an error is signalled.

To re-enter of the vehicle after methamphetamine contamination, the author wore a 3M 7200s full-face respirator and Tyvek $^{\circledR}$ suit in order to prevent exposure to high levels of methamphetamine. At this point the $\mathrm{JUNO}^{\circledR}$ and Sabre $^{\text {TM }} 4000$ were placed within the Dodge Neon, and the doors shut once again. Neither the Sabre ${ }^{\mathrm{TM}} 4000$ nor the $\mathrm{JUNO}^{\circledR}$ generated an alarm when placed in the vehicle for 10 minutes. The methamphetamine that was once vapor within the vehicle had likely settled on the surfaces of the interior of the car or escaped via openings (since vehicles are not considered gas tight). 
To evaluate the potential for methamphetamine settling on the surface, samples were taken for IMS analysis by swabbing over a $10 \times 10 \mathrm{~cm}^{2}$ area, and stored in glass 8-mL vials until they could be analyzed in the lab. To establish methamphetamine contamination as a result of settling vapor, surface swabs were taken in the previously sampled "background" analysis area. At this same time, surface swabs were also taken from the spiked location. The results of the IMS analysis of the vapor and spikes are provided in Table 5.3.

Table 5.3 Methamphetamine evaluation by IMS in the simulated mobile clandestine laboratory

\begin{tabular}{|c|c|c|}
\hline Site & $\begin{array}{c}\text { Peak Amplitude - Vaporized } \\
\text { Methamphetamine (dU) }\end{array}$ & $\begin{array}{c}\text { Peak Amplitude - Spiked } \\
\text { Methamphetamine (dU) }\end{array}$ \\
\hline 1 & 80.0 & 78.7 \\
\hline 2 & 511 & 490 \\
\hline 3 & 516 & 508 \\
\hline 4 & 77.5 & 162 \\
\hline 5 & 219 & 236 \\
\hline 6 & 412 & 457 \\
\hline
\end{tabular}

Positive IMS results occurred throughout the vehicle, demonstrating that methamphetamine likely settled throughout the surfaces of the vehicle. The peak amplitudes of swabs, taken from the trunk, were significantly less than those observed throughout the rest of the vehicle. It is likely that the high concentrations of methamphetamine came from that of the heated sample, which produced vapor that settled; however, due to the division in the vehicle, methamphetamine was less likely to penetrate into the trunk. It should be noted that in the swab analysis, methamphetamine was detected in both the vapor and spike locations for all sites. 
Materials used in HS analysis were also taken from both the spiked and background location. In this evaluation, it was seen that methamphetamine spiked on the surface presented positive signals for three of the four sites. Table 5.4 shows the average mass load of the four sampling sites for the both the spike and vapor. The peak area was used to calculate the measured mass on column in nanograms using Figure 3.11. Considering that $2 \mathrm{~mL}$ of $1,000 \mathrm{ppm}$ methamphetamine was deposited on each sampling site, this concentration is equivalent to $91.5 \mathrm{ng}$ on column. Therefore, the measured methamphetamine concentration was less than $1 \%$ of the theoretical amount. Since only the top layer of each surface was sampled, there is potential that the methamphetamine penetrated further into the material or was lost via other mechanisms.

Table 5.4 Methamphetamine spiked locations within simulated mobile clandestine laboratory

\begin{tabular}{|c|c|}
\hline $\begin{array}{c}\text { Theoretical Mass of } \\
\text { Methamphetamine on } \\
\text { Column (ng) } \\
\text { Spike }\end{array}$ & $\begin{array}{c}\text { Theoretical Mass of } \\
\text { Methamphetamine on Column } \\
(\mathbf{n g}) \\
\text { Vapor }\end{array}$ \\
\hline 0.197 & 0.0203 \\
\hline
\end{tabular}

HS samples taken to establish the potential of methamphetamine settling from the vaporization process, demonstrated two positive results: Site 1 and 4 . These locations also resulted in the highest concentrations of methamphetamine in the spike analysis. Since Sites 2 and 3 , as well as 1 and 4 were made of similar materials, it was expected that their ability to retain methamphetamine without simply passing through to the next layer would be similar. In both cases, it is likely that some of the methamphetamine spiked nearby produced a positive 
response due to solution spreading, caused the methamphetamine to end up within the "background" block. Additionally, methamphetamine vaporized on the hot plate had the potential of distributing throughout the air environment in the car before settling.

Throughout all analysis with the $\mathrm{JUNO}^{\circledR}$ instrument in the vehicle no "alarm" was ever produced. It was expected that at these levels of contamination $\mathrm{JUNO}^{\circledR}$ would produce some response; however, it is possible that the vapor concentration was below that of the LOD for $\mathrm{JUNO}^{\circledR}$. According to Motor Trend Magazine, Dodge Neons produced in 1999 have an interior volume of 2,582 L. ${ }^{74}$ If an assumption is made that the entire $1.000 \mathrm{~g}$ of methamphetamine placed into the vehicle vaporized and remained airborne until the third day of analysis, this would produce an airborne concentration of $0.3873 \mathrm{ppm}$. The estimated concentration of methamphetamine is significantly lower than those studied within the box chamber, which typically used $0.1000 \mathrm{~g}$ of methamphetamine in a $56.7 \mathrm{~L}$ chamber, equivalent to $1.76 \mathrm{ppm}$. Therefore, it is possible that even if all of the methamphetamine had remained airborne, $\mathrm{JUNO}^{\circledR}$ would not be able to detect its presence. It should also be considered that much of the methamphetamine had likely settled to the surfaces of the vehicle upon return for analysis reducing the airborne concentration even more.

\subsection{Summary and Future Work}

Contamination of a vehicle with methamphetamine can occur by the occupants of the vehicle smoking and/or cooking methamphetamine. These hazards lead us to investigate multiple analysis techniques for the detection of 
methamphetamine in a vehicle. While IMS and DMS are both known to be screening methods, their identification of the contamination proved the need for better methods. The DMS produced no response in presence of $1 \mathrm{~g}$ of vaporized methamphetamine; however, according to user forums, roughly $0.5 \mathrm{~g}$ of methamphetamine is smoked at one time. This suggests, that DMS detection of methamphetamine is not viable method for analysis at this time, until lower detection limits can be established.

Additionally, false positives from nicotine contamination in the IMS present a challenge for investigators. An estimated 45.3 million people smoke cigarettes in the United States, ${ }^{75}$ with the likelihood increasing if they are an illicit drug user (71\% of illicit drug users smoke cigarettes).$^{76}$ Therefore, we recommend that investigators move away from the use of IMS and DMS in field methamphetamine analysis, and focus on technologies with potential for lower limits of detection and decreased false positives. 


\section{APPENDIX A: ANALYSIS OF CHEMICAL INTERFERENCE BY DMS}

\section{Acetone}

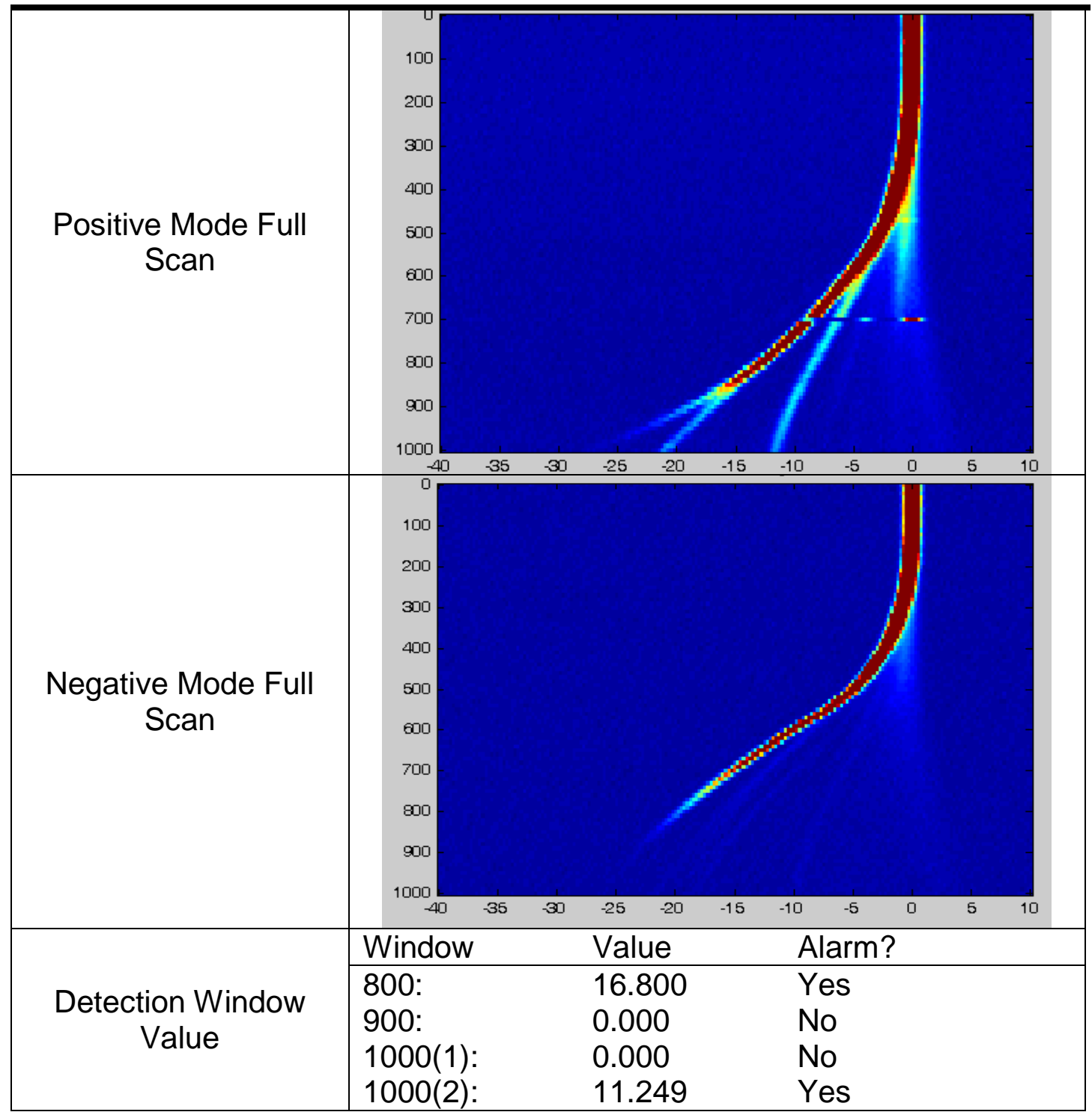




\section{Benzene}

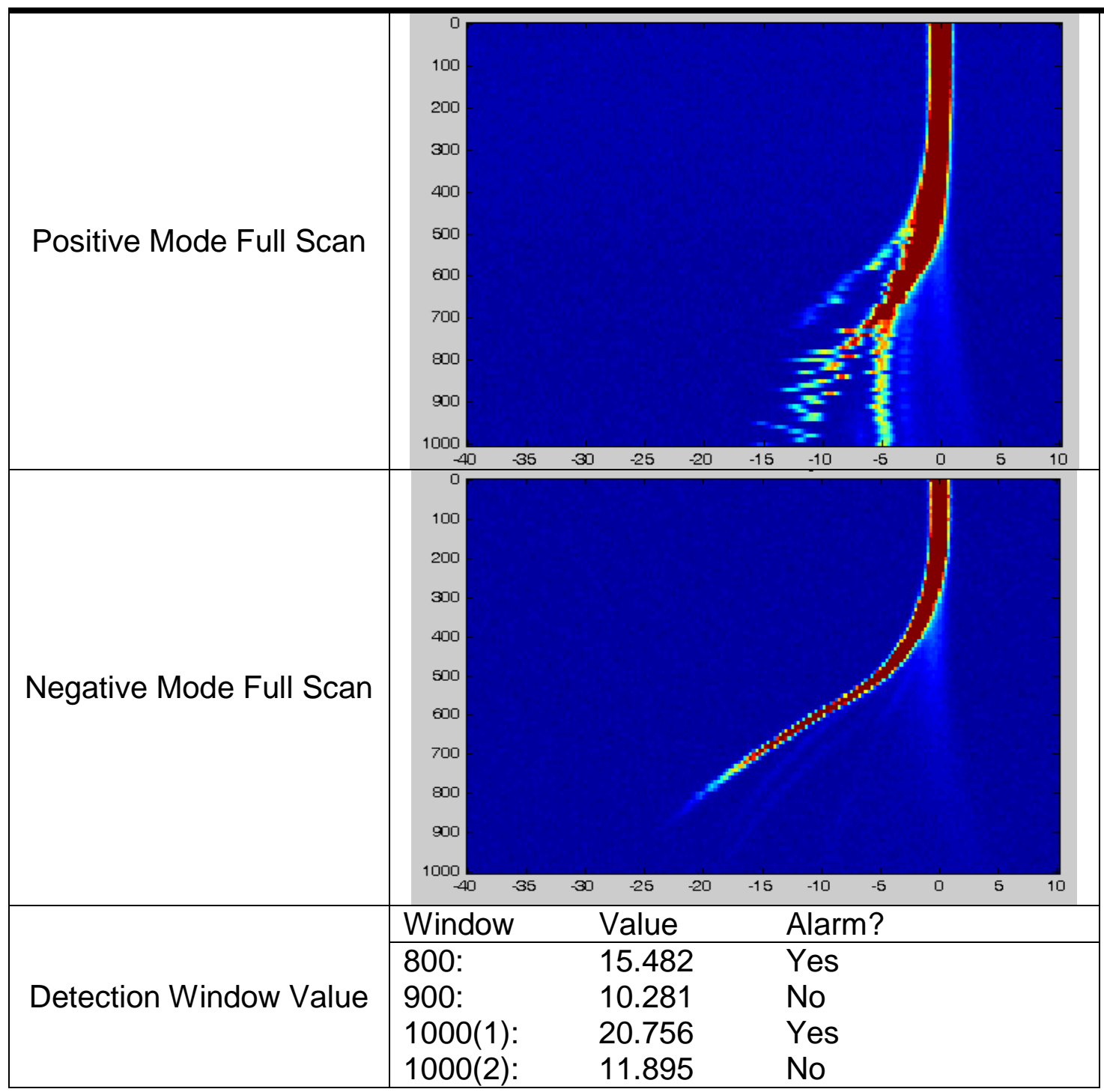


Hexane

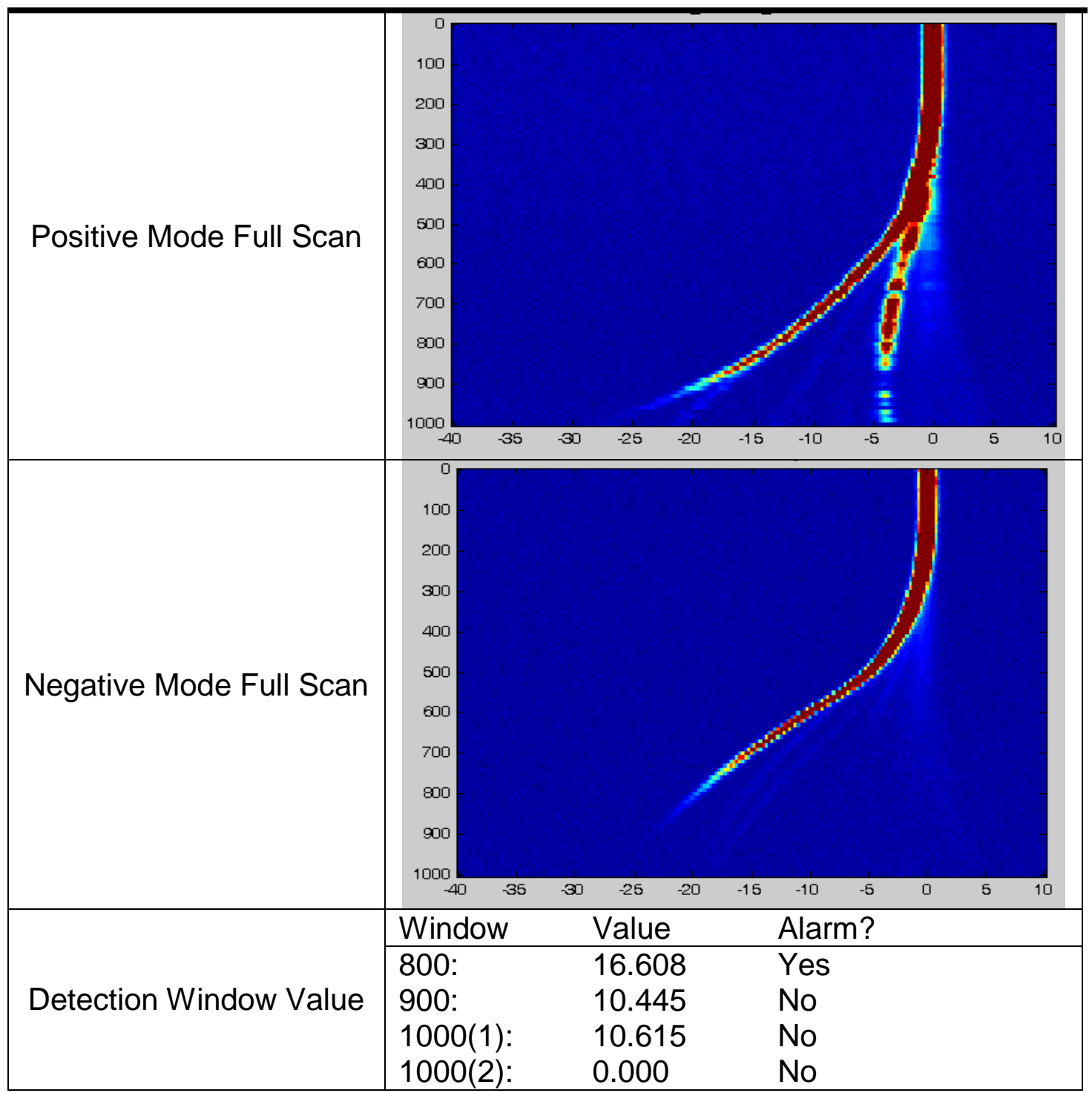


Methanol

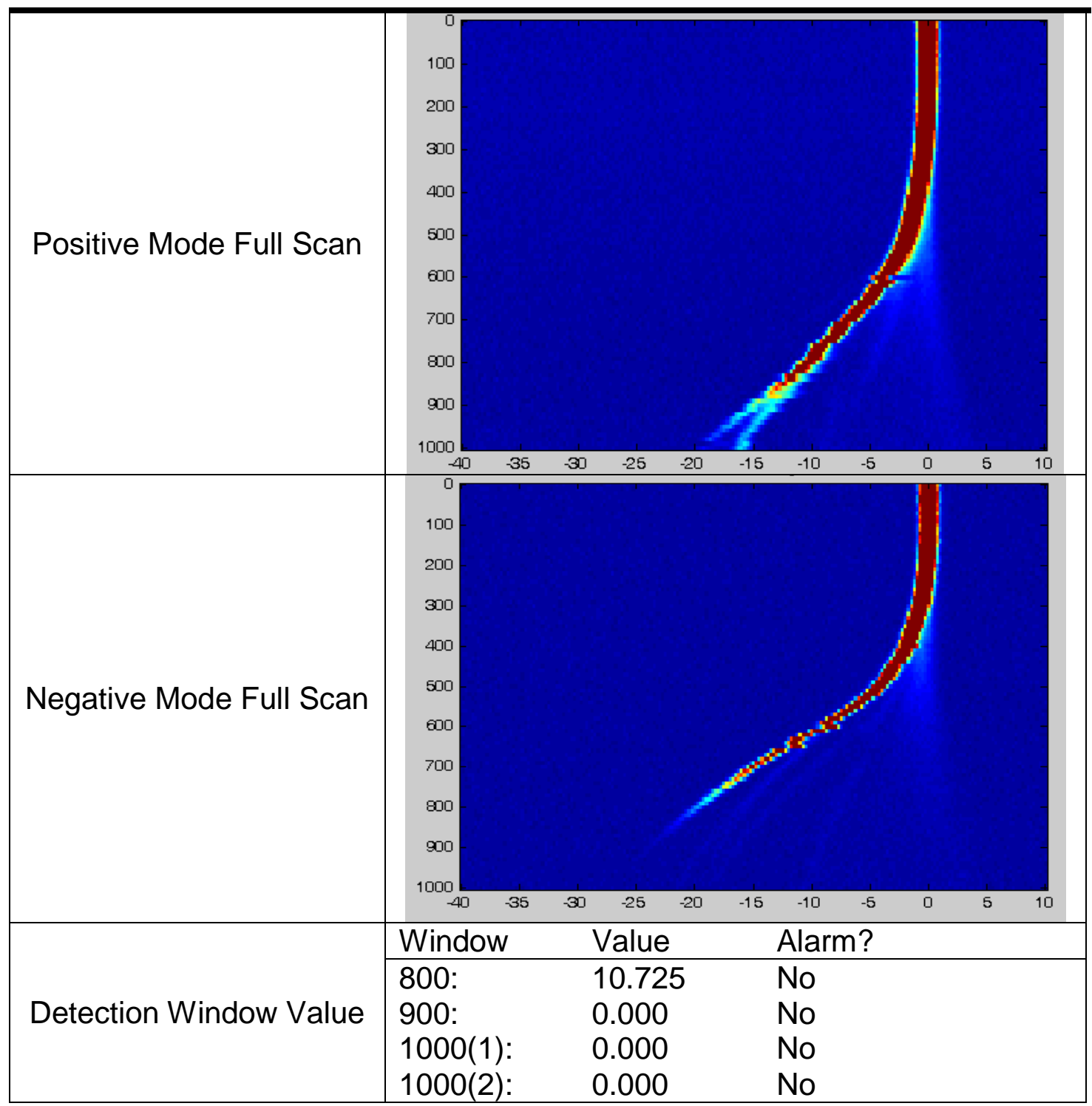




\section{Pentane}

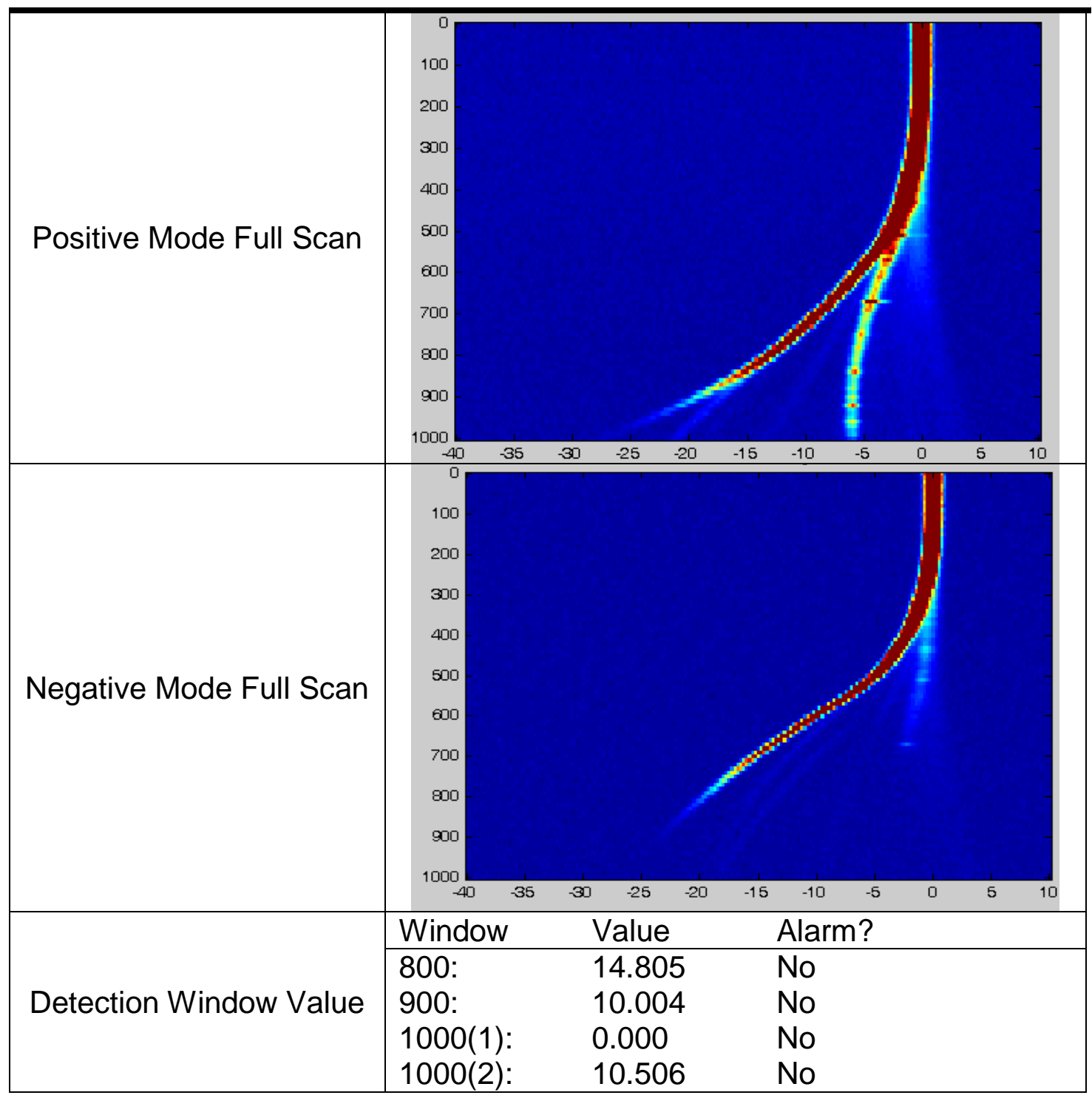




\section{2-Propanol}

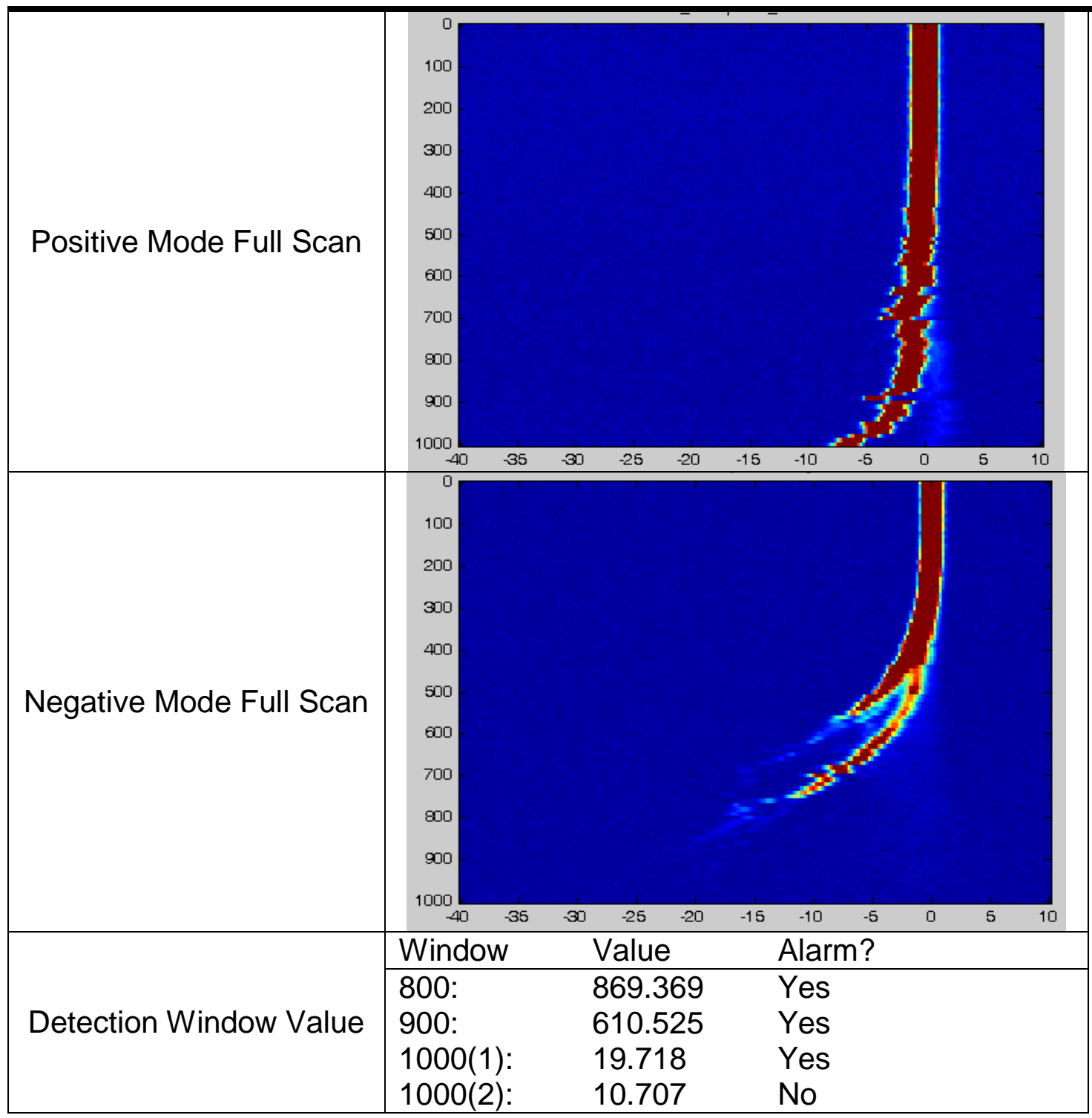


Toluene

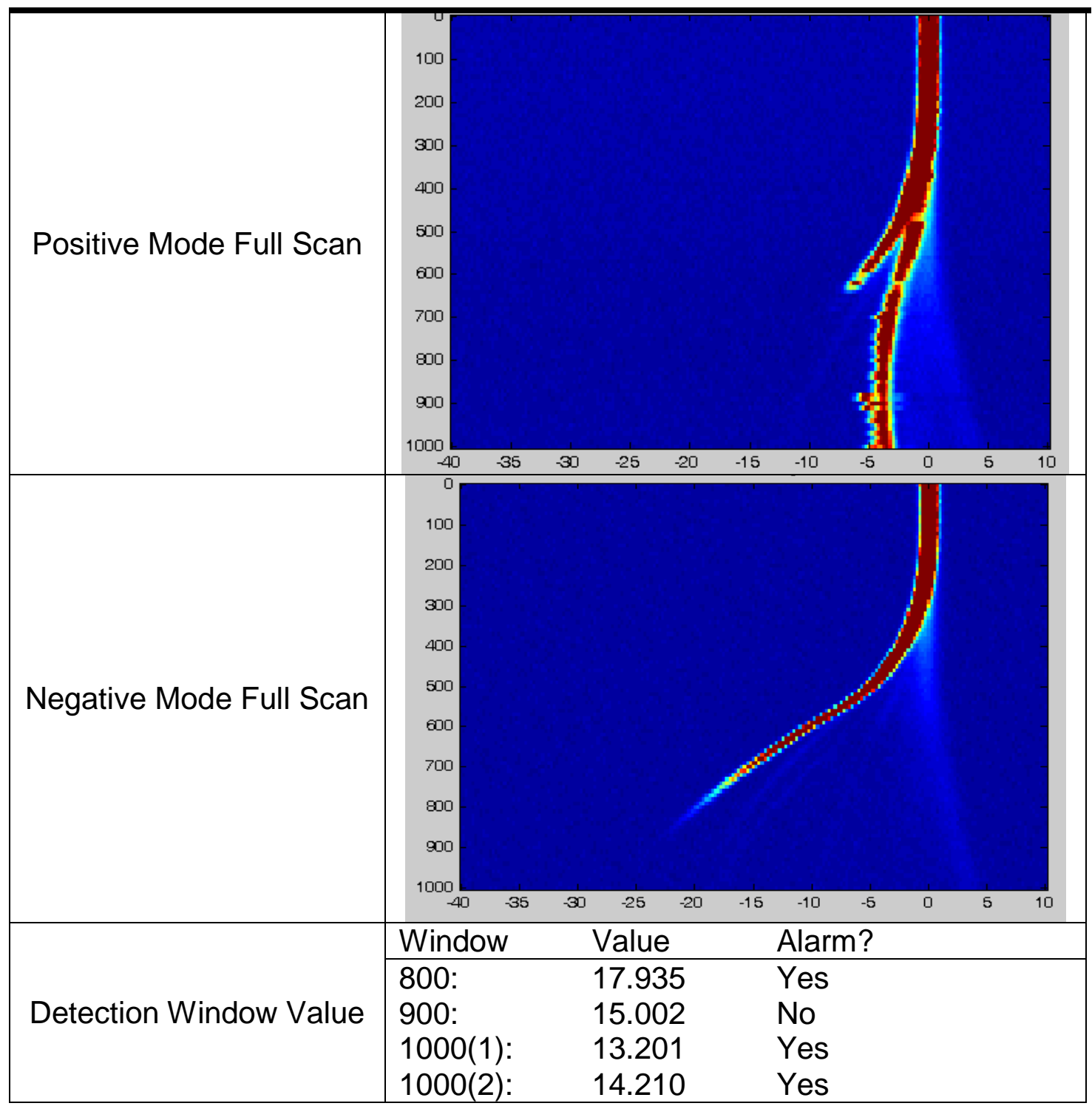




\section{Simple Green ${ }^{\circledast}$}

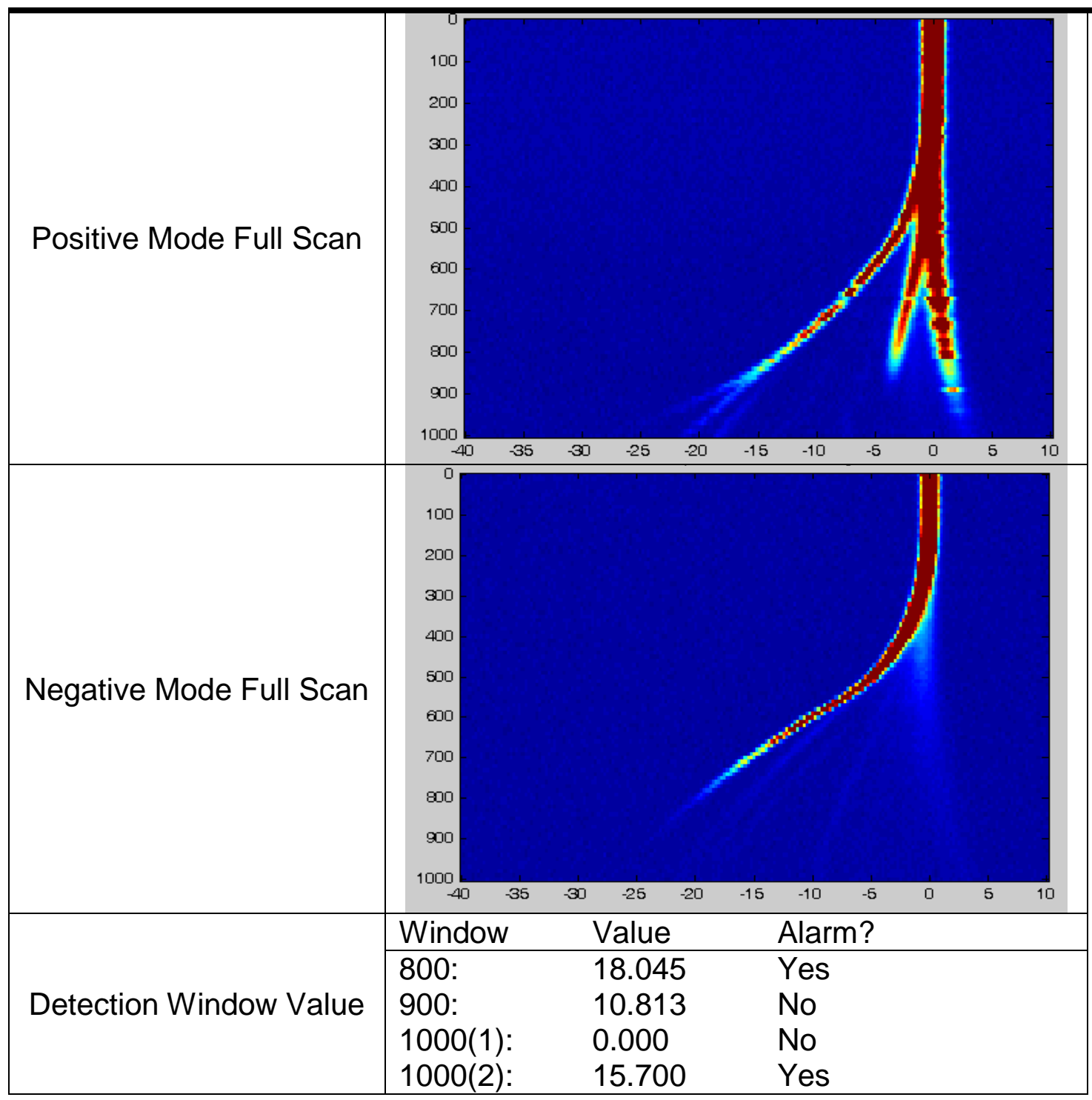




\section{APPENDIX B: SAMPLING LOCATIONS FOR THE ANALYSIS OF METHAMPHETAMINE IN A 1999 DODGE NEON}

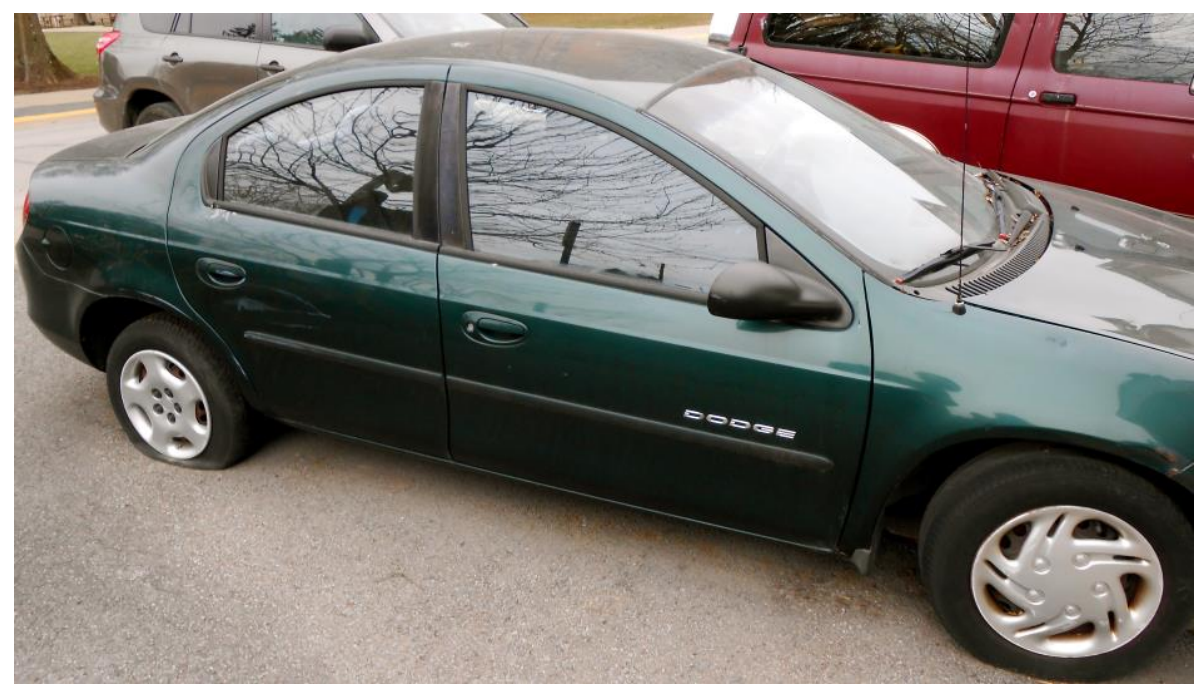

Passenger's side view

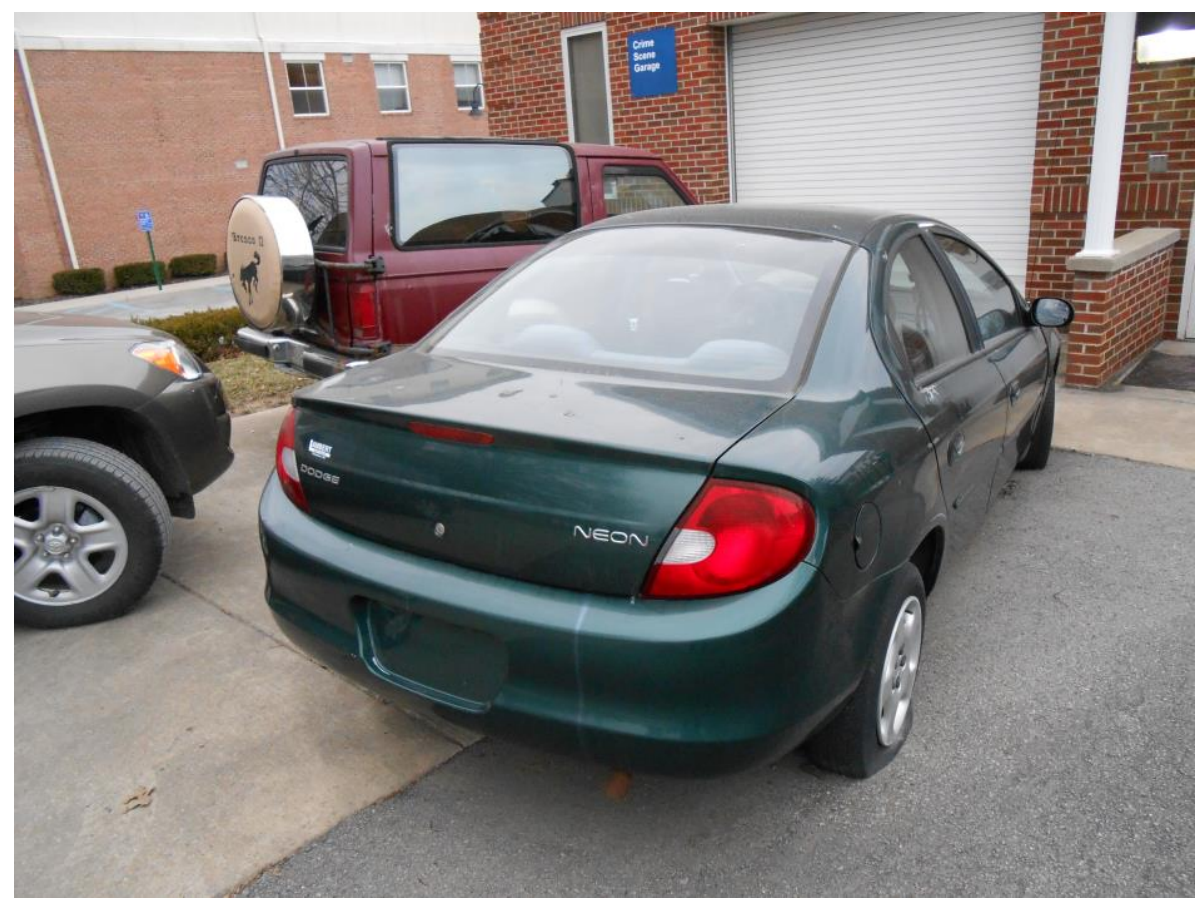

Rear view 


\section{Sampling Site 1: Trunk}
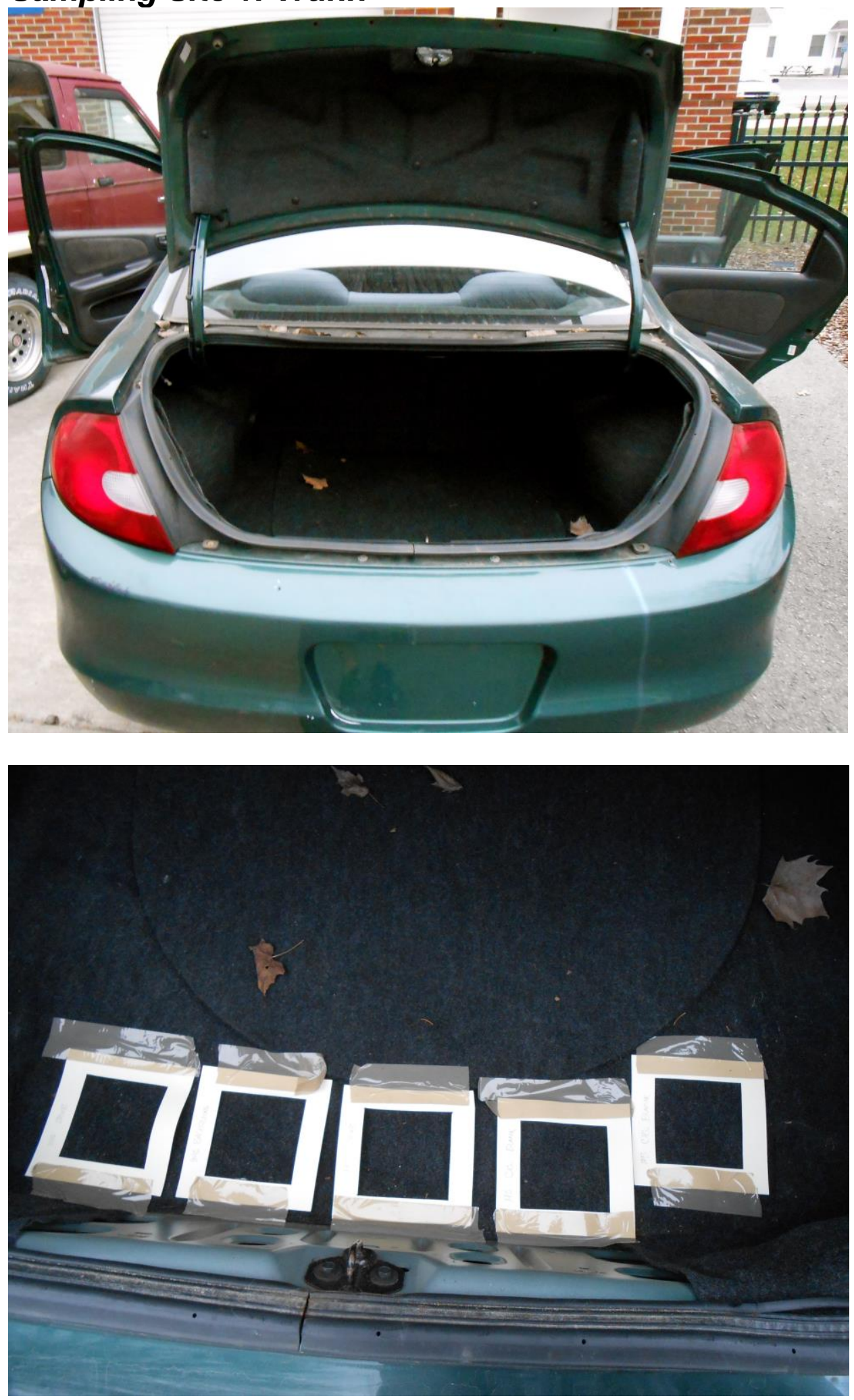
Sampling Site 2: Passenger's side, back seat - seat padding

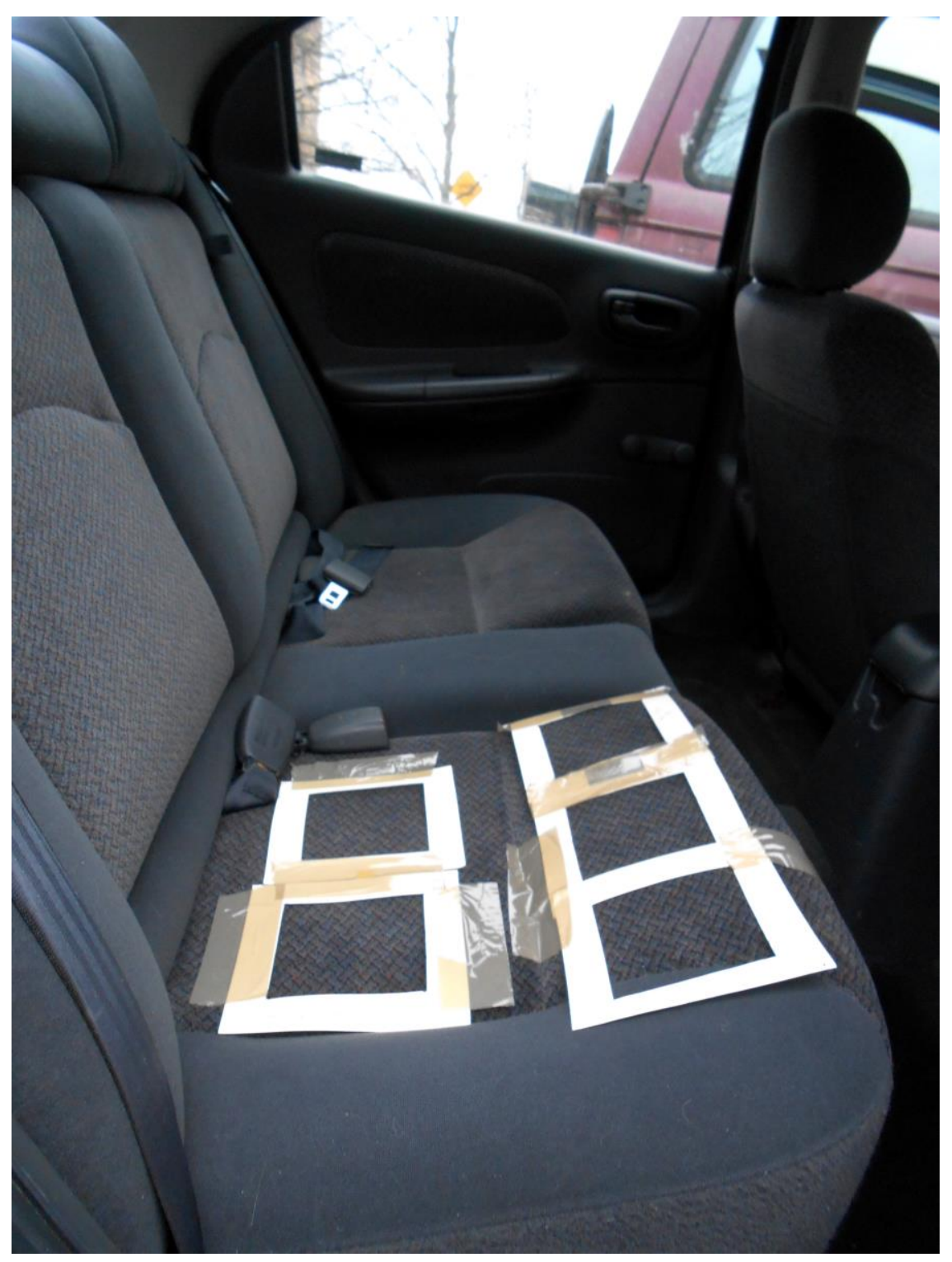


Sampling Site 3: Driver's seat - back padding
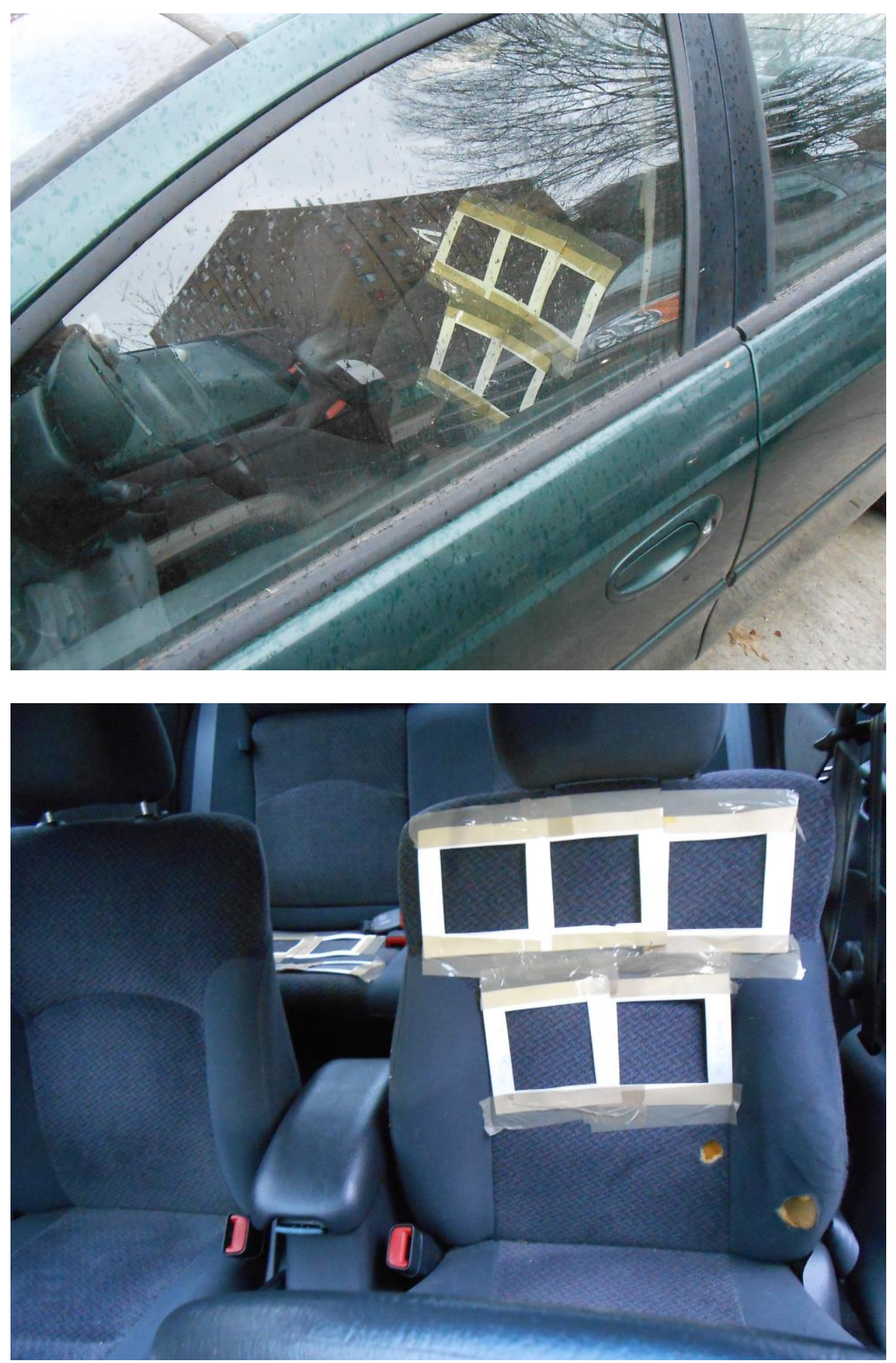
Sampling Site 4: Driver's side, floor boards
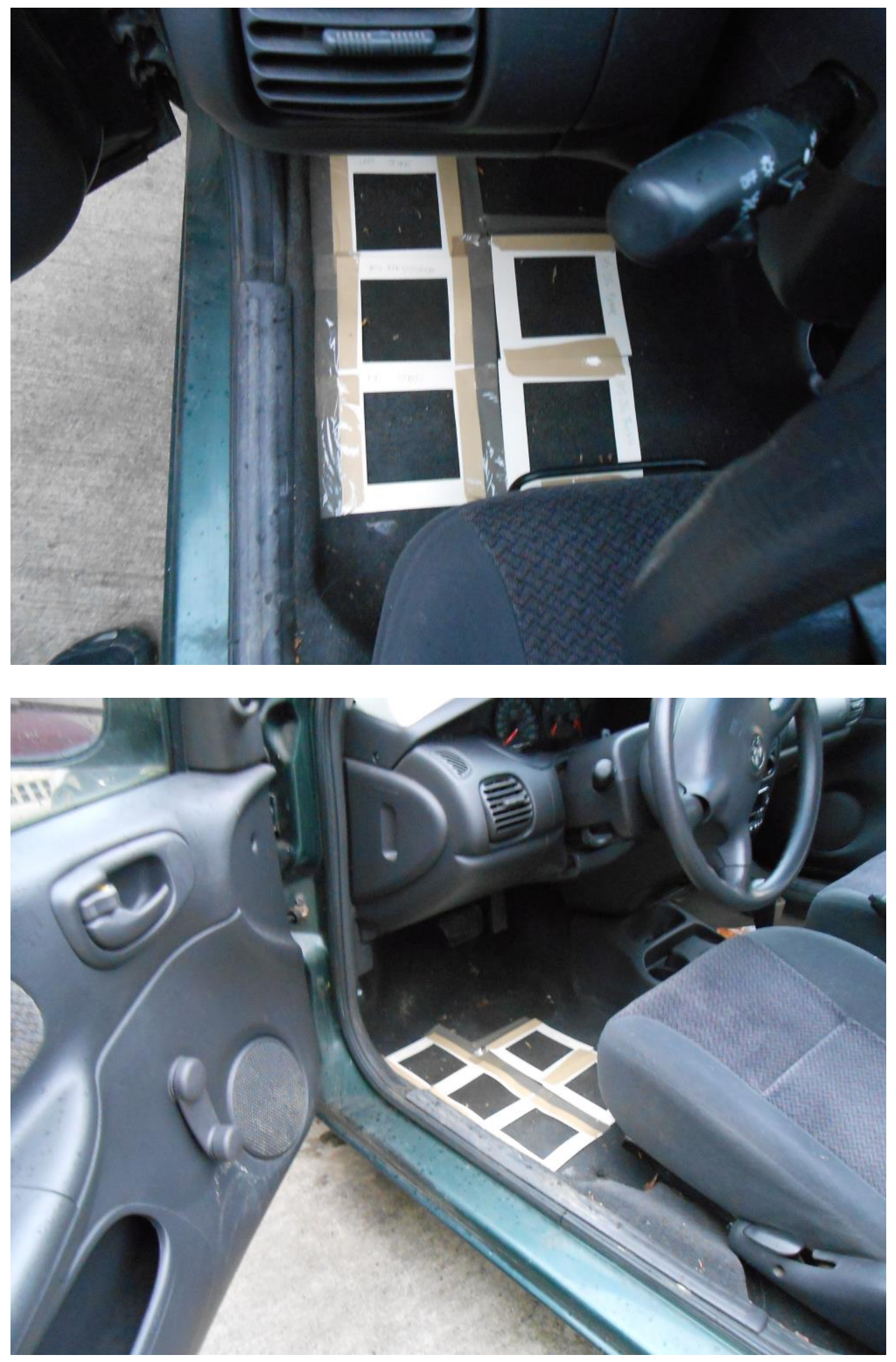
Sampling Site 5: Passenger's side, front side door - glass window
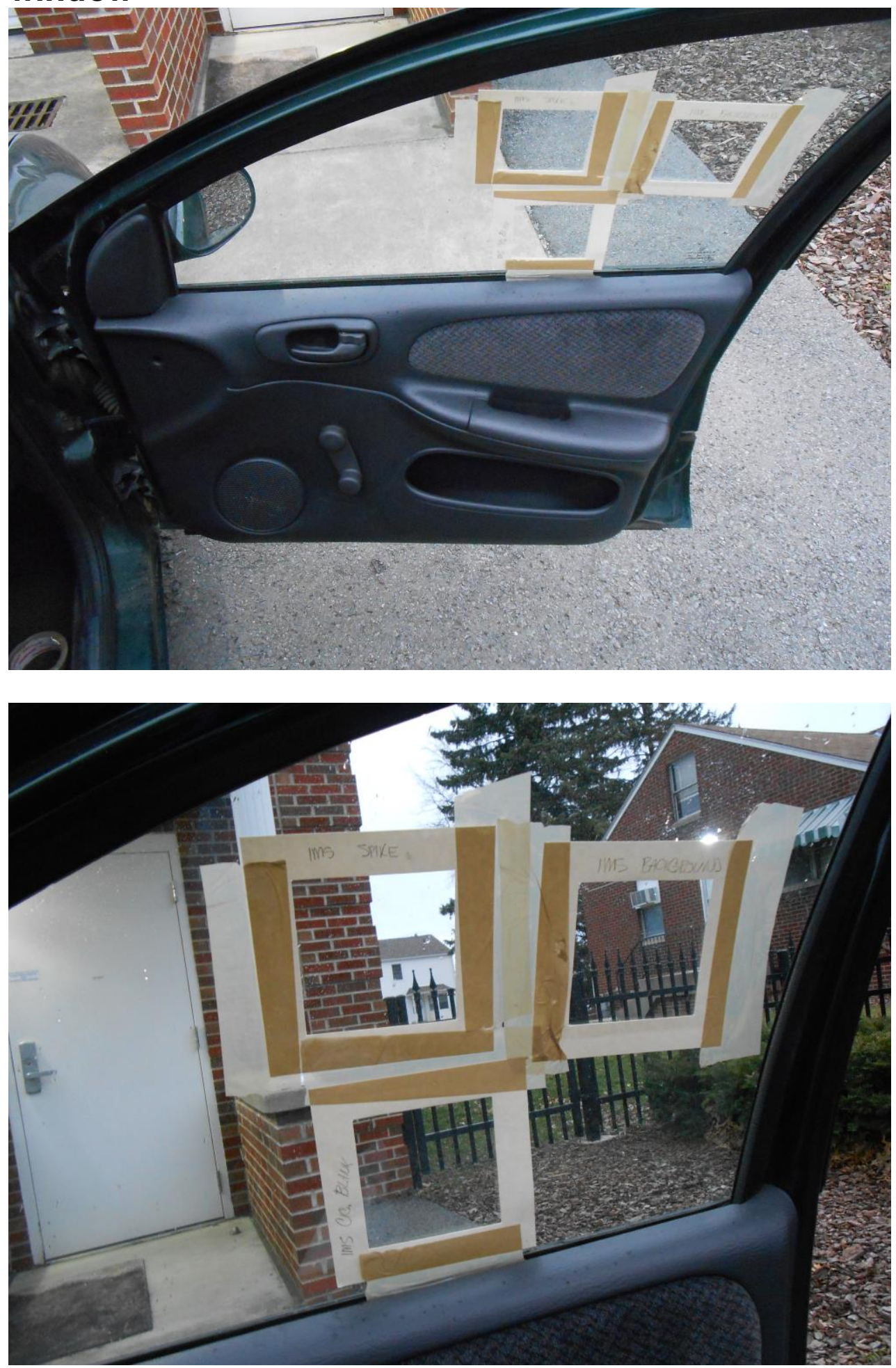
Sampling Site 6: Passenger's side, front - dashboard
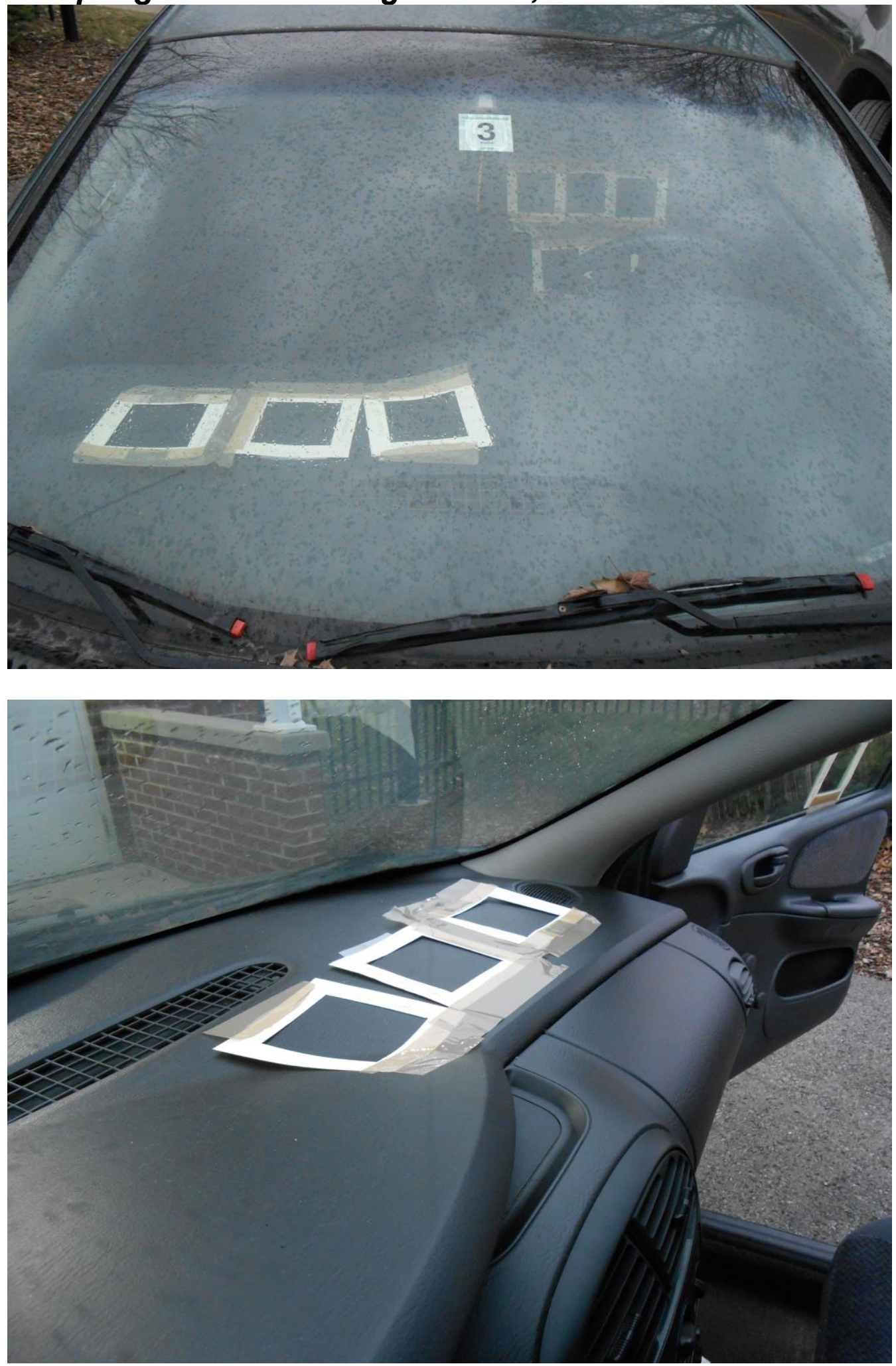


\section{References}

1. Maps of Methamphetamine Lab Incidents. http://www.justice.gov/dea/index.htm (accessed September 10).

2. $\quad$ Burgess, J.; Kovalchick, D.; Siegel, E.; Hysong, T.; McCurdy, S., Medical Surveillance of Clandestine Drug Laboratory Investigations. Journal of Occupational and Environmental Medicine 2002, 44, 184-189.

3. (a) Voluntary Guidelines for Methamphetamine Laboratory Cleanup; U.S. Evironmental Protection Agency: 2009; (b) Agency, U. S. E. P., Voluntary Guidelines for Methamphetamine Laboratory Cleanup. 2009.

4. Man, G.; Stoeber, B.; Walus, K., An Assessment of Sensing Technologies for the Detection of Clandestine Methamphetamine Drug Laboratories. Forensic Science International 2009, 189 (1-3), 1-13.

5. VanDyke, M.; Erb, N.; Arbuckle, S.; Martyny, J., A 24-Hour Study to Investigate Persistent Chemical Exposures Associated with Clandestine Methamphetamine Laboratories. J Occup Environ Hyg 2009, 6 (2), 82-89. 6. $\quad$ Patrick, G.; Daniell, W.; Treser, C., Residual Methamphetamine in Decontaminated Clandestine Drug Laboratories. Journal of Occupational and Environmental Hygiene 2009, 6 (3), 151-156.

7. Methamphetamine Remediation Research Act of 2007. In 121 STAT. 1809, United States, 2007.

8. National Institute of Drug Abuse: Methamphetamine. www.drugabuse.gov.

9. Office of National Drug Control Policy: Methamphetamine Facts \& Figures. http://whitehousedrugpolicy.gov.

10. Drug Identification Bible. Amera-Chem, Inc.: 2004.

11. Clarke's Analysis of Drugs and Poisons in pharmaceuticals, body fluids and postmortem material. 3 ed.; Pharmaceutical Press: Chicago, 2004.

12. ChemIDplus Lite. http://chem.sis.nIm.nih.gov/chemidplus (accessed January 7 ).

13. Bell, S., Forensic Chemistry. Pearson Prentice Hall: Upper Saddle River, New Jersey, 2006.

14. McMurry, J., Organic Chemistry. 6 ed.; THomas Learning, Inc: Belmont, 2004.

15. Wisconsin Department of Health Services: Cleaning Up Hazardous Chemicals at Former Meth Labs. www.dhs.wisconsin.gov.

16. Illegal Methamphetamine Laboratory Decontamination and Re-occupancy Guidelines. Services, D. o. H. a. H., Ed. 2005.

17. Baker, R. R.; Massey, E. D.; Smith, G., An overview of the effects of tobacco ingredients on smoke chemistry and toxicity. Food Chem. Toxicol. 2004, 42, S53-S83.

18. Hunting, T. Clandestine Laboratory [Meth Lab] Cleanup. www.adeq.state.ar.us/hazwaste/branch programs/clcc.htm (accessed October

19).

19. Sekine, H.; Itoh, S.; Nakahara, Y.; Suzuki, Y., Smoking abuse of methamphetamine mixed with tobacco. Thermal properties of $\mathrm{N}$ - 
cyanomethylmethamphetamine and its degradation in plasma and aqueous media. Jpn. J. Toxicol. Environ. Health 1996, 42 (3), 223-235.

20. Center for Disease Control and Prevention: The National Institute for Occupational Safety and Health (NIOSH). http://www.cdc.gov/niosh.

21. Wells, P.; McCallum, G.; Chen, C.; Henderson, J.; Lee, C.; Perstin, J.; Preston, T.; Wiley, M.; Wong, A., Oxidative Stress in Developmental Origins of Disease: Teratogenesis, Neurodevelopmental Deficits, and Cancer. Toxicological Sciences 2009.

22. Founie, A., Gypsum. U.S. Geological Survey Minerals Yearbook 2003.

23. Burke, R.; Kingston, L. Gypsum Wallboard and Method of Making Same. 1999.

24. Christensen, A. N.; Jensen, T. R.; Nonat, A., A New Calcium Sulfate Hemi-hydrate. Dalton Transactions 2010, 39 (8), 2044-2048.

25. Clandestine Methamphetamine Labs and Wastes in Minnesota. http://www.pca.state.mn.us (accessed November 10).

26. Granstrom, K. Emissions of Volatile Organic Compounds from Wood. Karlstad University, Sweden, 2005.

27. (a) CAS Registry Number 1330-16-1. In SciFinder, American Chemical Society: 2013; (b) CAS Registry Number 74806-04-5. In SciFinder, March 2, 2013 ed.; American Chemical Society: 2013; (c) CAS Registry Number 138-86-3. In SciFinder, American Chemical Society: 2013.

28. Hinds, W. C., Aerosol Technology: Properties, Behavior, and

Measurement of Airborne Particles. 2nd ed.; Wiley-Interscience: NY, 1999.

29. Baird, C.; Cann, M., Environmental Chemistry. 4th ed.; W.H. Freeman and Co.: New York, NY, 2008; $p 776$.

30. Torikaiu, K.; Uwano, Y.; Nakamori, T.; Tarora, W.; Takahashi, H., Study on tobacco components involved in the pyrolytic generation of selected smoke constituents. Food Chem. Toxicol. 2005, 43 (4), 559-568.

31. Molecular and Biochemical Toxicology. 4 ed.; John Wiley \& Sons, Inc: Hoboken, NJ, 2008.

32. Support for Selection of a Cleanup Level for Methamphetamine at Clandestine Drug Laboratories. Environment, C. D. o. P. H. a., Ed. 2005.

33. Kiyatkin, E. A.; Brown, P. L.; Sharma, H. S., Brain edema and breakdown of the blood-brain barrier during methamphetamine intoxication: critical role of brain hyperthermia. European Journal of Neuroscience 2007, 26 (5), 1242-1253.

34. Atkins, P.; De Paula, J., Atkins' Physical Chemistry. 8 ed.; Oxford Unversity Press: Oxford, 2006.

35. Engel, T.; Reid, P., Physical Chemistry. Pearson Education, Inc.: San Francisco, 2006.

36. Harris, D. C., Quantitative Chemical Analysis. 7 ed.; W.H. Freeman and Co: New York, NY, 2007.

37. Skoog, D. A.; Holler, F. J.; Crouch, S. R., Principles of Instrumental Analysis. 6 ed.; Thomas Brooks/Cole: Belmont CA, 2007.

38. Burgess, J. L. M., MS, MPH; Kovalchick, Dana F. AB; Siegel, Erin M. $\mathrm{MPH}$; Hysong, Tracy A. MS; McCurdy, Stephen A. MD, MPH., Medical 
Surveillance of Clandestine Drug Laboratory Investigators. Journal of Occupational and Environmental Medicine 2002, 44 (2), 184-189.

39. Hammon, T. L.; Griffin, S., Support for Selection of a Methamphetamine Cleanup Standard in Colorado. Regul. Toxicol. Pharmacol. 2007, 48 (1), 102114.

40. Simple Green All-Purpose Cleaner MSDS No.13005-12B. www.simplegreen.com/pdfs/MSDS EN-US AllPurposeCleaner.pdf (accessed May 10).

41. Voluntary Guidelines for Methamphetamine Laboratory Cleanup. Agency, U. S. E. P., Ed. 2009.

42. (a) Hill, H. H.; Simpson, G., Capabilities and Limitations of Ion Mobility Spectrometry for Field Screening Applications. Field Analytical Chemistry \& Technology 1997, 1 (3), 119-134; (b) Mäkinen, M.; Sillanpää, M.; Viitanen, A. K.; Knap, A.; Mäkelä, J. M.; Puton, J., The Effect of Humidity on Sensitivity of Amine Detection in Ion Mobility Spectrometry. Talanta 2011, 84 (1), 116-121.

43. Daum, K. A.; Fox, S. L. Data for Users of Handheld lon Mobility Spectrometers; 2008.

44. NIOSH Manual of Analytical Methods. http://www.cdc.gov/niosh/docs. 45. Methamphetamine Remediation Research Act of 2007. In H.R. 365, US, 2007.

46. Ochoa, M. L.; Harrington, P. B., Detection of Methamphetamine in the Presence of Nicotine Using In Situ Chemical Derivatization and Ion Mobility Spectrometry. Analytical Chemistry 2004, 76 (4), 985-991.

47. Kent, E. J. M.; Elliot, D. A.; Miskelly, G. M., Inhibition of Bleach-Induced Luminol Chemiluminescence*. J. Forensic Sci. 2003, 48, 1-4.

48. Forester, C. D. Gas-Phase Reactions of Methamphetamine with Hydroxyl Radicals and Ozone. West Virginia University, 2013.

49. A Technical Guide for Static Headspace Analysis Using GC. Restek, Ed. Bellefonte, PA, 2000.

50. Kolb, B.; Ettre, L. S., Static Headspace-Gas Chromatography: Theory and Practice. Wiley-Interscience: Hoboken, NJ, 2006.

51. Atkins, P.; Paula, J. d., Atkins' Physical Chemistry. 8 ed.; Oxford University Press: Oxford, 2006.

52. Lee, M.-R.; Song, Y.-S.; Hwang, B.-H.; Chou, C.-C., Determination of Amphetamine and Methamphetamine in Serum via Headspace Derivatization Solid-Phase Microextraction-Gas Chromatography-Mass Spectrometry. Journal of Chromatography A 2000, 896 (1-2), 265-273.

53. Johansen, S. S.; Jornil, J., Determination of Amphetamine, Methamphetamine, MDA, MDMA in Human Hair by GC-El-MS After Derivatization with Perfluorooctanoyl Chloride. The Scandinavian Journal of Clinical \& Laboratory Investigation 2009, 69 (1), 113-120.

54. Jurado, C.; Giménez, M. P.; Soriano, T.; Menéndez, M.; Repetto, M., Rapid Analysis of Amphetamine, Methamphetamine, MDA, and MDMA in Urine Using Solid-Phase Microextraction, Direct On-Fiber Derivatization, and Analysis by GC-MS. Journal of Analytical Toxicology 2000, 24 (1), 11-16. 
55. Standard Practices for Method Validation in Forensic Toxicology. www.swgtox.org/documents/Validation public comment.pdf (accessed October 23).

56. AB SCIEX: Defining Lower Limits of Quantitation. Fostercity, CA, 2012.

57. Destaillats, H.; Singer, B. C.; Gundel, L. A., Evidence of Acid-Base Interactions Between Amines and Model Indoor Surfaces by ATR-FTIR Spectroscopy. Atmospheric Environment 2007, 41 (15), 3177-3181.

58. Kolakowski, B. M.; Mester, Z., Review of Applications of High-Field Asymmetric Waveform lon Mobility Spectrometry (FAIMS) and Differential Mobility Spectrometry (DMS). Analyst 2007, 132 (9), 842-864.

59. Krylov, E., Differential Mobility Spectrometer: Optimization of the Analytical Characteristics. Int. J. Ion Mobil. Spec. 2012, 15 (3), 85-90.

60. Krylov, E. V.; Coy, S. L.; Nazarov, E. G., Temperature Effects in Differential Mobility Spectrometry. International Journal of Mass Spectrometry 2009, $279(2-3), 119-125$.

61. Eiceman, G. A.; Karpas, Z., Ion Mobility Spectrometry. 2 ed.; Taylor \& Francis Group: Boca Raton, FL, 2005.

62. Rearden, P.; Harrington, P., Detection of VOCs Using Gas

Chromatography Differential Mobility Spectrometry (GC-DMS). LabPlus International 2006.

63. Griffin, T., Differential Mobility Spectroscopy for Chemical Agent Detection. Chemical and Biological Sensing VII 2006, 6218.

64. McCooeye, M. A.; Mester, Z.; Ells, B.; Barnett, D. A.; Purves, R. W.; Guevremont, R., Quantitation of Amphetamine, Methamphetamine, and Their Methylenedioxy Derivatives in Urine by Solid-Phase Microextraction Coupled with Electrospray lonization-High-Field Asymmetric Waveform Ion Mobility Spectrometry-Mass Spectrometry. Analytical Chemistry 2002, 74 (13), 3071 3075.

65. Hall, A. B.; Coy, S. L.; Nazarov, E. G.; Vouros, P., Rapid Separation and Characterization of Cocaine and Cocaine Cutting Agents by Differential Mobility Spectrometry-Mass Spectrometry. J. Forensic Sci. 2012, 57 (3), 750-756.

66. Gayton-Ely, M.; Shakleya, D. M.; Bell, S. C., Application of a Pyroprobe to Simulate Smoking and Metabolic Degradation of Abused Drugs Through Analytical Pyrolysis*. J. Forensic Sci. 2007, 52 (2), 473-478.

67. Prasad, S.; Schmidt, H.; Lampen, P.; Wang, M.; Guth, R.; Rao, J. V.; Smith, G. B.; Eiceman, G. A., Analysis of bacterial strains with pyrolysis-gas chromatography/differential mobility spectrometry. Analyst 2006, 131 (11), 12161225.

68. Schmidt, H.; Tadjimukhamedov, F.; Mohrenz, I. V.; Smith, G. B.; Eiceman, G. A., Microfabricated differential mobility spectrometry with pyrolysis gas chromatography for chemical characterization of bacteria. Analytical Chemistry 2004, 76 (17), 5208-5217.

69. Rauch, P. J. In A Method of Correlating Peak Locations to Moisture in $D M S$, International Society for Ion Mobility Spectrometry, Orlando, FL, Orlando, FL, 2012. 
70. One-Pot Methamphetamine Cooks Pose New Danger. www.dep.wv.gov (accessed April 21).

71. Cook, C. E.; Jeffcoat, A. R.; Hill, J. M.; Pugh, D. E.; Patetta, P. K.; Sadler, B. M.; White, W. R.; Perez-Reyes, M., Pharmacokinetics of Methamphetamine Self-Administered to Human Subjects by Smoking S-(+)-Methamphetamine Hydrochloride. Drug Metabolism and Disposition 1993, 21 (4), 717-723.

72. Harris, D. S.; Boxenbau, H.; Everhart, E. T.; Sequeira, G.; Mendelson, J. E.; Jones, R. T., The Bioavailability of Intranasal and Smoked Methamphetamine. Clinical Pharmacology \& Therapeutics 2003, 74, 475-486. 73. Martyny, J. W.; Arbuckle, S. L.; McCammon Jr, C. S.; Erb, N.; Van Dyke, M., Methamphetamine contamination on environmental surfaces caused by simulated smoking of methamphetamine. Journal of Chemical Health and Safety 2008, 15 (5), 25-31.

74. Used 1999 Dodge Neon Interior Specs. www.motortrend.com/cars.

75. . Adult Cigarette Smoking in the United States: Current Estimate 2012. www.cdc.gov/tobacco/data statistics.

76. $\quad$ Richter, K. P.; Ahluwalia, H. K.; Mosier, M. C.; Nazir, N.; Ahluwalia, J. S., A population-based study of cigarette smoking among illicit drug users in the United States. Addiction 2002, 97 (7), 861-869. 